\title{
Frugivore behavior and plant spatial genetics.
}

\author{
Dissertation for the \\ award of the degree \\ "Doctor of Philosophy" \\ Ph.D. Division of Mathematics and Natural Sciences \\ of the Georg-August-Universität Göttingen \\ within the doctoral program Biodiversity and Ecology \\ of the Georg-August University School of Science (GAUSS)
}

submitted by

Tiziana A. Gelmi Candusso

Göttingen, November 2017 


\section{THESIS COMMITTEE}

Prof. Dr. Eckhard W. Heymann

(Department of Behavioral Ecology and Sociobiology, German Primate Center)

Prof. Dr. Pierre-Michel Forget

(Department of Ecology and Biodiversity Management, Natural Museum of Natural History, Paris)

PD Dr. habil. Oliver Schülke

(Department of Behavioral Ecology, Johann Friedrich Blumenbach Institute for Zoology \& Anthropology, Georg August University of Göttingen)

\section{MEMBERS OF THE EXAMINATION BOARD}

Reviewer: $\quad$ Prof. Dr. Eckhard W. Heymann

(Behavioral Ecology and Sociobiology, German Primate center)

Second Reviewer: $\quad$ Prof. Dr. Pierre-Michel Forget

(Department of Ecology and Biodiversity Management, Natural Museum of Natural History, Paris)

Additional Reviewer: PD Dr. habil. Oliver Schülke (Department of Behavioral Ecology, Johann Friedrich Blumenbach Institute for Zoology \& Anthropology, Georg August University of Göttingen)

\section{Further members of the Examination Board:}

Prof. Dr. Erwin Bergmeier

(Department of Vegetation Analysis \& Plant Diversity, Albrecht von Haller Institute of Plant Sciences, Georg August University of Göttingen)

Prof. Dr. Elvira Hörandler

(Department of Systematics, Biodiversity and Evolution of Plants, Albrecht von Haller Institute for Plant Science, Georg August University of Göttingen)

PD Dr. habil. Christian Ross

(Department of Primate genetics, German Primate center) 


\section{$\underline{\text { ABSTRACT }}$}

Spatial genetics aims to understand the influence of environmental features and biological interactions on gene flow and genetic structure. In plants, spatial genetics is determined by the rate, pattern and spatial extent of gene dispersal within and between populations. Gene dispersal in plants is composed by seed dispersal and pollination. Seed dispersal increases the probabilities of mating between spatially distant, non-related, individuals, reducing the probability of biparental inbreeding, decreasing the incidence of unfavorable traits and increasing genetic diversity. In animal seed dispersal, foraging behavior and post-feeding movement range affect seed dispersal pattern and distance, with consequences in plant spatial genetics. This thesis aims to understand the relationship between frugivore behavior and spatial genetics while strengthening the current knowledge on seed dispersal by tamarins and using their dispersal of Leonia cymosa as a case study for a finer analysis of the effect of frugivore behavior on spatial genetics. Leonia cymosa Mart. (Violaceae), a small Neotropical understory tree, is exclusively dispersed at our study site by tamarins, Saguinus mystax, and Leontocebus nigrifrons. Leonia cymosa is, therefore, a good model for understanding the effects of frugivore behavior and plants spatial genetics. First, I analyzed the presence and strength of SGS in animal-dispersed plants studied in the last 20 years. I found animal behavior has an effect on spatial genetic structure, but pollination and marker type used could also have an influence on the strength of SGS. Second, I analyze seed dispersal distance of Leonia cymosa by tamarins, using plant genetics and animal behavior data in parallel. Methods for estimating seed dispersal distance did not differ significantly and mean seed dispersal distance for Leonia cymosa was between 218 and $304 \mathrm{~m}$. Third, I analyze spatial genetic structure (SGS) in Leonia cymosa through its life stages and put it in the context of tamarin behavior. SGS was present in seedlings, and weaker in juveniles and absent in adults of Leonia cymosa, likely due to tamarin seed dispersal patterns and extent. Clumped seed dispersal patterns might have a strong influence on SGS of seedlings, while the combination of-density-dependent mortality and relatively long seed dispersal distance likely reduces this effect in adulthood. Fourth, I analyzed the genetic composition of Leonia cymosa individuals growing on different tamarin home ranges. Home ranges were expected to create a seed dispersal barrier influencing overall gene flow. However, even though the parentage analysis showed no seed exchange across home 
ranges, genetic makeup shows no difference between individuals located in different home ranges, at all life stages, giving evidence that pollination or small shifts in time of home ranges, could have a strong effect in maintaining gene flow across home ranges. The results of this thesis give evidence that seed dispersal patterns and distance can strongly and differently affect plant spatial genetic structure, while, pollination might play an important role in maintaining gene flow in case of seed dispersal constraints. 


\section{ACKNOWLEDGMENTS}

The first and most important acknowledgment is for my supervisor Eckhard W. Heymann, for the constant intellectual support through these four years, always providing useful answers to my million questions, and never being short of suggestions for resources for me to investigate when I was doubtful about something. Thank you also for being openminded about my ideas and always being ready to discuss them. I really enjoyed exchanging points of view and always reaching a mutual decision on where to go next or how to answer our questions. You never made me feel unheard, and that gave me much confidence as a researcher. Finally, if all supervisors were like you, the drop out percentage of women in science would be cut by half. Without your unconditional and unjudgmental support, raising a child while doing my Ph.D. would've been difficult. I cannot thank you enough for giving me the opportunity to organize my time and come through with both tasks.

I would like to acknowledge my second unofficial, yet essential, supervisor Katrin Heer for always being ready to help me and guide me through long-distance, on top of her super busy schedule. Your knowledge of plant genetics is never-ending. From sampling to analysis, in every single step, you were my constant point of reference. I would also like to acknowledge Prof. Birgit Ziegenhagen's and her group at the University of Marburg, for making me feel part of the family when I was there. In particular, Sascha Liepelt and Christina Mengel. Tina, you are amazing, characterizing the microsatellite markers and interpreting the genotype results was a breeze because of your experience and how you shared it with me.

I would like to thank my thesis committee Prof. Dr. Pierre-Michel Forget and Prof. Dr. Oliver Schülke. The ideas that brewed during the committee meeting were of uttermost value for this project. Prof. Dr. Erwin Bergmeier, Prof. Dr. Elvira Hörandler, Prof. Dr. Christian Ross for taking the time to read this thesis.

The Department of Behavioral Ecology and Sociobiology at the German Primate Center. In particular, to Dr. Omer Nevo and Darja Slana for sharing your observations from the field. My office brother, Thiago Pereira, for always being available and for sharing all kinds of scientific information with me. Charlotte, for including me in all the Sohapi workshops. Klara, without you I would still be figuring out the bureaucracy to apply for the examination, all the current and 
long-gone members, you guys are family. To Prof. Dr. Peter Knappeler and Dr. Claudia Fichtel for your insights during seminars and for managing your labs in a way that there is no intergroup competition. Christina Glaschke, for the support at the lab; Mina and Anja, for not giving up on the KLR forms. Camilo and Ney, for being able to recognize the Leonias and being efficient field assistants. Christoph Knogge, Laurence Culot and Ronal Bialozyt for the nice discussions, sharing of ideas and experiences and for your old data that gave me numerous hours of fun $R$, GIS and NetLogo. Luis Alberto García Ayachi and Ricardo Zarate Gómez, for contributing to the research and Alex Cruz from the ministry of Agriculture in Peru for helping me out with the bureaucracy. The ministry of Agriculture in Peru for permitting us to investigate on the Peruvian territory ( $N^{\circ} 0134-2014-M I N A G R I$ DGFFS/DGEFFS), export the leaves and do the genetic analysis of the samples ( $N^{\circ} 0160-2014 \_M I N A G R I$ DGFFS/DGEFFS) that allowed for the core of this thesis. The department of Primate Genetics at the German Primate Center, in particular, Christiane, Nico, and Beatrix. The Georg-August University School of Science (GAUSS), and the familyoriented completion grant I was awarded in order to extend my funding for half a year, for which I am extremely grateful.

My Göttingen friends, in particular, my mom-friends, for sharing stress-releasing time while the kids played together. Precious play-dates that helped more with mom's sanity than the kids.

Finally, but not least importantly, my parents for supporting me since day one, my mom for answering all my questions when I was a kid and believing that one day, I would be a scientist, and my dad for being the sweetest, and caring father, loving me no matter what. My family and friends for always being there and accepting my disappearance the months before handing in the thesis. My husband for being my complement personally and scientifically. I love sharing this crazy world of science with you. To Leo, thank you for making me appreciate my time and force me to learn how to make better use of it. You changed our lives in the best possible way. 


\section{INDEX}

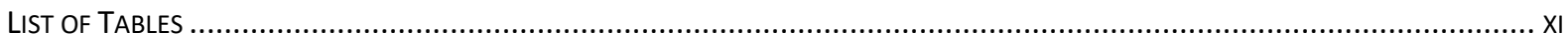

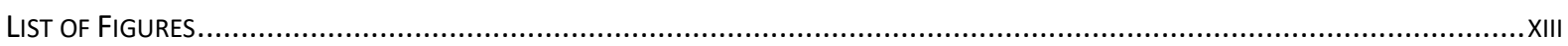

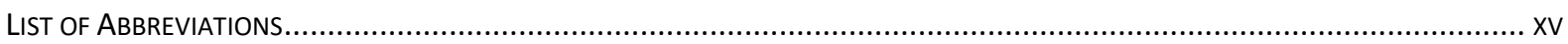

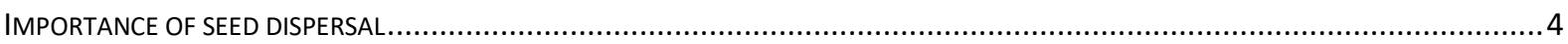

Advantages of Seed dispersal and its influence in spatial genetics .............................................................. 4

Frugivore behavior determines dispersal patterns and spatial genetics ..............................................

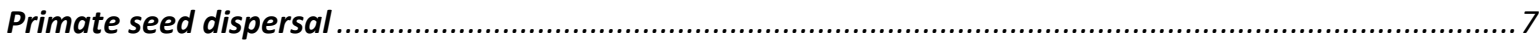

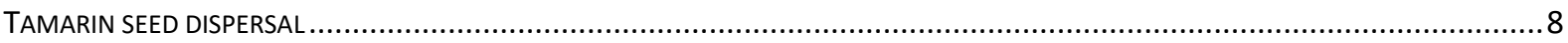

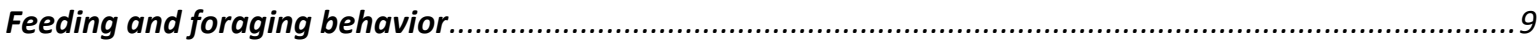

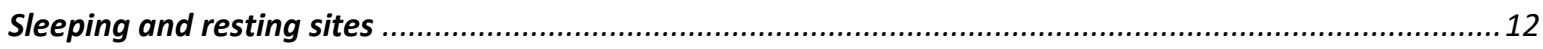

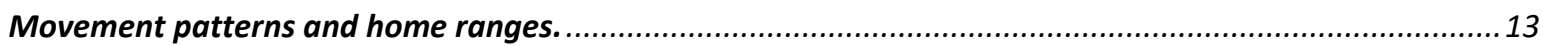

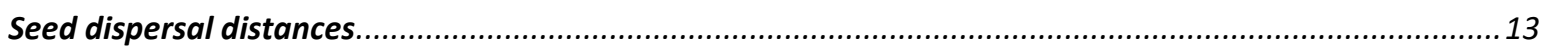

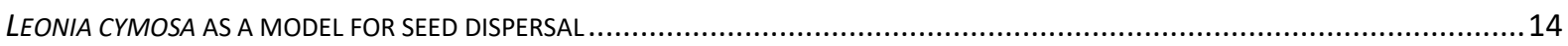

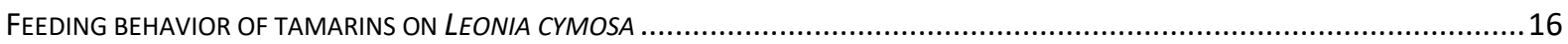

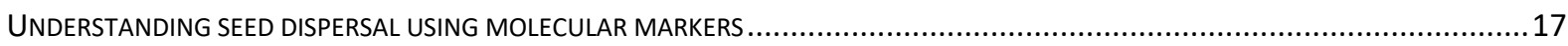

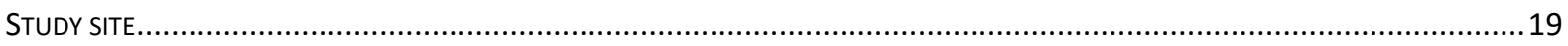

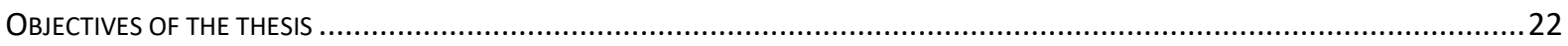

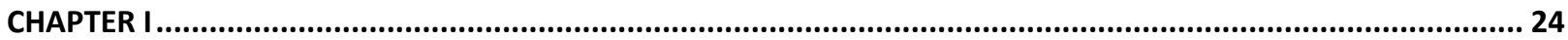

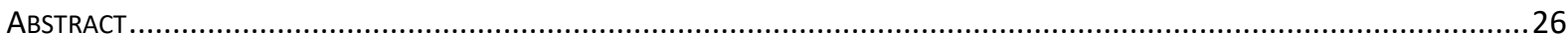

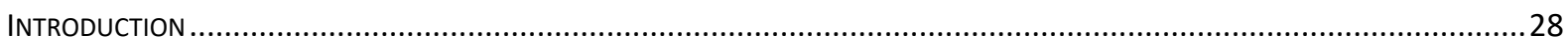

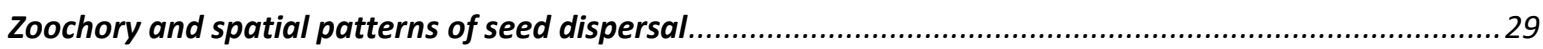

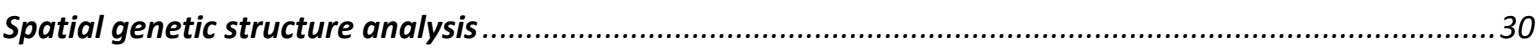

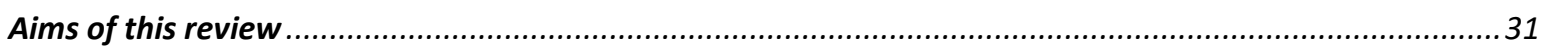

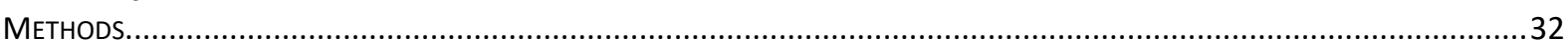

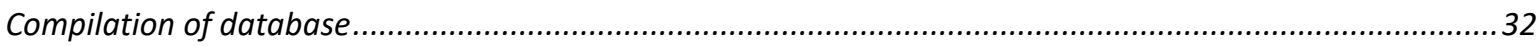

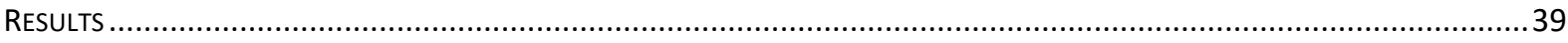

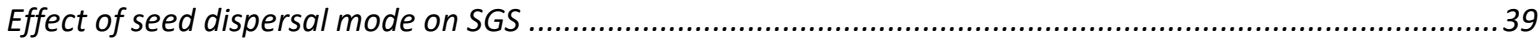

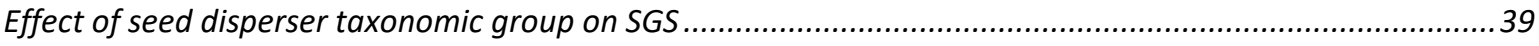

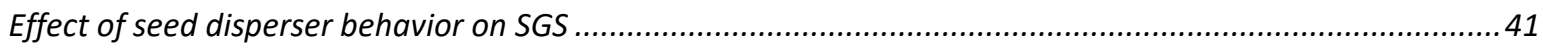

Additional factors influencing SGS of zoochorously dispersed species ..................................................44

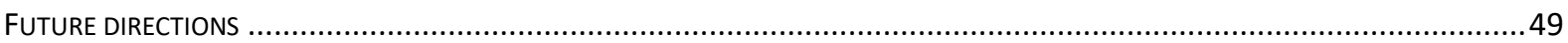

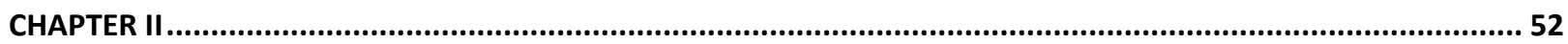

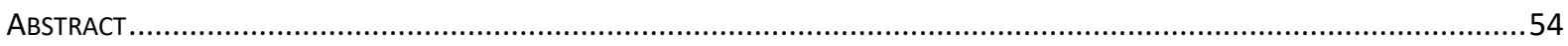

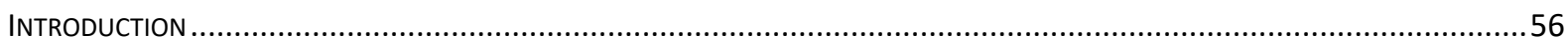

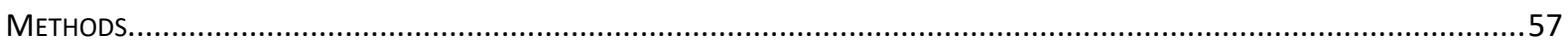

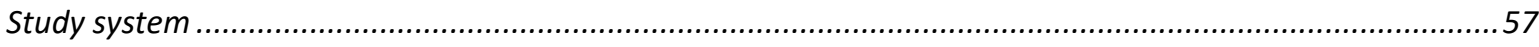

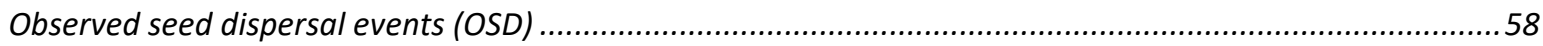

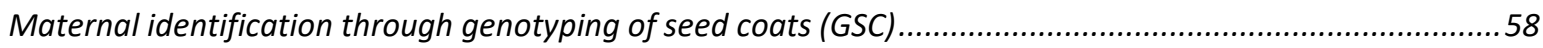

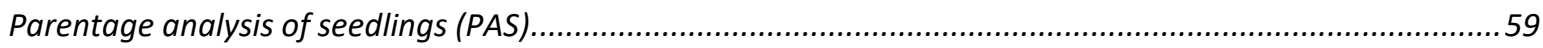

Combination of movement data with gut passage times (CMG) .........................................................61

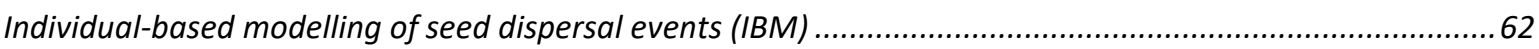

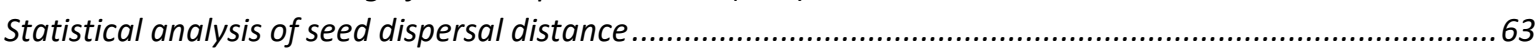

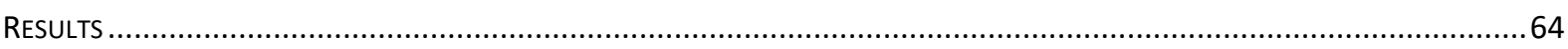

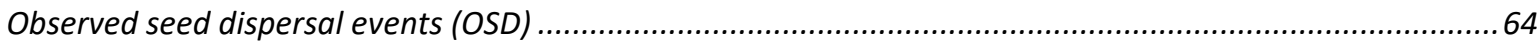

Maternal identification through genotyping of seed coats (GSC) ........................................................6.

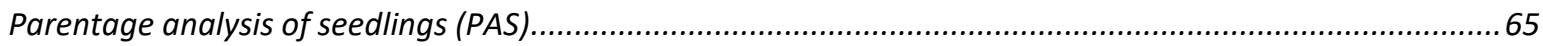

Combination of movement data with gut passage times (CMG) .......................................................66 


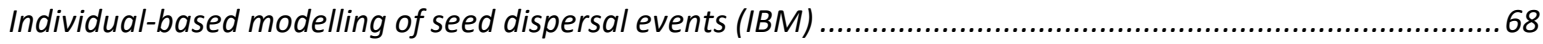

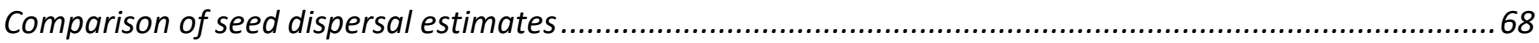

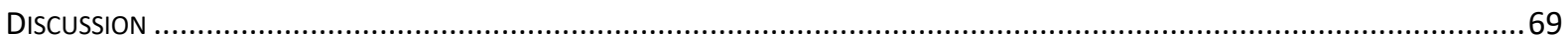

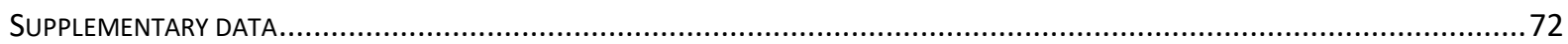

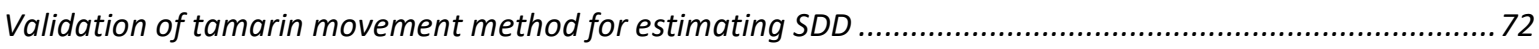

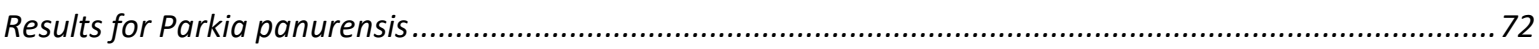

$R$ function for extracting linear travel distances from movement data and for executing the CMG method (combination of movement data and gut passage time). .................................................................... 73

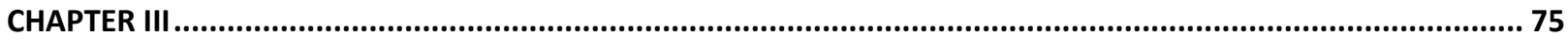

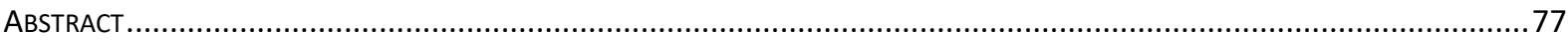

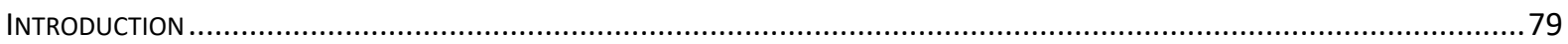

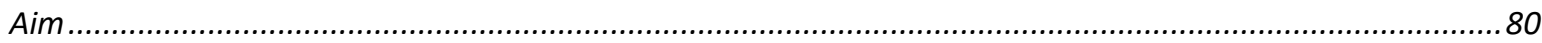

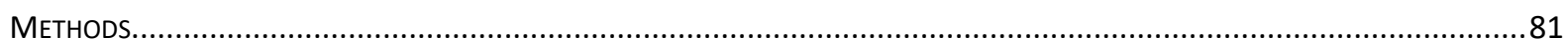

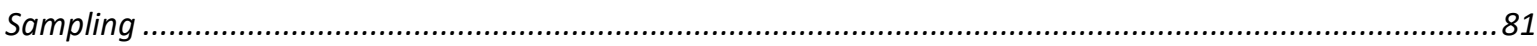

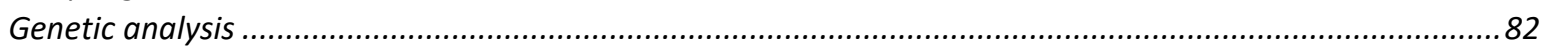

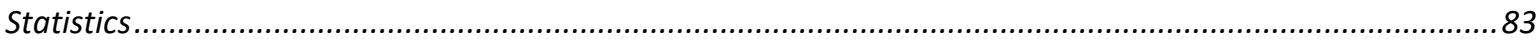

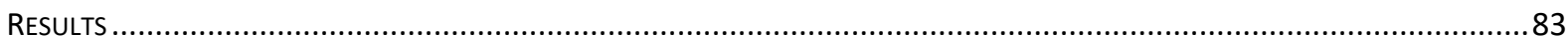

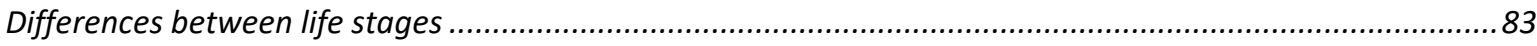

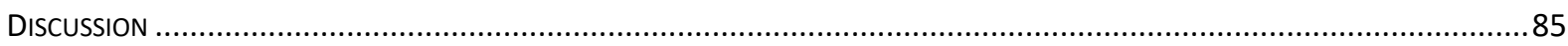

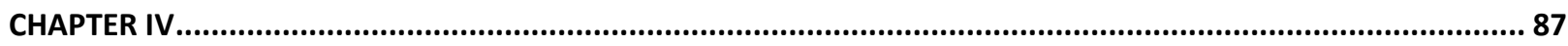

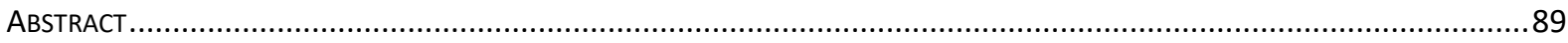

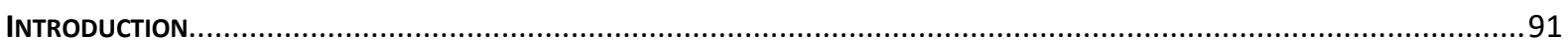

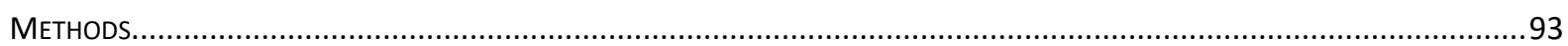

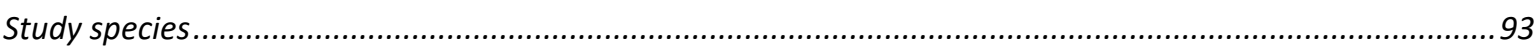

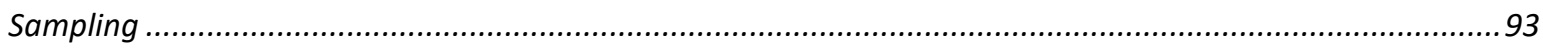

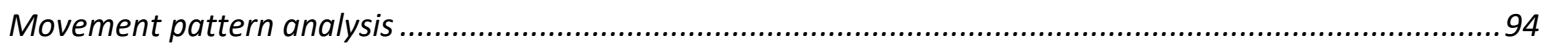

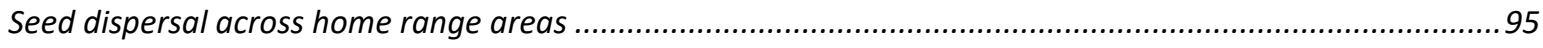

Plant genetic differences between home range areas................................................................95

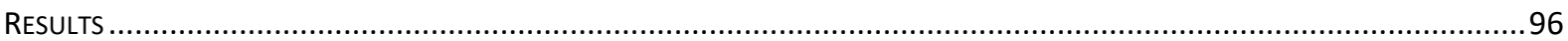

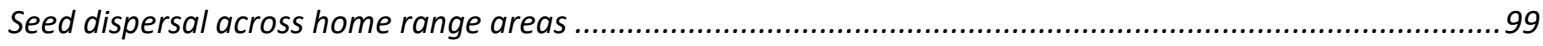

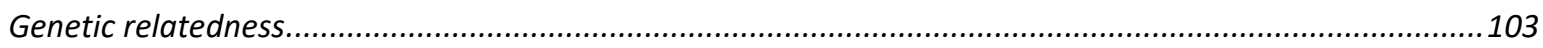

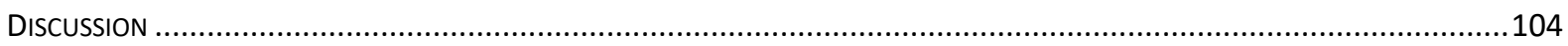

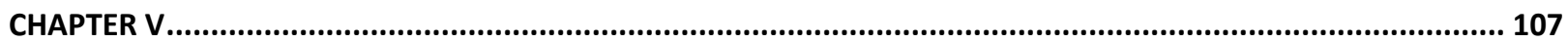

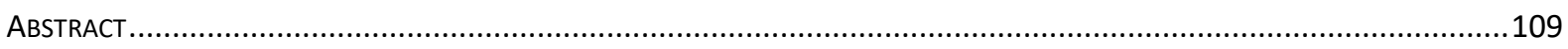

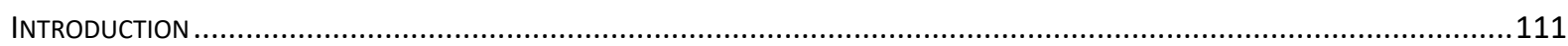

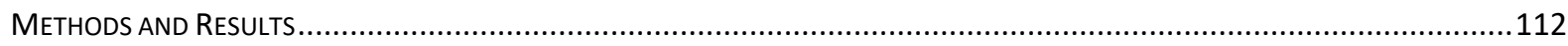

Microsatellite characterization ................................................................................................. 112

Validation of Whatman ${ }^{T M}$ FTA $^{T M}$ PlantSaver cards for microsatellite genotyping .....................................116

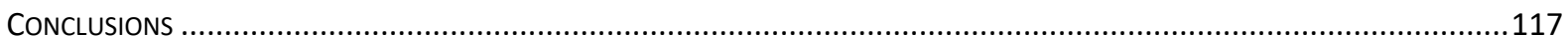

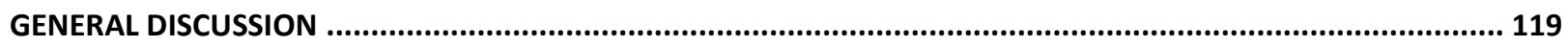

OBJECTIVE I: UNDERSTANDING THE EFFECTS OF ANIMAL BEHAVIOR ON SPATIAL GENETIC STRUCTURE. .....................................121

OBJECTIVE II: CLOSING THE LOOP ON SEED DISPERSAL BY TAMARINS OF LEONIA CYMOSA..............................................124

OBJECTIVE III: TAMARIN SEED DISPERSAL PATTERNS AND ITS INFLUENCE ON PLANT SPATIAL GENETICS OF LEONIA CYMOSA............126

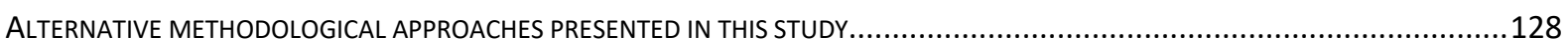

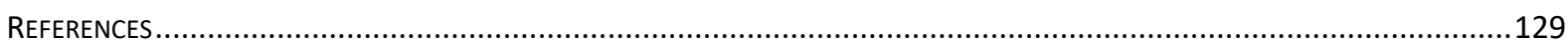




\section{LIST OF TABLES}

Table 1. Categorization of seed dispersers based on feeding and post-feeding behavior traits. ............ 33

Table 2. Information on zoochorously dispersed plant species included.............................................. 38

Table 3. Presence of SGS in zoochorously dispersed plant species. ...................................................... 39

Table 4. Comparison of the strength of SGS, via Sp statistics, among the seed disperser categories for seed dispersal mode, seed disperser taxonomy and seed disperser behavior. ................................... 40

Table 5. Effects of additional factors (i.e. factors other than seed dispersal) on the strength of SGS..... 46

Table 6. Comparison of $\mathrm{Sp}$ values for factors other than seed dispersal between previous studies and

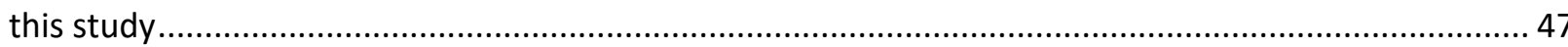

Table 7 Records of seed dispersal events from previous research on the study site.............................6 64

Table 8 Maternal recognition based on direct genotype match of pericarps to adult genotype. ........... 64

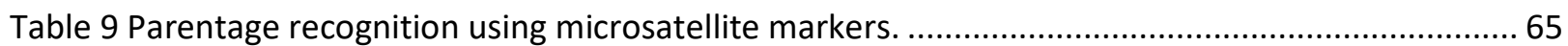

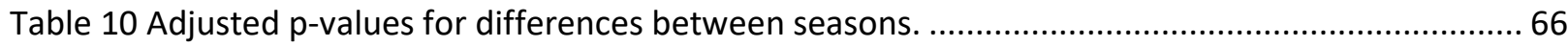

Table 11 Comparison of Seed dispersal (SD) estimates between methods. .......................................... 68

Table 12 Comparison between seed dispersal (SD) estimates for Parkia panurensis using different

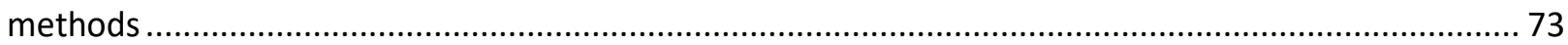

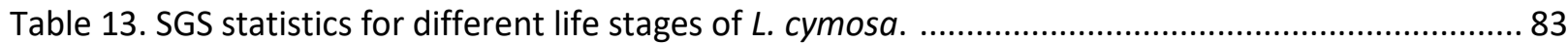

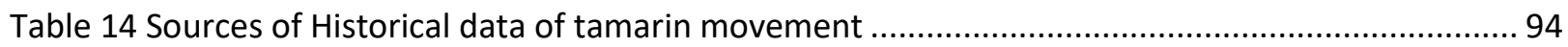

Table 15 Daily travel path lengths of tamarins Group 1,2,3, for the years 2012-2013........................99

Table 16 Parent pairs identified through Parentage Analysis (part 1) ............................................... 102

Table 17 Parent pairs identified through Parentage Analysis (part 2).............................................. 103

Table 18. Characteristics of 11 nuclear microsatellite loci for Leonia cymosa .................................... 115

Table 19 Results of primer application in three Leonia species. ...................................................... 115

Table 20 Compatibility of SSR primers with other populations and other species. ............................. 116 


\section{$\underline{\text { LIST OF FIGURES }}$}

Figure 1 Relationship between seed disperser behavior and plant spatial genetics.

Figure 2 Differences in mean gut passage times of plant species dispersed by Saguinus mystax and Leontocebus nigrifrons

Figure 3 Diurnal and Overnight Gut passage time differences between Saguinus mystax and Leontocebus nigrifrons.

Figure 4 Seed dispersal curve differences between Saguinus mystax and Leontocebus nigrifrons......... 14

Figure 5 Geographical distribution of L. cymosa. ........................................................................ 15

Figure 6 Seed deposition of Leonia cymosa related to tamarin Group 1 movement patterns............... 17

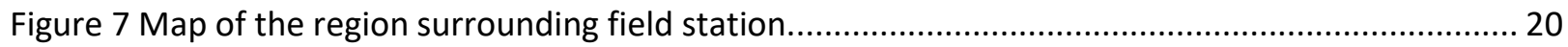

Figure 8. Comparison of $\mathrm{Sp}$ values of plant species with A) different dispersal modes: dispersal through defecation or regurgitation (endozoochory) vs. dispersal through actively carried seeds (synzoochory), B) different taxonomic groups of dispersal vectors, and (C) different functional groups of dispersal vectors.

Figure 9. Relationship between $\mathrm{Sp}$ values and observed seed dispersal distance.

Figure 10. Effects of additional factors on SGS of zoochorously dispersed plants: Pollination mechanism (A), Life form (B), Climate region (C), Sexual system/Breeding system (D). For the monoecious species in $D$, abbreviations indicate mixed-system (outcrossing and selfing) [M], outcrossing [O] and selfincompatible [SI] species).

Figure 11. Comparison of the strength of SGS among plant species that were studied with different types of markers (A), and comparison of Sp values for the subset of plant species for which SGS was determined with different marker types (B).

Figure 12. Effect of plant density on SGS of zoochorously dispersed plants. (A), Changes in Sp values across populations of the same Species with different densities (B).

Figure 13 Sampled areas shown on the map created using qGIS. Tamarin home range delimitation is given for Group 1 (left) and Group 2 (right).

Figure 14. SDD Kernel density estimate of seed dispersal distances according to parentage analysis and all possible maternal combinations.

Figure 15 Linear travel distance $(\mathrm{m})$ of tamarins across the time periods of movement

Figure 16 Movement rate of tamarins during the main rainy season, dissected over increasing time periods.

Figure 17 Changes in kernel density estimate of seed dispersal distances with changes of gut passage time range considered

Figure 18 Location of the 484 dispersed seeds obtained through individual-based modeling.

Figure 19 SDD estimates for Leonia cymosa based on the five methods: observed seed dispersal events (OSD), genotyped seed coats (GSC), parental analysis of seedlings (PAS), combination of movement data and gut passage (CMG), and individual-based modelling (IBM).

Figure 20 Kernel density estimates of seed dispersal distances for the five methods used for Leonia cymosa.

Figure 21 Seed dispersal loop as (modified from Wang and Smith 2002) showing which processes or steps of the dispersal loop are integrated by each method we used for estimating SDD ..................... 70

Figure 22 Seed dispersal curve for Parkia panurensis using tamarin movement data.......

Figure 23 Sampling map for 2014. Exhaustive sampling of seedlings (circles), juveniles (triangles) and adults (asterisks) was done in $50 \mathrm{~m} \times 50 \mathrm{~m}$ quadrats. $12-13$ for each home range area and additional adults sampled beyond quadrats. 
Figure 24 SGS of subpopulations (G1 and G2) of Leonia cymosa. Correlograms between pairwise kinship coefficient $\left(F_{i j}\right)$ and pairwise distance arranged in distance intervals according to a fixed number of distance intervals with a constant number of pairs.

Figure 25 home range areas of tamarin Groups 1-3 (G1, G2, G3) in years for which data were available:

2004, 2007, 2008.

Figure 26 Movement tracks of Tamarin Groups 1-3 for years 2012 (A) and 2013 (B).

Figure 27 Finer detail of Group 1 and Group 2 movement patterns. Daily movement tracks of tamarin Groups 1 and 2, for the years 2012-2013, overlaid to heatmap of locations. Heatmaps show areas with more frequent visitation by tamarins with a darker shade.

Figure 28 Parental links (purple lines) between offspring and the identified parent pair. The three members of each family area numerated with one number (1-17). territory boundaries are shown for year 2012-2013 (gray contours).

Figure 29 Offspring from the in-between area in detail. Map image shows the three offspring (orange O) sharing one parent (P1) within $16 \mathrm{~m}$ and the two offspring (green 0 ) sharing one parent in home range area from tamarin group 2.

Figure 30 Distribution curves of pairwise relatedness values between individuals growing on different territories (grey), and within seedlings on the same territories (black). Life stages are considered separately: seedlings $(<100 \mathrm{~cm})$, juveniles $(100 \mathrm{~cm}-250 \mathrm{~cm})$, adults $(>250 \mathrm{~cm})$

Figure 31 Example of genotyping results obtained using 3 multiplexes (1-3, upper left corner). Peaks are coloured according to the dyes used for each primer (FAM blue, HEX green, TMR black). 114 


\section{LIST OF ABBREVIATIONS}

SGS - Spatial genetic structure

SD - Seed dispersal

SDD - Seed dispersal distance

EBQB - Estación biológica Quebrada Blanco

$\mathrm{KDE}$ - Kernel density estimate

qGIS - Quantum geographic information system 


\section{$\underline{\text { INTRODUCTION }}$}

\section{Background knowledge and objectives}




\section{Importance of seed dispersal}

\section{Advantages of Seed dispersal and its influence in spatial genetics}

Spatial genetics aims to understand the influence of environmental features and biological interactions on gene flow and genetic structure (Guillot et al. 2009). Spatial genetics in plants is determined by the rate, pattern, and extent of gene dispersal within and between populations (Levin \& Kerster 1974; Adams 1992). Gene dispersal in plants is composed of seed dispersal and pollination (Clark 1998). Pollination will transfer only one set of alleles, while seed dispersal will transfer both sets of alleles, composing two-thirds of total gene dispersal (Crawford 1984). Seed dispersal patterns determine the location where seeds will be deposited and the number of conspecifics surrounding the seeds. Effective seed dispersal will take away seeds, to adequate environments, resulting in survival into adulthood (Schupp et al. 2010). The transort of seeds away from source trees brings many advantages concerning plant individual success, population survival to adversity and increased genetic diversity. The advantages of seed dispersal for the plant individuals' success have been addressed by three hypotheses: escape, colonization and directed hypotheses. These state the following advantages, respectively: 1 ) Seed dispersal will allow seeds to avoid overcrowding beneath parent trees, escaping potential density-dependent mortality by predation, diseased and intra-specific competition for resources resulting germination success and survival into adulthood (Janzen 1970; Connell 1971; Augspurger 1984). 2) Seed dispersal will take seeds to other environments increasing the probability of finding appropriate conditions for growth (Howe \& Smallwood 1982). 3) Seed dispersal will allow for species with particular needs, such as epiphytes, to directly get where they can grow (Wenny 2001). The advantages of seed dispersal regarding habitat and species conservation include seeds reaching degraded habitats and promoting regeneration (Culot et al. 2010). Furthermore, seed dispersal increases the probability of finding suitable areas where the species can survive in cases of disturbances potentially driven by climate change, deforestation and invasive species (Snyder 2011; Ruxton \& Schaefer 2012). Finally, seed dispersal brings advantages in terms of spatial genetics (Hamrick et al. 1993), it increases the probabilities of mating between spatially distant, non-related, individuals, reducing the probability of biparental inbreeding, decreasing the incidence of unfavorable traits and increasing genetic 
diversity (Lowe et al. 2004; Nature 2010). High genetic diversity defines a large gene pool that makes the population more resilient to environmental changes (Schaberg et al. 2008).

\section{Frugivore behavior determines dispersal patterns and spatial genetics}

Different mechanisms can disperse seeds, theese include abiotic mechanisms: barochory, hydrochory, anemochory, and biotic mechanisms, such as, zoochory (endo-, epi- or synzoochory) or self-propulsion (Murray 1986). Seed dispersal patterns vary according to seed dispersal mechanisms, abiotic mechanisms are related to higher spatial aggregation of seedlings than biotic mechanisms, which can last into adulthood (Seidler \& Plotkin 2006) and can translate into differences in spatial genetic structure (Hamrick et al. 1993). While seed shadows created by abiotic vectors depend on the physical properties of the environment, those created by animal vectors depend on their daily decisions (Côrtes \& Uriarte 2013). These daily decisions will depend on resource availability, environmental constraints, biological interactions and intrinsic characteristics of animal behavior. Foraging behavior and post-feeding movement range affect seed dispersal pattern and distance and resulting spatial genetics (Figure 1). Free roaming animals with few environmental constraints, like the Mongolian gazelles (Olson et al. 2010), can have very long dispersal distances consequently increasing the probability of seed shadow overlap between distantly located plant individuals, increasing future mating probability between these conceivably unrelated individuals. Reduced availability of resources or specific reproductive sites, might drive animals to make long distance movements, carrying over seeds with them and increasing connectivity between distant populations (Herrera et al. 2011; Uriarte et al. 2011). Animals with restricted home ranges or defined territories will feed only on those areas, reducing the probability of overlap between seeds shadows of plants growing on separate home ranges or territories, thereby increasing their spatial genetic distance with time (Karubian \& Durães 2009). Restricted seed dispersal could lead to genetic differentiation between populations. Differentiation risk increases with distance among population subdivisions and by restricted pollination (Williams \& Guries 1994). Lack of gene flow between territories has been analyzed for pollination by hummingbirds (Linhart 1973), and although gene flow across territories has not been studied for seed dispersal, research shows territories restrict seed dispersal and decrease seed dispersal distances even in animals with long daily paths (Yumoto et al. 1999) and long gut passage times (Rodríguez-Pérez et al. 2012). Furthermore, the frequent 
use of areas by dispersal vectors has been seen recurrently to have genetic effects on the dispersed plants (Hanson et al. 2007; García et al. 2009; Karubian et al. 2010, 2015; Muñoz Lazo et al. 2011).

The movement of seeds away from fruiting trees creates an area of seed deposition denominated seed shadow. Each fruiting tree has its own seed shadow, and the amount of overlap between these will determine the future genetic structure of plant populations (Fleming \& Heithaus 1981; Hamrick \& Loveless 1986). The shape of seed shadows will be determined by the seed dispersers' visitation rate and the number of seeds dispersed away from the seed source, and how far these are dispersed (Chapman \& Russo 2002). If seed shadows strongly overlap, the distribution of individuals in space will not be related to their genetic makeup, and it will be considered random. These individuals will not show any genetic patterns in space, i.e., no spatial genetic structure (SGS). Limited dispersal with reduced overlap of seed shadows causes genetic isolation to build up over generations, and relatives will exhibit a degree of spatial proximity creating a spatial genetic structure (Epperson 2003). Vice versa, when populations are strongly genetically structured it is an indication that seeds are not homogeneously mixed and seed dispersal distances are possibly restricted (Williams \& Guries 1994). This can happen when plant species are dispersed by gravity (Ibanes et al. 2015) or if dispersing vectors are absent in the area (Wang et al. 2009). It may also happen if biotic vectors are present in the area but their movement is limited after feeding, by physical or biological constraints, or if their feeding behavior itself creates an accumulation of seeds (Choo et al. 2012) or if they repetitively use sites for resting or sleeping (Karubian et al. 2015). There is a direct relationship between the presence of spatial genetic structure within a population and its seed dispersal system (Vekemans \& Hardy 2004). Moreover, even though pollination can counteract and maintain gene dispersal, it has not been seen to counteract the formation of SGS in the presence of restricted seed dispersal (Krauss et al. 2009). 


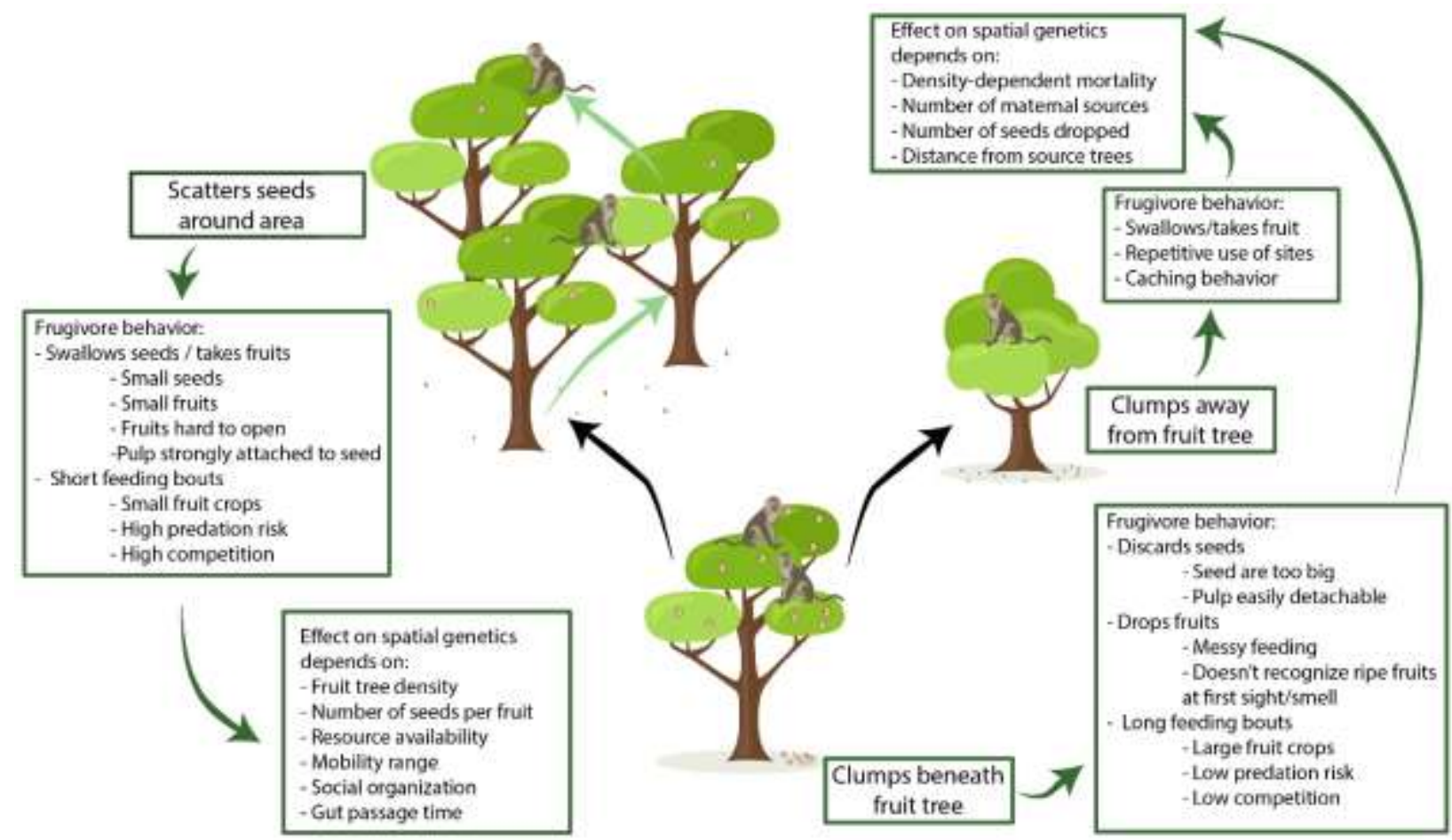

Figure 1 Relationship between seed disperser behavior and plant spatial genetics. Animals can either disperse seeds in clumps or scattered around area. The effect of these seed dispersal patterns on spatial genetics will depend on different factors. Whether clumps lead to spatial genetic structure will depend on the number of maternal sources, the size of the clump, the distance from source trees and whether survival is density dependent. Scattered seeds will affect spatial genetics differently according to seed dispersal distance and distance between conspecifics and siblings which will depend on several factors influencing movement pattern and extent of dispersers.

\section{Primate seed dispersal}

Large primates in the tropical rainforest disperse a $70-93 \%$ of the fruit species they handle (Bufalo et al. 2016). Seed shadows by primates are the result of the interaction between primate traits and the dispersed plants' traits (Chapman \& Russo 2002). Primates, as a group, display such a wide-ranging set of traits that the generated seed shadows will be highly heterogeneous. The main determinants of seed shadows will be seed handling, ranging pattern and gut passage time (Gross-Camp \& Kaplin 2011). Seed handling will depend on seed or fruit size, and primate size or internal anatomy. Most primates in the Neotropics and the Paleotropics swallow seeds, although seed spitting is common in African and Asian cheek-pouched monkeys (Cercopithecinae) (Corlett \& Lucas 1990; Dominy \& Duncan 2005). Large home ranges and long daily travel paths of primates can also contribute to wide seed shadows (Wehncke et al. 2003). Gut passage time can also increase the extent of seed shadows, and depends on body size, 
digestive anatomy, seed size and pulp consistency (Milton 1984; Benítez-Malvido et al. 2014). The gut passage can also affect germination success, sometimes enhancing it (Otani 2004; Petre et al. 2015).

Some case studies on seed dispersal by primates are available for the subtropical Asian region (Corlett 2017). For example, orangutans can spit out seeds up to $74 \mathrm{~m}$ away from the seed source (Corlett 1998; Nielsen et al. 2011). Gibbons can disperse seeds more than $90 \%$ of seeds for beyond $100 \mathrm{~m}$ and up to $1300 \mathrm{~m}$ (McConkey \& Chivers 2007). In contrast, Colobine monkeys destroy most of the species they consume, for example, only $11 \%$ of seeds were found in fecal samples of proboscis monkeys in Borneo (Matsuda et al. 2013). In the Neotropics, primates can disperse up to 112 species, with a rate of 50\%-99\% of intact seeds, and seed dispersal distances between $0 \mathrm{~m}$ and 1,540 m, most of which beyond $100 \mathrm{~m}$ (Fuzessy et al. 2017). Primarily frugivorous primates, with moderate gut passage time and long daily path lengths within large home ranges, dispersed the farthest away. Instead, large folivore-frugivore howler monkeys have long gut passage times but short daily paths within their home ranges and slow movement rates, potentially with shorter seed dispersal distance regardless of long gut passage time (Milton 1981). Several other factors can also influence the role of primates as seed dispersers, such as interspecific associations, human activities and crop-access (McConkey \& O'Farrill 2016). Therefore, primates can have very different seed shadows, which will lead to different effects at the spatial genetics level.

\section{Tamarin seed dispersal}

Tamarins are small primates, but they are no exception to the seed dispersal role of primates, as they disperse almost $60 \%$ of the fruit species they handle (Knogge \& Heymann 2003). Tamarins are also efficient seed dispersers: $95 \%$ of their depositions contain intact seeds and in low numbers (mean 1.4 seeds) (Garber 1986; Knogge et al. 2003), which guarantees low competition for germination and low predation risk (Culot 2009). Tamarins disperse a wide range of seed sizes (0.1 to $23 \mathrm{~mm}$ ) (Knogge \& Heymann 2003). The gut passage times of the seeds they consume changes with seed size and pulp composition (Knogge pers. comm.) for some species it can be as a long as 4 hours, and it has been proven to have no negative effects on germination (Knogge 1999; Knogge et al. 2003). The average gut passage time through tamarins is $174 \pm 57$ min for S. mystax and $133 \pm 21 \mathrm{~min}$ for L. nigrifrons (unpub. data). Tamarins 
can have strong ecological impacts regarding forest regeneration, since, given their small size, tamarins can enter disturbed forests, bringing seeds in their guts with them, promoting regeneration (Culot et al. 2010). Overall, tamarins seem to have a high probability of being effective seed dispersers: many fruits are dispersed far away from each fruiting tree mostly singularly, reducing competition and density-dependent mortality (Schupp et al. 2010, 2017; Schupp \& Jordano 2011).

The two species of tamarins of this study live in mixed-species group: Saguinus mystax (commonly known as moustached tamarin) and Leontocebus nigrifrons (commonly known as saddle-back tamarin, previously named Saguinus fuscicollis nigrifrons (Hershkovitz 1977) and later Saguinus nigrifrons (Rylands \& Mittermeier 2014) but recently reproposed as a distinct genus, Leontocebus (Sampaio et al. 2015; Rylands et al. 2016) given their genetic divergence (Matauschek et al. 2011). Living in a mixed-species group provides the safety advantages of large group associations with reduced intra-specific competition. Both species live in two different vertical strata of the rainforest (S. mystax $5-15 \mathrm{~m}$, L. nigrifrons $<5 \mathrm{~m}$ ), possibly reducing resource competition and having a complementary role when it comes to vigilance against predators (Stojan-Dolar \& Heymann 2010b). The two species are in association an average of $82 \%$ of the time, S. mystax being dominant over L. nigrifrons, with predominant access to large food patches, and most often initiating feeding bouts. If food patches are large enough, both species can feed together, while in smaller patches $L$. nigrifrons are excluded. Therefore, if $L$. nigrifrons finds small patches of fruit, they rapidly eat these before S. mystax individuals arrive (Peres 1996). Most direct interactions are agonistic, however, competition costs are low and counterbalanced by the advantages of their association, such as a higher detection rate of fruits (Heymann 1990). The feeding behavior and ranging pattern of the two species is highly coordinated (Garber 1986), sharing $80-85 \%$ of the fruit species eaten (Peres 1993), one of these being Leonia cymosa (Knogge 1999; Culot 2009).

\section{Feeding and foraging behavior}

Tamarins spend circa $40-55 \%$ of their daily activity budget on feeding and foraging (Knogge \& Heymann 2003; Reinehr 2010). The two species eat fruits, insects and trunk exudates, and when fruits are scarce, nectar from flowers as well. Fruit pulp composes a mean of $65 \%$ of their diets, and their fruit feeding activity is most intense during the first three to four hours 
after sunrise (Garber 1986). Tamarins are generalist frugivores: they eat a high number of fruit species with small fruit crop sizes, changing species consumption based on fruit availability (Garber et al. 1993). Almost 40\% of fruits they consume are yellow, and the preference for these does not change over the year with fruit-color availability (Knogge 1999). Green, brown and red fruits are also consumed but in lower quantities. As a result, over $45 \%$ of the seeds defecated by tamarins belong only to yellow-colored fruits (Knogge 1999).

Tamarins usually open the fruits, discard the exocarp (outer layer) and consume the mesocarp (pulp). They have not been observed masticating seeds, nor destroyed seeds have been seen in their depositions (Knogge 1999). This evidence shows tamarins do not usually act as seed predators, except for certain species with small, juicy berries (E.g., Ficus spp. Tococa guianensis) from which they consume the juice, crashing the seeds and spitting them with the residual fruit (Knogge, 1998). Nonetheless, over $70 \%$ of the fruits they consume have a jelly-like, slimy pulp, with the seeds strongly adhered to the pulp, which swallowed completely. Tamarins also eat fruits with mealy or fibrous pulp, albeit in lower proportions (Knogge 1999). Seeds from these fruits are rarely swallowed, the fibrous pulp is gnawed, and then the seed is spat while mealy pulp is scraped from the seed's surface leaving the seed behind.

The fruit species they consume are mostly single-seeded fruits, with seeds over $1.5 \mathrm{~cm}$ and $0.70 \mathrm{~cm}$, only $20 \%$ of these with seeds over $1.5 \mathrm{~cm}$ (Garber 1986). However, they also eat many-seeded fruits with thin pericarps that are often ingested as a whole. Large seeds with fibrous, thick pericarps are usually discarded, but if the fibrous fruits are relatively juicy, and small, they are ingested with the seed as well (Peres, 1993). Seeds that are ingested will leave the intestinal tract without damage. Field experiments showed over $90 \%$ of seeds that had been through the tamarins' gut had a germination success rate equal to the control seeds, and around $5 \%$ had a positive effect on germination success.

Depending of fruit pulp composition, seed volume and resting patterns, tamarins have a gut passage rate of one to five hours (Garber 1986; Knogge 1999), 90\% of the seed species have an average gut passage time $\leq 3.5$ hours in S. mystax $(\mathrm{N}=49)$ and $<4$ hours in L. nigrifrons $(\mathrm{N}=65)$ [Knogge, 2009]. Gut passage times have been previously related to body mass of seed dispersers and its gut complexity (Wotton \& Kelly 2012; Fuzessy et al. 2017). Supporting this theory, S. mystax, is bigger than L. nigrifrons (in average $515 \mathrm{~g}$ and $362 \mathrm{~g} .$, respectively) and has overall 
significantly longer gut passage times $(2.9 \pm 1 \mathrm{hr}$ and $3.9 \pm 0.3 \mathrm{hr}$, respectively; Figure $2 \mathrm{~A})$ (Knogge 1999). Furthermore, they also differ in the distribution density curves of the mean gut passage time of the several plant species they disperse. Saguinus mystax has a wider bell curve, with more species having a mean gut passage time between 1.5 and $3.5 \mathrm{hrs}$. while $L$. nigrifrons has a higher frequency of species dispersed in average between $1.75 \mathrm{hrs}$ and $2.75 \mathrm{hrs}$ after feeding (Figure 2B). Gut passage time of plant species consumed by tamarins has been previously significantly correlated with seed dispersal distances (Knogge 1999).
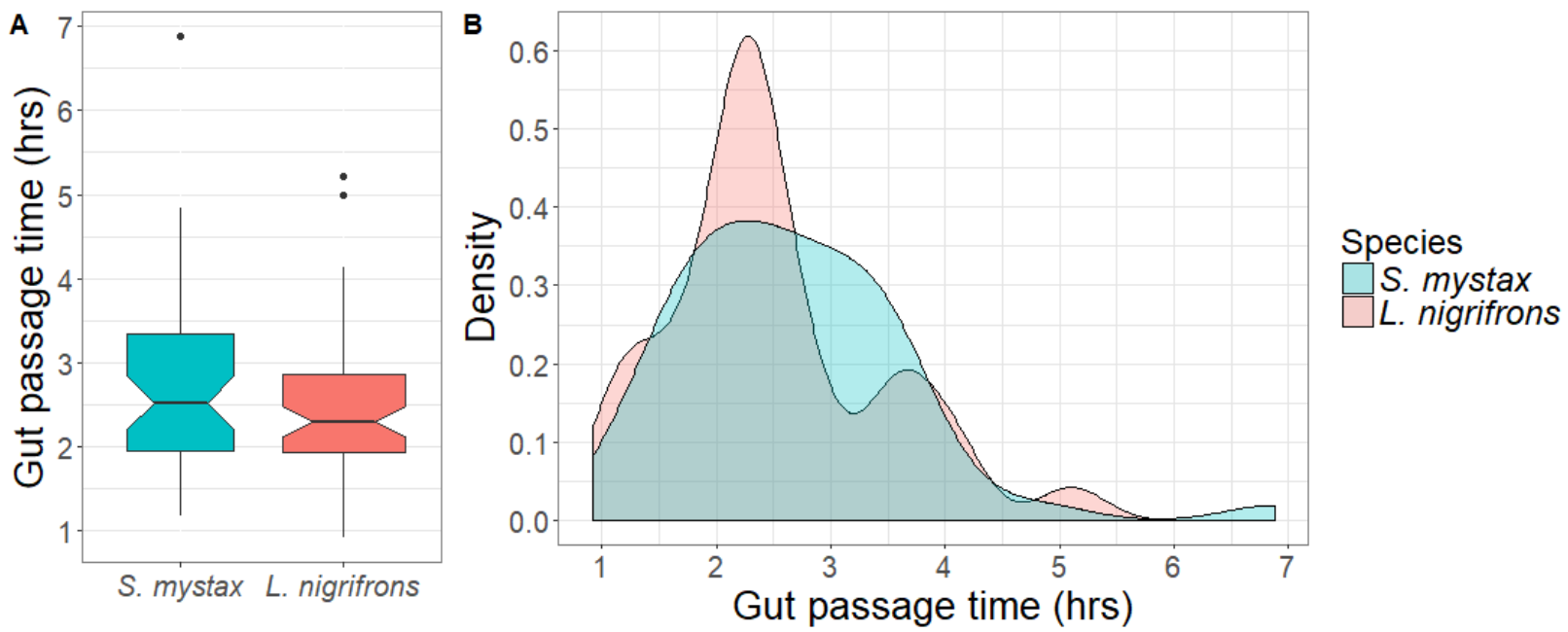

Figure 2 Differences in mean gut passage times of plant species dispersed by Saguinus mystax and Leontocebus nigrifrons (A). Distribution curve of diurnal gut passage times of the plant species dispersed by the tamarins (B) plot made with the ggplot2 package, geom_boxplot(), geom_smooth() function in $R$, with data from Knogge, 1998.

Seeds that remain on the tamarins' gut when the tamarins retire to their sleeping sites are deposited within the first few hours of the following morning (Figure 3). 


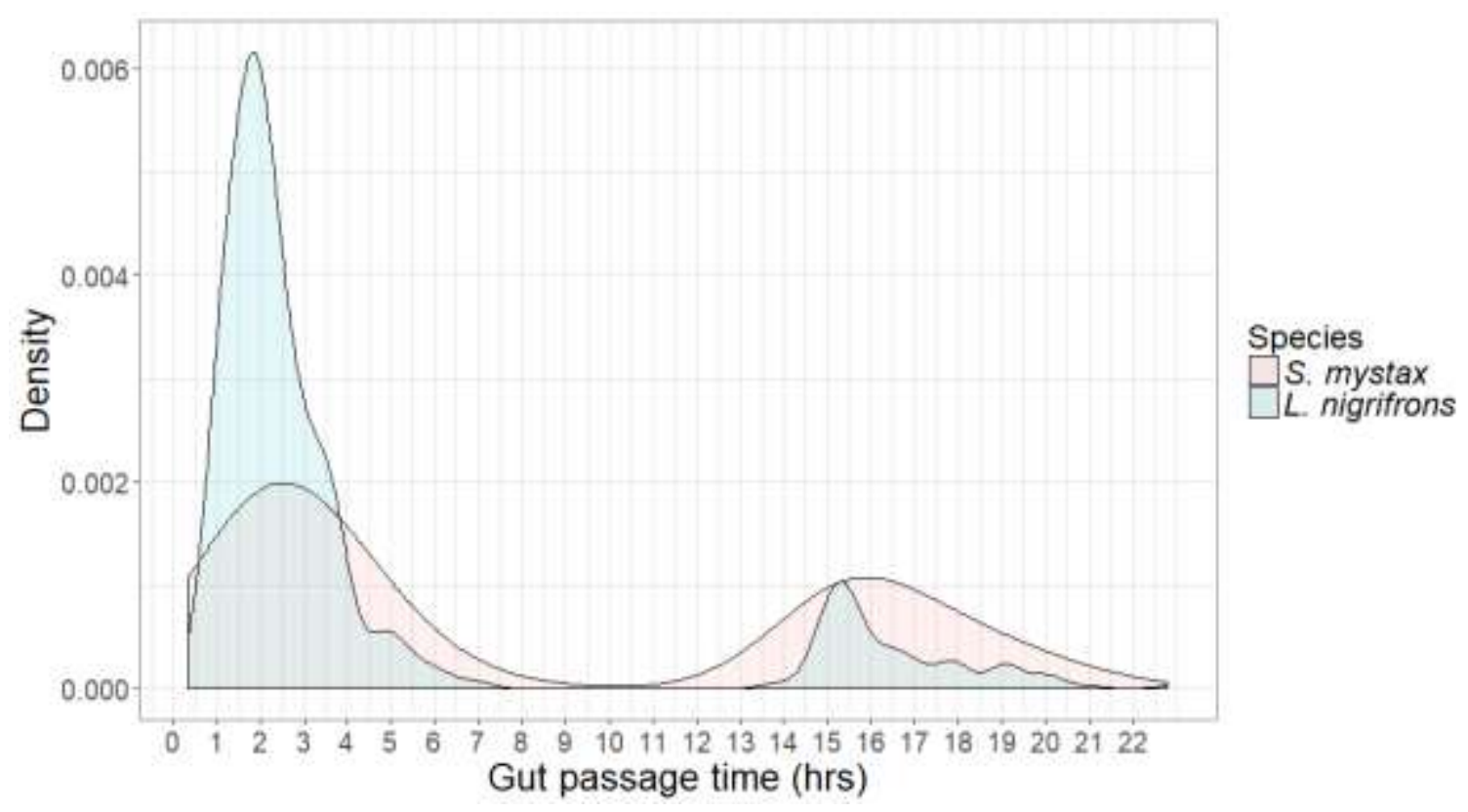

Figure 3 Diurnal and Overnight Gut passage time differences between Saguinus mystax and Leontocebus nigrifrons. Plot made with ggplot2 package, geom_smooth() function in R, with data from Knogge, 1998.

\section{Sleeping and resting sites}

Repetitive use of areas, such as sleeping or resting sites, can influence seed dispersal, creating an accumulation of seeds under these (Chapman \& Russo 2002; Muñoz Lazo et al. 2011). Tamarins can use $>80$ sleeping trees in their home range, with an average of 2.75-3.35 nights spent on each sleeping site (Smith et al. 2007). These sleeping sites are mainly located in the central area of their home ranges (Smith et al. 2007). Tamarins spend between $23 \%$ and $30 \%$ of their daily activity budget resting on resting trees, of which $61 \%$ are used repetitively (Reinehr 2010; Muñoz Lazo et al. 2011). The number of sleeping trees and resting trees, the number of nights spent on these and the total resting time during the day, are positively correlated with seed deposition densities (Knogge 1999). Even though within resting sites tamarins disperse significantly more seeds than outside resting sites, seed survival is not influenced by this clustering of seeds under resting and sleeping sites (Muñoz Lazo et al. 2011). Therefore, a higher concentration of seedlings is generally found under these sites. Tamarins visit resting sites a median of 2 times per day $(\max =5, \mathrm{n}=86)$. The two species rest mainly in trees $(S$. mystax $=$ $60.6 \%$, L. nigrifrons $=89.2 \%$ ), however L. nigrifrons uses dead trunks too. Given the vertical stratification, S. mystax rests in higher places $(12.5 \mathrm{~m})$ than L. nigrifrons $(5 \mathrm{~m})$. Resting sites are 
abundant in areas with a high density of feeding trees (Muñoz Lazo et al. 2011). According to fruit availability, resting sites may change seasonally and yearly, potentially homogenizing seed dispersal patterns.

\section{Movement patterns and home ranges.}

Around our study site, there are six mixed-species groups of tamarins. Their home ranges have little spatial and temporal overlap; however, the home range areas of these groups have shifted gradually in 20 years (Heymann et al. 2017). Fruit availability seems to be the main determinant of these temporal shifts in home range delimitations (Culot 2009). The groups under analysis within this Ph.D. project are Group 1, located NW of the field station and Group 2 located SE of the field station. Leonia cymosa, the focus plant species of the project, is present in both group areas. These two groups have been adjacent to each other for several years until the year before our sampling, 2013. In 2013 Group 3, normally located N of the field station has shifted its home range to in between these groups. The area covered by group 3 previous to 2013 does not contain any Leonia cymosa. However, area in-between group 1 and group 2, now covered by group 3, does contain low numbers of L. cymosa.

Tamarins are stable foragers, keeping the same feeding and movement patterns (Garber et al. 1993). Movement patterns of the tamarins are random and convoluted, especially during prey foraging (Knogge 1999). However, they can remember locations and fruiting schedules of trees, therefore, during fruit feeding bouts, they usually travel in a direct line between fruiting individuals (traplining behavior). Consequently, they can travel over much of their home range each day, efficiently concentrating their efforts on a large number of fruiting individuals from a limited number of fruiting species (Garber 1986). Average daily travel distance is $1508.9 \pm 251.8$ $\mathrm{m}$ for S. mystax and $1425.3 \pm 288.6 \mathrm{~m}$ for L. nigrifrons (Reinehr 2010). However, the marked the delimitations of their home range area, and seldomly cross over these (Culot 2009), limiting their maximum seed dispersal distances to the diameter of their home range areas.

\section{Seed dispersal distances}

Seed dispersal curve by tamarin shows a leptokurtic distribution ( $N=1180$ seed dispersal events observed by Knogge in 1998), with the mode between 50 and 150m from fruit sources. 
Despite their gut passage time difference described above, the two species of tamarins show no evidence of differences among their seed dispersal patterns (Figure 4, Knogge 1999).

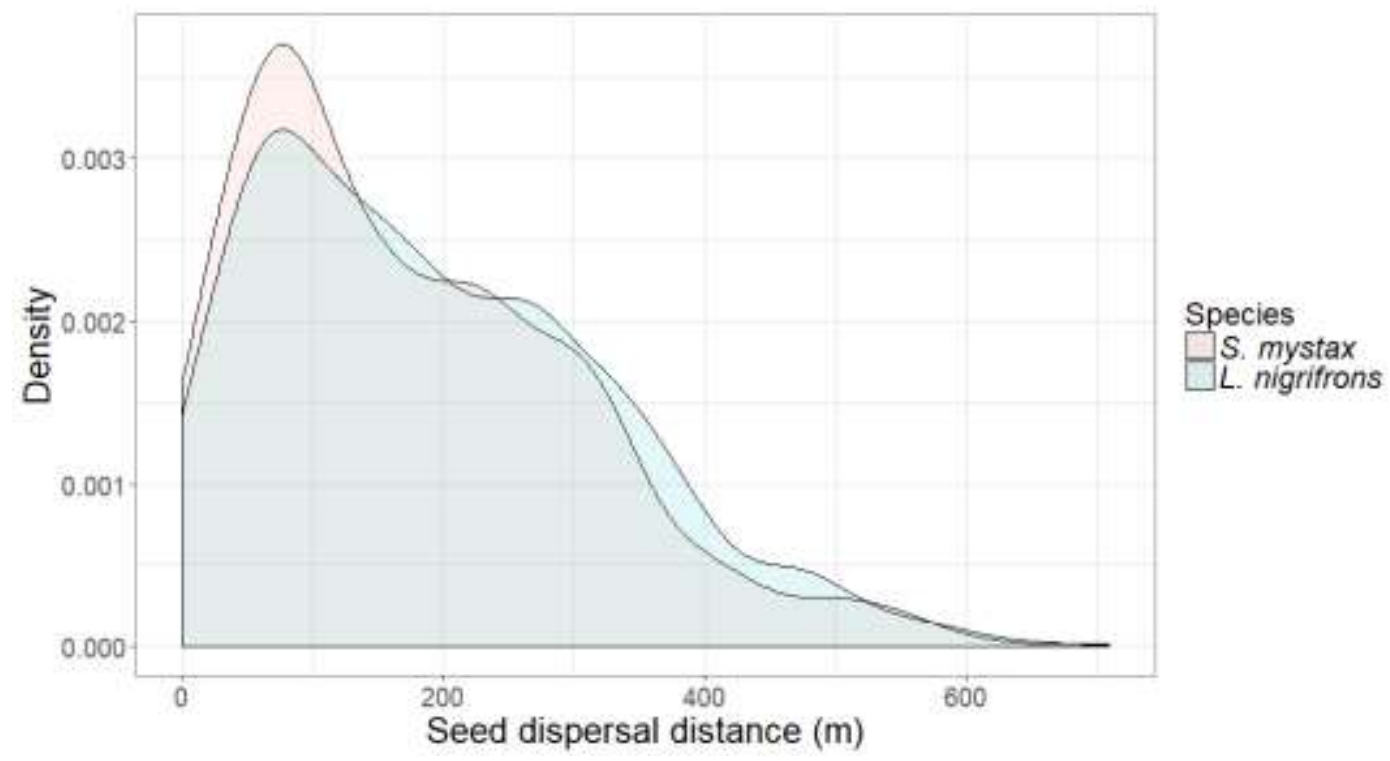

Figure 4 Seed dispersal curve differences between Saguinus mystax and Leontocebus nigrifrons. Plot made with ggplot2 package, geom_smooth() function in R, with data from Knogge, 1998.

Tamarins disperse 88 of the 155 species exploited for fruit (Knogge \& Heymann 2003). Plant, fruit and seed characteristics of dispersed species do not differ between S. mystax and $L$. nigrifrons (Knogge 1999). For both tamarin species, seed dispersal distance estimates remained constant over time and range between 0-730 m, with most seeds being dispersed around 152$183 \mathrm{~m}$ and less than 3\% dispersed beyond 10m (Heymann et al. 2017).

\section{Leonia cymosa as a model for seed dispersal}

Leonia cymosa is a relatively unknown species. Its seed dispersal ecology has been previously studied in Ecuador (Pfrommer 2009), where height, phenology, and dispersal systems differ from our study site in Peru (Reinehr 2010). L. cymosa has also been studied for its pharmacological application in relationship to HIV, and its biochemical content in relationship to scent component and its role in seed dispersal by primates (Hallock et al. 2000; Nevo 2015).

Leonia cymosa Mart. (Violaceae) is a small Neotropical understory tree, with an average height of 7m (Adults: min 2.5 m.; max 11.5m) (Reinehr 2010), a diameter at breast height (dbh) of $\leq 10 \mathrm{~cm}$ and a crown volume significantly correlated with height (5-115 $\mathrm{m}^{3}$ ) (Pfrommer 2009). L. cymosa can be identified by their irregularly curved thin trunks and their characteristic leaves: 
oblong-elliptical leaves, $10-18 \mathrm{~cm}$ long and $4-7.5 \mathrm{~cm}$ wide with the sides slightly serrated and with an alternate arrangement (Pfrommer 2009). It is geographically distributed on the north and north-west area of the Amazon rainforest (Figure 5). Leonia cymosa is spatially arranged in clusters of different sizes and has high variance when it comes to plant population density (3.823 ind/ha) (Pfrommer 2009).

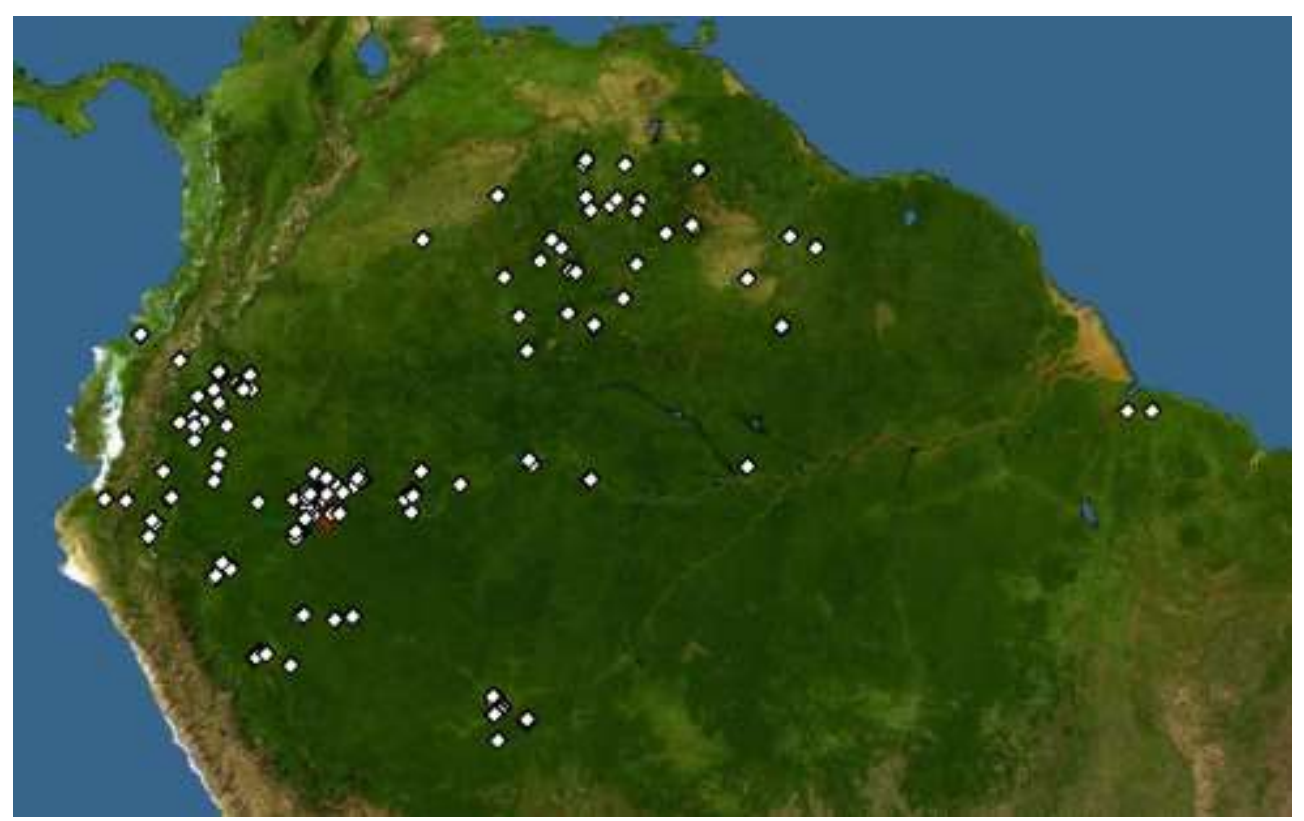

Figure 5 Geographical distribution of $L$. cymosa. Paces were $L$. cymosa has ben observed ( ). Field station EBQB marked in red.

Flowers are small, yellow-orange, $3-4 \mathrm{~mm}$ each, irregularly arranged in a sympodial inflorescence (Macbride 1941). Based on flower morphology, it is most probably pollinated by insects (Michael Schwerdtfeger, pers. com.). Stingless bees (Meliponinae) have been observed around crowns during flowering, in Ecuador (Pfrommer 2009). After flowering, fruiting development requires up to two months, and fruit maturity requires three more months (Pfrommer 2009). Fruiting seasons can have a duration of 2-4.5 months (Pfrommer 2009)ere fruits ripen asynchronously. Fruiting periods can be variable between areas, for example, in Ecuador, its fruiting season repeats twice a year, while on our study site, fruits usually ripen once a year, from February to May, within the main rainy season (Reinehr 2010).

Fruit crop size ranges between 1 to 120 fruits, with high inter-annual variation even within individuals (Pfrommer 2009). Fruits are spherical berries with a mean diameter of $1.8 \mathrm{~cm}$ (range 1-3.4 cm) and a mean mass of $2.1 \mathrm{~g}$ (range 1.2-15 g) (Reinehr 2010). During the ripening 
process, fruits change in color (dark green to yellow) (Reinehr 2010), and in scent complexity (Nevo et al. 2016), woody pericarps become softer and easily detachable from the pulp. The pulp is white-yellow, fibrous, high in sugars and proteins, and tightly adhered to the contained seeds (Pfrommer 2009; Reinehr 2010). Fruits contain mostly 1-2 seeds, (max seven seeds), with an average weight of $0.45 \mathrm{~g}$. (Reinehr 2010). Fruit size has been significantly correlated to seed number (Pfrommer 2009). Fruits must be consumed in order to germinate, seeds that remain inside the husk will inevitably be decomposed in 1-2 weeks (Pfrommer 2009).

Leonia cymosa shows characteristics of having a specialized seed dispersal system by producing few fruits per tree and having a high nutrient content (Howe 1993; Pfrommer 2009). The only known consumers and primary seed dispersers are tamarins (Saguinus spp. and Leontocebus spp.) and squirrel monkeys (Saimiri spp.) (Pfrommer 2009; Reinehr 2010). At our study site, camera traps done by Reinehr (2010) revealed that L. cymosa is exclusively dispersed by S. mystax and L. nigrifrons. Leonia cymosa is, therefore, a good model for understanding the effects of frugivore behavior and plants spatial genetics.

\section{Feeding behavior of tamarins on Leonia cymosa}

During the field work time of this thesis Leonia cymosa did not fruit, but from previous analysis (Reinehr 2010) 164 feeding episodes on 95 different L. cymosa were recorded. A mean of $7.5 \pm 4.3$ individuals of $L$. cymosa ( $\min =1, \max =14, \mathrm{n}=20$ days) were visited per day, from which a single individual of $L$. cymosa was visited a mean of $1.8 \pm 1.1$ times during the recordings $(\max =6, n=89)$. A mean of $5.2 \pm 4.3$ fruits $(\min =1, \max =38, n=157)$ were eaten per feeding episode. From the fruits eaten, $70 \pm 28 \%$ were ripe ( $\min =0 \%$, $\max =100 \%, n=71$ ). Fruiting trees were visited by a mean of $2.17 \pm 1.19$ individuals at a time $(n=82)$, with a maximum of 4 individuals of S. mystax and a maximum of 5 individuals of L. nigrifrons. Both tamarin species fed together on the same tree $23.4 \%$ of the feeding episodes recorded $(n=110), 13.3 \%$ S. mystax fed alone and $63 \%$ of the time L. nigrifrons fed alone. The whole intra-specific group of S. mystax (5 individuals) was never seen completely on one L. cymosa tree, while for L. nigrifrons this was seen 4 times out 110 feeding episodes recorded. Feeding bouts were 2:08 \pm 2:01 minutes long $(\min =0: 08 \mathrm{~m}, \max =9: 57 \mathrm{~m}$.$) for S$. mystax and 1:48 $\pm 1: 30$ minutes long (min=0:06m, $\max =10: 13 m$.) for L. nigrifrons. 
Reinehr (2010) showed seed depositions are not homogenous across the home range. Tamarins spent $50 \%$ of their time in 9 ha out of the 26 ha they spent $95 \%$ of their time on. Within these 9 ha, they also deposited $50 \%$ of L. cymosa seeds (Figure 6). Reinehr shows how tamarin movement patterns and seed deposition of L. cymosa are strongly correlated.

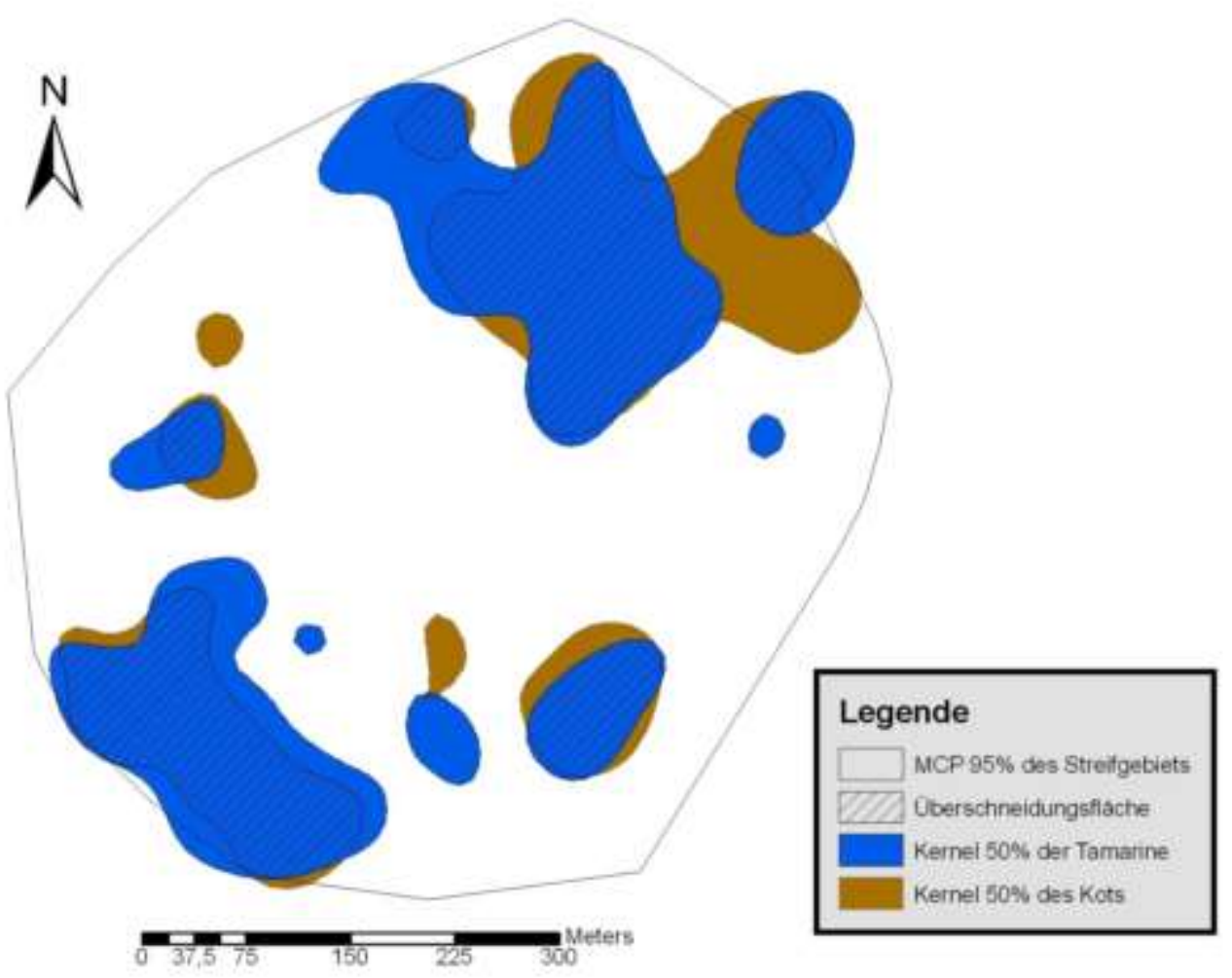

Figure 6 Seed deposition of Leonia cymosa related to tamarin Group 1 movement patterns. 50\% kernel of seed depositions (brown) overlaps $\mathbf{5 0 \%}$ kernel of area used by tamarins (blue) within the 95\% of area used (i.e. home range) (--). Image from Reinehr (2010).

\section{Understanding seed dispersal using molecular markers}

Seed dispersal can be very hard to quantify for species that have dispersal vectors with complex behaviors or seeds that are hard to follow from source to deposition area. Fruit traps or removal count (Davidar \& Morton 1986), seed tags (Sidhu \& Datta 2015) radio-tags (Pons \& Pausas 2007), camera traps (Koike 1994; Kitamura et al. 2009; McConkey et al. 2015), vector radio-tagging, and isotope impregnation, have been used to overcome these limitations and understand seed dispersal. An alternative and recently a very common approach, is to use molecular markers to analyze the genetics of the plant and work backwards towards understanding seed dispersal and how environment and vectors affect it. In fact, since the 
genetic makeup of populations is related to seed dispersal, analyses of genotypes can give a backward insight on seed dispersal and the processes related to it.

Molecular markers (e.g., microsatellites, AFLP, RAPD, SNPs, and DNA barcoding) are used to distinguish individuals and their relatedness through its genetic information. Hence, without the need to follow the precise movements of vectors or seeds, we can understand distances and patterns with which seeds are being deposited (Hamrick \& Trapnell 2011). Relatedness in space between individuals and within and among life stages gives an insight on temporal and spatial patterns of seed dispersal. With molecular markers, direct observations of seed dispersal events are not needed, but these two approaches can also be combined to directly recognize maternal sources from seed tissue (Heymann et al. 2012; Thompson et al. 2014). Furthermore, molecular markers can also be used to recognize which frugivore species dispersed the seeds, through DNA fingerprinting (González-Varo et al. 2014) and to quantify genetic influx of populations through parentage analysis, either using known parental sexes or sex-specific markers (ie. ctDNA) (Ramos et al. 2016b; Torroba-Balmori et al. 2017).

Microsatellite markers are the most popular and versatile marker type for ecological studies. These markers are regularly used to study population differentiation, spatial genetic structure analysis, migration rates, population size, bottlenecks, parentage analysis (Selkoe \& Toonen 2006). Microsatellites (a.k.a. simple sequence repeats SSRs) are short tandem repeats of DNA (10-50 copies), with high mutation rates, present in non-coding regions (Vieira et al. 2016). The tandem repeats can be made of repetitions of one to four bases (i.e., mono- to tetranucleotide repeats). Polymorphisms of these repeats are usually the result of changes in the number of repeat units due to mutations that cause the addition or deletion of bases. Therefore genotyping of microsatellites is based on the different size forms each microsatellite locus can have (Lowe et al. 2004). Lowe et al. (2004) identified the advantages of microsatellites. These include: 1) Abundancy and uniform coverage across the genome; 2) Codominant markers so allelic polymorphisms can be distinguished; 3) Possibility to detect nuclear DNA and organelle DNA polymorphisms in total DNA extracts, potentially useful for distinguishing between pollen and seed gene flow, 4) High mutation rates compared to other DNA markers, useful for intrapopulation studies, such as spatial genetic structure; 5) Microsatellite loci are defined by the primer pairs, facilitating information exchange between research groups, other groups only 
need the primer sequence, and they can analyze their samples. Disadvantages include the high costs of identification and the specificity of primers, although cross-species amplification is possible. Rather than a high number of microsatellite loci, for spatial studies, it is important to have microsatellite loci with a high number of alleles, i.e., - high polymorphism (Kalinowski \& Waples 2002).

\section{Study site}

Study site, Estación Biológica Quebrada Blanco (EBQB) is located 90km SE from lquitos, Loreto in the lowland Amazon Rainforest from Northeastern Peru ( $\left.04^{\circ} 21^{\prime} \mathrm{S}, 73^{\circ} 09^{\prime} \mathrm{W}\right)$ (Figure 7 ). The field station is located on the valley (in spanish Quebrada) of the Blanco river, a tributary of the Tahuayo river, which flows into the Amazon river. The Blanco river is characterized for its white-water, hence the name. The study area is circa 100 ha and is crossed by perpendicular pathways every $100 \mathrm{~m}$ forming a grid system, making the whole area easily accessible. Dominantly composed of primary forest, surrounding some secondary forest. Primary forest in the study area is characterized by 1) Tierra firme (or Terra firme) forest, high-ground rainforest, not inundated by flooded rivers, standing on a slightly undulating, dry, well-drained firm soil, and 2) Palmal de Altura areas, small swampy areas scattered around the Tierra firme forest (Heymann \& Hartmann 1991). Tierra firme soil is acid, strongly nutrient-limited, and its vegetation growth is limited by Phosphorus availability (Cuevas \& Medina 1986; Lavelle \& Spain 2001). Regardless of the poor soils, this forest is noticeably taller $(<26 \mathrm{~m})$ and more diverse $(>400$ species/hectare in some areas) than flooded forests (de Oliveira \& Mori 1999; Montagnini \& Muñiz-Miret 1999; Duque \& Cavelier 2003; de Mendonça et al. 2017). The canopy is composed of hardwood trees, vines, and palms, the middle layer of the forest is composed of shrubs and 10-17m high trees and the lower layer or understory, where we find Leonia cymosa, includes shrubs and herbs and trees measuring up to 6-9m (Culot 2009).

Tamarins live mainly on the primary forest but can also travel back and forth to secondary forest, although they rarely sleep in it (Culot et al. 2010). The secondary forest was originated by slash and burn agriculture in 1984, which then became a pasture for Buffalos and was abandoned in 2000 (Culot 2009). Altitude of the study area is about $110 \mathrm{~m}$. Temperatures range between 16 and $8{ }^{\circ} \mathrm{C}$ but have a yearly average of $26.2^{\circ} \mathrm{C}$ (SENAMHI, 2006-2012, Tamshiyacu meteorological station, $40 \mathrm{~km}$ north of EBQB). Rainfall can reach $>3600 \mathrm{~mm}$, and is 
generally constant throughout the year with a short dry season from July to September, an early wet season with increasing rainfall from October to January, a main wet season from February to May, and a late wet season with decreasing rainfall in June (Garber et al. 1993; Culot 2009).

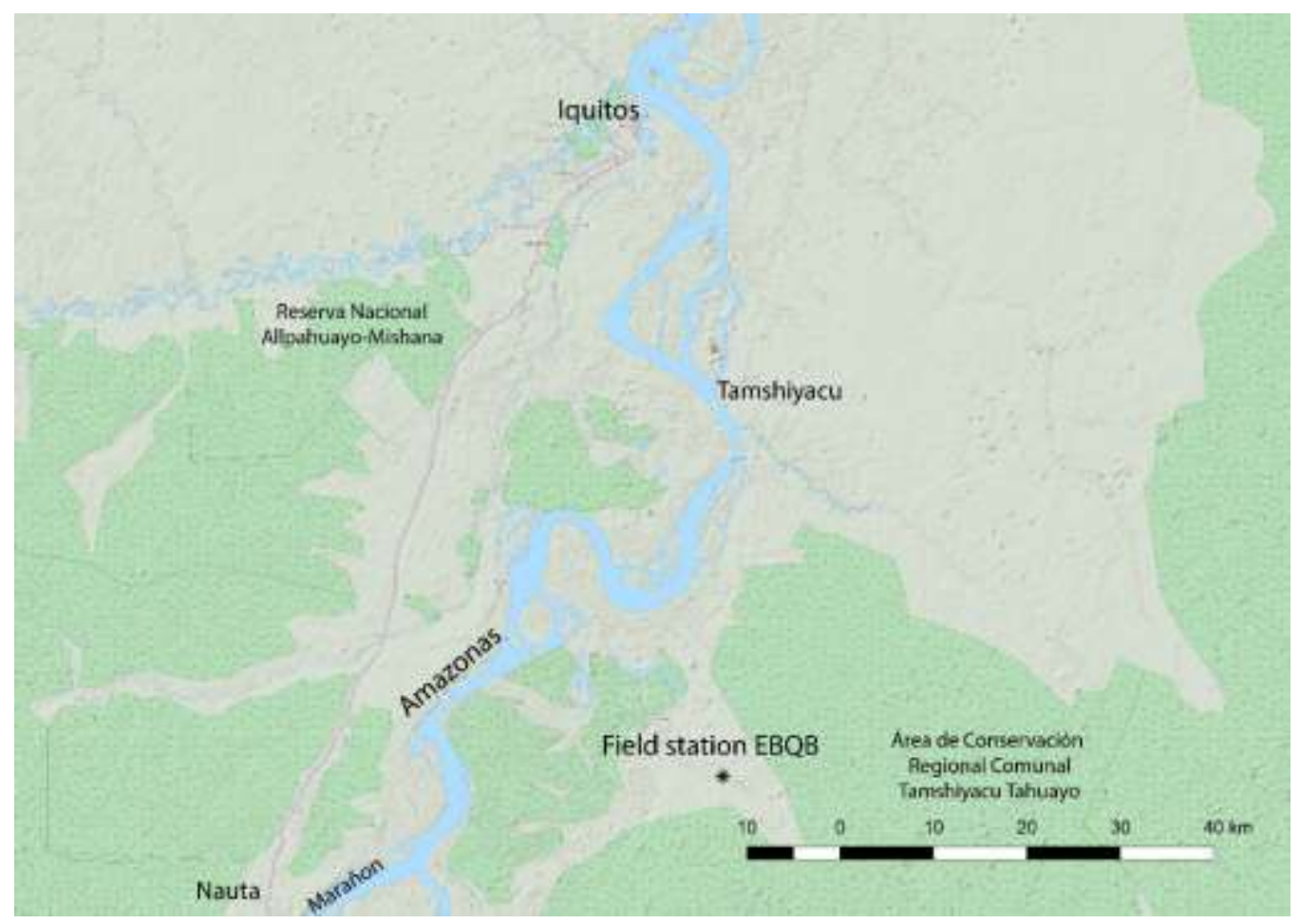

Figure 7 Map of the region surrounding field station. Map created using qGIS and the open layers plugin 


\section{Objectives of the thesis}

This thesis aims to understand the relationship between frugivore behavior and spatial genetics while strengthening the current knowledge on seed dispersal by tamarins and using their dispersal of Leonia cymosa as a case study for a finer analysis of the effect of frugivore on spatial genetics.

The first objective is to understand, from previews literature, general patterns between seed disperser behavior and spatial genetic structure. In Chapter I I analyze the relationship between seed dispersal mode, seed disperser taxa and seed disperser behavior with the spatial genetic structure of plant species dispersed by animal vectors (i.e., zoochorously dispersed plant species). Given the strong relationship between animal behavior and seed dispersal patterns, we expect that animal behavior that enhances seed dispersal distance and reduces seed clumping will be associated with reduced SGS.

The second objective is to use genetic markers to further understand seed dispersal by tamarins in L. cymosa, overcoming species-specific observation limitations. In Chapter II I estimate seed dispersal distance by tamarins using animal behavior data and plant genetics in parallel and compare these to the few field observations available. From tamarins' short-timed feeding behavior, and long daily travel paths, we expect seed dispersal by tamarins to be moderate to long and seed dispersal curves to have a higher density of seeds dispersed away from seed sources.

The third objective is to understand the effects of tamarin seed dispersal on spatial genetic effects of L. cymosa. In Chapter III I analyze spatial genetic structure within different life stages of L. cymosa and compare these with pattern and extent of tamarin seed dispersal. If spatial genetic pattern and seed dispersal distance are strongly associated with SGS, we expect tamarins to decrease SGS of L. cymosa at least in the adult stage. In Chapter IV I analyze how the social organization of tamarins affects seed dispersal patterns and its effect on $L$. cymosa spatial genetics. The social organization of tamarins confines small groups into delimited home ranges with a small overlap and small spatio-temporal shifts; this could generate a seed dispersal barrier. Therefore, we expect a small number of seeds crossing home range borders and a resulting difference in the genetic makeup of the subpopulations. 
The characterization of microsatellites used for this study and the validation of an alternative form of sampling for tropical studies is presented in Chapter V. In this final chapter; I analyze the characteristics of the microsatellite loci and test for intra-genera cross-species amplification. Moreover, the alternative form of sample storage and DNA extraction is compared to the extraction of DNA from leaves stored in dry silica gel; I expect this alternative method, currently used only in agricultural studies, to have an excellent application in tropical studies. 


\section{CHAPTER I}

\section{EFFECTS OF ZOOCHORY ON THE SPATIAL GENETIC STRUCTURE OF PLANT POPULATIONS}

Gelmi-Candusso, Tiziana A.; Heymann Eckhard W.; Heer, Katrin (2017). Molecular Ecology. in press.

DOI: 10.1111/mec.14351 


\section{Abstract}

Spatial genetic structure (SGS) of plants results from the non-random distribution of related individuals. SGS provides information on gene flow and spatial patterns of genetic diversity within populations. The spatial template for plant distribution is created by seed dispersal. Thus, in zoochorous plants, dispersal mode and disperser behavior might have a strong impact on SGS. However, many studies only report the taxonomic group of seed dispersers, without further details. The recent increase in studies on SGS provides the opportunity to review findings and test for the influence of dispersal mode, taxonomic affiliation of dispersers and their behavior. We compared the proportions of studies with SGS among groups and tested for differences in strength of SGS using Sp statistics. Presence of SGS differed among taxonomic groups, with reduced presence in plants dispersed by birds. Strength of SGS was instead significantly influenced by the behavior of seed dispersal vectors, with higher $S p$ values in plant species dispersed by animals with behavior traits that result in short seed dispersal distances. We observed a high variance in SGS of plants dispersed by animals that actively or passively accumulate seeds. Additionally, we found SGS was also affected by pollination and marker type used. Our study highlights the importance of seed disperser behavior on SGS even in the presence of variance created by other factors. Thus, more detailed information on the behavior of seed dispersers would contribute to better understand which factors shape the spatial scale of gene flow in animal-dispersed plant species. 


\section{Introduction}

Fine-scale spatial genetic structure (SGS) is the non-random spatial distribution of related individuals within a population (Hamrick \& Loveless 1986; Vekemans \& Hardy 2004). SGS in plants results primarily from gene flow via pollen and seed dispersal. A number of additional factors, such as environmental conditions, the plant's life history traits, morphology and demographics, might also influence the presence and strength of SGS by affecting the pattern and spatial scale of gene flow, and the seedling survival rate (Hamrick \& Godt 1996; Hardy et al. 2006). Pollination and seed dispersal differ in strength and scale of their effect on gene flow (Hardy et al. 2006). While pollen grains carry only the paternal set of chromosomes, seeds carry the combined set from both parents and thereby contribute twice as much to overall gene flow. The contribution of pollen $\left(\sigma_{p}\right)$ and seed $\left(\sigma_{s}\right)$ dispersal variance to the overall parent-offspring dispersal variance $\left(\sigma_{\mathrm{g}}\right)$ can thus be expressed as $\sigma_{\mathrm{g}}{ }^{2}=1 / 2 \sigma_{\mathrm{p}}{ }^{2}+\sigma_{\mathrm{s}}{ }^{2}$ (Crawford 1984). Furthermore, seed dispersal creates the spatial template for recruitment and the resulting genotype distribution of future generations (Howe \& Miriti 2004). While pollen dispersal can compensate for genetic drift within populations and counteract genetic differentiation among populations (Howe \& Miriti 2004) by homogenizing spatial genetic patterns on large scales (Isagi et al. 2004), seed dispersal is generally regarded to have a stronger effect on small-scale genetic patterns (Hamilton 1999). In fact, the analysis of SGS can shed light on the patterns of seed dispersal (Slatkin 1985; Hamrick \& Trapnell 2011) and allow for an approximation of dispersal distances (Heuertz et al. 2003).

Post-dispersal processes that affect seed germination and establishment can influence SGS as well and have to be considered for the interpretation of SGS patterns. These processes include seed and seedling predation, pathogen attacks, and intra- and inter-specific competition for nutrients and light. Density-dependent mortality, and host-specific predation or pathogens, by increasing mortality with increasing density of conspecific seedlings (Janzen 1970; Connell 1971), can reduce SGS. Similarly, random demographic thinning with increasing age of cohorts can also reduce SGS (Schroeder et al. 2014). Conversely, micro-geographic environmental heterogeneity might favor survival of locally well-adapted and potentially related genotypes, resulting in the aggregation of quantitative traits within populations (Yeaman \& Jarvis 2006; Scotti et al. 2015). In such cases, the importance of the spatial scale of gene flow for evolutionary 
processes becomes evident. While large-scale gene flow can increase local genetic diversity and provide a varied gene pool for adaptation under high selective pressure, in sites with low to intermediate selective pressure it can instead counteract adaptation. In this case, restricted gene flow facilitates local adaptation (Savolainen et al. 2007; Scotti et al. 2015). This scenario might also result in high levels of biparental inbreeding (in absence of self-incompatibility) resulting in a reduction of genetic diversity within the population (Ellstrand \& Elam 1993) and, in the long-term, of fitness and adaptability (Lankau 2009). Presence of spatial patterns in genetic variation is therefore an important prerequisite for evolutionary processes (Sokal \& Wartenberg 1983; Rundle \& Nosil 2005).

In this review, we focus on the influence of zoochory, i.e. seed dispersal by animals, on SGS.

\section{Zoochory and spatial patterns of seed dispersal}

Zoochorous seed dispersal occurs through three different mechanisms. Seeds can be (a) swallowed, transported inside the guts of frugivores and deposited through defecation or regurgitation (endozoochory); (b) actively carried in hands, mouths, bills or mandibles and dropped after the edible part of the fruit has been removed (synzoochory) or (c) transported passively attached to skin, fur or feathers (epizoochory) (Howe \& Smallwood 1982). Animals can act as primary seed dispersers when they deposit seeds after having removed fruits from the plant, or as secondary dispersers when already dispersed seeds are moved further on (Wang \& Smith 2002). Since zoochorous seed dispersal is an interaction between animals and fruits/seeds, it is plausible that the behavior of animal dispersal vectors influences patterns of seed dispersal (Russo et al. 2006; Sasal \& Morales 2013; Côrtes \& Uriarte 2013). Generally, the behavior of vectors, e.g. frequency of visits to fruiting plants, quality and quantity of fruit and seed handling, play a role in determining seed dispersal efficiency (Schupp 1993; Schupp et al. 2010). More specifically, spatial patterns of seed dispersal are directly related to vectors' movement patterns which in turn are affected by intrinsic (vector-specific) and extrinsic (ecological/environmental) factors (Patterson et al. 2008; Laundré et al. 2010). Intrinsic factors include body size, nutrient requirements and dietary strategies, physiological condition, social organization and mating system (e.g. Wehncke et al. 2004; Jordano et al. 2007; Karubian et al. 2012; Lichti et al. 2017). Extrinsic factors include seasonal and inter-annual variation in fruit 
abundance, the spatial distribution of feeding, sleeping, resting and singing sites, and predation risk (e.g., Julliot 1997; Wenny \& Levey 1998; Perea et al. 2011; Abedi-Lartey et al. 2016). Although the influence of behavior of seed dispersal vectors on spatial patterns of seed dispersal has been empirically studied and theoretically modelled for a long time (Estrada \& CoatesEstrada 1984; Fleming \& Williams 1990; Jordano \& Herrera 1995; Russo et al. 2006; Cousens et al. 2010; Sasal \& Morales 2013; Côrtes \& Uriarte 2013; Bialozyt et al. 2014a), its implications for SGS of plant populations have come under intensive study only recently.

\section{Spatial genetic structure analysis}

SGS is analyzed by genotyping georeferenced plant individuals and by assessing changes in genetic relatedness with spatial distance. For genotyping, a variety of different marker types have been used, but in the last few years, most SGS studies have used microsatellites whose high variability allows to determine kinship even between closely related individuals. The relatedness between pairs of individuals can be calculated with a number of kinship coefficients (e.g., Sokal \& Oden 1978; Burgman \& Williams 1995; Loiselle et al. 1995). Following the recommendations of Vekemans and Hardy (2004), most recent studies employ the coefficient published by Loiselle et al. (1995) which has proven to be more robust than other coefficients if rare alleles occur in the data set (e.g. Ritland 1996; Rousset 2000). This is frequently the case when highly variable microsatellites are used. For spatial autocorrelation analysis, the kinship coefficient of pairs of individuals is averaged in predefined distance classes and tested for significance by permutations within in each distance class. Alternatively, for a one-value measure of SGS, Vekemans and Hardy (2004) introduced the Sp statistics. It is calculated by regressing pairwise genetic relatedness over the logarithm of pairwise spatial distance. $S p$ is calculated as $S p=-\hat{b}_{F} / 1-\hat{F}_{(1)}$, with $\hat{b}_{F}$ as the slope of the linear regression, and $\hat{F}_{(1)}$ as the mean kinship coefficient of the first distance class which comprises closest neighbors. Thus, $S p$ values primarily depend on the rate of decrease of pairwise kinship over distance. By providing a numerical value for the strength of SGS that is largely independent of sampling scheme and of arbitrarily chosen distance classes, it allows for the comparison of SGS between populations and species (Vekemans \& Hardy 2004).

Previous reviews used the $S p$ statistics to compare SGS among plant groups in order to determine the influence of different factors on SGS. For example, Nazareno et al. (2013) showed 
a relationship between plant sexual system and the strength of SGS. Vekemans and Hardy (2004) found significant effects of breeding system, life form and plant population density, but no significant effects of pollination mechanism or of seed dispersal on SGS. Dick et al. (2008) compared SGS of plant species focusing on gene dispersal distances and climate region. While mean $S p$ values did not differ between tropical and temperate regions, a significant difference was found between wind- and animal-pollinated species in temperate regions, and among seed dispersal vectors (birds, bats and primates vs. gravity, wind, water and rodents) in tropical regions. However, none of these reviews focused on the effects of animal seed dispersal on SGS.

\section{Aims of this review}

The number of studies on SGS in animal-dispersed plant species has increased as a result of methodological advances. This includes plant species whose seeds are dispersed endo- or synzoochorously by vectors from different taxonomic and functional groups. Thus, it is timely to review the effect of zoochorous seed dispersal on the occurrences and strength of SGS.

In our review, we address the following questions:

1. Does seed dispersal mode (endozoochory vs. synzoochory) influences the occurrence and strength of SGS? We expect seeds transported in guts are dispersed over longer distances than seeds carried in hands, mouths, bills or mandibles (Herrera \& Jordano 1981; Howe 1989; Vander Wall \& Beck 2012; Wehncke et al. 2003). Under this assumption, SGS should occur more frequently and be stronger (i.e. $S p$ values higher) in synzoochorously compared to endozoochorously dispersed plant species.

2. Does taxonomic affiliation of the seed dispersal vector influence the occurrence and strength of SGS? Since the major groups of seed dispersal vectors (bats, birds, primates, rodents and ants) vary in their morphological features of physiology and mobility, we expect differences in the occurrence frequency and strength of SGS between these (Ness et al. 2004; Côrtes \& Uriarte 2013). More specifically, we expect plant species dispersed by highly mobile animals (bats, birds) are less likely to show SGS and have weaker SGS compared to less mobile taxa.

3. Does the behavior of seed dispersal vectors influence the occurrence and strength of SGS? While vectors from different taxonomic groups differ in various basic aspects of their biology, they may nevertheless show functionally similar behavior, such as hoarding of seeds by 
rodents and birds or dropping of seeds at specific roosting sites by birds and bats. Specifically, we expect plant species dispersed by vectors that move over large distances immediately after feeding or that cache seeds far away from food sources are less likely to show SGS or have weaker SGS compared to animals that remain close to fruiting plants after feeding or discard seeds while feeding. Furthermore, since vector behaviors also determine seed dispersal distances, we expect $S p$ values to be related to observed seed dispersal distances.

4. Which additional factors have an influence on occurrence and strength of SGS of zoochorous plants?

Other factors besides seed dispersal have been previously seen to influence SGS of plant species, but the number of animal-dispersed species was low in these studies (Vekemans \& Hardy 2004; Dick et al. 2008; Nazareno et al. 2013). In line with previous reviews, we examine the effect of pollination mechanism (animal vs. wind), climate region (temperate vs. tropical), plant life form, sexual and breeding system, population density and genetic marker type used (AFLP, Allozymes, ISSR, Microsatellites and RAPD) on the strength of SGS.

\section{Methods}

\section{Compilation of database}

We queried Web of Science ${ }^{T M}$ for articles listed until July 2017, describing SGS of zoochorously dispersed plant species (query: "spatial genetic structure" or "population genetic structure" + "seed dispersal" or "frugivory" or "endozoochory" or "synzoochory" or "ants" or "bats" or "birds" or "primates" or "rodents"). Additionally, we included studies on animaldispersed plant species included in previously published reviews on SGS. For each study, we extracted data on plant characteristics (habitat, plant population density, pollination mechanism, sexual system, etc.), and data on the analytical methods (marker type used) from the publication itself or from the publications referenced therein. We also noted the presence or absence of SGS and, if provided, its strength in terms of $S p$ values (Table 1). Presence or absence of SGS was based on whether the authors identified significant SGS through one of the following three methods: (1) spatial auto-correlogram based on permutations, (2) the slope of the linear regression over the pairwise distance matrix or (3) significance of $S p$ statistics. Strength of SGS was assessed by the Sp statistics whenever values were provided or when we 
could obtain the regression slope and first distance class kinship coefficient values for its calculation. We calculated the mean of all analyzed populations if more than one population of the same species was analyzed in the same or different studies and if there was no indication seed dispersal system differed. In cases where seed dispersers differed between studied populations of the same plant species, we considered them separately. As many publications did not provide detailed information on the animal species that acted as seed dispersal vectors or on vector behavior, we extracted pertinent information from publications referenced in the studies. For our analysis, we only considered studies on adult life stage of the plant since we were ultimately interested in the long-term effects of animal seed dispersal in SGS. In total, we obtained data for SGS in adult plants of 65 zoochorously dispersed species from 54 studies.

Table 1. Categorization of seed dispersers based on feeding and post-feeding behavior traits. Seed dispersers were assigned to a given category if they were described as having one or more behavior traits of the respective category.

\begin{tabular}{|c|c|c|}
\hline & Feeding / foraging Behavior & Post-feeding behavior \\
\hline Category A & $\begin{array}{l}\text { Swallows seeds at source } \\
\text { Spits/ Regurgitates seeds after } \\
\text { transport } \\
\text { Short feeding bouts }\end{array}$ & $\begin{array}{l}\text { Moves away from source after } \\
\text { feeding } \\
\text { High mobility }\end{array}$ \\
\hline Category B & $\begin{array}{l}\text { Spits/regurgitates seeds at source } \\
\text { High loss of fruits while foraging } \\
\text { Long feeding bouts }\end{array}$ & $\begin{array}{l}\text { Remains close to source after } \\
\text { feeding } \\
\text { Low mobility }\end{array}$ \\
\hline Category C & Swallows seeds at source & $\begin{array}{l}\text { Low or high mobility } \\
\text { Passive accumulation of seeds i.e. } \\
\text { consistently used roosting, } \\
\text { perching or lekking sites }\end{array}$ \\
\hline Category D & $\begin{array}{l}\text { Takes fruits/seeds and feeds away } \\
\text { from source }\end{array}$ & $\begin{array}{l}\text { Active accumulation of seeds } \\
\text { through caching or hoarding } \\
\text { Low mobility } \\
\quad \text { E.g. rodents, ants }\end{array}$ \\
\hline Category E & $\begin{array}{l}\text { Takes fruits/seeds and feeds away } \\
\text { from source }\end{array}$ & $\begin{array}{l}\text { Active accumulation of seeds } \\
\text { through caching or hoarding } \\
\text { High mobility } \\
\text { E.g. scatter-hoarding birds }\end{array}$ \\
\hline
\end{tabular}

\section{Statistical analyses}

First, we examined the effect of seed dispersal mode (endozoochory or synzoochory) on the presence and strength of SGS in plant species. Epizoochorously dispersed species were underrepresented, therefore we excluded them from the analysis (Williams \& Guries 1994; 
Bonnin et al. 2001; Rico \& Wagner 2016). Second, we tested whether the presence and strength of SGS in plant species was related to the taxon of the seed dispersers (ants, bats, birds, primates, rodents). We assigned plant species for which more than one animal taxon was described as seed disperser to the category "mixed". Third, we tested for the effect of seed disperser behavior on SGS. For this, whenever this information was available in the respective publications or in literature referenced therein, we assigned dispersers to five categories according to behavior traits (Table 2). Fourth, we compared $S p$ values between groups of zoochorous plants that differed in pollination mechanism, climatic region, breeding system and genetic marker used. Finally, we correlated $S p$ values with observed seed dispersal distance and plant population density using the Spearman rank correlation.

To determine whether dispersal mode, disperser taxa and behavior had a statistically significant influence on the occurrence of SGS in a plant population, we used the prop.test() function in R which tests for the null hypothesis that the proportion of studies with presence of SGS is equal across all categories. For testing the influence of different categories of dispersal vectors on SGS, we first identified outliers with the modified Thompson tau test (Thompson, 1985) and based on the results, excluded two studies from the subsequent analysis [Moronobea coccinea (Hardy et al. 2006) and Ficus pumila (Wang et al. 2009)]. Moronobea coccinea was variably described as rodent or gravity-dispersed by Hardy et al. (2006) and Dick et al. (2008), respectively. Similarly, F. pumila was described as bat-, ant- and rodent-dispersed, but in an urban area without seed dispersers where most fruits fell to the ground without further removal. Therefore, in both cases, seeds might have been mainly gravity-dispersed which explains the high $S p$ values. Second, we examined whether the assumptions for an ANOVA were met, namely, the normal distribution of residuals and homogeneity of variance, which we tested with Shapiro Wilk test a Barlett's K-squared test. Both assumptions were met after logtransformation of Sp values, which were then used for further analysis.

We conducted Factorial ANOVAs to analyze the influence of seed dispersal (mode, taxa and behavior) on the strength of SGS using the aov() function in R (Rstudio team 2015). In each model, we included additional factors previously considered as relevant for SGS (i.e. pollination mechanism, climate region, plant life form, sexual and breeding system, and marker type) to account for potential interactions with seed dispersal. In cases where significant differences 
between categories were detected, we performed a Tukey post-hoc comparison using the TukeyHSD() function.

We then analyzed, separately, the main effects of these additional factors on SGS strength using again a Factorial ANOVA. In addition, to maintain comparability with previous reviews, we also tested each factor separately with either a one-way ANOVA or a $t$-test, depending on the number of levels.

Finally, to analyze the correlation of $S p$ values with plant population density and observed seed dispersal distance, we conducted the Spearman rank correlation. For cases where populations of the same plant species were analyzed, we used the geom_smooth() function to visualize intra-specific differences of the effect of plant population density and marker type use on the strength of SGS. For statistical analysis and its graphical representation, we used the $\mathrm{R}$ packages "stats", "doBy", "userfriendlyscience", "ggplot2" and "ggpubr" (Wickham 2009; R core team 2015, 2016; Højsgaard \& Halekoh 2016; Kassambara 2017; Peters 2017) 


\begin{tabular}{|c|c|c|c|c|c|c|c|c|c|c|c|}
\hline $\begin{array}{l}\text { Species } \\
\text { (Family) }\end{array}$ & 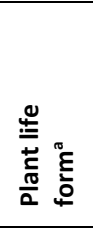 & 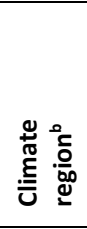 & 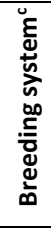 & 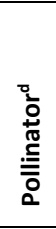 & 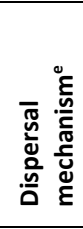 & 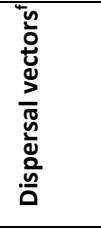 & 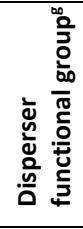 & 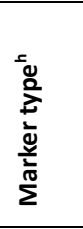 & 心 & ลें & References \\
\hline $\begin{array}{l}\text { Adansonia digitata } \\
\text { (Bombacaceae) }\end{array}$ & $\mathrm{T}$ & Tr-d & $\mathrm{m}$ & $A$ & Endo & $\mathrm{Ba}$ & C & AFLP & $Y$ & 0.022 & $\begin{array}{l}\text { Kyndt et al. } \\
\text { (2009) }\end{array}$ \\
\hline $\begin{array}{l}\text { Araucaria angustifolia } \\
\text { (Araucariaceae) }\end{array}$ & $\mathrm{T}$ & Tr-w & $\mathrm{d}$ & $\mathrm{W}$ & Syn & $\mathrm{Bi}$ & $E$ & $\mathrm{Mi}$ & $\mathrm{Y}$ & 0.006 & $\begin{array}{l}\text { Stefenon et al. } \\
\text { (2008), } \\
\text { Sant'Anna et } \\
\text { al. (2013) }\end{array}$ \\
\hline $\begin{array}{l}\text { Attalea phalerata } \\
\text { (Arecaceae) }\end{array}$ & $\mathrm{T}$ & Tr-w & $\mathrm{d}$ & $A$ & Endo & $\mathrm{P}$ & $\mathrm{B}$ & $\mathrm{Mi}$ & $\mathrm{Y}$ & 0.024 & $\begin{array}{l}\text { Choo et al. } \\
(2012)\end{array}$ \\
\hline $\begin{array}{l}\text { Baillonella toxisperma } \\
\text { (Sapotaceae) }\end{array}$ & $\mathrm{T}$ & Tr-w & $\mathrm{m}$ & $A$ & Endo & P, Ro, E & $\mathrm{n} / \mathrm{a}$ & $\mathrm{Mi}$ & $\mathrm{Y}$ & 0.010 & $\begin{array}{l}\text { Duminil et al. } \\
(2016 a)\end{array}$ \\
\hline $\begin{array}{l}\text { Cabralea canjerana } \\
\text { (Meliaceae) }\end{array}$ & $\mathrm{T}$ & Tr-w & $\mathrm{d}$ & $A$ & Endo & $\mathrm{Bi}$ & $\mathrm{n} / \mathrm{a}$ & $\mathrm{Mi}$ & $\mathrm{N}$ & $\mathrm{n} / \mathrm{a}$ & $\begin{array}{l}\text { Tavares De } \\
\text { Oliveira Melo } \\
\text { et al. (2014) }\end{array}$ \\
\hline $\begin{array}{l}\text { Carapa guianensis } \\
\text { (Meliaceae) }\end{array}$ & $\mathrm{T}$ & $\mathrm{Tr}-\mathrm{w}$ & $\mathrm{m}$ & A & Syn & Ro & $\mathrm{D}$ & $\mathrm{Mi}$ & $Y$ & 0.005 & $\begin{array}{l}\text { Cloutier et al. } \\
\text { (2007), Dick et } \\
\text { al. (2008) }\end{array}$ \\
\hline $\begin{array}{l}\text { Carapa procera } \\
\text { (Meliaceae) }\end{array}$ & $\mathrm{T}$ & Tr-w & $\mathrm{m}$ & $A$ & Syn & Ro & $\mathrm{D}$ & RAPD & $\mathrm{Y}$ & 0.028 & $\begin{array}{l}\text { Hardy et al. } \\
(2006)\end{array}$ \\
\hline $\begin{array}{l}\text { Castanopsis sclerophylla } \\
\text { (Fagaceae) }\end{array}$ & $\mathrm{T}$ & $\mathrm{Te}$ & $\mathrm{m}$ & W & Syn & Ro & $\mathrm{D}$ & $\mathrm{Mi}$ & $\mathrm{Y}$ & 0.005 & $\begin{array}{l}\text { Wang et al. } \\
\text { (2011) }\end{array}$ \\
\hline $\begin{array}{l}\text { Ceratiola ericoides } \\
\text { (Ericaceae) }\end{array}$ & $\mathrm{S}$ & Tr-d & $d$ & W & Endo & $\mathrm{Bi}$ & $n / a^{k}$ & $\mathrm{Al}$ & $\mathrm{N}$ & $\mathrm{n} / \mathrm{a}$ & $\begin{array}{l}\text { Trapnell et al. } \\
(2008)\end{array}$ \\
\hline $\begin{array}{l}\text { Chrysophyllum sanguinolentum } \\
\text { (Sapotaceae) }\end{array}$ & $\mathrm{T}$ & Tr-w & $\mathrm{d}$ & $A$ & Endo & $P$ & $\mathrm{n} / \mathrm{a}$ & $\begin{array}{l}\text { AFLP, } \\
\text { RAPD }\end{array}$ & $\mathrm{Y}$ & 0.015 & $\begin{array}{l}\text { Hardy et al. } \\
(2006)\end{array}$ \\
\hline $\begin{array}{l}\text { Cinnamomum insularimontanum } \\
\text { (Lauraceae) }\end{array}$ & $\mathrm{T}$ & $\mathrm{Te}$ & $\mathrm{m}$ & $A$ & Endo & $\mathrm{Bi}$ & $A$ & $\mathrm{Al}$ & $\mathrm{N}$ & $\mathrm{n} / \mathrm{a}$ & $\begin{array}{l}\text { Chung et al. } \\
(2003)\end{array}$ \\
\hline $\begin{array}{l}\text { Clusia lechleri } \\
\text { (Clusiaceae) }\end{array}$ & $\mathrm{T}$ & $\mathrm{Tr}-\mathrm{w}$ & $\mathrm{d}$ & $A$ & Endo & $\mathrm{Bi}$ & $A$ & $\mathrm{Mi}$ & $\mathrm{N}$ & $\mathrm{n} / \mathrm{a}$ & $\begin{array}{l}\text { Quevedo et al. } \\
(2013)\end{array}$ \\
\hline $\begin{array}{l}\text { Clusia sphaerocarpa } \\
\text { (Clusiaceae) }\end{array}$ & $\mathrm{T}$ & Tr-w & $\mathrm{d}$ & $A$ & Endo & $\mathrm{Bi}$ & $A$ & $\mathrm{Mi}$ & $\mathrm{N}$ & $\mathrm{n} / \mathrm{a}$ & $\begin{array}{l}\text { Quevedo et al. } \\
(2013)\end{array}$ \\
\hline $\begin{array}{l}\text { Dicorynia guianensis } \\
\text { (Leguminosea) }\end{array}$ & $\mathrm{T}$ & $\mathrm{Tr}-\mathrm{w}$ & $\mathrm{m}$ & $A$ & Syn & Ro & $D$ & RAPD & $Y$ & 0.019 & $\begin{array}{l}\text { Hardy et al. } \\
(2006)\end{array}$ \\
\hline $\begin{array}{l}\text { Dioscorea japonica } \\
\text { (Dioscoreaceae) }\end{array}$ & $E$ & $\mathrm{Te}$ & $d$ & $A$ & Syn & Ro & $D$ & $\mathrm{Mi}$ & $Y$ & 0.014 & $\begin{array}{l}\text { Mizuki et al. } \\
(2010)\end{array}$ \\
\hline $\begin{array}{l}\text { Disoxylum malabaricum } \\
\text { (Meliaceae) }\end{array}$ & $\mathrm{T}$ & Tr-w & $\mathrm{m}$ & $A$ & Endo & $\mathrm{Bi}$ & $B$ & & $\mathrm{~N}$ & $\mathrm{n} / \mathrm{a}$ & $\begin{array}{l}\text { Bodare et al. } \\
(2016)\end{array}$ \\
\hline $\begin{array}{l}\text { Erythrophleum suaveolens } \\
\text { (Fabaceae) }\end{array}$ & $\mathrm{T}$ & Tr-w & $\mathrm{m}$ & $A$ & Endo & $P$ & $\mathrm{n} / \mathrm{a}$ & $\mathrm{Mi}$ & $Y$ & 0.006 & $\begin{array}{l}\text { Duminil et al. } \\
(2016 \mathrm{~b})\end{array}$ \\
\hline $\begin{array}{l}\text { Fagus crenata } \\
\text { (Fagaceae) }\end{array}$ & $\mathrm{T}$ & $\mathrm{Te}$ & $m$ & W & Syn & Ro & $\mathrm{D}$ & $\mathrm{Mi}$ & $Y$ & 0.003 & $\begin{array}{l}\text { Oddou- } \\
\text { Muratorio et } \\
\text { al. (2010) }\end{array}$ \\
\hline \multirow[t]{2}{*}{$\begin{array}{l}\text { Fagus sylvatica } \\
\text { (Fagaceae) }\end{array}$} & $\mathrm{T}$ & $\mathrm{Te}$ & $\mathrm{m}$ & W & Syn & Ro & $D$ & AFLP & $Y$ & 0.022 & $\begin{array}{l}\text { Jump et al. } \\
(2012)\end{array}$ \\
\hline & $\mathrm{T}$ & $\mathrm{Te}$ & $\mathrm{m}$ & W & Syn & $\mathrm{Bi}$ & $E$ & $\mathrm{Mi}$ & $Y$ & 0.014 & $\begin{array}{l}\text { Oddou- } \\
\text { Muratorio et } \\
\text { al. (2010) }\end{array}$ \\
\hline \multirow[t]{2}{*}{$\begin{array}{l}\text { Ficus citrifolia } \\
\text { (Moraceae) }\end{array}$} & $E$ & Tr-w & $\mathrm{m}$ & $A$ & Endo & $\mathrm{Ba}$ & C & $\mathrm{Mi}$ & $Y$ & 0.013 & $\begin{array}{l}\text { Heer et al. } \\
(2015)\end{array}$ \\
\hline & $E$ & $\mathrm{Tr}-\mathrm{w}$ & $\mathrm{m}$ & $A$ & Endo & $\mathrm{Ba}$ & $\mathrm{n} / \mathrm{a}$ & $\mathrm{Mi}$ & $Y$ & 0.007 & $\begin{array}{l}\text { Nazareno et al. } \\
(2013)\end{array}$ \\
\hline $\begin{array}{l}\text { Ficus cyrtophylla } \\
\text { (Moraceae) }\end{array}$ & $\mathrm{T}$ & Tr-w & $d$ & $A$ & Endo & $\mathrm{Bi}$ & B & $\mathrm{Mi}$ & $\mathrm{N}$ & 0.029 & $\begin{array}{l}\text { Zhou \& Chen } \\
(2010)\end{array}$ \\
\hline $\begin{array}{l}\text { Ficus exasperata } \\
\text { (Moraceae) }\end{array}$ & $T$ & $\mathrm{Te}$ & $d$ & $A$ & Endo & $\mathrm{Bi}$ & $\mathrm{n} / \mathrm{a}$ & $\mathrm{Mi}$ & $Y$ & 0.035 & $\begin{array}{l}\text { Dev et al. } \\
(2011)\end{array}$ \\
\hline $\begin{array}{l}\text { Ficus eximia } \\
\text { (Moraceae) }\end{array}$ & $\mathrm{T}$ & $\mathrm{Tr}-\mathrm{w}$ & $\mathrm{m}$ & $A$ & Endo & $\mathrm{Ba}$ & $\mathrm{n} / \mathrm{a}$ & $\mathrm{Mi}$ & $\mathrm{Y}$ & 0.006 & $\begin{array}{l}\text { Nazareno et al. } \\
(2013)\end{array}$ \\
\hline $\begin{array}{l}\text { Ficus hispida } \\
\text { (Moraceae) }\end{array}$ & $T$ & $\mathrm{Te}$ & $d$ & $A$ & Endo & $\mathrm{Ba}$ & $\mathrm{n} / \mathrm{a}$ & $\mathrm{Mi}$ & $Y$ & 0.031 & $\begin{array}{l}\text { Dev et al. } \\
(2011)^{1}\end{array}$ \\
\hline $\begin{array}{l}\text { Ficus insipida } \\
\text { (Moraceae) }\end{array}$ & $\mathrm{T}$ & Tr-w & $\mathrm{m}$ & $A$ & Endo & $\mathrm{Ba}$ & $C$ & $\mathrm{Mi}$ & $Y$ & 0.004 & $\begin{array}{l}\text { Heer et al. } \\
(2015)\end{array}$ \\
\hline
\end{tabular}




\begin{tabular}{|c|c|c|c|c|c|c|c|c|c|c|c|}
\hline $\begin{array}{l}\text { Ficus obtusifolia } \\
\text { (Moraceae) }\end{array}$ & $E$ & Tr-w & $\mathrm{m}$ & $A$ & Endo & $\mathrm{Ba}$ & C & $\mathrm{Mi}$ & $Y$ & 0.031 & $\begin{array}{l}\text { Heer et al. } \\
(2015)\end{array}$ \\
\hline $\begin{array}{l}\text { Ficus pumila } \\
\text { (Moraceae) }\end{array}$ & $E$ & $\mathrm{Te}$ & $d$ & $A$ & Endol & $\mathrm{Ba}, \mathrm{Bi}^{*}$ & $\mathrm{n} / \mathrm{a}$ & $\mathrm{Mi}$ & $Y$ & 0.074 & $\begin{array}{l}\text { Wang et al. } \\
\text { (2009) }\end{array}$ \\
\hline $\begin{array}{l}\text { Ficus yoponensis } \\
\text { (Moraceae) }\end{array}$ & $\mathrm{T}$ & Tr-w & $\mathrm{m}$ & $A$ & Endo & $\mathrm{Ba}$ & C & $\mathrm{Mi}$ & $Y$ & 0.008 & $\begin{array}{l}\text { Heer et al. } \\
(2015)\end{array}$ \\
\hline $\begin{array}{l}\text { Globba lancangensis } \\
\text { (Zingiberaceae) }\end{array}$ & $\mathrm{H}$ & $\mathrm{Te}$ & $\mathrm{m}$ & $A$ & Syn & $A$ & $\mathrm{n} / \mathrm{a}$ & ISSR & $Y$ & $\mathrm{n} / \mathrm{a}$ & $\begin{array}{l}\text { Zhou et al. } \\
\text { (2007) }\end{array}$ \\
\hline $\begin{array}{l}\text { Manilkara máxima } \\
\text { (Sapotaceae) }\end{array}$ & $\mathrm{T}$ & Tr-w & $M$ & $A$ & Endo & $\begin{array}{l}\mathrm{Ba}, \mathrm{Bi}, \\
\mathrm{P}\end{array}$ & $\mathrm{n} / \mathrm{a}$ & $\mathrm{Mi}$ & $Y$ & 0.015 & $\begin{array}{l}\text { Ganzhorn et al. } \\
(2015)\end{array}$ \\
\hline $\begin{array}{l}\text { Milicia excelsa } \\
\text { (Moraceae) }\end{array}$ & $\mathrm{T}$ & $\mathrm{Te}$ & $d$ & W & Endo & $\mathrm{Ba}$ & $A$ & $\mathrm{Mi}$ & $\mathrm{Y}$ & 0.005 & $\begin{array}{l}\text { Bizoux et al. } \\
\text { (2009) }\end{array}$ \\
\hline $\begin{array}{l}\text { Moronobea coccinea } \\
\text { (Clusiaceae) }\end{array}$ & $\mathrm{T}$ & Tr-w & $\mathrm{m}$ & $A$ & Syn & Ro & $\mathrm{D}$ & RAPD & $Y$ & 0.053 & $\begin{array}{l}\text { Hardy et al. } \\
\text { (2006) }\end{array}$ \\
\hline $\begin{array}{l}\text { Neolitsea sericea } \\
\text { (Lauraceae) }\end{array}$ & $\mathrm{T}$ & $\mathrm{Te}$ & $d$ & $A$ & Endo & $\mathrm{Bi}$ & $A$ & $\mathrm{Al}$ & $\mathrm{N}$ & $\mathrm{n} / \mathrm{a}$ & $\begin{array}{l}\text { Chung et al. } \\
\text { (2000b) }\end{array}$ \\
\hline $\begin{array}{l}\text { Notholithocarpus densiflorus } \\
\text { (Fagaceae) }\end{array}$ & $\mathrm{S}$ & $\mathrm{Te}$ & $\mathrm{m}$ & $A$ & Syn & $\mathrm{Bi}$ & $E$ & $\mathrm{Mi}$ & $Y$ & 0.010 & $\begin{array}{l}\text { Dodd et al. } \\
\text { (2013) }\end{array}$ \\
\hline $\begin{array}{l}\text { Oenocarpus bataua } \\
\text { (Arecaceae) }\end{array}$ & $\mathrm{T}$ & Tr-w & $\mathrm{m}$ & $\mathrm{n} / \mathrm{a}$ & Syn & $\mathrm{Bi}$ & $\mathrm{n} / \mathrm{a}$ & $\mathrm{Mi}$ & $Y$ & $\mathrm{n} / \mathrm{a}$ & $\begin{array}{l}\text { Karubian et al. } \\
\text { (2010) }\end{array}$ \\
\hline $\begin{array}{l}\text { Olea europaea } \\
\text { (Oleaceae) }\end{array}$ & $\mathrm{T}$ & $\mathrm{Te}$ & $d$ & W & Endo & $\mathrm{Bi}$ & $\mathrm{n} / \mathrm{a}$ & $\mathrm{Mi}$ & $\mathrm{Y}$ & 0.005 & $\begin{array}{l}\text { Beghè et al. } \\
\text { (2017) }\end{array}$ \\
\hline $\begin{array}{l}\text { Parkia panurensis } \\
\text { (Fabaceae) }\end{array}$ & $\mathrm{T}$ & Tr-w & $\mathrm{m}$ & $A$ & Endo & $P$ & $\mathrm{n} / \mathrm{a}$ & $\mathrm{Mi}$ & $Y$ & $\mathrm{n} / \mathrm{a}$ & $\begin{array}{l}\text { Bialozyt et al. } \\
(2014 b)\end{array}$ \\
\hline $\begin{array}{l}\text { Pinus pumila } \\
\text { (Pinaceae) }\end{array}$ & $\mathrm{T}$ & $\mathrm{Te}$ & $\mathrm{m}$ & W & Syn & $\mathrm{Bi}$ & $\mathrm{n} / \mathrm{a}$ & $\mathrm{Al}$ & $\mathrm{Y}$ & $\mathrm{n} / \mathrm{a}$ & $\begin{array}{l}\text { Tani et al. } \\
\text { (1998) }\end{array}$ \\
\hline $\begin{array}{l}\text { Polygala reinii } \\
\text { (Polygalaceae) }\end{array}$ & $\mathrm{S}$ & $\mathrm{Te}$ & $\mathrm{n} / \mathrm{a}$ & $A$ & Syn & $A$ & $\mathrm{D}$ & $\mathrm{Al}$ & $\mathrm{Y}$ & 0.026 & $\begin{array}{l}\text { Nakagawa } \\
(2010)\end{array}$ \\
\hline $\begin{array}{l}\text { Pouteria reticulata } \\
\text { (Sapotaceae) }\end{array}$ & $\mathrm{T}$ & Tr-w & $d$ & $A$ & Endo & $\mathrm{Bi}, \mathrm{P}$ & $A$ & $\mathrm{Mi}$ & $\mathrm{Y}$ & 0.006 & $\begin{array}{l}\text { Schroeder et } \\
\text { al. (2014) }\end{array}$ \\
\hline $\begin{array}{l}\text { Protium spruceanum } \\
\text { (Burseraceae) }\end{array}$ & $\mathrm{T}$ & Tr-w & $d$ & $\mathrm{n} / \mathrm{a}$ & Endo & $\mathrm{Bi}$ & $\mathrm{n} / \mathrm{a}$ & $\mathrm{Al}$ & $\mathrm{N}$ & 0.011 & $\begin{array}{l}\text { Vieira et al. } \\
(2012)\end{array}$ \\
\hline $\begin{array}{l}\text { Prunus africana } \\
\text { (Rosaceae) }\end{array}$ & $T$ & Tr-w & $\mathrm{m}$ & $A$ & Endo & $\mathrm{Bi}, \mathrm{P}$ & B & $\mathrm{Mi}$ & $Y$ & 0.014 & $\begin{array}{l}\text { Berens et al. } \\
(2014)^{1}\end{array}$ \\
\hline $\begin{array}{l}\text { Prunus avium } \\
\text { (Rosaceae) }\end{array}$ & $\mathrm{T}$ & $\mathrm{Te}$ & $\mathrm{m}$ & $A$ & Endo & $\mathrm{Bi}$ & $A$ & $\mathrm{Mi}$ & $\mathrm{Y}$ & 0.009 & $\begin{array}{l}\text { Schueler et al. } \\
\text { (2006) }\end{array}$ \\
\hline Psychotria acuminata (Rubiaceae) & $\mathrm{S}$ & Tr-w & $\mathrm{m}$ & $\mathrm{A}$ & Endo & $\mathrm{Bi}$ & $\mathrm{C}$ & AFLP & $\mathrm{Y}$ & 0.036 & $\begin{array}{l}\text { Theim et al. } \\
\text { (2014) }\end{array}$ \\
\hline $\begin{array}{l}\text { Psychotria hoffmannseggiana } \\
\text { (Rubiaceae) }\end{array}$ & $\mathrm{S}$ & Tr-w & $\mathrm{m}$ & A & Endo & $\mathrm{Bi}$ & $\mathrm{C}$ & AFLP & $\mathrm{Y}$ & 0.023 & $\begin{array}{l}\text { Theim et al. } \\
\text { (2014) }\end{array}$ \\
\hline Psychotria horizontalis (Rubiaceae) & $\mathrm{S}$ & Tr-w & $\mathrm{m}$ & $A$ & Endo & $\mathrm{Bi}$ & $\mathrm{C}$ & AFLP & $\mathrm{Y}$ & 0.015 & $\begin{array}{l}\text { Theim et al. } \\
\text { (2014) }\end{array}$ \\
\hline Psychotria marginata (Rubiaceae) & $\mathrm{S}$ & Tr-w & $\mathrm{m}$ & A & Endo & $\mathrm{Bi}$ & $\mathrm{C}$ & AFLP & $\mathrm{Y}$ & 0.046 & $\begin{array}{l}\text { Theim et al. } \\
\text { (2014) }\end{array}$ \\
\hline $\begin{array}{l}\text { Psychotria nervosa } \\
\text { (Rubiaceae) }\end{array}$ & $\mathrm{S}$ & Tr-w & $\mathrm{m}$ & $\mathrm{A}$ & Endo & $\mathrm{Bi}$ & $\mathrm{n} / \mathrm{a}$ & $\mathrm{Al}$ & $\mathrm{N}$ & 0.012 & $\begin{array}{l}\text { Dewey \& } \\
\text { Heywood } \\
(1988), \\
\text { Vekemans \& } \\
\text { Hardy (2004) }\end{array}$ \\
\hline $\begin{array}{l}\text { Psychotria officinalis } \\
\text { (Rubiaceae) }\end{array}$ & $\mathrm{S}$ & Tr-w & $\mathrm{m}$ & A & Endo & $\mathrm{Bi}$ & A & $\mathrm{Al}$ & $Y$ & 0.010 & $\begin{array}{l}\text { Loiselle et al. } \\
\text { (1995), } \\
\text { Vekeman \& } \\
\text { Hardy (2004) }\end{array}$ \\
\hline $\begin{array}{l}\text { Pulmonaria officinalis } \\
\text { (Boraginaceae) }\end{array}$ & $\mathrm{H}$ & $\mathrm{Te}$ & $\mathrm{m}$ & $A$ & Syn & $A$ & $\mathrm{D}$ & $\mathrm{Mi}$ & $\mathrm{Y}$ & 0.004 & $\begin{array}{l}\text { Meeus et al. } \\
\text { (2013) }\end{array}$ \\
\hline $\begin{array}{l}\text { Quercus ellipsoidalis } \\
\text { (Fagaceae) }\end{array}$ & $\mathrm{T}$ & $\mathrm{Te}$ & $\mathrm{m}$ & W & Syn & $\mathrm{Bi}$ & $E$ & $\mathrm{Mi}$ & $Y$ & 0.011 & $\begin{array}{l}\text { Lind-Riehl \& } \\
\text { Gailing (2015) }\end{array}$ \\
\hline $\begin{array}{l}\text { Quercus ilex } \\
\text { (Fagaceae) }\end{array}$ & $\mathrm{T}$ & $\mathrm{Te}$ & $\mathrm{m}$ & W & Syn & $\mathrm{Bi}$ & $E$ & $\mathrm{Mi}$ & $\mathrm{N}$ & 0.004 & $\begin{array}{l}\text { Soto et al. } \\
\text { (2007) }\end{array}$ \\
\hline $\begin{array}{l}\text { Quercus lobata } \\
\text { (Fagaceae) }\end{array}$ & $\mathrm{T}$ & Tr-d & $\mathrm{m}$ & W & Syn & $\mathrm{Bi}$ & $E$ & $\mathrm{Mi}$ & $\mathrm{Y}$ & 0.005 & $\begin{array}{l}\text { Sork et al. } \\
\text { (2015) }\end{array}$ \\
\hline $\begin{array}{l}\text { Quercus mongolica } \\
\text { (Fagaceae) }\end{array}$ & $\mathrm{T}$ & $\mathrm{Te}$ & $\mathrm{m}$ & W & Syn & $\mathrm{Bi}$ & $\mathrm{n} / \mathrm{a}$ & $\mathrm{Al}$ & $\mathrm{Y}$ & $\mathrm{n} / \mathrm{a}$ & $\begin{array}{l}\text { Chung \& } \\
\text { Chung (2004) }\end{array}$ \\
\hline $\begin{array}{l}\text { Quercus petraea } \\
\text { (Fagaceae) }\end{array}$ & $\mathrm{T}$ & $\mathrm{Te}$ & $\mathrm{m}$ & w & Syn & Ro & $\mathrm{D}$ & $\mathrm{Mi}$ & $\mathrm{Y}$ & 0.008 & $\begin{array}{l}\text { Streiff et al. } \\
\text { (1998), } \\
\text { Vekemans \& } \\
\text { Hardy (2004) }\end{array}$ \\
\hline
\end{tabular}




\begin{tabular}{|c|c|c|c|c|c|c|c|c|c|c|c|}
\hline $\begin{array}{l}\text { Quercus robur } \\
\text { (Fagaceae) }\end{array}$ & $\mathrm{T}$ & $\mathrm{Te}$ & $m$ & W & Syn & $\mathrm{Bi}$ & $E$ & $\mathrm{Mi}$ & $\mathrm{Y}$ & 0.003 & $\begin{array}{l}\text { Streiff et al. } \\
\text { (1998), } \\
\text { Vekemans \& } \\
\text { Hardy (2004) }\end{array}$ \\
\hline $\begin{array}{l}\text { Quercus rubra } \\
\text { (Fagaceae) }\end{array}$ & $\mathrm{T}$ & $\mathrm{Te}$ & $\mathrm{m}$ & W & Syn & $\mathrm{Bi}$ & $E$ & $\mathrm{Mi}$ & $Y$ & 0.005 & $\begin{array}{l}\text { Lind-Riehl \& } \\
\text { Gailing (2015) }\end{array}$ \\
\hline $\begin{array}{l}\text { Rhus javanica } \\
\text { (Anacardiaceae) }\end{array}$ & $\mathrm{T}$ & $\mathrm{Te}$ & $\mathrm{d}$ & $A$ & Endo & $\mathrm{Bi}$ & $\mathrm{n} / \mathrm{a}$ & Mi & $Y$ & 0.015 & $\begin{array}{l}\text { Chung et al. } \\
\text { (2000a), } \\
\text { Vekemans \& } \\
\text { Hardy (2004) }\end{array}$ \\
\hline $\begin{array}{l}\text { Schinus molle } \\
\text { (Anacardiaceae) }\end{array}$ & $\mathrm{T}$ & Tr-d & $\mathrm{d}$ & $A$ & Endo & $\mathrm{Bi}$ & $B$ & $\mathrm{AF}$ & $Y$ & 0.021 & $\begin{array}{l}\text { Lemos et al. } \\
(2015)\end{array}$ \\
\hline $\begin{array}{l}\text { Sclerolaena diacantha } \\
\text { (Chenopodiaceae) }\end{array}$ & $\mathrm{S}$ & $T r-d$ & $\mathrm{~m}$ & $W$ & Syn & $A$ & $\mathrm{n} / \mathrm{a}$ & $\mathrm{Al}$ & $Y$ & $\mathrm{n} / \mathrm{a}$ & $\begin{array}{l}\text { Peakall \& } \\
\text { Beattie (1995) } \\
\end{array}$ \\
\hline $\begin{array}{l}\text { Sextonia rubra } \\
\text { (Laureaceae) }\end{array}$ & $\mathrm{T}$ & Tr-w & $\mathrm{m}$ & $A$ & Endo & $\mathrm{Bi}$ & $A$ & $\begin{array}{l}\text { Mi, } \\
\text { RAPD }\end{array}$ & $\mathrm{N}$ & 0.006 & $\begin{array}{l}\text { Hardy et al. } \\
(2006)\end{array}$ \\
\hline $\begin{array}{l}\text { Simarouba amara } \\
\text { (Simaroubaceae) }\end{array}$ & $\mathrm{T}$ & Tr-w & $d$ & $A$ & Endo & $\begin{array}{l}\mathrm{Ba}, \mathrm{Bi}, \\
\mathrm{P}\end{array}$ & $n / a$ & AFLP, Mi & $Y$ & 0.008 & $\begin{array}{l}\text { Hardesty et al. } \\
\text { (2005), Dick et } \\
\text { al. (2008) }\end{array}$ \\
\hline $\begin{array}{l}\text { Sorbus torminalis } \\
\text { (Rosaceae) }\end{array}$ & $T$ & $\mathrm{Te}$ & $\mathrm{m}$ & $A$ & Endo & $\mathrm{Bi}$ & B & $\mathrm{Mi}$ & $Y$ & 0.014 & $\begin{array}{l}\text { Jankowska- } \\
\text { Wroblewska et } \\
\text { al. (2016), } \\
\text { Oddou- } \\
\text { Muratorio et } \\
\text { al. } 2004\end{array}$ \\
\hline \multirow[t]{3}{*}{$\begin{array}{l}\text { Symphonia globulifera } \\
\text { (Clusiaceae) }\end{array}$} & $T$ & Tr-w & $m$ & $A$ & Endo & $\begin{array}{l}\mathrm{Ba}, \mathrm{P}, \\
\mathrm{R}, \mathrm{AM}, \\
\mathrm{T}\end{array}$ & A & $\mathrm{Mi}$ & $Y$ & 0.011 & $\begin{array}{l}\text { Torroba- } \\
\text { Balmori et al. } \\
(2017)\end{array}$ \\
\hline & $T$ & Tr-w & $m$ & $A$ & Endo & $\begin{array}{l}\mathrm{Bi}, \mathrm{P}, \\
\mathrm{SR}\end{array}$ & B & $\mathrm{Mi}$ & $Y$ & 0.025 & $\begin{array}{l}\text { Torroba- } \\
\text { Balmori et al. } \\
(2017)\end{array}$ \\
\hline & $T$ & Tr-w & $\mathrm{m}$ & $A$ & Endo & $\begin{array}{l}\mathrm{Ba}, \\
\mathrm{AM}, \mathrm{SR}\end{array}$ & $\mathrm{n} / \mathrm{a}$ & $\begin{array}{l}\text { Mi, } \\
\text { RAPD }\end{array}$ & $Y$ & 0.017 & $\begin{array}{l}\text { Hardy et al. } \\
(2006)\end{array}$ \\
\hline $\begin{array}{l}\text { Trillium grandiflorum } \\
\text { (Melanthiaceae) }\end{array}$ & $\mathrm{H}$ & $\mathrm{Te}$ & $m$ & $A$ & Syn & $A$ & $\mathrm{n} / \mathrm{a}$ & $\mathrm{Al}$ & $\mathrm{Y}$ & 0.025 & $\begin{array}{l}\text { Kalisz et al. } \\
(2001), \\
\text { Vekemans \& } \\
\text { Hardy (2004) }\end{array}$ \\
\hline $\begin{array}{l}\text { Trillium maculatum } \\
\text { (Melanthiaceae) }\end{array}$ & $\mathrm{H}$ & $\mathrm{Te}$ & $\mathrm{n} / \mathrm{a}$ & $\mathrm{n} / \mathrm{a}$ & Syn & $A$ & $D$ & $\mathrm{Al}$ & $N$ & $\mathrm{n} / \mathrm{a}$ & $\begin{array}{l}\text { Walker et al. } \\
\text { 2009) }\end{array}$ \\
\hline $\begin{array}{l}\text { Virola michelii } \\
\text { (Myristicaceae) }\end{array}$ & $T$ & Tr-w & $d$ & $A$ & Endo & $\begin{array}{l}\mathrm{Bi}, \mathrm{P}, \\
\mathrm{AM}\end{array}$ & $\mathrm{n} / \mathrm{a}$ & $\begin{array}{l}\text { AFLP, } \\
\text { RAPD }\end{array}$ & $Y$ & 0.015 & $\begin{array}{l}\text { Hardy et al. } \\
(2006)\end{array}$ \\
\hline $\begin{array}{l}\text { Voucapoua americana } \\
\text { (Fabaceae) }\end{array}$ & $\mathrm{T}$ & Tr-w & $\mathrm{m}$ & $A$ & Syn & Ro & $D$ & $\begin{array}{l}\text { Mi, } \\
\text { RAPD }\end{array}$ & $Y$ & 0.028 & $\begin{array}{l}\text { Dutech et al. } \\
(2002)^{1}, \text { Hardy } \\
\text { et al. (2006) }\end{array}$ \\
\hline
\end{tabular}

Table 2. Information on zoochorously dispersed plant species included in this review.

${ }^{a n} \mathrm{E}$ : epiphyte or hemi-epiphyte: $\mathrm{H}$ : herb; S: shrub; T: tree.

${ }^{\mathrm{b}} \mathrm{Tr}$-d: tropical-dry; Tr-w: tropical-wet/moist; Te: temperate.

${ }^{c} \mathrm{~d}$ : dioecious; m: monoecious.

${ }^{d}$ a: animal (insect or vertebrate); w: wind.

e Endo: Endozoochory, Syn: Synzoochory.

${ }^{f}$ A: ants; Ba: bats; Bi: birds; P: primates; Ro: Rodents; Mix: including various taxa (AM: Nocturnal arboreal mammals, E: Elephants, SR: Small ruminants, T: Tapirs)

${ }^{\mathrm{g}} \mathrm{A}$ : Long-distance movements after feeding; B: short-distance dispersal behavior; C: roosting behavior; D: hoarding; E: long-distance caching.

h AFLP: Amplified fragment length polymorphism; Al: Allozymes; ISSR: inter-sequence short repeats; Mi: Microsatellites; RAPD: Random amplified polymorphic DNA.

'Y: SGS present; N: SGS absent.

${ }^{j}$ Mean $S p$ values for adults of all populations of that species or specific study.

${ }^{k}$ Information not available.

' absent seed dispersers Ficus pumila.

${ }^{1} \mathrm{Sp}$ value calculated from published results. 


\section{Results}

\section{Effect of seed dispersal mode on SGS}

Seed dispersal mode (endozoochory or synzoochory) had a marginally significant influence on the occurrence of SGS: synzoochorous plants tended to have SGS more frequently compared to endozoochorous plant species (Table $3 ; \chi^{2}(1)=3.1, p=0.058$.). Strength of SGS differed significantly between endozoochorously and synzoochorously dispersed plant species (ANOVA, $F(1,18)=7.04, p=0.016)$ with lower $S p$ values in synzoochorously dispersed species compared to endozoochorously dispersed species. However, the effect of seed dispersal mode on SGS strength was significantly dependent on marker type used (ANOVA, $\mathrm{F}(1,18)=4.49, p=$ 0.048). Therefore, with the available data we cannot disentangle the effects of seed dispersal mode and marker type used.

Table 3. Presence of SGS in zoochorously dispersed plant species. We report the number and percentage of plant species with SGS for which we obtained information on seed dispersal mode, seed disperser group and/or seed disperser behavior.

\begin{tabular}{lllll}
\hline & Category & $\begin{array}{l}\text { \# of plant species } \\
\text { studied }\end{array}$ & \multicolumn{2}{l}{$\begin{array}{l}\text { \# (\%) of plant species } \\
\text { with SGS }\end{array}$} \\
\hline Seed dispersal mode & $\begin{array}{l}\text { Endozoochory } \\
\text { Synzoochory }\end{array}$ & 42 & 31 & $(74)$ \\
& 26 & 24 & $(92)$ \\
\hline Seed disperser taxonomy & Ants & 6 & 5 & $(83)$ \\
& Bats & 7 & 7 & $(100)$ \\
& Birds & 32 & 20 & $(63)$ \\
& Primates & 4 & 4 & $(100)$ \\
& Rodents & 10 & 10 & $(100)$ \\
\hline \multirow{3}{*}{ Seed disperser behavior } & Category A & 10 & 5 & $(50)$ \\
& Category B & 7 & 5 & $(71)$ \\
& Category C & 9 & 9 & $(100)$ \\
& Category D & 13 & 12 & $(92)$ \\
& Category E & 8 & 7 & $(88)$ \\
\hline
\end{tabular}

\section{Effect of seed disperser taxonomic group on SGS}

The proportion of plant species with SGS varied significantly between dispersers from different taxonomic groups $\left(\chi^{2}(5)=14.894, p=0.011\right.$; Table 3$)$. This difference could be attributed to the much lower proportion of plant species dispersed by birds that showed SGS (Tab. 2). However, the strength of SGS did not differ between taxonomic groups (ANOVA, F(4,16) 
$=0.17, p=0.94$.; Figure 8A, Table 4). No interaction effects were found with the additional factors. Our results suggest seed dispersal by birds reduces the likelihood of the formation of SGS, but when present, strength is comparable to that produced by other seed disperser groups. High variance in $S p$ values within categories indicates other factors that we could not account for affected the strength of SGS within the taxonomic groups.

Table 4. Comparison of the strength of SGS, via Sp statistics, among the seed disperser categories for seed dispersal mode, seed disperser taxonomy and seed disperser behavior. Mean Sp, median, standard deviation (SD) and the number of studies (N) are given for each category. Significance was tested with a Factorial ANOVA.

\begin{tabular}{llllll}
\hline & & Sp mean & Sp median & SD & N \\
\hline $\begin{array}{l}\text { Seed dispersal } \\
\text { mode }\end{array}$ & Endozoochory & 0.0164 & 0.0145 & 0.0108 & 29 \\
& Synzoochory & 0.0144 & 0.0102 & 0.0129 & 19 \\
& ANOVA, F(1,18)=7.04, $p=0.02$ & & & \\
\hline Seed disperser & Ants & 0.0182 & 0.0250 & 0.0122 & 3 \\
taxonomy & Bats & 0.0149 & 0.0098 & 0.0108 & 9 \\
& Birds & 0.0156 & 0.0120 & 0.0122 & 18 \\
& Primates & 0.0151 & 0.0151 & 0.0073 & 4 \\
& Rodents & 0.0185 & 0.0163 & 0.0152 & 10 \\
\hline Seed disperser & ANOVA, F(4,16)=0.17, $p=0.94$ & & & \\
behavior & Category A & 0.0084 & 0.0094 & 0.0026 & 5 \\
& Category B & 0.0195 & 0.0212 & 0.0053 & 5 \\
& Category C & 0.0221 & 0.0221 & 0.0136 & 9 \\
& Category D & 0.0178 & 0.0163 & 0.0146 & 12 \\
& Category E & 0.0075 & 0.0058 & 0.0039 & 7 \\
& ANOVA, F(4,12)=4.35, $p=0.02$. & & & \\
\hline
\end{tabular}

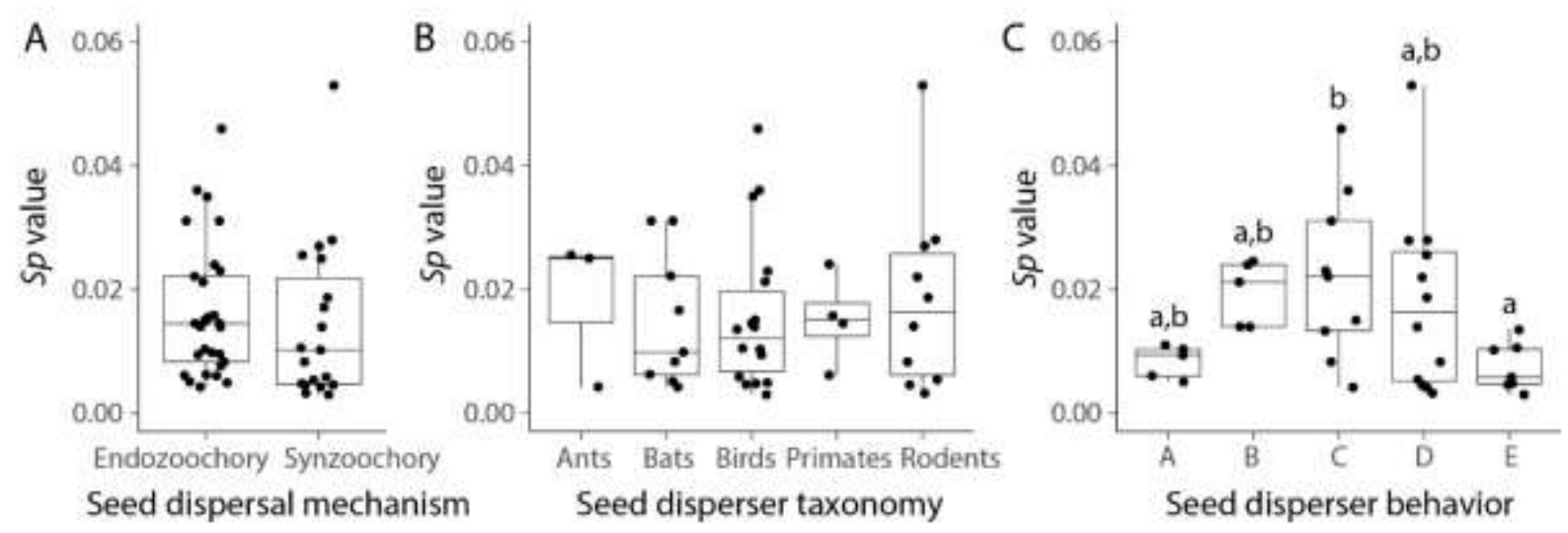

Figure 8. Comparison of Sp values of plant species with A) different dispersal modes: dispersal through defecation or regurgitation (endozoochory) vs. dispersal through actively carried seeds (synzoochory), B) different taxonomic groups of dispersal vectors, and (C) different functional groups of dispersal vectors. 
In (C), bars with different superscripts differ at $p<0.05$ (Tukey post-hoc test). Horizontal lines are median values, boxes indicate $25 \%$ and $75 \%$ quartiles.

\section{Effect of seed disperser behavior on SGS}

The occurrence of SGS differed significantly among behavioral groups of seed dispersers $(\chi 2(4)=11.9, p=0.018 ;$ Table 3$)$. Plant species dispersed by vectors of category A were less

likely to have SGS compared to other groups. These dispersers were characterized by having short feeding bouts or travel faster and longer away from the source plant. $S p$ values were also significantly different between categories (ANOVA: $\mathrm{F}(4,12)=4.35, p=0.02$; Figure 8C, Table 4), without significant interaction effects of the additional factors. SGS was the weakest for plant species dispersed by highly mobile animals which move away from source plants immediately after feeding (category A), and which accumulate seeds in widely distributed caches (category $E$, see below). In contrast, $S p$ values were the highest for plants dispersed by animals with shortrange movement and behaviors that maintain individuals around fruit sources after feeding or that increase the rate of fruit or seed droppings around sources (category B), and for plants with dispersers that accumulate seeds in roosts (category $\mathrm{C}$ ).

The Tukey post-hoc test indicated only categories C and E differed significantly in the strength of SGS $(p=0.044)$, and the difference between B and E was marginally significant $(p=$ 0.071). Thus, if seeds were accumulated either actively in roosts, or passively in close vicinity to the maternal plant, SGS was higher than in plants whose seeds were actively distributed to caches by scatter-hoarding birds.

One noticeable result was the high variance in $S p$ values within plants from category $C$ and plants dispersed by terrestrial animals that accumulate seeds in e.g. caches or anthills (category D) (Figure 8C, Table 4). In both cases, seeds are accumulated, either in in roosts by flying animals or in caches by scatter hoarding mammals or in ant mounds. In contrast, SGS was generally low in species dispersed by scatter- hoarding birds (E). In all three cases, the strength of SGS will strongly depend on i) the number of seeds taken from each source plant, ii) the number of seeds accumulated in a single cache or roosting site, iii) the number of source plants for a single caching site, and iv) the distance between source plant(s) and the caching or roosting sites. Although the respective studies did not report whether dispersers tended to accumulate seeds from a few or many source plants, research shows scatter hoarding birds fly for long 
distances after fruit and seed collection, transporting a small number of seeds in their beaks (Lovette \& Fitzpatrick 2016), which results in a wide distribution of dispersed seeds and could potentially reduce SGS. For example, blue jays carry a mean of 2.2 acorns from the same tree at a time, and travel on average $1.1 \mathrm{~km}$ before depositing seeds in widely distributed caches (Darley-Hill \& Johnson 1981). In contrast, category D comprised ground-dwelling rodents and ants which frequently stay near source plants after collecting seeds. For example, rodents transport fallen seeds of Holm oaks (Quercus ilex) over short distances (median $=1.5 \mathrm{~m}$ ) before depositing them in caches (Gómez et al. 2008), thus increasing the potential for formation of SGS. Category $\mathrm{C}$ included studies of Paleotropical and Neotropical bats that often deposit seeds beyond feeding roosts and birds with roosting behavior. We expect seed dispersal by birds with lekking behavior or primates with recurrent sleeping or resting sites to result in similar dispersal patterns, but we did not find studies on strength of SGS for these. The high variance in category $\mathrm{C}$ might be further explained by factors previously shown to influence seed deposition by bats: spatial distribution of resources, body size, social structure and feeding competition (Heithaus et al. 1975). In all cases where seeds are accumulated under roosts, leks or in caches; the number of source plants, and potentially also the distance to source plants, can be determined with genetic markers providing information on how hoarding and roosting behavior shape SGS (Godoy \& Jordano 2001; García et al. 2009; Hamrick \& Trapnell 2011).

The spatial distribution of resources, body size, social structure and feeding competition likely influence dispersal patterns in all behavioral categories. Therefore, the differences we detected between behavior categories, despite these additional influencing factors, make the detected differences even more notable. Our results confirm SGS strength is strongly dependent on how animals feed, whether they deposit seeds around fruit source and whether they stay close to the fruit sources after feeding or gathering seeds, which directly influences seed deposition patterns and seed dispersal distance. In fact, based on the few studies that provided estimates or observations of seed dispersal distances $(N=13)$, we found a trend towards lower $S p$ values with longer seed dispersal distances (Spearman's rank correlation, $r_{s}=-0.320, p=$ 0.113, Figure 9). 


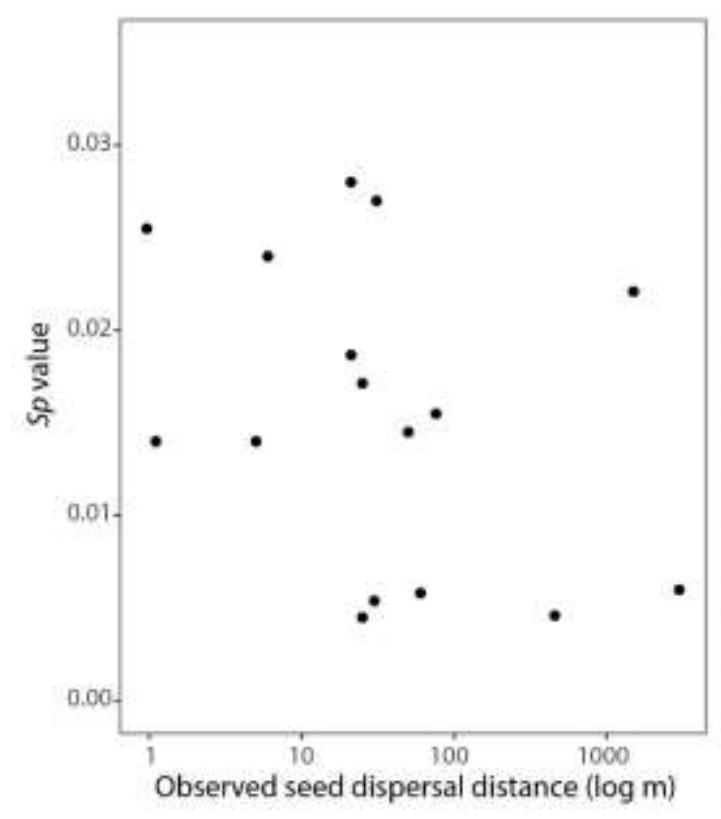

\begin{tabular}{|c|c|c|}
\hline Species & SDD & Sp \\
\hline Adansonia digitata & 1500.00 & 0.0221 \\
\hline Araucaria angustifolia & 60.00 & 0.0058 \\
\hline Attalea phalerata & 6.00 & 0.0240 \\
\hline Carapa guianensis & 25.00 & 0.0045 \\
\hline Carapa procera & 21.00 & 0.0280 \\
\hline Castanopsis sclerophylla & 30.00 & 0.0054 \\
\hline Chrysophyllum sanguinolentum & 50.00 & 0.0145 \\
\hline Dicorynia guianensis & 21.00 & 0.0187 \\
\hline Dioscorea japonica & 1.10 & 0.0140 \\
\hline Fagus sylvatica & 25.00 & 0.0171 \\
\hline Polygala reinil & 0.96 & 0.0255 \\
\hline Pouteria reticulata & 3000.00 & 0.0060 \\
\hline Prunus africana & 5.00 & 0.0140 \\
\hline Quercus lobata & 457.00 & 0.0046 \\
\hline Virola michelil & 76.00 & 0.0155 \\
\hline Vouacopoua americana & 31.00 & 0.0270 \\
\hline
\end{tabular}

Figure 9. Relationship between $\mathrm{Sp}$ values and observed seed dispersal distance (SDD, given in meters; Spearman rank correlation. $\left(r_{s}=-0.32, p=0.11\right)$

Several studies did not supply $S p$ statistics but nevertheless provide strong indications for effects of animal behavior on SGS. (i) Trapnell et al. (2008) studied two populations of the shrub Ceratiola ericoides, whose seeds are dispersed by frugivorous birds in sand dunes. The population where the surrounding tree community offered safe perching sites for birds had higher mean kinship coefficients between neighboring shrub individuals than the population where forest cover was reduced. In the latter, birds flew away more rapidly after collecting fruits as a strategy to reduce predation risk. (ii) The trees Neolitsea sericea and Cinnamomum insularimontanum are mainly dispersed by frugivorous birds that tend to leave the fruiting tree immediately after the collection of single fruits (Chung et al. 2003, Chung et al., 2000). No SGS was detected in populations of these trees. (iii) Seeds of Ficus hispida are mainly dispersed by large green pigeons (Treron capellei), solitary fig specialist that frequently drops fruits while feeding (Lambert 1989; Birdlife International 2001). In an autocorrelation analysis, adult $F$. hispida showed high kinship coefficient values within the first distance class (Dev et al. 2011). (iv) Seeds of the palm Oenocarpus bataua are dispersed by the umbrella bird (Cephalopterus penduliger). Male umbrella birds had individual-specific leks to which they returned constantly after feeding. They spent $80 \%$ of their time at their leks and deposited there $50 \%$ of the ingested seeds. This created a diverse pool of seeds within the leks, with five times more seed sources 
than outside the leks. SGS within leks was weaker than in the surrounding areas (Karubian et al. 2012). (v) The same plant species, Oenocarpus bataua, is also dispersed by white-bellied spider monkeys (Ateles belzebuth). These monkeys used sleeping sites repeatedly which resulted in an accumulation of seeds but only from the few palms on which they fed before retiring to sleep. Consequently, seed source diversity beneath sleeping sites was high and SGS significant. (Karubian et al. 2015).

Secondary seed dispersal, i.e. subsequent movement of the seeds after its primary deposition, can also influence SGS strength by increasing seed dispersal distances and further modifying the spatial patterns of seed dispersal (Mizuki \& Takahashi 2009; Hirsch et al. 2012; Gallegos et al. 2014; Hämäläinen et al. 2017). A study on agoutis showed a large number of seeds were stolen from caches and transported further, which resulted in final dispersal distances of $>100 \mathrm{~m}$ (Jansen et al. 2012). This suggests secondary seed dispersal might be more efficient than previously considered, and thus might have a non-trivial influence on SGS.

\section{Additional factors influencing SGS of zoochorously dispersed species}

In our data set of zoochorously dispersed plant species, among the additional factors, we found only pollination mechanisms (ANOVA: $\mathrm{F}(1,20)=5.92, p=0.02)$ and marker type used (ANOVA: $\mathrm{F}(3,20)=4.23, p=0.02)$ had a significant influence the strength of SGS (Table 5). Plant species pollinated by animals had higher $S p$ values than wind-pollinated species (Figure 10). A similar trend of pollination on SGS has been seen before for temperate species (Dick et al., 2008), but not for species from diverse climatic regions (Vekemans \& Hardy, 2004) (Table 6). We found no effect of sexual system, nor breeding system, in contrast to previous reviews (Vekemans et al., 2004, Nazareno et al.,2013), however our results showed high variance within categories and a low number of self-compatible species. Like previous findings, we did not detect a difference in the strength of SGS between plants growing in different climatic regions (Dick et al., 2008). Neither did we detect differences among plant life forms, but our data set consisted mainly of tree species so the results cannot be compared to other studies. Jump et al. (2012) suspected that the use of different markers might impact the strength of SGS. In our data set, studies using microsatellites resulted in significantly lower $S p$ values compared to studies using AFLPs (Figure 11A). However, when we restricted the comparison to plant species investigated in parallel with two different marker types, we could not confirm the finding by Jump et al. 
(2012) (Figure 11B). The potential interaction effect of pollination and marker type use was accounted for on all our analysis by testing for interactions using the Factorial ANOVA.

\begin{tabular}{|c|c|c|c|c|c|}
\hline & & Sp mean & Sp median & SD & $\mathbf{N}$ \\
\hline $\begin{array}{l}\text { Pollination } \\
\text { mechanism }\end{array}$ & $\begin{array}{l}\text { Animal } \\
\text { Wind } \\
\text { ANOVA, } \quad F(1,20)=0.39, p=0.02\end{array}$ & $\begin{array}{l}0.0183 \\
0.0066\end{array}$ & $\begin{array}{l}0.0150 \\
0.0051\end{array}$ & $\begin{array}{l}0.0117 \\
0.0041\end{array}$ & $\begin{array}{l}37 \\
11\end{array}$ \\
\hline Plant life form & $\begin{array}{l}\text { Epiphyte } \\
\text { Herbs } \\
\text { Shrub } \\
\text { Tree } \\
\text { ANOVA, } F(3,20)=2.31, p=0.11 \\
\end{array}$ & $\begin{array}{l}0.0183 \\
0.0146 \\
0.0237 \\
0.0138\end{array}$ & $\begin{array}{l}0.0140 \\
0.0146 \\
0.0230 \\
0.0100\end{array}$ & $\begin{array}{l}0.0113 \\
0.0147 \\
0.0135 \\
0.0108\end{array}$ & $\begin{array}{l}3 \\
2 \\
7 \\
36\end{array}$ \\
\hline $\begin{array}{l}\text { Sexual system/ } \\
\text { Breeding system }\end{array}$ & $\begin{array}{l}\text { Monoecious (Mixed) } \\
\text { Monoecious (Outcrossing) } \\
\text { Monoecious (Self-incompatible) } \\
\text { Dioecious } \\
\text { ANOVA, } F(3,20)=2.06, p=0.14 \text {. }\end{array}$ & $\begin{array}{l}0.0179 \\
0.0120 \\
0.0140 \\
0.0162\end{array}$ & $\begin{array}{l}0.0187 \\
0.0100 \\
0.0103 \\
0.0145\end{array}$ & $\begin{array}{l}0.0099 \\
0.0078 \\
0.0119 \\
0.0099\end{array}$ & $\begin{array}{l}5 \\
11 \\
31 \\
12\end{array}$ \\
\hline Climate region & $\begin{array}{l}\text { Temperate } \\
\text { Tropical } \\
\text { ANOVA, } F(1,20)=2.91, p=0.10 \text {. }\end{array}$ & $\begin{array}{l}0.0129 \\
0.0177\end{array}$ & $\begin{array}{l}0.0102 \\
0.0150\end{array}$ & $\begin{array}{l}0.0096 \\
0.0127\end{array}$ & $\begin{array}{l}21 \\
27\end{array}$ \\
\hline Markers & $\begin{array}{l}\text { AFLP } \\
\text { Allozyme } \\
\text { Microsatellite } \\
\text { RAPD } \\
\text { ANOVA, } F(3,20)=0.85, p=0.02 \text {. }\end{array}$ & $\begin{array}{l}0.0231 \\
0.0203 \\
0.0123 \\
0.0184\end{array}$ & $\begin{array}{l}0.0212 \\
0.0250 \\
0.0094 \\
0.0150\end{array}$ & $\begin{array}{l}0.0110 \\
0.0086 \\
0.0094 \\
0.0076\end{array}$ & $\begin{array}{l}9 \\
3 \\
35 \\
6\end{array}$ \\
\hline
\end{tabular}


Table 5. Effects of additional factors (i.e. factors other than seed dispersal) on the strength of SGS.

\begin{tabular}{|c|c|c|c|c|}
\hline Pollination & \multicolumn{2}{|c|}{ Vekemans et al. 2004} & \multicolumn{2}{|l|}{ This study } \\
\hline$\overline{\text { Animals }}$ & $0.017 \pm 0.014$ & $\mathrm{n}=17$ & $0.018 \pm 0.012$ & $n=37$ \\
\hline Wind & $0.006 \pm 0.004$ & $n=6$ & $0.007 \pm 0.004$ & $n=11$ \\
\hline \multirow[t]{2}{*}{$t$-test } & n.s. & & $\mathrm{t}(21.51)=4.99$ & \\
\hline & \multicolumn{2}{|l|}{ Dick et al. 2008} & & \\
\hline Animals & $0.029(\mathrm{SD} n / \mathrm{a})$ & $\mathrm{n}=8$ & & \\
\hline Wind & 0.010 (SD n/a) & $\mathrm{n}=15$ & & \\
\hline$t$-test & $p<0.02$ & & & \\
\hline Life form & \multicolumn{2}{|c|}{ Vekemans et al. 2004} & This study & \\
\hline Epiphytes & $\mathrm{n} / \mathrm{a}$ & & $0.018 \pm 0.011$ & $n=3$ \\
\hline Herbs & $0.046 \pm 0.064$ & $n=24$ & $0.015 \pm 0.015$ & $n=2$ \\
\hline Shrubs & $0.026 \pm 0.156$ & $n=6$ & $0.024 \pm 0.013$ & $n=7$ \\
\hline Trees & $0.010 \pm 0.01$ & $\mathrm{n}=17$ & $0.014 \pm 0.011$ & $n=36$ \\
\hline ANOVA & $p<0.01$ & & $\mathrm{~F}(3,44)=1.80, p$ & \\
\hline Sexual system & \multicolumn{2}{|c|}{ Nazareno et al. 2012} & This study & \\
\hline Monoecious & $0.010 \pm 0.008$ & $\mathrm{n}=14$ & $0.015 \pm 0.012$ & $n=35$ \\
\hline Dioecious & $0.025 \pm 0.017$ & $\mathrm{n}=15$ & $0.016 \pm 0.010$ & $\mathrm{n}=12$ \\
\hline$t$-test & $p<0.001$ & & $t(22.35)=0.75$ & \\
\hline Breeding system & \multicolumn{2}{|c|}{ Vekemans et al. 2004} & This study & \\
\hline Selfing & $0.143 \pm 0.008$ & $n=5$ & $\mathrm{n} / \mathrm{a}$ & \\
\hline Mixed & $0.037 \pm 0.008$ & $n=7$ & $0.018 \pm 0.010$ & $n=5$ \\
\hline Outcrossing & $0.013 \pm 0.017$ & $\mathrm{n}=18$ & $0.013 \pm 0.009$ & $n=11$ \\
\hline Self-incompatible & $0.013 \pm 0.017$ & $n=17$ & $0.015 \pm 0.011$ & $n=31$ \\
\hline$t$-test & $p<0.001$ & & $F(2,44)=0.40$ & \\
\hline Climate region & \multicolumn{2}{|l|}{ Dick et al. 2008} & This study & \\
\hline Temperate & 0.0166 (SD n/a) & $n=24$ & $0.013 \pm 0.010$ & $n=21$ \\
\hline Tropical & 0.0173 (SD n/a) & $\mathrm{n}=15$ & $0.018 \pm 0.013$ & $n=27$ \\
\hline$t$-test & n.s. & & $\mathrm{t}(41.39)=-1.62$ & \\
\hline \multicolumn{3}{|l|}{ Marker system } & \multicolumn{2}{|l|}{ This study } \\
\hline AFLP & & & $0.023 \pm 0.011$ & $n=9$ \\
\hline Allozymes & & & $0.020 \pm 0.009$ & $n=3$ \\
\hline Microsatellites & & & $0.012 \pm 0.010$ & $n=35$ \\
\hline RAPD & & & $0.018 \pm 0.008$ & $n=6$ \\
\hline ANOVA & & & $\mathrm{F}(3,49)=4.94, p$ & \\
\hline
\end{tabular}


Table 6. Comparison of $\mathrm{Sp}$ values for factors other than seed dispersal between previous studies and this study
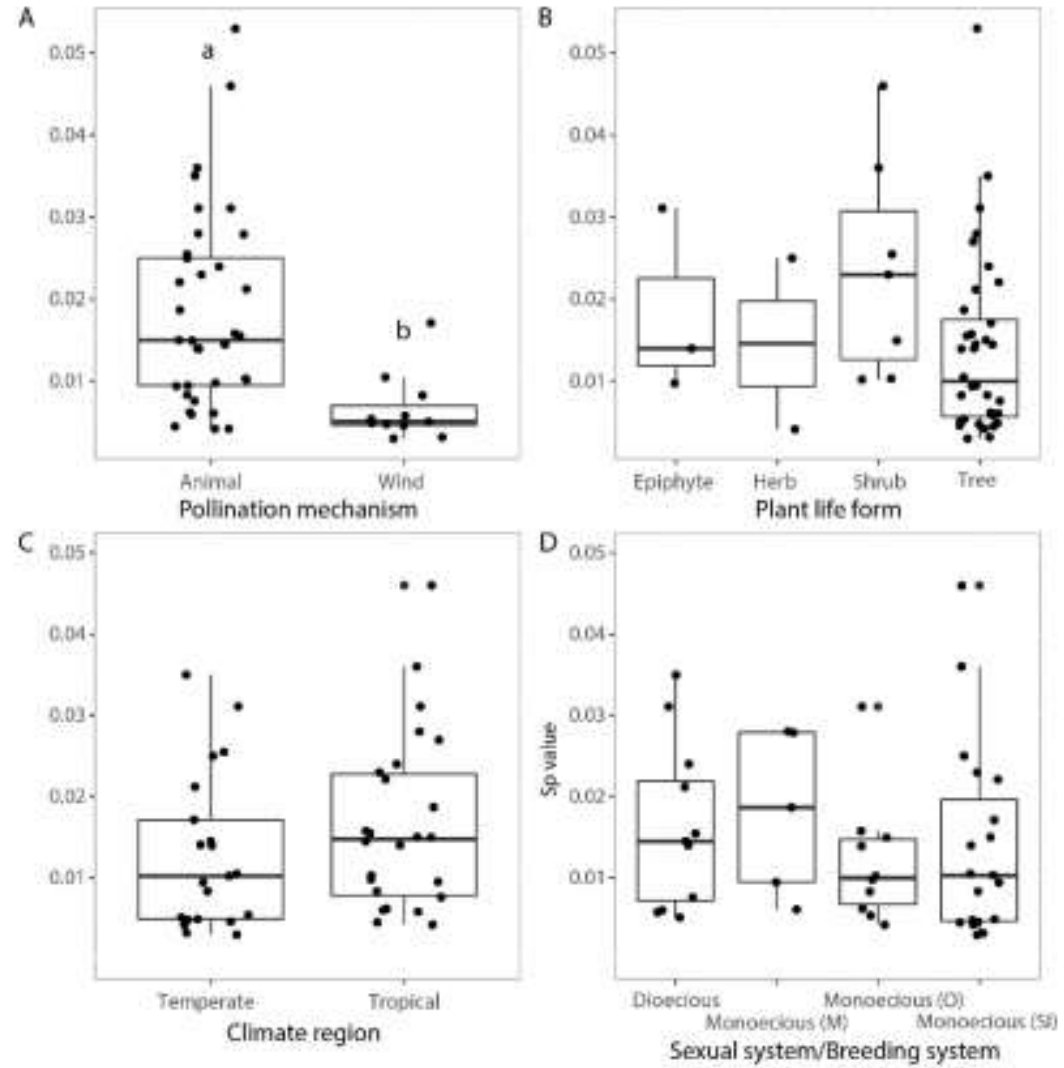

Figure 10. Effects of additional factors on SGS of zoochorously dispersed plants: Pollination mechanism (A), Life form (B), Climate region (C), Sexual system/Breeding system (D). For the monoecious species in $D$, abbreviations indicate mixed-system (outcrossing and selfing) [M], outcrossing [O] and selfincompatible [SI] species). Letters above box plots indicate significant difference among categories which was only the case for the pollination mechanisms.
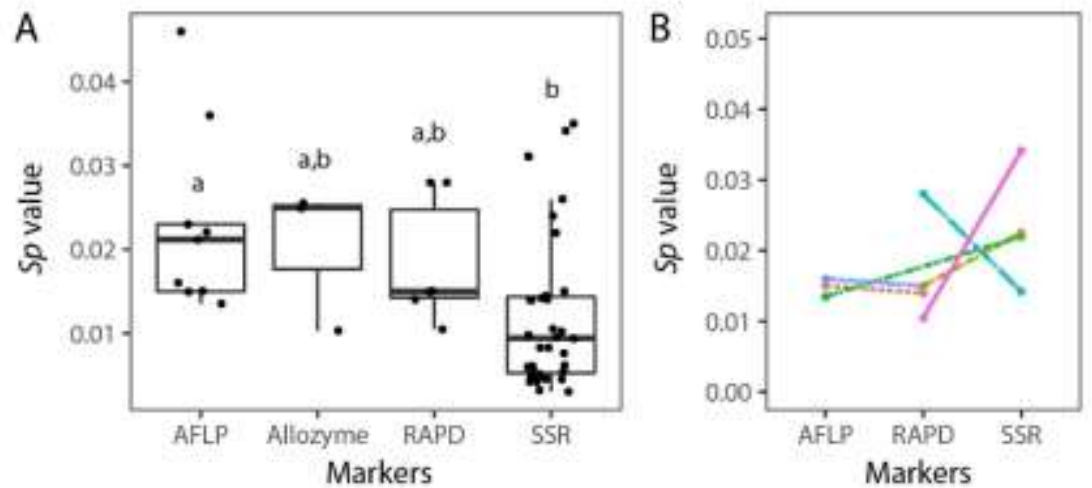

Species

..... Chrysophyllum sanguinolentum ( $n=2)$

$\rightarrow$ Dicorynia guianensis $(\mathrm{n}=2)$

-. Fagus sylvatica $(n=2)$

- Symphoniaglobulifera $(n=2)$

- Virola michelii $(n=2)$

- Vouacapoua americana (n=2)

Figure 11. Comparison of the strength of SGS among plant species that were studied with different types of markers (A), and comparison of Sp values for the subset of plant species for which SGS was determined 
with different marker types (B). Letters above box plots indicate significant difference among categories which was only the case for the pollination mechanisms.

Contrary to what we expected, plant population density showed no correlation with strength of SGS (Spearman's rank correlation, $r_{s}=-0.01, p=0.48$, Figure 12A). Furthermore, when we compared populations from the same plant species with different adult plant densities through a generalized linear regression, there was no clear pattern (Figure 12B). Nine out of fifteen plant species showed a decrease in $S p$ value with an increase in plant population density, while seven out of fifteen showed an increase in $S p$ values.
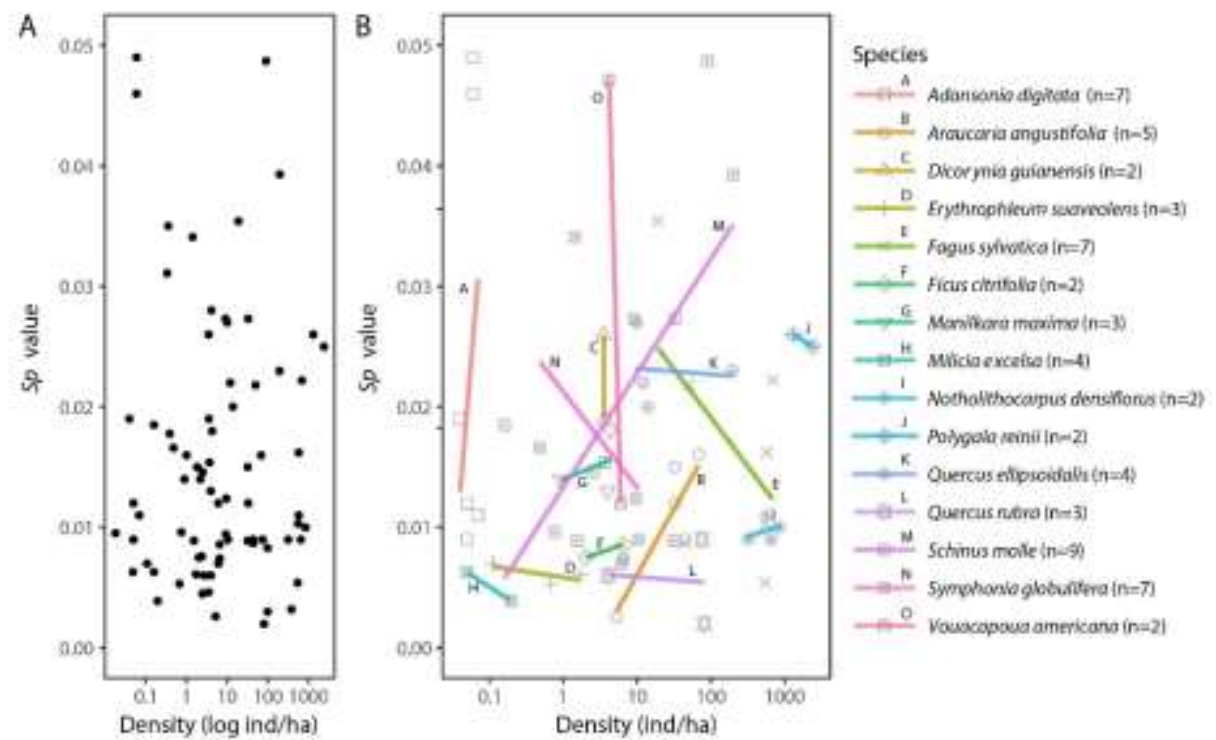

Figure 12. Effect of plant density on SGS of zoochorously dispersed plants. Sp values for are plotted against adult density of each population for every species $(r s=-0.01, p=0.48)(A)$, Changes in $S p$ values across populations of the same Species with different densities (B).

The list of additional factors that might potentially influence SGS in the surveyed studies, but were present in too few studies to include in the analysis, included fruit availability and plant distribution (Trapnell et al. 2008, Bizoux et al, 2009), management situation of plant populations (Lind-Riehl \& Gailing 2015), habitat fragmentation (WANG et al. 2011; Vieira et al. 2012), urbanization level of study site (Wang et al. 2009), specific microhabitat requirements limiting germination success (Chung et al. 2003; Heer et al. 2015) and plant life history, such as masting events or high fruiting yields (Vieira et al. 2012; Lind-Riehl \& Gailing 2015), clonality (Dodd et al. 2013) or plant life form (Heer et al. 2015). Many of these factors influence directly or indirectly foraging behavior of the seed dispersal vectors. The available evidence on our study shows 
zoochorous seed dispersal has an important impact on spatial distribution of genotypes at local scales.

\section{Future directions}

In many studies that analyze spatial genetic structure of zoochorous plants, behavior of seed dispersal vectors was neglected. Our study provides evidence that vector behavior impacts SGS via shaping seed dispersal patterns (Stiles 2000). These patterns can be highly consistent over time (Heymann et al. 2017), increasing the probability of an effect of seed dispersal on SGS. Anthropogenic disturbances that might modify vector behavior are thus likely to influence seed dispersal patterns and in turn SGS (McConkey \& O'Farrill 2015; Jones et al. 2017). Our results emphasize the need for future studies on population genetics of animal-dispersed plants to include ecological and behavioral observations of dispersal vectors as a key for understanding gene flow and spatial distribution of genetic diversity in animal-dispersed plant species.

Focal observations of fruiting trees (Jordano \& Godoy 2002; Donatti et al. 2011) can provide data on number and identity of dispersers present in the area, and their behavior during and immediately after feeding. Furthermore, focal-animal sampling (Morales et al. 2013) or radio-tracking dispersers or seeds (Holbrook \& Smith 2000; Levey \& Sargent 2000; Pons \& Pausas 2007) can determine whether seed dispersers deposit seeds in clusters or clumps. If so, molecular markers can be used to determine the number of maternal source plants, and potentially, also their location (Heymann et al. 2012; Agrawal et al. 2013).

Our analyses were based on studies that examine SGS in adult plants, however, the scale and strength of SGS may change over life stages (e.g. Bialozyt et al. 2014). Future studies relating seed dispersal to SGS in zoochorously dispersed plants should consistently include earlier life stages (seedlings, saplings). Although seedlings are not fully representative of seed dispersal shadows, as surviving seedlings passed the bottlenecks of seed and seedling mortality due to predators and pathogens, they are still more likely to reflect the initial spatial template created by seed dispersal. Furthermore, our analysis showed that besides seed dispersal behavior, pollination mechanism and marker type used can have a significant effect on SGS. Therefore, future studies on the effect of animal seed dispersal on SGS should consider the impact of pollination on SGS and take caution when comparing studies that used different marker types. 
Overall, our results show SGS is strongly dependent on plant-animal interaction. Consequently, a more integrative approach between plant and animal ecology is needed to fully comprehend its formation and strength in zoochorous plants.

Although not widely acknowledged, the analyses of SGS can also have practical implications for conservation (Escudero et al. 2003). The spatial extent of SGS can be used to identify the scale over which seeds should be collected and planted to optimize genetic diversity of recruits in managed forest regeneration (Jin et al. 2003; Cruse-Sanders \& Hamrick 2004; Yao et al. 2011; Melo Júnior et al. 2015; Ramos et al. 2016a). Understanding the impact of zoochorous seed dispersal on SGS may help to integrate frugivore behavior in forest conservation and management strategies. 


\section{$\underline{\text { CHAPTER II }}$}

SEED DISPERSAL DISTANCE: COMPARING ESTIMATES USING ANIMAL MOVEMENT DATA, PLANT GENETIC MATERIAL AND MODELING.

CASE STUDY OF TAMARINS AND LEONIA CYMOSA (VIOLACEAE) 


\section{Abstract}

Seed dispersal distances (SDD) critically influence the survival of seedlings, spatial patterns of genetic diversity within plant populations and gene flow among plant populations. In zoochorously dispersed plant species, distances are determined by an interaction between seed size, shape and number, fruit attractiveness, retention times, movement ability and animal behavior. Observations of feeding and deposition moments are a direct method to estimate seed dispersal event. However these are commonly constrained by the high mobility and low visibility of the vectors or low fruit availability, as in our case. Diverse alternative methods are used to estimate SDD, but a comparison of these approaches within the same seed dispersal system is mostly missing. In this chapter, I compare SDD estimates obtained from direct observations, genetic identification of mother plants from seed coats, parentage analysis of seedlings, and modelling approaches, including the combination of movement data and gut passage times and an individual-based model. Furthermore, I examine in detail how gut passage time and seasonality affects the model combining movement data and gut passage time in our tamarin species. The highest mean seed dispersal distance obtained was $318 \pm 137 \mathrm{~m}$ through the combination of movement data and gut passage estimates. The lowest mean distance was $178 \mathrm{~m}$ $\pm 201 \mathrm{~m}$ through parentage analysis of seedlings. Parentage analysis can include undispersed seedlings discarded or fallen beneath fruiting trees and will include germination success. Therefore this method can underestimate seed dispersal distance if germination under densitydependent processes is high. Given that each method includes different processes within the seed dispersal loop, a combination of methods may be used to understand the whole ecosystem service in detail. 


\section{Introduction}

Seed dispersal distances determine the degree of seed shadow overlap between fruiting trees. Seed shadows are the areas where seeds belonging to the same fruiting tree are deposited (Jordano 2007). High seed shadow overlap increases future mating probability between unrelated offspring, reducing spatial genetic structure and maintaining high genetic diversity. Seed dispersal distance can also influence seed survival by reducing predation risk and increasing germination success (Janzen 1970; Connell 1971; Valenta \& Fedigan 2010). Short seed dispersal distances are related to stronger spatial genetic structures (WANG et al. 2011; Theim et al. 2014; Beghè et al. 2016). Long distance seed dispersal can promote inter-population seed exchange (Cain et al. 2000; He et al. 2010) and colonization of more suitable areas in case of anthropogenic disturbances such as climate change (Ruxton \& Schaefer 2012)

How far seeds are deposited from sources varies according to dispersal mechanism and dispersal vectors. In abiotically dispersed species, distances are determined by seed aerodynamics and wind strength and direction (Thomson et al. 2011). In zoochorously dispersed species, distances are determined by an interaction between seed size, shape and number, fruit attractiveness, retention times (e.g., gut passage), movement ability and animal behavior (Ruxton \& Schaefer 2012). In detail, seed dispersal distance by zoochorous vectors can be determined by extrinsic factors to the vectors, such as resource availability, fruit nutrient content, seed size, and landscape configuration, and by intrinsic factors, such as home range extent, migration patterns, social, mating and foraging behaviors, body size and group size (Miyaki \& Kikuzawa 1988; Ness et al. 2004; Abe et al. 2006; Moore et al. 2007; Carlo \& Morales 2008; Karubian \& Durães 2009; Uriarte et al. 2011; Karubian et al. 2012; Wang et al. 2014; Viana et al. 2015; Takahashi \& Itino 2015; Pesendorfer et al. 2016). For example, in bat-dispersed plants, seed dispersal distance is influenced by gut passage, seed size, urbanization, and seasonality in bats (Shilton et al. 1999; Abedi-Lartey et al. 2016). In primate-dispersed plants, dispersal distances can be determined by body size, fruit handling behavior, oral and digestive anatomy, social organization, species-specific diets,(Lledo-Ferrer et al. 2011) sex and age of disperser, and the interaction between movement patterns and gut passage times (Garber \& Lambert 1998; Chapman \& Russo 2002; Wehncke et al. 2003; Razafindratsima et al. 2014). 
Seed dispersal distances can be calculated through several methods, for example, the tracking of vectors (Knogge 1999; Stevenson 2000; Valenta \& Fedigan 2010) or marked seeds (Chauvet et al. 2004; Pons \& Pausas 2007; Hirsch et al. 2012; Jansen et al. 2012; Sork 2016). Polymorphic genomic markers can be used to identify seed source by genotyping maternal tissue surrounding seeds (seed coat) or through parentage analysis of seedlings (Dow \& Ashley 1996; Grivet et al. 2005; Bittencourt \& Sebbenn 2007; Smouse et al. 2012; Heymann et al. 2012). Knowledge on the seed dispersers can be used to do individual-based spatially-explicit modelling (Nathan et al. 2001; Schurr et al. 2005; Williams et al. 2006; Levey et al. 2008; Uriarte et al. 2011; Bialozyt et al. 2014a).

Some methods can have species-specific limitations. For example, identifying seed source during field observations can give limited results if seed dispersers feed on more plant individuals from the same species before defecating (e.g., traplining), not necessarily the first seed is the first the animal swallowed. If plant species is monoecious, i.e., female and male flowers are on the same plant, parentage analysis gives parents with unknown sex. Hence it does not directly give seed dispersal distance. The latter is usually overcome by considering the closest parent as the seed source (Burczyk et al. 2006; Hadfield et al. 2006; González-Martínez et al. 2006), but this has been previously considered as misleading (Smouse et al. 2012).

The aim of this chapter is to compare methods for estimating seed dispersal distances, in a seed dispersal system comprised of one plant species, Leonia cymosa, and two vector species, tamarins Leontocebus nigrifrons and Saguinus mystax. I compare SDD estimates based on five methods: (1) observed seed dispersal events (OSD), (2) seed dispersal estimates from maternal identification through genotyping of seed coats (GSC), (3) parentage analysis of seedlings (PAS), (4) modelling of SDD through a combination of movement data with gut passage times (CMG), and (5) simulation of seed dispersal by individual-based modelling (IBM).

\section{Methods}

\section{Study system}

The Estación Biológica Quebrada Blanco ( $4^{\circ} 21^{\prime} \mathrm{S}, 73^{\circ} 09^{\prime} \mathrm{W}$, Loreto, Peru) within the Neotropical rainforest contains Tierra firme habitat, where Leonia cymosa grows. Previous research through focal tree observation using camera traps (Reinehr, 2010) showed a seed 
dispersal system for L. cymosa with reduced complexity. Leonia cymosa is an Amazonian understory tree which at our study site is dispersed only by mixed-species groups of tamarins, Leontocebus nigrifrons, and Saguinus mystax. These two species live in mixed-species troops, in which they move through the joint home range in a highly coordinated way (Heymann \& Buchanan-Smith 2000). These primates are mainly frugivorous, but also eat gum and insects (Peres 1993), and their movements patterns are determined by fruit availability (Culot 2009). Leonia cymosa produces pulpy fruits, consisting of 2-7 seeds, that will ripe asynchronously over a period of three or more months during the rainy season. This seed dispersal system is a good example where an estimate of seed dispersal distance through field observations of seed dispersal events is limited. Leonia cymosa has a cluster distribution. Therefore tamarins will usually feed on several trees of $L$ cymosa in a row before defecating, making maternal identification through observation difficult. Furthermore, L. cymosa has a monoecious sexual system, where female and male flowers are on the same plant, making seed source and pollen source of seedlings unknown. Consequently, parentage analysis gives parent pairs with undetermined sex, making seed dispersal distance estimates difficult. However, because pericarp (i.e., maternal tissue) remains attached to seeds after gut passage, maternal identification directly from seeds is possible.

\section{Observed seed dispersal events (OSD)}

Direct observations of seed dispersal events of Leonia cymosa where taken from historical data collected by Culot (2009) and Knogge (1998). These observations were made during daily animal behavior sampling of tamarins concerning feeding behavior, movement pattern and seed dispersal efficiency. Focal observations started when tamarins left the sleeping site in the morning and ended when they went to sleep in the afternoon. Time and place of feeding observations were recorded using GPS Garmin GPSMapH 76CSx, except for data collected by Knogge in 1993, where GPS was not available yet, and positions were determined through reference to the trail system and mapped trees.

\section{Maternal identification through genotyping of seed coats (GSC)}

During regular behavior observation of tamarins by the field assistants in 2016, Leonia cymosa was finally observed to fruit. Therefore, whenever feeding events on L. cymosa happened, 
subsequent scats were collected, and seeds of L. cymosa found were stored on a saline solution. Seeds were rehydrated at room temperature to separate outer layer of seeds. Seed coats were then dried on filter paper, grinded and total genomic DNA was extracted following ATMAB protocol (Dumolin et al. 1995). I genotyped seed coat DNA using eleven nuclear microsatellites (Error! Reference source not found.) following the protocol described in Chapter V. Seed coat DNA, is maternal DNA. Therefore seed coat genotypes were matched to our adult genotype database (obtained from the genetic analysis described in the next paragraph) using GenAlex (Peakall \& Smouse 2006). To estimate seed dispersal distance, I calculated distances between seed deposition location and recognized source tree using qGIS.

\section{Parentage analysis of seedlings (PAS)}

Exhaustive sampling of seedlings $(<100 \mathrm{~cm})$, juveniles $(100-250 \mathrm{~cm})$ and adults $(>250 \mathrm{~cm})$ within $50 \mathrm{~m} \times 50 \mathrm{~m}$ plots on a checkerboard arrangement was done within home ranges of two mixed-species groups of tamarins. We used crossings of walking pathways available on the study site as a reference for the checkerboard arrangement of quadrats. Additionally, to increase the probability of finding parents, we sampled adults exhaustively using the following sampling schemes based to the locations adult plant density: Within home range area of tamarin Group 1, adult plant density was high. Therefore we connected the previously described quadrats by sampling $15 \mathrm{~m}$-wide transects. Within home range area of tamarin Group 2, adult plant density was lower. Hence we increased the number $50 \mathrm{~m} \times 50 \mathrm{~m}$ quadrats on the alternate crossing of pathways. In-between home range areas, adult plant density was very low. Therefore we randomly chose pathways crossing to sample $50 \mathrm{~m} \times 50 \mathrm{~m}$ quadrats. In 2016, for an additional project on gene flow, not included in this thesis, we increased the area of exhaustive sampling: we sampled intensively a $200 \mathrm{~m} \times 200 \mathrm{~m}$ quadrat for adults with embedded in this, a $100 \mathrm{~m} \times$ $100 \mathrm{~m}$ quadrat for juveniles for seedlings. To increase the probability of finding parent pairs, individuals sampled for this alternate project were also used in the parentage analysis. Figure 13 shows the several sampling schemes. In total, we sampled 475 seedlings and juveniles (candidate

offspring) and 175 adults (candidate parents). Each individual's location was geographically recorded using GPS Garmin GPSMapH 76CSx, and leaves were sampled and stored in silica gel beads or Whatman ${ }^{\mathrm{TM}}$ FTA $^{\mathrm{TM}}$ PlantSaver cards. 


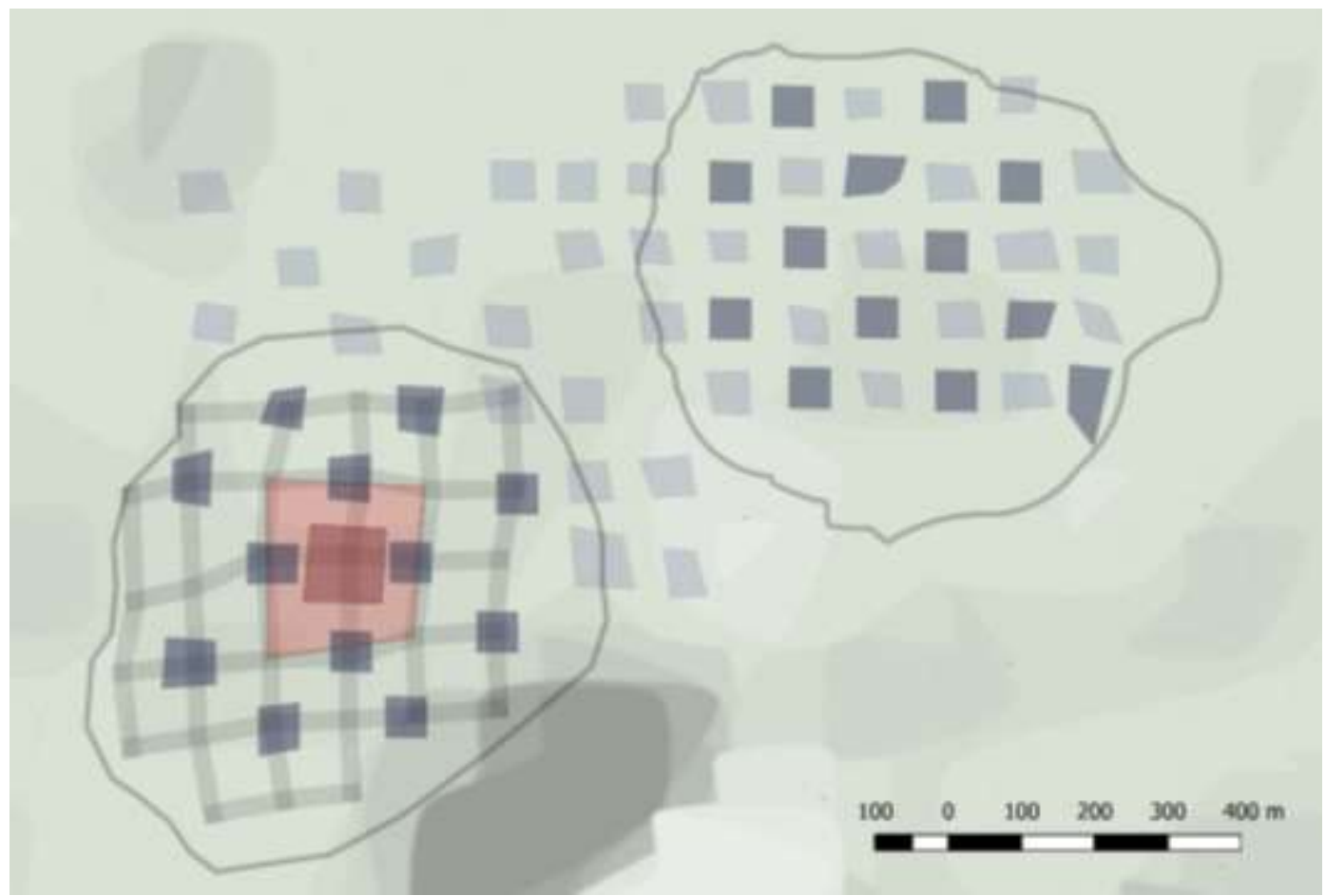

Figure 13 Sampled areas shown on the map created using qGIS. Maps shows $50 \mathrm{mx} 50 \mathrm{~m}$ quadrats sampled exhaustively for candidate offspring and parents (dark grey), $50 \mathrm{~m} \times 50 \mathrm{~m}$ quadrats sampled exhaustively for candidate parents (light grey), $15 \mathrm{~m}$ wide transects sampled exhaustively for candidate parents (grey transects), $100 \mathrm{~m} \times 100 \mathrm{~m}$ quadrat sampled exhaustively for candidate offspring (dark red) and $200 \mathrm{~m} \times 200 \mathrm{~m}$ quadrat sampled exhaustively for candidate parents (light red). Tamarin home range delimitation is given for Group 1 (left) and Group 2 (right).

Total genomic DNA was extracted from leaf samples following ATMAB protocol (Dumolin et al. 1995). We genotyped ten nuclear microsatellites (Error! Reference source not found.) following the protocol described in Chapter V. To identify parent pairs for each candidate offspring, we input candidate offspring and candidate parent genotypes in Cervus v3.0. First, we calculated allele frequencies using the default parameters. Second, we ran the simulation for parent pairs with unknown sexes with parameters set at 0.15 proportion sampled, 0.05 proportion loci mistyped and to consider only samples with 6 minimum typed loci. We calculated confidence level using LOD scores, and these were set to relaxed at $80 \%$ and strict at $95 \%$. Third, we used the allele frequencies and the simulation output files to run the parentage analysis for parents with unknown sex. We only considered results of parent pairs with TRIO LOD significance higher than $95 \%$.

Euclidean distances between parents and offspring $\left(D_{P, O}\right)$ were calculated using coordinates in UTM of parents $\left(X_{P}, Y_{P}\right)$ and of offspring $\left.X_{O}, Y_{O}\right): D_{P, O}=$ $\sqrt{\left(X_{P}-X_{O}\right)^{2}+\left(Y_{P}-Y_{O}\right)^{2}}$. To avoid bias of considering closest parent as mother when sexes 
are an unknown (see above), like in monoecious species such L. cymosa, we assumed any parent could be either a mother or a father. Following this assumption, we used all possible motherseedling combinations to calculate the mean seed dispersal distance. In parallel, we calculated the same seed dispersal kernel density curve through bootstrapping 10000 random re-samples of mother-seedling distances from the parent pairs and got equivalent mean seed dispersal distance. Both methods proved good options for calculating mean seed dispersal distance from parent pairs with unknown sexes. Bootstrapping could prove more appropriate for larger datasets. Our dataset was not large; therefore, we show results for the first method only. A comparison of both results is shown on the supplementary material. To estimate the kernel density curve, I used all possible parent-seedling combinations to calculate kernel density curves. As observations of seed dispersal events showed that seed dispersal distances by tamarins do not exceed $709 \mathrm{~m}$ ( $\mathrm{N}=1884$; Knogge, 1998) which corresponds to the diameter of a tamarin home range, we excluded seedling-parent pairs at distances $>709 \mathrm{~m}$ from this analysis assuming that this is rather a pollen than a seed source.

\section{Combination of movement data with gut passage times (CMG)}

For determination of tamarin movement patterns, sampling was planned in order to collect feeding locations and following tamarin movement during L. cymosa's fruiting period. However it did not fruit during the duration of this project 2014-2015. Research shows seed dispersal patterns, of the tamarin groups at our study site, stay constant throughout the years (Heymann et al. 2017). Therefore I used the movement data set collected by Darja Slana the year before our plant sampling. For this data set, tamarin's geographic location was recorded every 30 minutes from the time they wake up until the time they went to sleep. Movement data were recorded for a total of 62 days, a mean 7.7 \pm 2.8 days per month from December 2012 to July 2013. Geographic location was recorded with GPS Garmin GPSMapH 76CSx. GPS positions were input into qGIS (Quantum GIS Development Team, 2016) to visualize their movement.

I developed a function in $\mathrm{R}$ (see supplementary data) to calculate the linear travel distance of tamarins between each same-day scan points separated by 0:30hr, 1:00hr, 1:30hr and so on, to a maximum of $9 \mathrm{hrs}$. The time between scan points was then related to distance travelled in the form of a histogram and its regression using the method "loess" from the function "geom_smooth" in ggplot2 package of R (Wickham, 2009; Rstudio Team, 2015). I first did the 
analyses separately for the seasons described by Garber (1993), given changes in the seasonal movement described by Culot (2010). I tested for seasonality difference throughout the time periods using two-way ANOVA. Then, according to whether we found seasonality difference we used the season where L. cymosa generally has its fruiting period at our study site. I then proceeded to restrict the time periods considered for the analysis to the time periods that correspond to the estimated gut passage time of L. cymosa. For this estimate, I used the few observations recorded in previous studies by Culot (2009) and Knogge (1998), from which I only used observations where tamarins had not fed on any other L. cymosa tree between feeding and deposition. Estimate of mean gut passage time range using the few observations available was $177 \pm 59 \mathrm{~min}(\mathrm{~N}=3)$, so I considered a gut passage time range of $2-4 \mathrm{hrs}$ (Table 7$)$. This estimate was then used to create a subset of data points considering only linear distance travelled in 2:00, $2: 30,3: 00,3: 30,4: 00 \mathrm{hrs}$. This subset of distance data points was then used to plot a kernel density estimate. Additionally, to understand what the effect of gut passage estimates has on the overall result, I calculated kernel density estimated considering different gut passage times. The kernel density estimate gives the probability of a seed deposition event at a given distance. For this, I plotted the density distance kernel using the bkde() function from the "KernSmooth" package (Wand and Ripley, 2015) following suggestions by Deng and Wickham (2011). For each method, I decided the bandwidth for the density curve based on the function density().

\section{Individual-based modelling of seed dispersal events (IBM)}

A previous model on Parkia panurensis (Bialozyt, 2014) was adjusted by Ronal Bialozyt himself for the seed dispersal scenario of L. cymosa. Four critical aspects were adjusted. First, since L. cymosa is never the only fruit source available in this area, we needed to add other species as fruit source to allow for enough energy input during the daily routine of the tamarins. We used the other species of feeding trees observed during L. cymosa's fruiting season in 2013 as additional fruit sources. Furthermore, not all L. cymosa trees fruit yearly; therefore, we used the subset of L. cymosa trees $(N=8)$ observed that same year. Second, L. cymosa contains 415$642 \mathrm{mg}$ of soluble sugars per g dry matter, whereas P. panurensis contains $811 \mathrm{mg} / \mathrm{g}$ (Pfrommer, 2009); therefore, we adjusted the mean energy level provided by the trees in the simulation model. Third, different time intervals in feeding trees for a single feeding event were implemented for $\mathrm{P}$. panurensis and L. cymosa to reflect the respective fruit crop sizes and the 
resulting shorter feeding times in L. cymosa. Fourth, we adjusted gut passage time for L. cymosa according to field observations of seed dispersal events reported by Knogge (1999) and Culot (2009). All other parameters were kept at values of the P. panurensis simulation (Bialozyt et al. 2014a).

Simulations of daily movements were carried out for 200 days to get enough L. cymosa seed dispersal events. we then determined the Euclidian distance between dispersed seeds and their mother trees.

\section{Statistical analysis of seed dispersal distance}

To evaluate differences between methods I used the non-parametric Kruskal-Wallis test through the kruskal.test() function from the stats package in R (R Core Team, 2018). I did further posthoc comparisons with the non-parametric multiple comparison test and Bonferroni corrections, using the pairwise.wilcox.test() function, from the stats package in $\mathrm{R}$ (R Core Team, 2018).

To estimate seed dispersal curves, I determined the empirical frequency distribution (i.e., density distance kernels) of dispersal distances for each method by adjusting a non-parametric function (smooth spline curve) and its confidence envelope estimated by bootstrapping ( $n=100$ resamplings) using the mykernel() function (Jordano 2016). Bandwidth size was calculated with the function density() from the "stats" package (R Core Team, 2018).

Finally, to compare seed dispersal curves between methods I estimated the probability distribution of all methods using the stat_ecdf() function from the "ggplot2" package in R (Wickham, 2016). Subsequently, I tested differences between the empirical cumulative distribution functions of each method with the two-sample Kolmogorov-Smirnov test, which is sensitive to differences in both location and shape of the cumulative distribution function. For the Kolmogorov-Smirnov test, I used the ks.test() function from the package "stats" in R (R Core Team, 2018). 


\section{Results}

\section{Observed seed dispersal events (OSD)}

Observations of seed dispersal events gave a mean seed dispersal distance of $234 \mathrm{~m} \pm$ $111 \mathrm{~m}(\mathrm{~N}=4)$ (Table 7).

Table 7 Records of seed dispersal events from previous research on the study site. year of observations, seed dispersal distance (SDD), and gut passage time are given.

\begin{tabular}{lll}
\hline year & SDD (M) & $\begin{array}{l}\text { Gut passage time } \\
\text { (MIN) }\end{array}$ \\
\hline $\mathbf{2 0 0 7}$ & 335 & 167 \\
$\mathbf{2 0 0 7}$ & 215 & 124 \\
$\mathbf{1 9 9 3}$ & 300 & N/A \\
$\mathbf{1 9 9 3}$ & 86 & 240
\end{tabular}

\section{Maternal identification through genotyping of seed coats (GSC)}

After two years of no fruiting of Leonia cymosa, fruit crop in 2016 was small. Therefore only nine seeds were collected. The mean estimated seed dispersal distance considering all seeds was $300 \mathrm{~m} \pm 74 \mathrm{~m}$ (Table 8 , Figure 18), and the kernel density curve shows $50 \%$ of all seed dispersal events within $339 \mathrm{~m}$.

Table 8 Maternal recognition based on direct genotype match of pericarps to adult genotype. Seed and match labels, Geographic location of seed $\left(X_{S}, Y_{S}\right)$ and mother $\left(X_{M}, Y_{M}\right)$, and the distance between these is given as seed dispersal distance (SDD)

\begin{tabular}{|c|c|c|c|c|c|c|}
\hline SEED & $\begin{array}{l}\text { IDENTIFIED } \\
\text { MATCH }\end{array}$ & & & & & $\begin{array}{l}\text { SDD } \\
\text { (m) }\end{array}$ \\
\hline LS16I-001 & LA14I-112 & 704087 & 9517256 & 704355 & 9517494 & 357 \\
\hline LS16I-002 & LA14I-112 & 704086 & 9517257 & 704355 & 9517494 & 358 \\
\hline LS16I-003 & LA14I-112 & 704099 & 9517250 & 704355 & 9517494 & 352 \\
\hline LS16I-004 & LA14I-112 & 704148 & 9517225 & 704355 & 9517494 & 339 \\
\hline LS16I-005 & LA14I-112 & 704155 & 9517223 & 704355 & 9517494 & 336 \\
\hline LS16I-006 & LA14I-112 & 704362 & 9517327 & 704355 & 9517494 & 166 \\
\hline LS16I-007 & LA16I-028 & 704025 & 9517452 & 704250 & 9517434 & 225 \\
\hline LS16I-009 & LA14I-090 & 703965 & 9517617 & 703920 & 9517400 & 222 \\
\hline
\end{tabular}




\section{Parentage analysis of seedlings (PAS)}

I found parent pairs with significant TRIO LOD scores for 17 offspring (Table 9). The kernel density estimate, based on the parentage analysis, calculated using an all-possible-combinations approach, had a mean seed dispersal distance of $218 \mathrm{~m} \pm 60 \mathrm{~m}$ (Figure 14), 95\% of the events were probabilistically calculated to be between $163 \mathrm{~m}$ and $273 \mathrm{~m}$. If we use the parents with the shortest distance as maternal sources, then the mean seed dispersal distance is $178 \mathrm{~m} \pm 201 \mathrm{~m}$, and the kernel density curve shows $50 \%$ of all seed dispersal events within $118 \mathrm{~m}$.

Table 9 Parentage recognition using microsatellite markers. Offspring and parents (Parent A, Parent B) labels, and between offspring and each of the parents (Distance A, Distance B) are given.

\begin{tabular}{|c|c|c|c|c|c|c|}
\hline $\begin{array}{r}\text { Offspring } \\
I D\end{array}$ & $\begin{array}{l}\text { Parent1 } \\
\text { (P1) ID }\end{array}$ & $\begin{array}{l}\text { Parent } 2 \\
(P 2) I D\end{array}$ & $\begin{array}{l}\text { Distance. } \\
O-P 1\end{array}$ & $\begin{array}{l}\text { Distance. } \\
O-P 2\end{array}$ & $\begin{array}{l}\text { Distance } \\
P 1-P 2\end{array}$ & $\begin{array}{l}\text { Nearest } \\
\text { Parent }\end{array}$ \\
\hline LP16I-016 & LA14II-019 & LA15II-034 & 887 & 361 & 620 & 361 \\
\hline LP16I-045 & LA14I-064 & LA16I-016 & 292 & 13 & 290 & 13 \\
\hline LP16I-135 & LA14I-113 & LA16I-041 & 175 & 19 & 193 & 19 \\
\hline LP14III-017 & LA14I-090 & LA14III-001 & 739 & 615 & 1338 & 615 \\
\hline LP14III-002 & LA14I-091 & LA14III-001 & 717 & 615 & 1329 & 615 \\
\hline LP14II-024 & LA14II-007 & LA15II-024 & 52 & 20 & 35 & 20 \\
\hline LP14I-061 & LA14I-112 & LA14I-113 & 208 & 209 & 8 & 208 \\
\hline LP14I-062 & LA14I-112 & LA14I-113 & 208 & 209 & 8 & 208 \\
\hline LP16I-025 & LA14I-102 & LA16I-053 & 116 & 131 & 48 & 116 \\
\hline LP14I-082 & LA14I-076 & LA14I-097 & 325 & 341 & 231 & 325 \\
\hline LP14I-100 & LA14I-051 & LA14I-062 & 133 & 166 & 33 & 133 \\
\hline LP14I-071 & LA14I-093 & LA16I-049 & 244 & 322 & 240 & 244 \\
\hline LP14I-070 & LA14I-087 & LA14I-091 & 118 & 210 & 99 & 118 \\
\hline LP14III-004 & LA14III-001 & LA15II-009 & 4 & 296 & 292 & 4 \\
\hline LP14III-008 & LA14III-001 & LA16I-027 & 7 & 442 & 436 & 7 \\
\hline LP14II-066 & LA14II-032 & LA14III-006 & 9 & 466 & 470 & 9 \\
\hline LP14III-013 & LA14III-001 & LA15II-020 & 16 & 731 & 730 & 16 \\
\hline
\end{tabular}

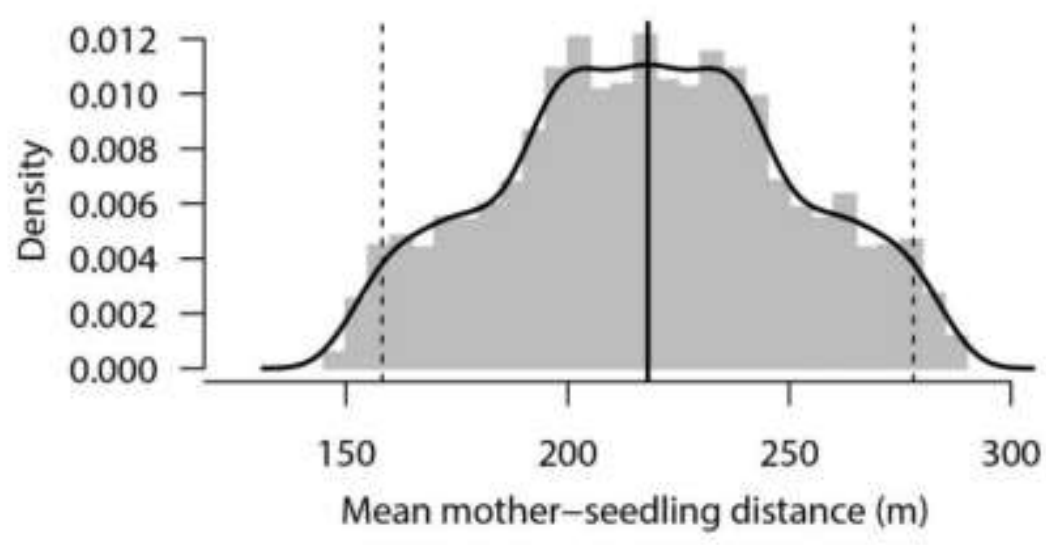

Figure 14. SDD Kernel density estimate of seed dispersal distances according to parentage analysis and all possible maternal combinations. Mean seed dispersal density (---) and 95\% confidence intervals (- - -) are shown 


\section{Combination of movement data with gut passage times (CMG)}

Seasons showed a significant difference in the linear movements obtained from the movement data (Factorial ANOVA, $F(3,6386)=62.44, P<0.001$, Error! Reference source not found.). The main rainy season ( $\mathrm{N}=32$ ), between February and May (L. cymosa's fruiting season) and the late rainy $(\mathrm{N}=12)$, June, had longer linear distances throughout the time periods than the dry season $(\mathrm{N}=10)$, July, and early rainy season $(\mathrm{N}=8)$, December and January (Figure 15 , Table 10). Therefore, to estimate seed dispersal, we only considered linear movement from the season in which L. cymosa has mature fruits, the main rainy season (Figure 16)

Table 10 Adjusted p-values for differences between seasons using Tukey's honestly significant difference (HSD) post hoc test.

\begin{tabular}{ll}
\hline Seasons compared & $\begin{array}{l}\text { Adjusted } \\
\text { P-value }\end{array}$ \\
\hline Early rainy season-Dry season & 0.103 \\
Late rainy season-Dry season & $<0.001$ \\
Main rainy season-Dry season & $<0.001$ \\
Late rainy season-Early rainy season & $<0.001$ \\
Main rainy season-Early rainy season & $<0.001$ \\
Main rainy season-Late rainy season & 0.003
\end{tabular}

Linear movement of tamarins, comparison between seasons

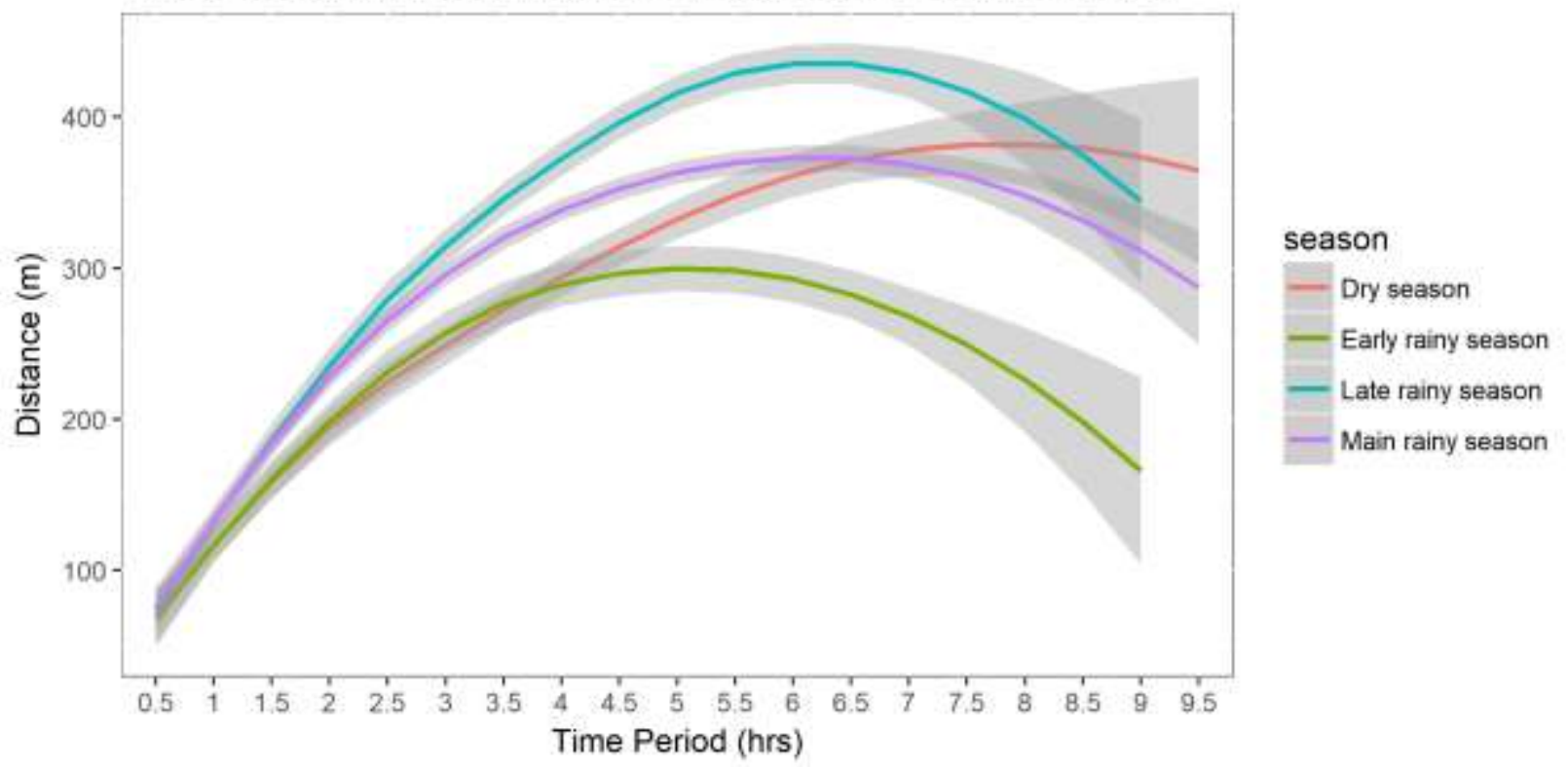

Figure 15 Linear travel distance $(\mathrm{m})$ of tamarins across the time periods of movement 


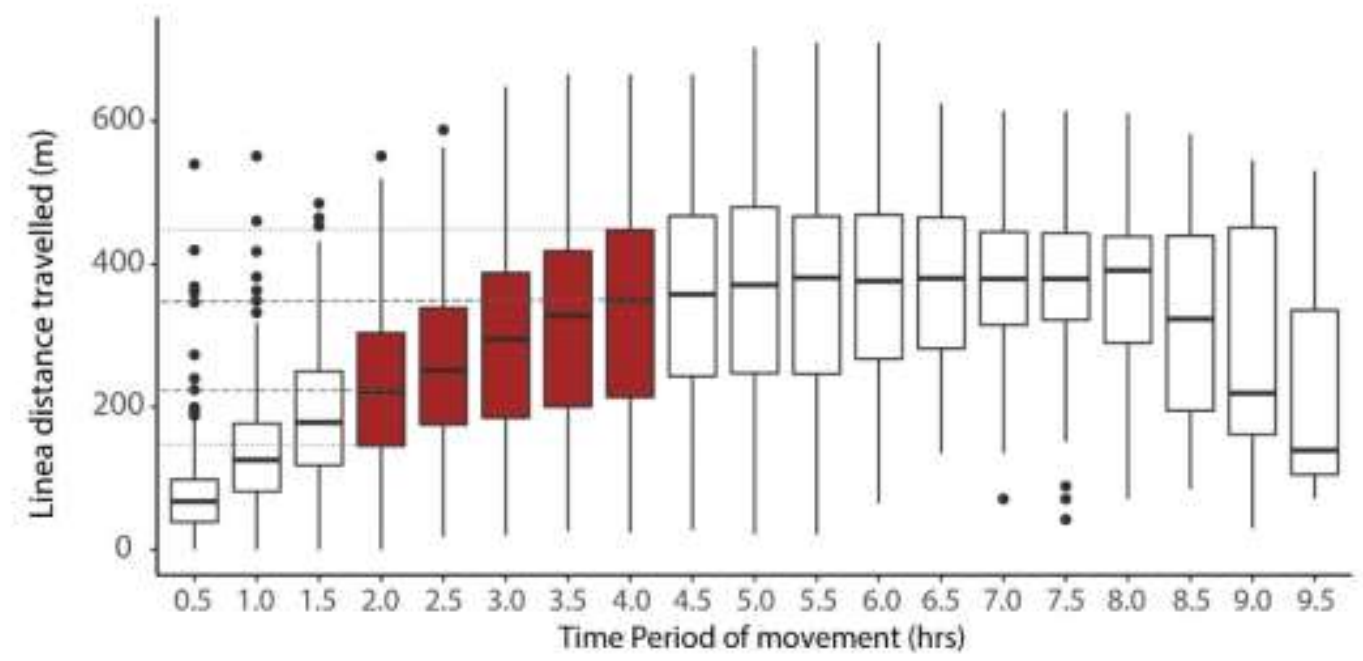

Figure 16 Movement rate of tamarins during the main rainy season, dissected over increasing time periods. Time periods corresponding to gut passage time are shaded in red.

Mean seed dispersal distance obtained from linear movement rate within gut passage time range was $318 m \pm 137 m, 50 \%$ of the seed dispersal events were probabilistically calculated to be deposited within 315m from source tree (Table 11) Kernel density estimate had a bell shaped curve (Figure 20, CMG). Furthermore, further analysis showed shorter gut passage times lead not only a shorter mean seed dispersal distance, but also to a taller and narrower probability distribution curve of seed dispersal events (Figure 17).

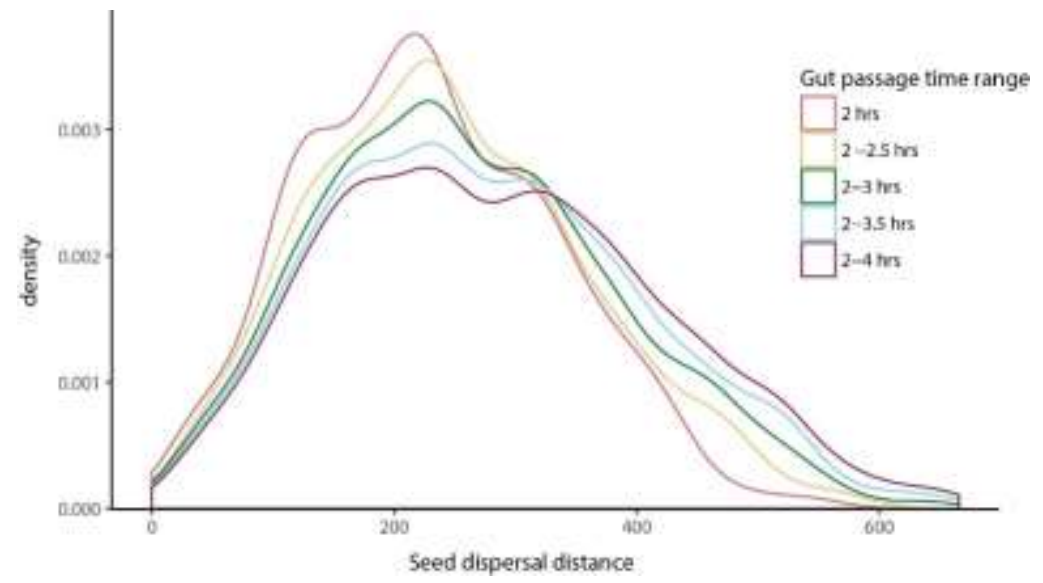

Figure 17 Changes in kernel density estimate of seed dispersal distances with changes of gut passage time range considered 


\section{Individual-based modelling of seed dispersal events (IBM)}

Through the individual-based modelling developed by Ronald Bialozyt, we obtained a series of deposition events (Figure 18), with a range of seed dispersal distances between 0m and $700 \mathrm{~m}$, from which $50 \%$ of the seed dispersal events were within $276 \mathrm{~m}$ (Table 11).

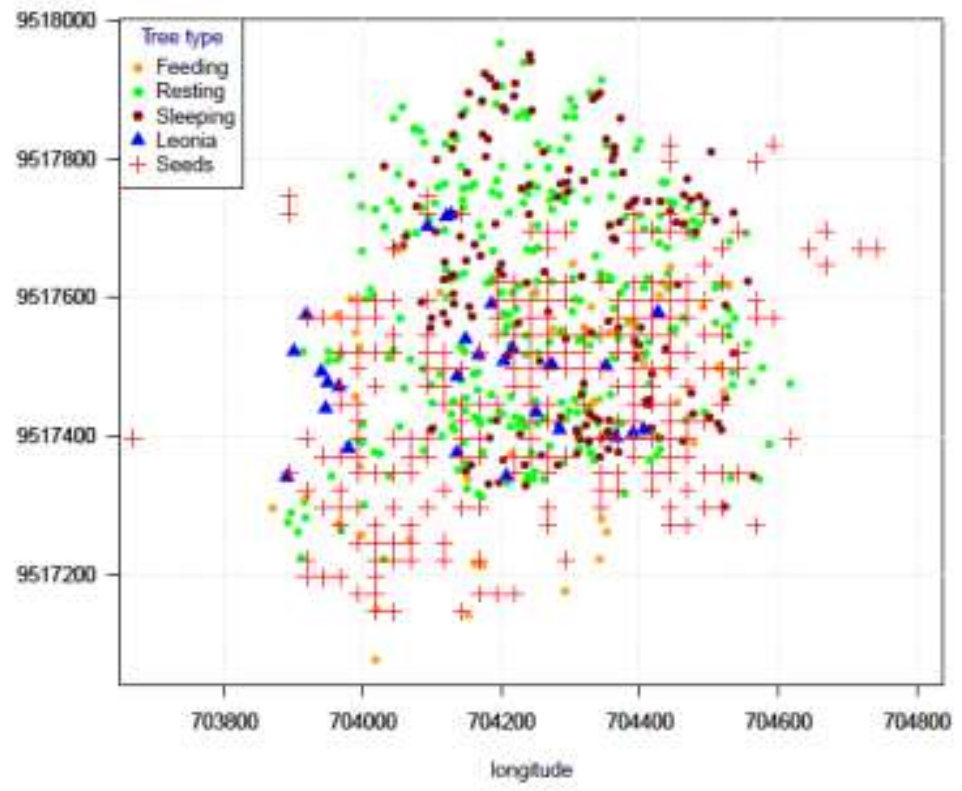

Figure 18 Location of the $\mathbf{4 8 4}$ dispersed seeds obtained through individual-based modeling.

\section{Comparison of seed dispersal estimates}

Depending on the method used, mean SDD estimates range between 178 and $318 \mathrm{~m}$ (Error! Reference source not found.) for L. cymosa. Overall, methods varied significantly in the resulting SDD estimates (L. cymosa: $H(4)=17.3, p=0.002$, Figure 19). Specifically, Wilcoxon pairwise comparisons revealed SDD estimates from PAS were significantly lower than those from GSC, CMG, and IBM in L. cymosa (Figure 19). Moreover, the shape of the SDD distributions was highly variable on results from methods executed with small sample number. However, the PAS curve was significantly more left-skewed than GSC, CMG, and IBM (Kolmogorov-Smirnov test, $p=0.03, p<0.001$, and $p<0.001$, respectively) (Figure 20)

\begin{tabular}{l|rr|r|rr|rrr|r}
\hline & Mean & SD & SE & Mode 1 Mode 2 & $5 \%$ & $50 \%$ & $95 \%$ & N \\
\hline \hline OSD & $234 \pm$ & 111 & 48 & 295 & - & 0 & 258 & 584 & 4 \\
MS & $300 \pm$ & 74 & 24 & 215 & 346 & 97 & 339 & 486 & 9 \\
PA & $178 \pm$ & 201 & 46 & 49 & 612 & 0 & 118 & 639 & 17 \\
DTP & $318 \pm$ & 137 & 5 & 240 & 347 & 105 & 315 & 552 & 791 \\
MO & $262 \pm$ & 139 & 7 & 149 & 305 & 51 & 276 & 494 & 449
\end{tabular}

Table 11 Comparison of Seed dispersal (SD) estimates between methods. Mean deed dispersal density standard deviations (SD) and standard error of bootstrap (SE), Modes, SDD of $5 \%, 50 \%$, $\mathbf{9 5 \%}$ of seed dispersal events, sample number $(\mathrm{N})$ 


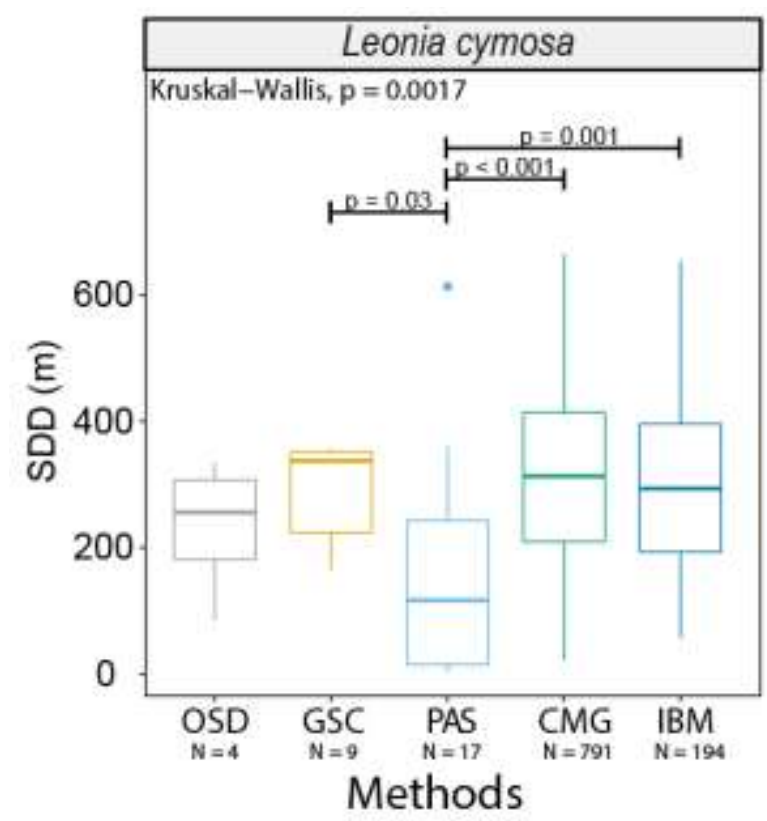

Figure 19 SDD estimates for Leonia cymosa based on the five methods: observed seed dispersal events (OSD), genotyped seed coats (GSC), parental analysis of seedlings (PAS), combination of movement data and gut passage (CMG), and individualbased modelling (IBM). Horizontal lines represent medians, boxes the 25$75 \%$ quartiles, dots are outliers. Bars above the boxplots indicate differences among methods based on a Kruskal Wallis test and multiple pairwise comparisons with Wilcoxon rank sum test.
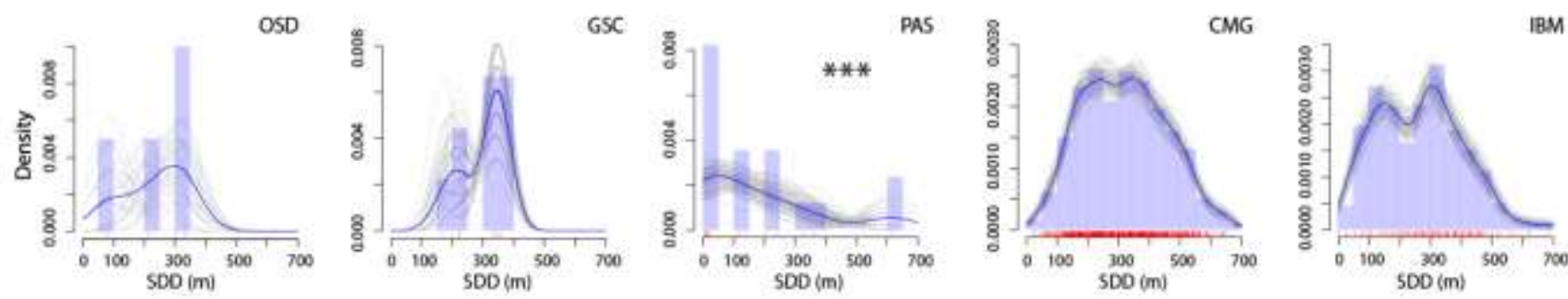

Figure 20 Kernel density estimates of seed dispersal distances for the five methods used for Leonia cymosa. The figures show for each method, the density of dispersal events within the distance class (blue bars), a nonparametric smoothing spline fit to the empirical distance distributions (blue lines) together with bootstrapped estimates (grey lines). Red vertical bars along the $x$-axis represent each observed dispersal event.

\section{Discussion}

The main difference between methods were seed dispersal distances obtained through parentage analysis. This difference is likely for two reasons 1) Parentage analysis also includes undispersed seedlings fallen beneath fruiting trees, or 2) it includes seeds discarded during feeding events, and the lower outcome in SDD in comparison to methods that do not include such individuals suggests there is no near source density-dependent mortality. The PAS method gives a great example of how different methodologies can measure different processes of the seed dispersal system described originally by Wang \& Smith (2002) (Figure 21), such as including post-dispersal or pre-dispersal processes, that might create differences between the outcomes 
on SDD obtained and how a combination of methodologies can explain further the seed dispersal system.

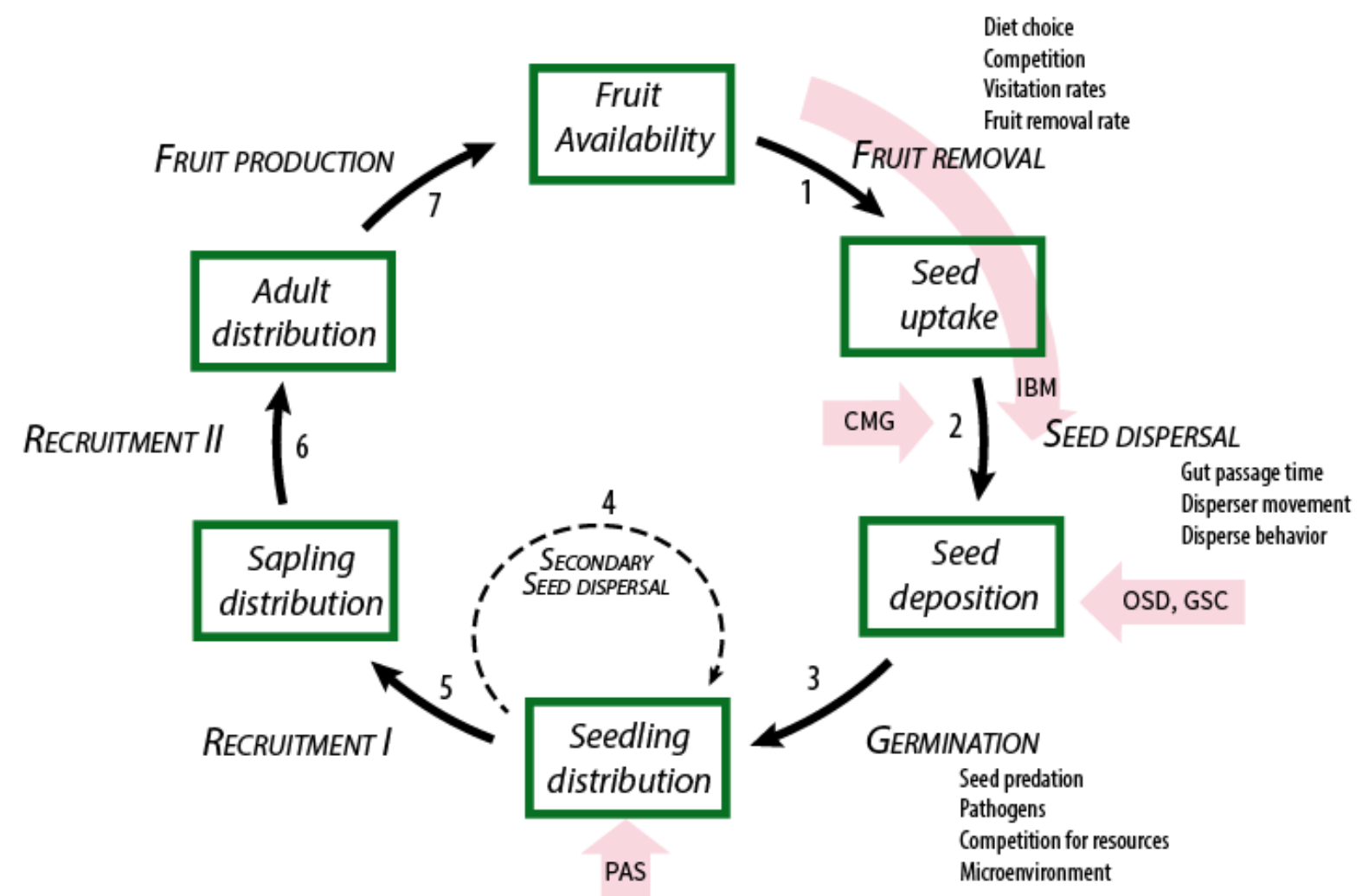

Figure 21 Seed dispersal loop as (modified from Wang and Smith 2002) showing which processes or steps of the dispersal loop are integrated by each method we used for estimating SDD

In technical terms, each method has its own limitations. Methods using plant genetic material, require highly polymorphic markers, and a high percentage of the area sampled to avoid underestimating. A low number of loci genotyped, low polymorphic markers and a reduced percentage of area sampled might also reduce the probability of finding parents in both methods. For example, genotyping 11 loci with 3-14 alleles each (mean 6 \pm 3 alleles), albeit low effective alleles (mean $1.9 \pm 1.7 A_{E}$ ), and $15 \%$ of the area sampled, I found parent pairs for only $6 \%$ of the offspring sampled through parentage analysis. Furthermore, parentage analysis (PAS) results may be affected by sampling scheme; for example, quadrat sampling could increase the possibility of only sampling individuals that were deposited close to maternal trees, leaving gaps were offspring-parent pairs are not sampled. Finally, even though maternal recognition seems a robust and direct method for calculating seed dispersal distance, it is ultimately, also affected by the same factors the OSD method, since animals must be followed, and defecations collected. 
Using animal movement data and gut passage time estimates show no difference with the other methods (except PAS), providing a good alternative for researchers that have only animal movement data. This method might increase in popularity with the arrival of new and smaller tracking devices increasing the availability of movement data. However, as our results show, the method is sensible to gut passage time range used. In the analysis of this chapter, gut passage estimates were based on a small number of observations $(\mathrm{N}=3)$, and a more reliable range of retention time would provide more accurate results, however, given the absence of difference with the other methods, a rough estimate also provides practical results.

The OSD method had a small sample number given that observation of seed dispersal events of Leona cymosa fruits are difficult because tamarins regularly feed on more than one $L$. cymosa tree in a row before depositing seeds (traplining behavior). Therefore, it is rarely possible to identify in-situ the source tree of a dispersed seed. With such a small number of dispersal events recorded in situ, we cannot distinguish properly whether the function created for the CMG method can identify SDD accurately. Therefore, I successfully validated my CMG R function on a previously studied species (Parkia panurensis) sharing the same seed dispersal system but with a high number of seed dispersal observations ( $N=358)$ (Knogge, 1998) (see supplementary data).

Our results show methods can be used interchangeably according to the resources available while providing ecologically meaningful results. However, when pooling SDD estimates obtained from different studies, the methodology used for obtaining each estimate and the processes of seed dispersal they include should be carefully considered. 


\section{Supplementary data}

\section{Validation of tamarin movement method for estimating SDD}

The tamarins at our study site also disperse Parkia panurensis, a species studied previously by Heymann et al. (2012). Previously, seed dispersal distance of P. panurensis was analyzed using observations of seed dispersal events and maternal recognition by genotyping pericarp of seeds and adults with microsatellite markers. Seed dispersal distance of $P$. panurensis was also modelled by Bialozyt et al. (2012) through a spatially explicit individual-based model, where tree used, and geographic disposition was paired with simulated energy-driven animal movements. Since seed dispersal distance of $P$. panurensis has been analyzed through several other methods, and gut passage times were available from previous seed dispersal observations (Knogge), we further validated our CMG method with data from P. panurensis.

\section{Results for Parkia panurensis}

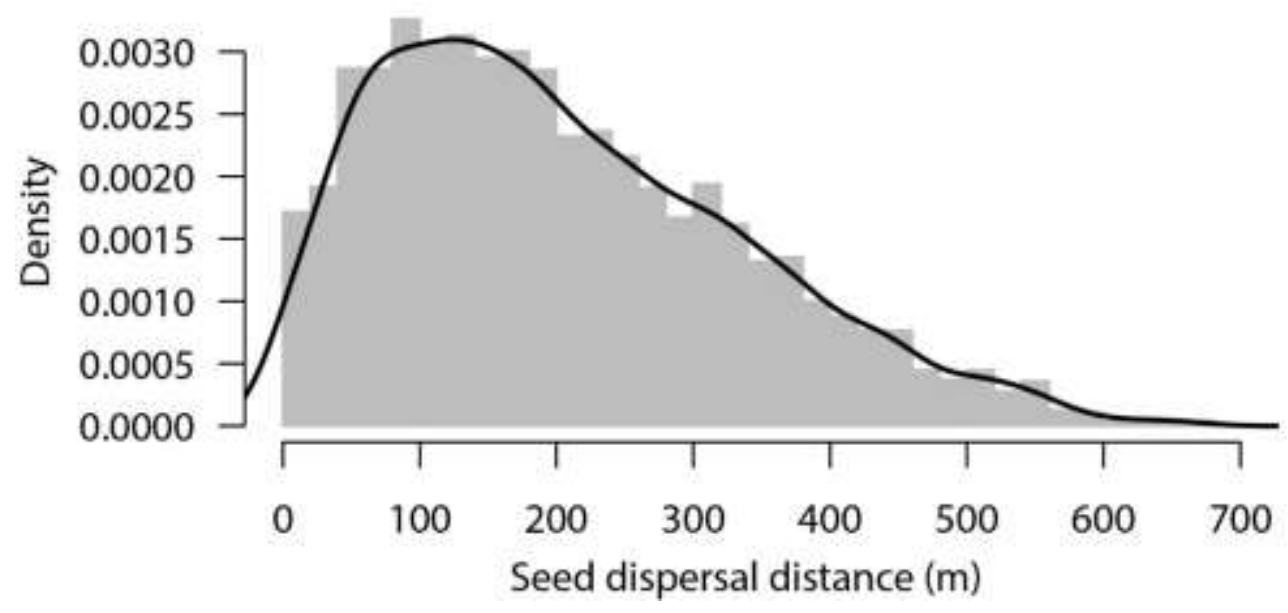

Figure 22 Seed dispersal curve for Parkia panurensis using tamarin movement data

The results of $P$. panurensis show comparable results to both, analysis using the individual-based modelling approach and through maternal recognition from pericarps (Table 12, Figure 22). Seed dispersal distance estimates showed no significant differences (ANOVA $F(2,53)=0.23, p=0.80)$, and shape of KDE were all left skewed. Seed dispersal kernel showed a mean seed dispersal distance is $212 \pm 140 \mathrm{~m}$, and $95 \%$ of the events were probabilistically calculated to be between $27 \mathrm{~m}$ and $478 \mathrm{~m}$, a minimum of $0 \mathrm{~m}$ and a maximum of $665 \mathrm{~m}$ (Table 12). 
Table 12 Comparison between seed dispersal (SD) estimates for Parkia panurensis using different methods

\begin{tabular}{llll}
\hline Method & Min & Max & Mean (SD) \\
\hline Observed (Heymann el al., 2012) & $9.5 \mathrm{~m}$ & $656 \mathrm{~m}$ & $239 \mathrm{~m}(103 \mathrm{~m})$ \\
Genetic (Heymann et al., 2012) & $9.5 \mathrm{~m}$ & $513 \mathrm{~m}$ & $229 \mathrm{~m}(99 \mathrm{~m})$ \\
Model (Bialozyt et al., 2014) & $0 \mathrm{~m}$ & $643 \mathrm{~m}$ & $201 \mathrm{~m}(136 \mathrm{~m})$ \\
CMG method & $0 \mathrm{~m}$ & $665 \mathrm{~m}$ & $205 \mathrm{~m}(133 \mathrm{~m})$
\end{tabular}

Analysis for L. cymosa and for P. panurensis use the same animal movement data, but seeds of these plant have different gut passage times. The contrast between their KDE shows the strong difference gut passage estimate determines. This shows how important gut passage time is for dispersal distances and seed shadow overlap. The same seed disperser will have a different seed dispersal pattern of different plant species with a different gut passage time, consequently affecting their population dynamics differently.

\section{$R$ function for extracting linear travel distances from movement data and for executing the CMG method (combination of movement data and gut passage time).}

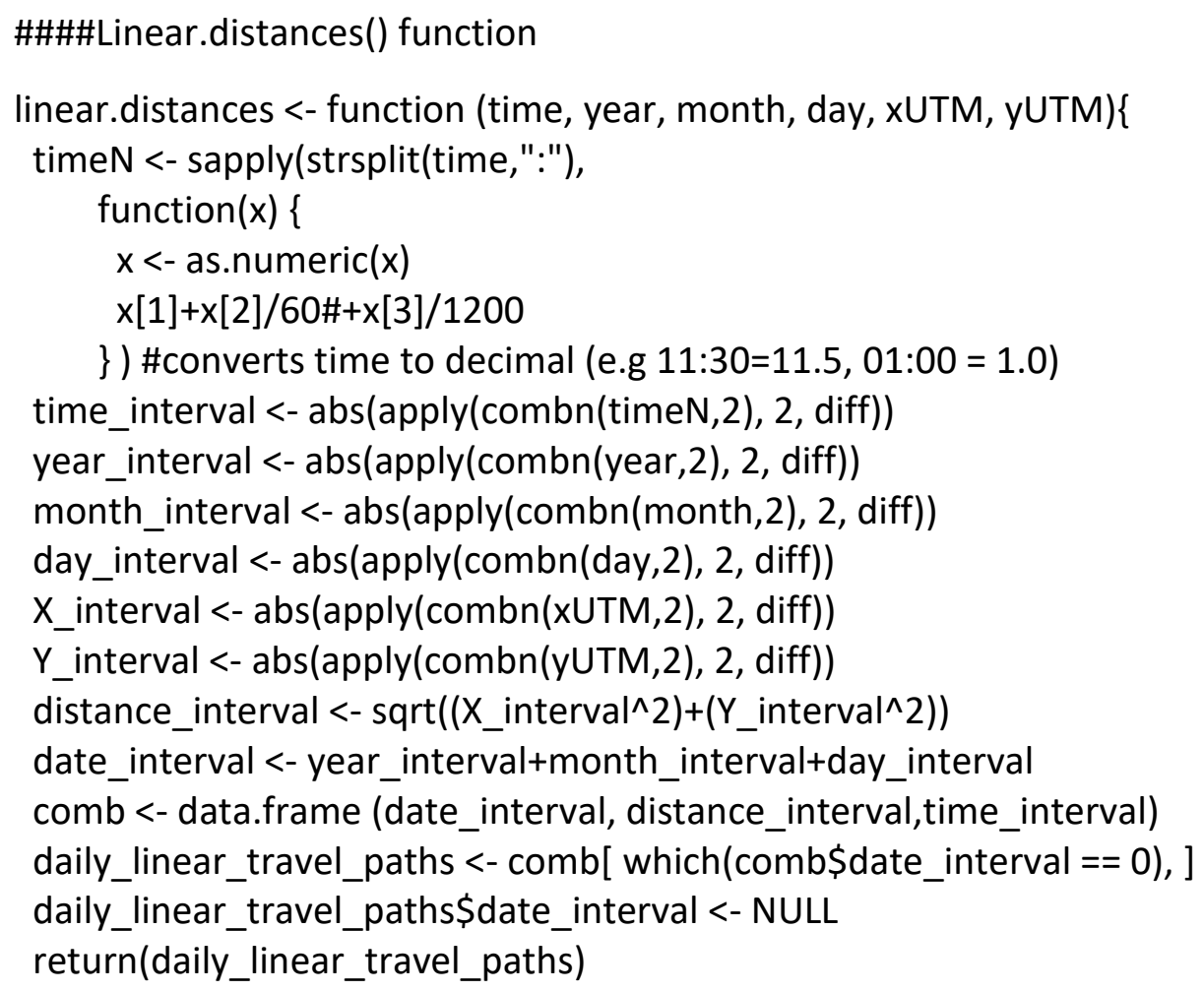


\#example of input parameteres

time <- as.character(c("11:00", "11:30", "12:00", "12:30", "13:00", "13:30"))

year <- as.numeric(c(2012,2012,2012,2012, 2012))

month <- as.numeric $(c(12,12,12,12,12,12))$

day <- as.numeric $(\mathrm{c}(14,14,14,14,14,14))$

xUTM <- as.numeric(c(704265,704256, 704249, 704146, 704090, 704010))

yUTM <- as.numeric(c(9517640, 9517554, 9517526, 9517567, 9517564, 9517571))

\#\#\#\#\#\#\#\#\#to obtain SDD estimates using the CMG method\#\#\#\#\#\#\#

\#\#1. Load data file from csv, time format should be in "\%H:\%M" or "\%H:\%M:\%S", and date should be separated in columns according to day, month, year.

trial <-read_csv(" /linearmovement_automatization_trial.csv",

locale $=$ locale $($ date_format $=" \% \mathrm{Y}-\% \mathrm{~m}-\% \mathrm{~d} "$, time_format = "\%H:\%M:\%S",tz = "UTC"))

\#\#2. Restrict data to fruiting season

trial[trial\$̣Month \%in\% c("3","4","5"),]-> trial_FS

\#\#3. Order data chronologically

trial_FS <- trial_FS [order(trial_FS\$YYear, trial_FS\$Month, trial_FS\$Day, trial_FS\$Time),]

\#\# 4. Determine input parameters for function

as.character(trial_FS\$Time) ->time \#format "\%H:\%M" if "\%H:\%M:\%S" then add $+x[3] / 1200$ to function by deleting "\#" on line 5 .

as.numeric (trial_FS \$Year )-> year

as.numeric(trial_FS\$Month) -> month

as.numeric(trial_FS\$Day) -> day \#data points have to be in chronological order

as.numeric(trial_FS\$X) $->$ xUTM

as.numeric(trial_FS\$Y) -> yUTM

\#\#5. execute function

linear.distances (time, year, month, day, xUTM, yUTM) -> daily_linear_travel

\#\#6. restrict linear travel paths to those within the gut passage time of a particular plant species or a mean for the animal species.

CMG_SDDestimates <-daily_linear_travel[daily_linear_travel\$time\%in\% c(1,1.5,2),] \#e.g. gut passage of $1-2 \mathrm{hrs}$ 


\section{CHAPTER III}

SPATIAL GENETIC STRUCTURE OF THE PRIMATE-DISPERSED AMAZONIAN $\underline{\text { TREE LEONIA CYMOSA }}$ 


\section{Abstract}

The degree to which plant individuals growing closer together are genetically more related than individuals growing further apart is denominated Spatial genetic structure (SGS). Strong spatial genetic structure has been linked to restricted seed dispersal and clumped seed dispersal patterns. Leonia cymosa provides the opportunity to study the influence of primate behavior on spatial genetic structure, since it is exclusively dispersed by two primate species Saguinus mystax and Leontocebus nigrifrons the live in mixed-species groups. To understand whether SGS is related to tamarin behavior I tested for the presence of fine-scale spatial genetic structure across life stages and put it into context of previous research of tamarin behavior. Furthermore, I test the difference in SGS between two subpopulations with different plant population density. Fine-scale genetic structure was present for seedlings and juveniles, and absent for adults. Tamarins discard $40 \%$ of the seeds beneath the feeding site and $21 \%$ beneath resting sites, however dispersed seeds have long seed dispersal distances between 200-300m. Strong SGS in seedlings reflects the cumulative seed dispersal patterns. However, its decrease through older life stages and the absence of SGS in adults suggests demographic thinning of accumulated seeds probably due to density-dependent processes, and a higher persistence of seeds dispersed seeds beyond these agglomerations of seeds. A comparison with $P$. panurensis, a tree species sharing the same exclusive seed dispersers but a different life history, suggests that gut passage time, number of seeds per fruit, and fruits consumed per tree may also influence the strength of SGS. 


\section{Introduction}

The degree in which plant individuals growing closer together are genetically more related than individuals growing further apart is denominated spatial genetic structure (SGS) (Wright 1949). The absence of SGS is an indication of high gene flow within populations. High gene flow maintains low biparental inbreeding and keeps a highly varied gene pool reducing susceptibility to environmental changes (Epperson 2003; Lowe et al. 2004). Gene flow in plants depends on seed dispersal, and pollination, the farther the distances the vectors cover, the higher the probability unrelated individuals will mate. Restricted dispersal distances have been widely linked to a strong presence of spatial genetic structure (Wright 1949; Vekemans \& Hardy 2004; Hardy et al. 2006; Dick et al. 2008). A clumped distribution of seeds from the same maternal sources is more likely to result in strong SGS (Epperson 2003; Walker et al. 2009; Choo et al. 2012; Ibanes et al. 2015). However, predation and diseases will thin out populations, usually in a density-dependent manner, regardless of the seed dispersal pattern, reducing SGS over life stages (Hamrick et al. 1993; Schroeder et al. 2014). If survival is density-independent, and several seeds/seedlings survive into adulthood after clumped seed deposition, SGS is expected to be consistent over life stages (Chung et al. 2003).

Leonia cymosa (Violaceae) is a small Neotropical understorey tree, widely distributed among the Amazon basin, mainly in tierra firme forest (Vásquez 1997; Newing \& Parellada 1998). It is spatially clustered and has a highly variant adult population density (3.8-23 ind/ha). Each cluster has differently sized individuals, but the degree of clustering decreases with life stages (Pfrommer, 2009). It grows up to $10 \mathrm{~m}$ in height, with a diameter at breast height of up to $10 \mathrm{~cm}$. L. cymosa has oblong-elliptical leaves, $10-18 \mathrm{~cm}$ long and $4-7.5 \mathrm{~cm}$ wide with the sides slightly serrated with an alternate arrangement. It has small yellow-orange flowers, $3-4 \mathrm{~mm}$ each, irregularly arranged in a sympodial inflorescence (Macbride, 1941). The floral structure indicates that L. cymosa flowers are pollinated by insects (Michael Schwerdtfeger, pers. comm., Pfrommer 2009). Fruits are spherical berries with a mean diameter of $1.8 \mathrm{~cm}$ (range 1-3.4 cm) and a mean mass of $2.1 \mathrm{~g}$ (range 1.2-15 g) (Reinehr 2010). Fruit crop size ranges between 1 to 120 fruits that ripen asynchronously from February to May which corresponds to the rainy season (Reinehr, 2010). During the ripening process, fruits change color from dark green to yellow, and also the complexity of their scent (Nevo, Heymann, Schulz, \& Ayasse, 2016). Fruits contain mostly 1-2, 
sometimes up to 7 seeds surrounded by an edible fibrous pulp (Reinehr 2010). The only known consumers and primary seed dispersers are tamarins (Saguinus spp. and Leontocebus spp.) and squirrel monkeys (Saimiri spp.) (Pfrommer, 2009; Reinehr, 2010).

At our study site, Estación Biológica Quebrada Blanco (4² $21^{\prime} \mathrm{S}, 73^{\circ} 09^{\prime} \mathrm{W}$, Loreto, Peru), Saguinus mystax and Leontocebus nigrifrons are the only seed dispersers of L. cymosa (Reinehr, 2010). These two tamarin species live together in sympatric heterospecific groups, interspecific group size ranges between 3 and 10, occasionally more (Löttker et al. 2004), sharing movement patterns and vigilance duties from two different vertical layers of the rainforest (Heymann \& Buchanan-Smith 2000; Stojan-Dolar \& Heymann 2010a). Six groups are present around our study site, and their home ranges vary in size between ca. 30-60 ha. Their diet consists of fruit pulp, insects and exudates (Garber 1986; Knogge \& Heymann 2003). They are opportunistic frugivorous, and their movement patterns mainly follow fruit availability (Culot et al. 2010). $L$. cymosa fruit crops ripen asynchronously, tamarins eat a mean of 5 fruits per feeding episode, and since tree crown size is small and fruit availability is low, a mean of two individuals can eat from the same tree individual at a time (Reinehr 2010). Feeding bouts on L. cymosa, of the two species of tamarins have a mean of 1:58 $\pm 1: 46 \mathrm{~min}$, a minimum of 6 seconds and a maximum of 10:13 minutes (Reinehr 2010). Furthermore, tamarins have a mean gut passage time of $148 \pm 72$ $\min (n=1047)$, a minimum of $20 \mathrm{~min}$. and a maximum of $514 \mathrm{~min}$ (8.6 hrs.) (Knogge 1998). Therefore, tamarins can generally disperse seeds for up to $700 \mathrm{~m}$, although $85 \%$ of seeds dispersed are within 300m, and the mean is 185 \pm 133 m (Knogge 1999; Knogge \& Heymann 2003; Heymann et al. 2017). For L. cymosa a few seed dispersal observations indicate the gut passage time to be around 2-4 hours (Culot, Knogge, unpub. data) and a mean seed dispersal distance of 214-305m (Chapter II). Furthermore, tamarins repeatedly use sleeping and resting sites (Smith et al. 2007), and beneath these sites they disperse six times the seeds they disperse outside, without a reduction in seedling survival (Muñoz Lazo et al. 2011). Movement patterns of tamarins have been seen to affect seed and seedling distribution of the several fruit species they consume (Culot et al. 2010), and also spatial genetic structure of Parkia panurensis (Bialozyt et al. 2014b)

\section{Aim}

Leonia cymosa provides the opportunity to study the direct influence of primate behavior on spatial genetic structure, which has not been studied thoroughly so far. We know primate 
behavior affects seed dispersal patterns (Stevenson 2000; Wehncke et al. 2004; Valenta \& Fedigan 2010; Razafindratsima et al. 2014; Valenta et al. 2015) and that recurrent use of sleeping sites by white-bellied spider monkeys can affect SGS of seeds dispersed beneath these sites (Karubian et al. 2015), but information is limited on how primate foraging behavior and seed dispersal extent can affect SGS within the plant population. Previous research on our study area shows tamarins can affect SGS for Parkia panurensis (Bialozyt et al. 2014b). P. panurensis is a canopy tree with low adult population densities and large fruit crop size. Leonia cymosa instead is an understorey tree with high population densities and small fruit crop size. Therefore, tamarins' feeding behavior on L. cymosa is different, with short feeding bouts and a small number of fruits eaten per visit (Reinehr, 2010). In this chapter, I aim to understand the spatial genetic structure of L. cymosa, its relationship to tamarin behavior and whether it changes through life stages and plant population density. Given the fruiting phenology of L. cymosa and the short feeding bouts of the tamarins, it is expected for L. cymosa to show an absence of SGS.

\section{Methods}

\section{Sampling}

I examined the population of Leonia cymosa present at the study site Estación Biológica Quebrada Blanco ( $4^{\circ} 21^{\prime} \mathrm{S}, 73^{\circ} 09^{\prime} \mathrm{W}$ ) in Loreto, Peru. The study site is lowland tropical rainforest (100m alt.) and is mainly composed of Tierra firme habitat. Leonia cymosa grows in the understory, grows up to $7 \mathrm{~m}$. and maintains a small diameter of the trunk $(\mathrm{dbh}<10 \mathrm{~cm})$. Within trees, fruits ripen asynchronously, once a year, during the whole fruiting period of around 3 months, between February and May.

Exhaustive sampling was done in 2014 for all life stages in $50 \mathrm{mx} 50 \mathrm{~m}$ quadrats covering $15 \%$ of the study area (Figure 23). Life stages were defined as following: seedlings $<100 \mathrm{~cm}$, juveniles $100-250 \mathrm{~cm}$, adults $>250 \mathrm{~cm}$. For each individual height, the number of leaves and the geographical position was recorded using a GPS [Garmin GPSMapH 76CSx] and leaves were collected and stored either on silica beads or Whatman ${ }^{\mathrm{TM}}$ FTA $^{\mathrm{TM}}$ PlantSaver cards. 


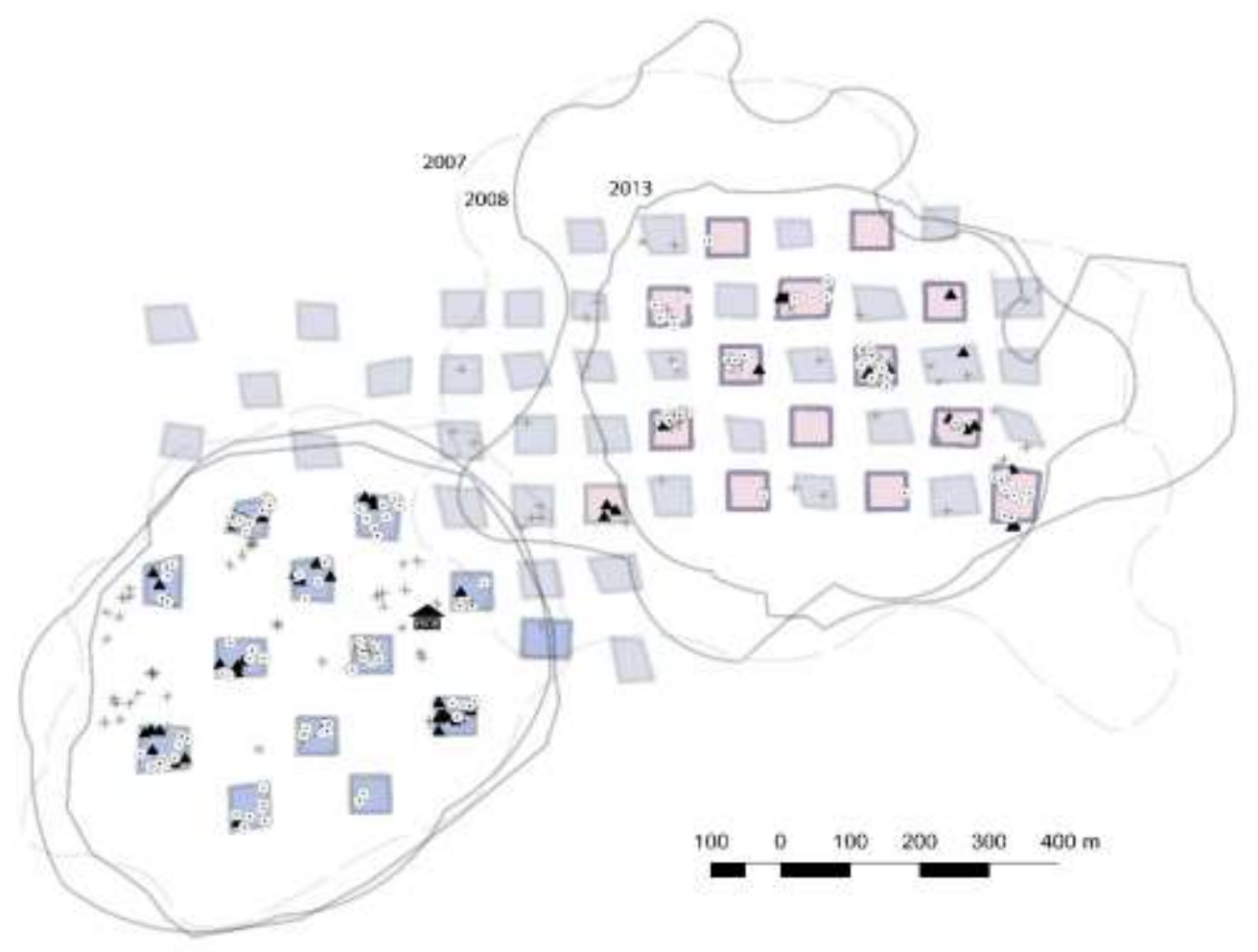

Figure 23 Sampling map for 2014. Exhaustive sampling of seedlings (circles), juveniles (triangles) and adults (asterisks) was done in $50 \mathrm{~m} \times 50 \mathrm{~m}$ quadrats. 12-13 for each home range area and additional adults sampled beyond quadrats.

\section{Genetic analysis}

DNA was extracted from the leaves using the ATMAB protocol (Dumolin et al. 1995). For DNA extraction from Whatman ${ }^{\mathrm{TM}}$ FTA $^{\mathrm{TM}}$ PlantSaver cards., $2 \mathrm{~mm}$ diameter disks of the membranes were then washed, using FTA reagent buffer and TE Buffer (TRIS, EDTA), and dried at $56^{\circ} \mathrm{C}$ for 20 minutes. Washed disks were incubated for $5 \mathrm{~min}$ in TE buffer at $95^{\circ} \mathrm{C}$ to obtain eluted DNA.

The amplification of 10 microsatellites (SSR) loci was done using Qiagen Type-it microsatellite PCR kit according to manufactures instructions (Qiagen, Venlo, Netherlands) and the following PCR conditions: $5 \mathrm{~min}$ at $94{ }^{\circ} \mathrm{C}$ for denaturation, followed by 34 cycles with $30 \mathrm{~s}$ at $94^{\circ} \mathrm{C} 90 \mathrm{~s}$ at the respective annealing temperature and $30 \mathrm{~s}$ at $72^{\circ} \mathrm{C}$, and a final extension at $60^{\circ}$ C for $30 \mathrm{~min}$. PCR products were then genotyped using capillary sequencing using the MegaBACE 1000 automated sequencer (GE Healthcare) with the size standard MegaBACE ET400-R (GE Healthcare). Alleles were called using the MegaBACE Genetic Profiler version 2. 


\section{Statistics}

To test for the presence of fine-scale spatial genetic structure I executed an autocorrelation analysis with SPAGeDi 1.4c. This calculates pairwise kinship coefficients $\left(F_{i j}\right)$ (Loiselle et al. 1995) for all pairs of individuals and regressed these on pairwise spatial distances. I defined nine distance intervals based on a constant number of pairs of individuals within each distance class, keeping $>50 \%$ partic and $\leq 1$ CV partic as suggested by Hardy \& Vekemans (2002). We used 95\% confidence intervals and determined significance of the logarithmic regression slope (b) using 10,000 permutations. The strength of SGS was estimated using Sp statistics: Sp = $-b /\left(1-F_{i j(1)}\right)$, where $F_{i j(1)}$ is the mean pairwise kinship coefficient $F_{i j}$ of the first distance interval. a Standard error for each distance class and Sp statistic was done through jackknifing genetic loci

\section{Results}

\section{Differences between life stages}

A fine-scale genetic structure was present for seedlings and juveniles, and absent for adults. Strength of SGS gradually decreased through life stages in both subpopulations (Table 13, Figure 24). However, the juvenile stage on the area with a lower population density (G2) had a higher Sp value, indicating stronger SGS for this life stage.

Table 13. SGS statistics for different life stages of L. cymosa. Sp values (Sp), kinship coefficient at first distance class $\left(F_{\mathrm{ij}(1)}\right)$, regression with linear distance in the logarithmic form (b slope), and sample number (N) are given.

A. Leonia cymosa: Group 1

\begin{tabular}{lllll}
\hline Life stage & $S p$ & $\mathrm{~F}_{\mathrm{ij}(1)}$ & $b$ slope & $N$ \\
\hline Seedlings & $0.015(0.003)$ & $0.022^{* * *}$ & $-0.014^{* * *}$ & 131 \\
Juveniles & $0.011(0.006)$ & $0.028^{*}$ & $-0.011^{*}$ & 45 \\
Adults & $-0.0001(0.003)$ & 0.013 & $7.33 \mathrm{E}-05^{\text {n.s }}$ & 69
\end{tabular}

B. Leonia cymosa: Group 2

\begin{tabular}{lllll}
\hline Life stage & $S p$ & $\mathrm{~F}_{\mathrm{ij}(1)}$ & $b$ slope & $N$ \\
\hline Seedlings & $0.013(0.004)$ & $0.051^{* * *}$ & $-0.012^{* * *}$ & 80 \\
Juveniles & $0.034(0.010)$ & $0.070^{*}$ & $-0.032^{* *}$ & 19 \\
Adults & $-0.001(0.006)$ & $0.014^{\text {n.s }}$ & $0.0011^{\text {n.s }}$ & 56
\end{tabular}


Seedlings_Leonia cymosa(G1)

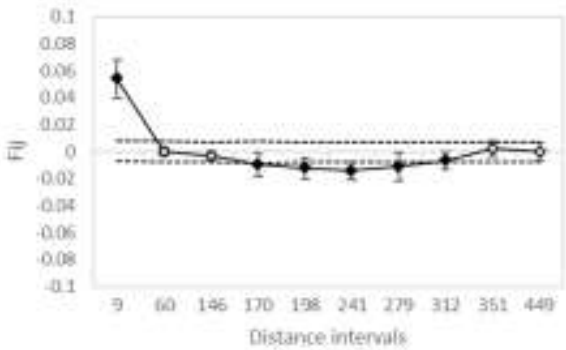

Seedlings_Leonia cymosa(G2)

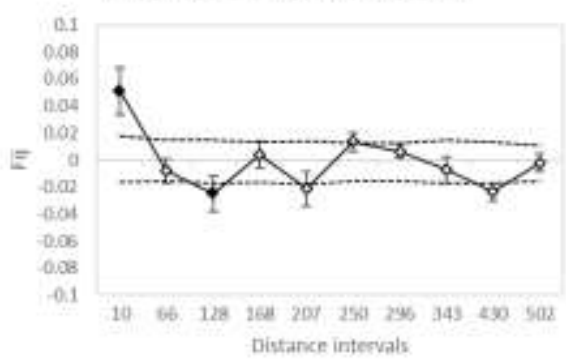

Juveniles_Leonia cymosa(G1)

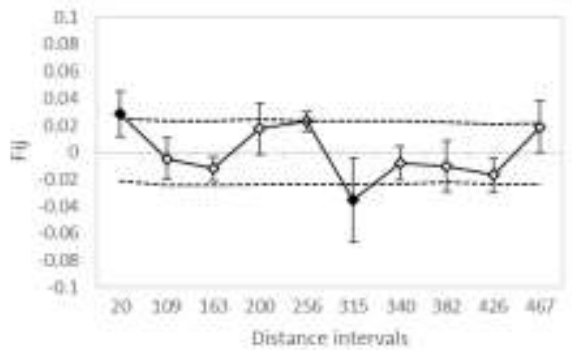

Juveniles_Leonia cymosa[G2)

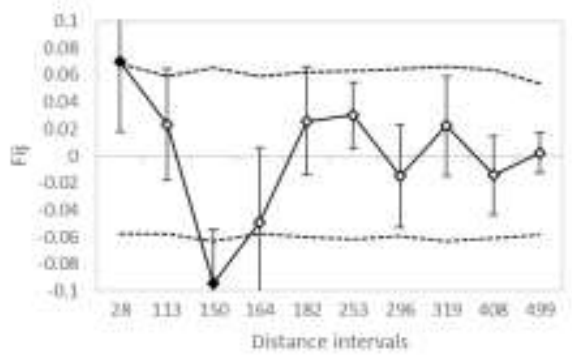

Adults_Leonia cymosa (G1)

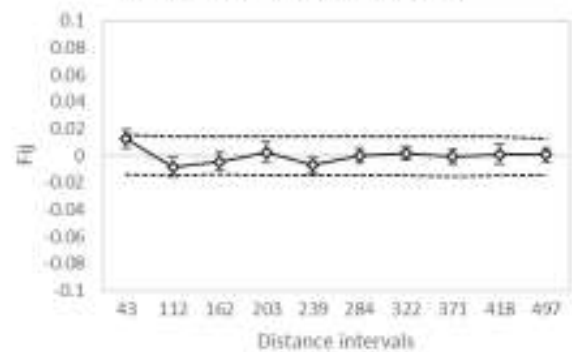

Adults_Leonia cymosa(G2)

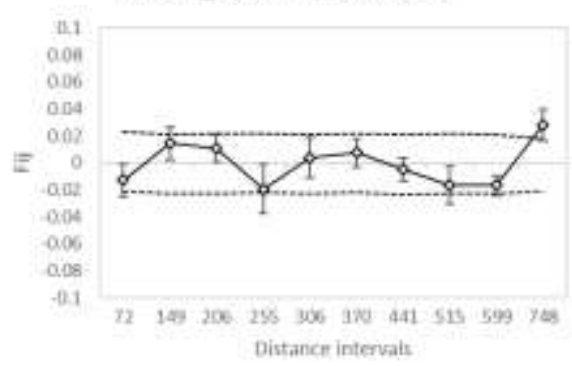

Figure 24 SGS of subpopulations (G1 and G2) of Leonia cymosa. Correlograms between pairwise kinship coefficient $\left(F_{i j}\right)$ and pairwise distance arranged in distance intervals according to a fixed number of distance intervals with a constant number of pairs. Life stages are analyzed separately 1. Seedlings $(<100 \mathrm{~cm}), 2$. Juveniles $(100-250 \mathrm{~cm})$ and 3 . Adults $(<250 \mathrm{~cm})$. Correlograms show correlation between mean $F_{i j}$ of each distance interval (__ ) and 95\% confidence intervals (- - -) and standard error (SE) of each value. 


\section{Discussion}

SGS is present differently across life stages, in both subpopulations, regardless of plant population density. Juveniles of subpopulation with lower population density shows stronger SGS in juveniles, however this could be confounded with the small sample number of juveniles in its area, given the similarities between subpopulations of life stage classes with higher sample number. Our results give evidence that plant population density is not a main determinant of SGS in L. cymosa.

Estimates of seed dispersal distance (SDD) of L. cymosa by tamarins at our study site show mean SDD of 205-304m (see chapter II). With such SDD estimates one would expect low SGS even at the seedling stage, but our results show the opposite. The generalized presence of SGS in younger life stages may be related to: 1) The high percentage of seeds discarded with fruit rests beneath the fruiting trees $(40 \%)$ or the high rate of seed deposition near conspecifics $(22 \%)$ (Reinehr 2010). 2) The use of resting sites repeatedly (61\% of resting sites used repeatedly) and the high deposition rate beneath these (21\%) (Muñoz Lazo et al. , 2011). Therefore, successfully dispersed seedlings with the average SDD cannot compensate, in terms of seedling SGS, for the high accumulation of seeds beneath trees and beneath resting sites due to foraging behavior and repetitive behavior. These results give evidence seed dispersal patterns seem to have a stronger effect than average seed dispersal distance in SGS of seedlings.

The decrease seen in our results across life stages the contrasts with previous studies on seed dispersal by tamarins in Parkia panurensis, where SGS is present in all life stages. The absence of SGS in adults for L. cymosa could be attributed to 1) high density-dependent mortality leading to demographic thinning, 2) high density of seeds dispersed with moderate to long distance. When we sampled the different life stages of L. cymosa, we observed a reduction in the cluster spatial distribution with increasing life stage, which could indicate a system under densitymortality pressure. Furthermore, kernel density estimates in Chapter II show seed dispersal curves with have a bell shape for L. cymosa with its mean between $200-300 \mathrm{~m}$, while $P$. panurensis shows a right-skewed curve with its peak around $100 \mathrm{~m}$, indicating $P$. panurensis has a high proportion of seeds dispersed within 100m (Heymann et al. 2012, 2017). This could indicate that in seed dispersal systems with long distance dispersal events and high density-dependent 
mortality, even if feeding behavior or repetitive use of sites creates clumping of seedlings, any resulting SGS of this clumping seed dispersal pattern is not maintained into adulthood.

However, Leonia cymosa and Parkia panurensis show other differences that could give information on additional factors affecting SGS. First, in contrast to P. panurensis, L. cymosa shows a clumped distribution of fruiting trees. Therefore, tamarins tend to feed on more individuals of $L$. cymosa before depositing the seeds. Consequently, seeds of L. cymosa beneath sleeping sites stem from more different maternal sources. Second, time of gut passage by $P$. panurensis can be much shorter than L. cymosa (Chapter II), increasing the number of seeds dispersed at lower distances. Third, P. panurensis has 16-23 seeds per fruit, while L. cymosa has between 1-7 seeds per fruits. A higher number of seeds per fruit increases the numbers of seeds co-dispersed. Furthermore, seeds within one fruit can have one or more pollen donors, in the case $P$. panurensis, only seeds within each fruit share the same pollen donor, increasing the genetic relatedness between these co-dispersed seeds. These first three differences could indicate that even though tamarins disperse both L. cymosa and $P$. panurensis in clumps beneath feeding sites and resting sites, $P$. panurensis' clumps will likely have a higher number of seeds with the stronger genetic relationship. This increases the likelihood that the seeds surviving density-dependent mortality will be strongly genetically related. Further research is needed to separate the influence between plant traits and disperser behavior on SGS.

Finally, both species are pollinated by animals, $P$. panurensis is pollinated by bats, and $L$. cymosa is very likely, based on flower morphology, pollinated by insects, possibly stingless bees (Euglossine) (Pfrommer, 2009). Both pollination vectors have been linked to long distance pollen flow. Thompson (2014) shows pollination by bats maintains high gene flow even in fragmented forests and with extinct seed dispersers, resulting in a low genetic structure in seedlings. Substantial long-distance gene flow has also been seen by insect pollination, in particular, stingless bees can also have been linked to high pollen flow (Janzen 1971; Williams \& Dodson 1972). The effect of pollination vectors on SGS needs to be further studied. However, both plant species show that even in the presence of high gene flow, clumped seed dispersal can potentially create SGS in seedlings which may or may not remain into older life stages, depending on densitydependent mortality and seed dispersal curves. 


\section{CHAPTER IV}

CAN SOCIAL ORGANIZATION OF TAMARINS CREATE A BARRIER FOR SEED DISPERSAL AND AFFECT GENETIC RELATEDNESS BETWEEN TWO SUBPOPULATIONS OF LEONIA CYMOSA? 


\section{Abstract}

Social behavior, in particular, social organization, territoriality, and mating system is a strong determinant of movement patterns. In frugivores, these will affect spatial patterns of seed dispersal. Tamarins Saguinus mystax and Leontocebus nigrifrons are organized into small groups that occupy home ranges which are majorly exclusively used. Thus, plants, in exclusively used areas of the home range, experience a restricted range of seed dispersal. This limited spatial extent of seed deposition area could potentially lead to higher intra-specific relatedness between plant individuals growing on the same home range areas than to plant individuals growing on other home range areas. At our study site, these tamarins are the exclusive seed dispersers of Leonia cymosa. Tamarins at our study site show long-term stability of home ranges. Therefore we expect these to influence the genetic makeup of Leonia cymosa subpopulations dispersed by different tamarin groups. Leonia cymosa is a model for examining the effect of seed dispersal on the genetic makeup of a population in a simplified system and without confounding effects of other seed dispersal vectors. Therefore, the aim of this chapter is to 1 . Analyze the spatiotemporal dynamics of tamarin home range areas, 2. Estimate the degree of seed dispersal across the analyzed home range areas, and 3. Analyze genetic relatedness between seedlings growing on different home range areas. First, we found tamarin home ranges show small overlap and a slight shift over the years. Second, only one seedling out of 12 had a parent on the other home range area, potentially a paternal parent. Therefore no seeds were found to have a tree source on the opposite home range area. Third, no differences in the genetic relatedness were found between home range areas. We discuss the lack of difference in the genetic makeup of the two subpopulations could be due to spatio-temporal shifts in the space of the tamarins' home range or potentially to long-distance pollination by insects maintaining high gene flow across seed dispersal barriers. 


\section{Introduction}

Seed dispersal is a process influencing (local) gene flow in plant populations (Heuertz et al. 2003). Together with pollination, it defines the genetic composition of plant populations over space and time. In contrast to pollination, seed dispersal moves the whole genome and directly determines the spatial area of potential recruits. Limited seed dispersal will restrict future recruits to areas near fruiting trees, subsequently increasing the probability of breeding between strongly related organisms, and consequently decreasing genetic diversity over space and time (Charlesworth 2003). Previous research shows the effects of restricted seed dispersal, for example, due to the absence of seed dispersers or presence of ecological barriers by anthropogenic activities, can cascade down to the genetic imprint of plant populations (PérezMéndez et al. 2016). These effects include increased inbreeding coefficient, increased homozygosity, reduced allelic richness and increased fine-scale spatial genetic structure (Williams \& Guries 1994; WANG et al. 2011; Ruxton \& Schaefer 2012).

Type of seed dispersal has a strong effect on seed dispersal outcomes. For instance, dispersal by gravity produces much shorter seed dispersal distances and thus stronger clustering of individuals than dispersal by wind (Seidler \& Plotkin 2006). In such abiotic dispersal physical properties of seeds and the environment (e.g., wind speed). Zoochorous seed dispersal, instead, will be determined by the fruits' and seeds 'physical and biochemical properties, the plant's phenology and spatial distribution, and how the animal behavior is affected by these properties and overall habitat conditions (Russo et al. 2006; Jordano et al. 2007; Sasal \& Morales 2013; Côrtes \& Uriarte 2013). Animals' decisions on which fruit plants to feed, or on which areas to forage, and their movement patterns in general, will have a strong impact on seed deposition patterns. Animal social behavior is a strong determinant of movement patterns and the resulting seed deposition patterns, in particular, social organization, territoriality, and mating system (Chapman \& Russo 2002; Karubian \& Durães 2009; Karubian et al. 2012). Larger group sizes, by influencing the degree of inter-group competition for resources and depletion rate of resources, can lead to longer seed dispersal distances and a higher degree of clumping (Karubian \& Durães 2009). Exclusive use of resources, through territoriality or defense, can increase the proportion of fruits consumed per fruiting source but the limit number of visitors per fruiting tree and number of fruit sources per deposition site (Karubian \& Durães 2009). By confining animal 
movements to a limited area, territoriality can restrict the spatial extent of seed dispersal, and by decreasing competition for resources and allowing animals to stay longer on feeding sites; territoriality can also increase the degree of seed clumping. Seed dispersal patterns, created by territoriality and the defense of few source trees, have been linked to a strong spatial genetic structure within granaries of acorn woodpeckers (Grivet et al. 2005).

Primates of the family Callitrichidae have a social organization where they form small, generally territorial, cooperative polyandrous groups (Sussman \& Kinzey 1984; Ferrari \& Lopes Ferrari 1989; Solomon \& French 1997). At our study site, Estación Biológica Quebrada Blanco (EBQB) (Loreto, Peru) Saguinus mystax and Leontocebus nigrifrons live together in stable mixedspecies troops (Heymann \& Buchanan-Smith 2000). Each species forms groups of 3-9 individuals and shares with the other species the same home range areas, the same movement patterns, and the same fruit resources, with the exception of a few species (Heymann \& Buchanan-Smith 2000; Knogge \& Heymann 2003). Home range areas of these mixed-species troops may or may not be actively defended and scent-marked. Intergroup encounters occur on average every other day, and 59\% of these encounters include aggressive interactions (Lledo-Ferrer et al. 2011). Nonetheless, previous research on the movement patterns of the tamarin groups shows exclusive use of central areas of home ranges and, on the delimiting periphery, small areas of overlap with neighboring groups which may vary over the years (Heymann 2000, Lledo-Ferrer et al. 2011). A social organization of small groups with exclusive use of areas of foraging, based on Karubian and Duraes (2009), the limited spatial extent of seed deposition area, potentially leading to higher intra-specific relatedness between individuals growing on the same home range area.

Tamarins at the study site EBQB feed on a variety of fruit species, insects and plant exudates (Peres 1993), and work as a unison, dispersing 50\% of the fruiting species they exploit (Knogge \& Heymann 2003; Culot et al. 2010). For their relatively small sizes (300-600gr.) they disperse relatively large seeds (up to $2.35 \mathrm{~cm}$ long and $1.35 \mathrm{~cm}$ wide) (Knogge \& Heymann 2003) around the whole area of their home ranges, but mostly within 300m (Knogge, 1998). At our study site, tamarins are the exclusive seed dispersers of the understory tropical tree Leonia cymosa (Reinehr, 2010). Given the exclusivity of its service, any movement patterns of the tamarins should have a direct effect on their seed deposition and potentially on the populations' 
genetic composition. The aim of this paper is to 1 . analyze the spatio-temporal dynamics of tamarin home range areas, 2. Estimate the number of seed dispersal events across the analyzed home range areas, and 3. Analyze genetic relatedness between seedlings growing on different home range areas in relationship to spatio-temporal dynamics of tamarins' home range areas.

\section{Methods}

\section{Study species}

Leonia cymosa (Violaceae) is a small Neotropical understorey tree, widely distributed among the Amazon basin, mainly in tierra firme forest (Vásquez 1997; Newing \& Parellada 1998). It is spatially clustered and has a highly variant adult population density (3.8-23 ind/ha). Each cluster has differently sized individuals, but the degree of clustering decreases with life stages (Pfrommer, 2009). It grows up to $10 \mathrm{~m}$ in height, with a diameter at breast height of up to $10 \mathrm{~cm}$. L. cymosa has oblong-elliptical leaves, $10-18 \mathrm{~cm}$ long and 4-7.5 cm wide with the sides slightly serrated with an alternate arrangement. It has small yellow-orange flowers, $3-4 \mathrm{~mm}$ each, irregularly arranged in a sympodial inflorescence (Macbride, 1941). The floral structure indicates that L. cymosa flowers are pollinated by insects (Michael Schwerdtfeger, pers. comm., Pfrommer 2009). Fruits are spherical berries with a mean diameter of $1.8 \mathrm{~cm}$ (range 1-3.4 cm) and a mean mass of $2.1 \mathrm{~g}$ (range 1.2-15 g) (Reinehr 2010). Fruit crop size ranges between 1 to 120 fruits that ripen asynchronously from February to May which corresponds to the rainy season (Reinehr, 2010). During the ripening process, fruits change color from dark green to yellow, and also the complexity of their scent (Nevo, Heymann, Schulz, \& Ayasse, 2016). Fruits contain mostly 1-2, sometimes up to 7 seeds surrounded by an edible fibrous pulp (Reinehr 2010).

\section{Sampling}

Historical data on tamarins' (Table 14) movement pattern are available for the years 2004-2011. For years 2012-2013, we used data collected by Darja Slana within the latest project before our plant sampling in 2014. In all studies, location was recorded every 15-30 minutes using GPS Garmin GPSMapH 76CSx. 


\begin{tabular}{r|l}
\hline Year & Reference \\
\hline 2004 & Johannes Bitz \\
$2007-08$ & (Stojan-Dolar 2009) \\
2009 & (Kubisch 2009; Neurath 2009) \\
2011 & (Kupsch 2009) \\
$2012-13$ & Darja Slana, Ph.D. thesis in prep
\end{tabular}

L. cymosa was sampled in 2014 within two adjacent home range areas of tamarins, in thirteen $50 \mathrm{~m} \times 50 \mathrm{~m}$ quadrats, covering $10 \%$ of each home range area in a checkerboard design. Sampling within each quadrat was exhaustive; life stages were distinguished based on height (seedlings $<100 \mathrm{~cm}$, juveniles $100-250 \mathrm{~cm}$, Adults $>250 \mathrm{~cm}$ ). Furthermore, to increase the success of parentage analysis adults were further sampled in transects $15 \mathrm{~m}$ wide transects connecting quadrats in Group 1 home range area and in additional quadrats inside Group 2 home range area and in the periphery of both groups. For each individual, height and location were recorded using GPS [Garmin GPSMapH 76CSx], and leaf samples were collected. Leaves were stored dried on silica gel and on Whatman ${ }^{\mathrm{TM}}$ FTA $^{\mathrm{TM}}$ PlantSaver cards.

\section{Movement pattern analysis}

Tamarins locations 2004-2013 were input into QGIS software (QGIS Development Team, 2016) and contour vectors were created for each year and for each tamarin group present around the sampling area and measured any movements of the home range areas. However, time of scan points was available only for years 2012-2013. Therefore we analyzed daily movement paths for these two years. These were made for each sampling day on qGIS using plugin pointstopath with a gap period of 30 . I calculated the daily travel path length using days for which continuous measurements were available for at least $6 \mathrm{hrs}$. Furthermore, since Leonia cymosa was present only within home range area of Group 1 and Group 2, I analyzed the use of these home range areas in more details using heatmaps of their scanned locations. Heatmaps of scan points were done by converting vector map of scan point to raster using plugin heatmap, with 30000 rows and 12239 columns, rendering bands in pseudo color using a minimum of 15 and a maximum of 450 map units, with discrete color interpolation. 


\section{Seed dispersal across home range areas}

We extracted DNA from dried leaves using the ATMAB protocol (Dumolin et al. 1995) and from the Whatman ${ }^{\mathrm{TM}}$ FTA $^{\mathrm{TM}}$ PlantSaver cards using protocol described in Chapter V. With the diluted DNA we performed PCR amplifications using Qiagen Type-it microsatellite PCR kit (Qiagen, Venlo, Netherlands) for 11 microsatellite loci previously characterized for L. cymosa (Chapter V). Microsatellite primers were amplified in multiplexes based on their annealing temperatures and product size. PCR reactions were performed using $14.6 \mu$ volume containing $20 \mathrm{ng}$ of template DNA, 1x Type-it multiplex PCR master mix and $2 \mathrm{mM}$ of each primer. For the PCR reactions we used thermal cycler "T1" from Biometra (Goettingen, Germany), programmed with the following conditions: $5 \mathrm{~min}$ at $94^{\circ} \mathrm{C}$ for denaturation, followed by 34 cycles with $30 \mathrm{~s}$ at $94^{\circ} \mathrm{C} 90 \mathrm{~s}$ at the respective annealing temperature (Chapter $\mathrm{V}$ ) and $30 \mathrm{~s}$ at $72^{\circ} \mathrm{C}$, and a final extension at $60^{\circ} \mathrm{C}$ for $30 \mathrm{~min}$. We then analyzed the PCR amplification products using capillary electrophoresis with the MegaBACE 1000 automated sequencer (GE Healthcare) and the size standard MegaBACE ET400-R (GE Healthcare). Alleles were called using the MegaBACE Genetic Profiler version 2 software.

To identify parent pairs and their offspring for the analysis of seed dispersal across home range areas I used the software Cervus 3.0 (Kalowinski et al., 2007). First, I calculated allele frequencies using the default parameters. Second, we ran the simulation for parent pairs with unknown sexes with parameters set at 0.15 proportion sampled, 0.05 proportion loci mistyped and to consider only samples with 6 minimum typed loci. We calculated confidence level using LOD scores, and these were set to relaxed at $80 \%$ and strict at $95 \%$. Third, we used the allele frequencies and the simulation output files to run the parentage analysis for parents with unknown sex. We only considered results of parent pairs with TRIO LOD significance higher than 95\%. We then input these individuals and their locations into qGIS were we connected seedlings and juveniles to their respective parents with linear vectors.

\section{Plant genetic differences between home range areas}

Genetic differences between plant populations growing on different home ranges were analyzed by comparing pairwise genetic relatedness (Queller \& Goodnight 1989) between individuals growing within the same home range and in different home range areas (Buston et 
al. 2009). We only considered individuals growing on home range area of Tamarin Group 1 and 2 because Leonia cymosa was scarcely present in the home range area of Group 3. Pairwise genetic relatedness was calculated using GenAlEx version 6.5 (Peakall \& Smouse 2006). We considered only individuals growing more than 10 meters away from each other to avoid bias due to undispersed or co-dispersed seeds. We then used a beta model regression to quantify and verify the difference between individuals growing within the same home range area and individuals growing on opposing home range areas. The beta model corrects for the independence of parameter and the parameter's characteristic of having a delimited value range $(-1,1)$. To run the model we used R package "devtools" and "brms" (Bürkner, in press).

\section{Results}

The three groups of tamarins historically sampled at the study site showed mainly exclusive use of areas with small overlap on the periphery between 2004 and 2008 (Figure 25). No information is available for Group 2 between 2009-2011. Sampling from 2012-2013, showed that rom 2008-2012 Group 2's western boundary had shifted towards east by around 270m, leaving a wider separation between Group 1 and Group 2 that remained steady for 2012-2013, while Group 3 shifted from 2008-2013 southeastward by around 330m, slowly occupying the area between these two groups, partially in 2012 (Figure 26A) and fully in 2013. (Figure 26B) 


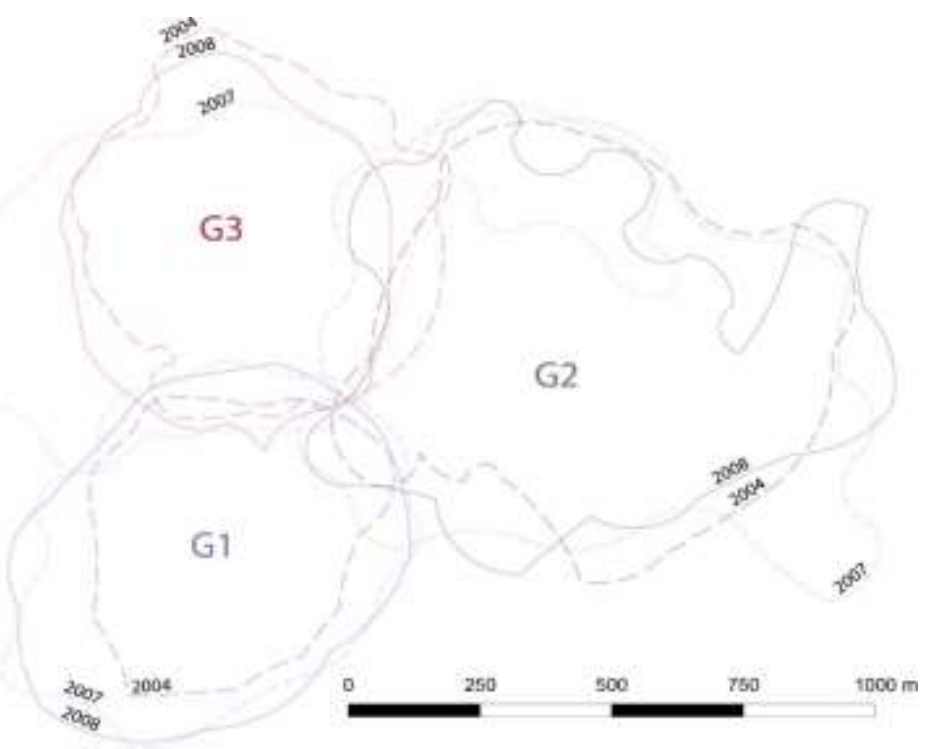

Figure 25 home range areas of tamarin Groups 1-3 (G1, G2, G3) in years for which data were available: 2004, 2007, 2008. Contour lines for different years are shown using different dash patterns and lighter purple color for Group 3 given its overlap with Group 2 in the year 2007. 
A. 2012

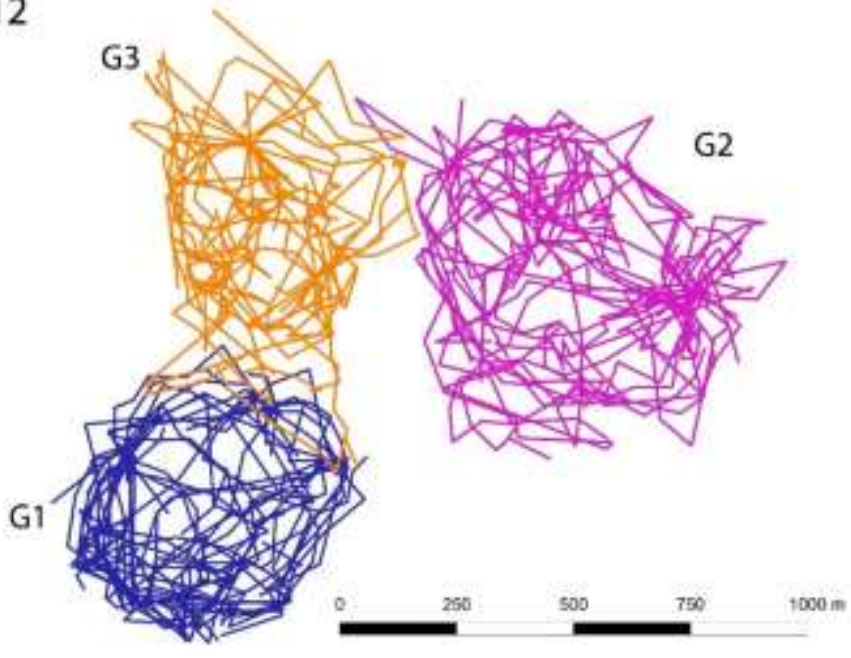

B. 2013

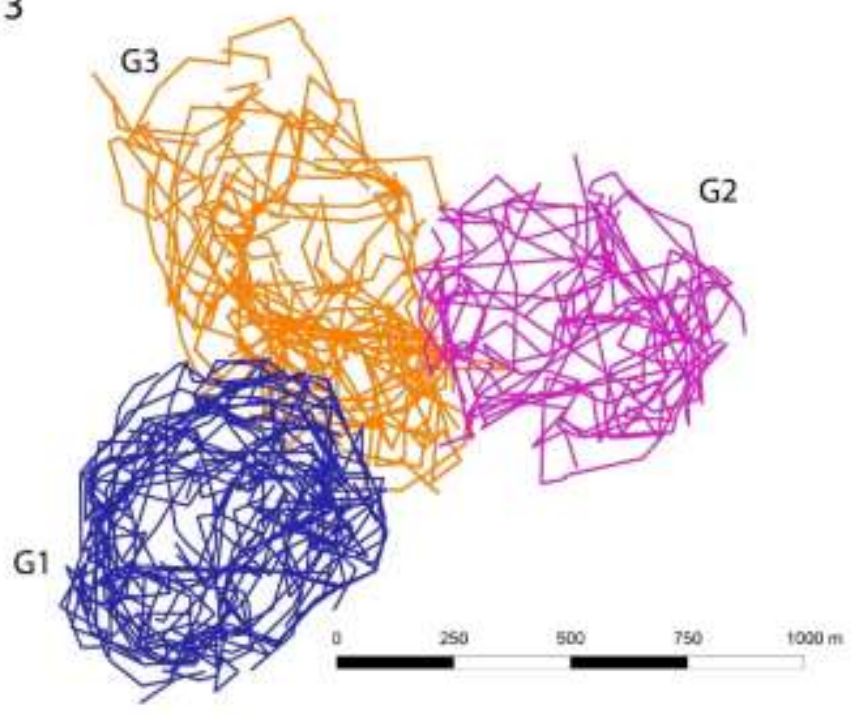

Figure 26 Movement tracks of Tamarin Groups 1-3 for years 2012 (A) and 2013 (B). Movement tracks are shown for these years instead of contours given its higher accuracy and finer detail on Group 3's occupation of area in-between Group 1 and 2.

Movement patterns of Group 1 and Group 2 show hotspot areas of activity that also persisted for the last two years before sampling as well (Figure 27). Heatmaps overlaid with daily movement paths showed tamarins really range over most of the home range areas with few lacunas and some areas of more intense use. The movement paths showed they don't necessarily spend whole days in these areas; they visit these areas over the days on a more frequent basis. Tamarins showed variable daily travel path length (Table 15 ) km and very rarely make excursions beyond the confines of the home range. The lack of overlap between home ranges of Group 1 
and 2 suggests that there is no area into which both groups can disperse seeds from their respective $L$. cymosa subpopulations.

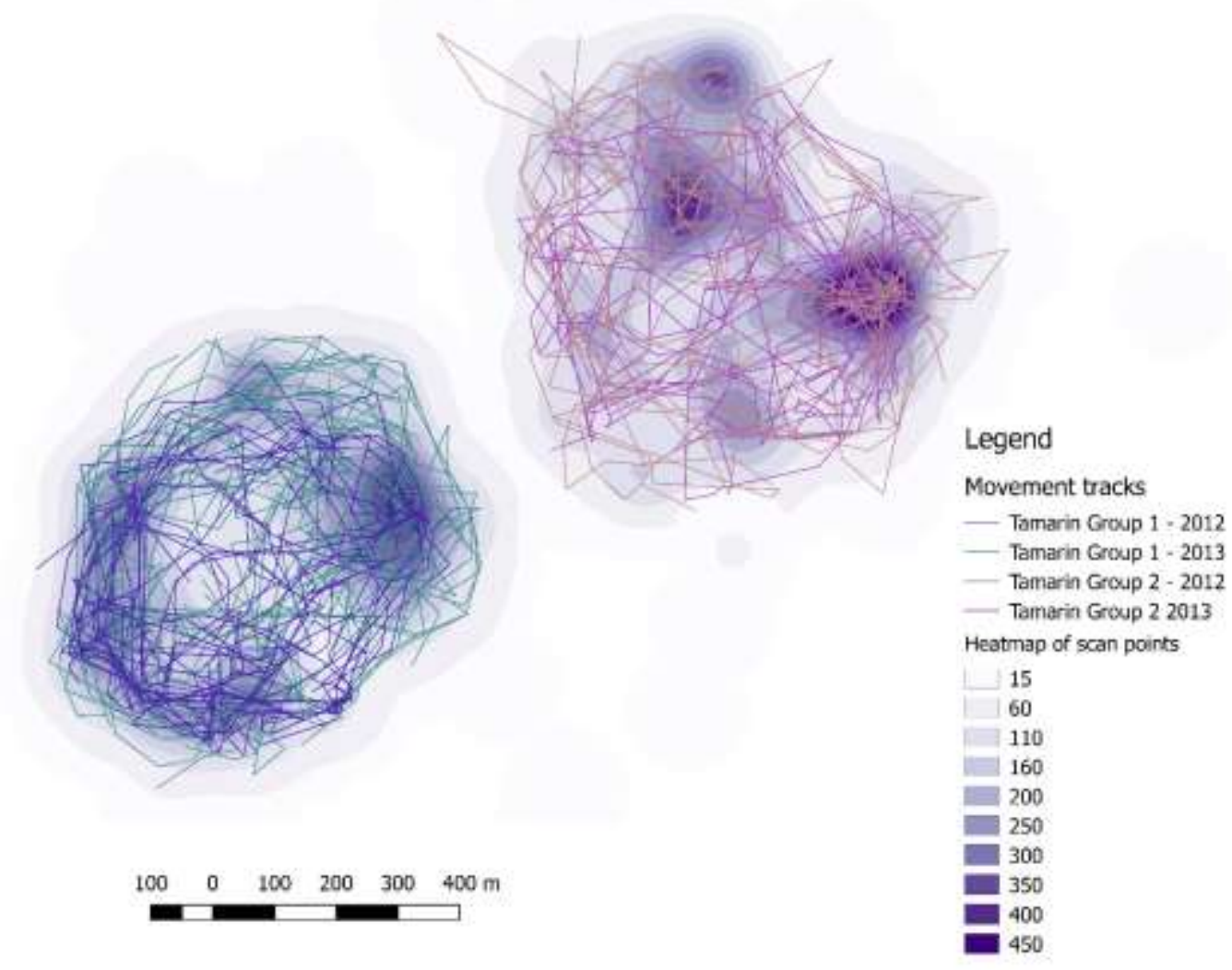

Figure 27 Finer detail of Group 1 and Group 2 movement patterns. Daily movement tracks of tamarin Groups 1 and 2, for the years 2012-2013, overlaid to heatmap of locations. Heatmaps show areas with more frequent visitation by tamarins with a darker shade.

Table 15 Daily travel path lengths of tamarins Group 1,2,3, for the years 2012-2013. Distances are given in meters. Sample number is days with minimum 6 hours of continuous observation.

\begin{tabular}{cllllll}
\hline Tamarin Group & Year & Mean & SD & Min. & Max. & N \\
\hline 1 & 2012 & 1467 & 1082 & 681 & 5914 & 25 \\
1 & 2013 & 1792 & 1201 & 922 & 6798 & 28 \\
2 & 2012 & 1598 & 969 & 572 & 5326 & 38 \\
2 & 2013 & 1312 & 773 & 663 & 3121 & 7 \\
3 & 2012 & 941 & 336 & 390 & 1528 & 17 \\
3 & 2013 & 1349 & 564 & 722 & 2642 & 8
\end{tabular}

\section{Seed dispersal across home range areas}

We identified parent pairs for 17 seedlings (Table 16,Figure 28). Twelve seedlings of these 17 were located in either home range of tamarin Group 1 or Group 2 and 11 out of these 12 seedlings had parent pairs on the same home range area where they were growing, while one 
seedling had one parent $50 \mathrm{~m}$ outside of the contour of the home range areas where it was located, and the other parent was located in home range area of tamarin group 2,620m away from the first parent. Five seedlings of the 17 seedlings for which parent pairs were identified were located in the in-between home range area, where tamarin Group 3 had recently moved into. Three of these five seedlings had one parent within $15 \mathrm{~m}$, and the other parent was located in the home range area of Group 2 ( $N=2,293 \mathrm{~m}$, and 731m away) or Group 1 ( $N=1,446 \mathrm{~m}$ away), while two of these five seedlings had parents on opposing home range areas $11320 \mathrm{~m}$ and $1330 \mathrm{~m}$ away from each other) (Table 17). These two seedlings shared one of the parents (the one in the home range area of Group 2) and were located $2 \mathrm{~m}$. away from each other, indicating a possible co-dispersal event from the shared parent, located 615m away from these (Figure 29). 


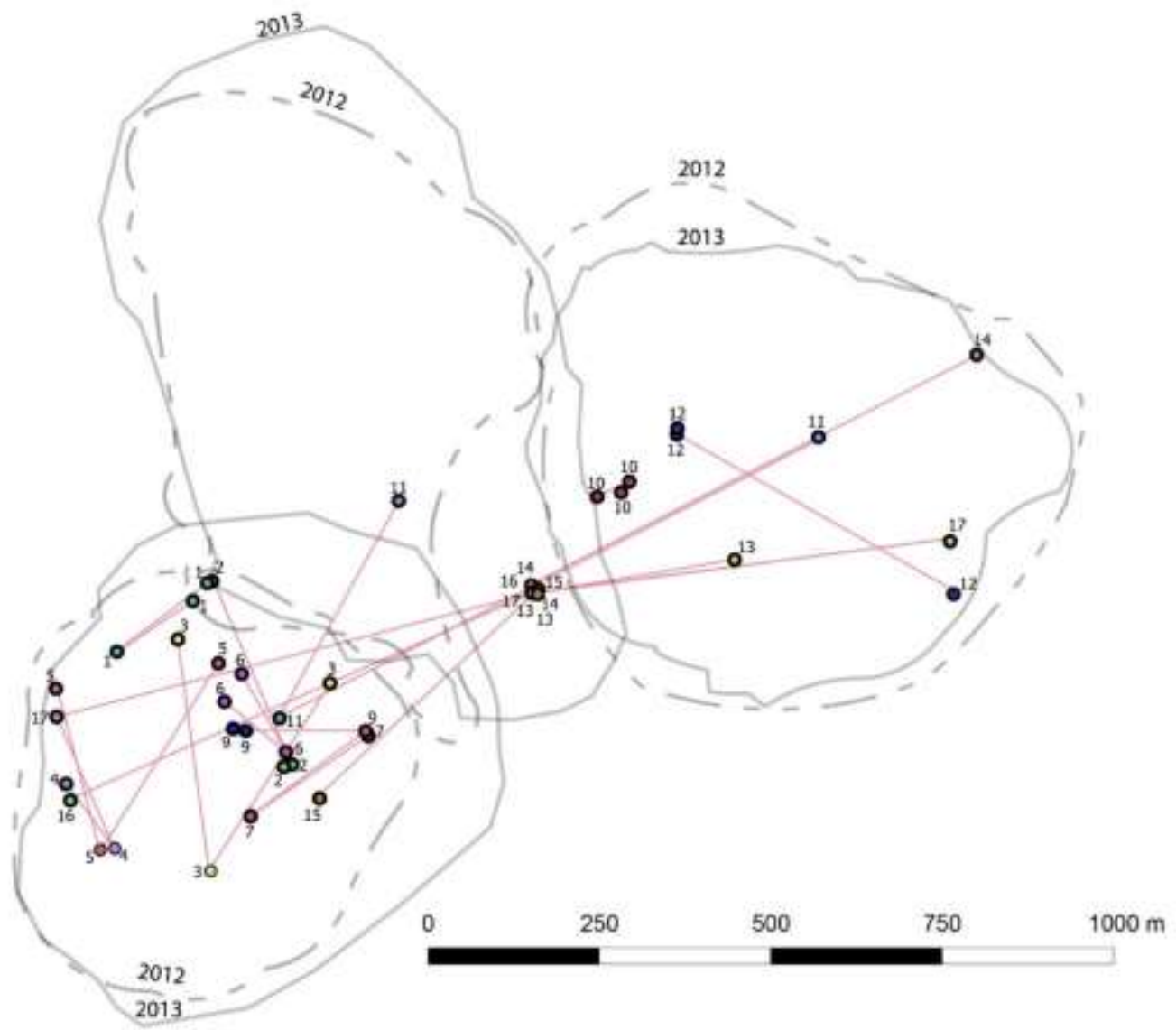

Figure 28 Parental links (purple lines) between offspring and the identified parent pair. The three members of each family area numerated with one number (1-17). territory boundaries are shown for year 2012-2013 (gray contours). 


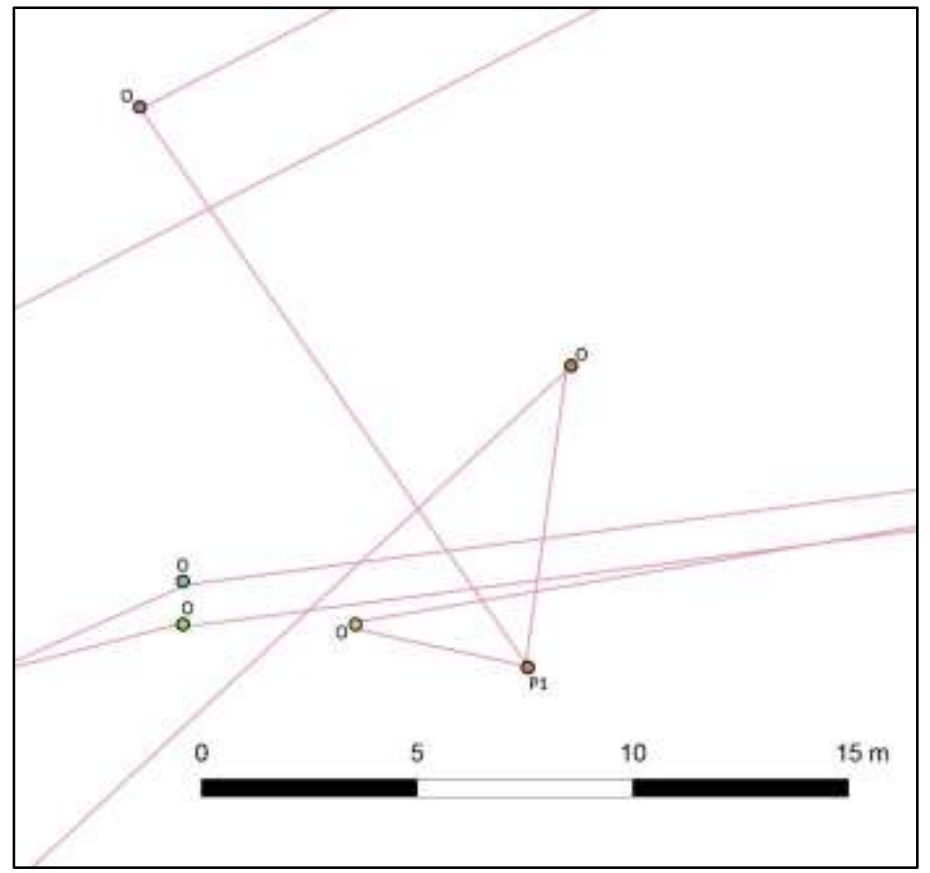

Figure 29 Offspring from the in-between area in detail. Map image shows the three offspring (orange 0 ) sharing one parent (P1) within $16 \mathrm{~m}$ and the two offspring (green $\mathrm{O}$ ) sharing one parent in home range area from tamarin group 2. Family links are shown with purple lines.

Table 16 Parent pairs identified through Parentage Analysis. Offspring list is given with respective parent pairs (P1 and P2) and their Pair LOD score, confidence, and Trio LOD score and confidence.

\begin{tabular}{|c|c|c|c|c|c|c|c|c|}
\hline Offspring & Parent 1 & $\begin{array}{l}\text { Pair LOD } \\
\text { score }\end{array}$ & $\begin{array}{l}\text { Pair } \\
\text { confidence }\end{array}$ & Parent 2 & $\begin{array}{ll}\text { Pair LOD } \\
\text { score }\end{array}$ & $\begin{array}{l}\text { Pair } \\
\text { confidence }\end{array}$ & $\begin{array}{l}\text { Trio LOD } \\
\text { score }\end{array}$ & $\begin{array}{l}\text { Trio } \\
\text { confidence }\end{array}$ \\
\hline LP14I-100 & LA14I-051 & $3.92 E+00$ & & LA14I-062 & $5.62 \mathrm{E}+00$ & $*$ & $1.18 \mathrm{E}+01$ & $*$ \\
\hline LP16I-045 & LA14I-064 & $6.09 E+00$ & $*$ & LA16I-016 & $4.85 E+00$ & + & $1.17 \mathrm{E}+01$ & $*$ \\
\hline LP14I-082 & LA14I-076 & $3.86 \mathrm{E}+00$ & & LA14I-097 & $4.10 E+00$ & - & $1.13 \mathrm{E}+01$ & $*$ \\
\hline LP14I-070 & LA14I-087 & $1.48 \mathrm{E}+00$ & & LA14I-091 & $1.09 \mathrm{E}+01$ & $*$ & $1.39 \mathrm{E}+01$ & $*$ \\
\hline LP14I-071 & LA14I-093 & $8.78 \mathrm{E}+00$ & $*$ & LA16I-049 & $5.84 \mathrm{E}-01$ & & $1.25 \mathrm{E}+01$ & $*$ \\
\hline LP16I-025 & LA14I-102 & $7.73 E+00$ & $*$ & LA16I-053 & 4.16E-01 & & $1.14 \mathrm{E}+01$ & $*$ \\
\hline LP14I-061 & LA14I-112 & $4.97 E+00$ & + & LA14I-113 & $4.40 E+00$ & + & $1.22 \mathrm{E}+01$ & $*$ \\
\hline LP14I-062 & LA14I-112 & $6.83 E+00$ & $*$ & LA14I-113 & $2.95 \mathrm{E}+00$ & & $1.17 \mathrm{E}+01$ & $*$ \\
\hline LP16I-135 & LA14I-113 & $4.26 \mathrm{E}+00$ & - & LA16I-041 & $4.96 \mathrm{E}+00$ & + & $1.16 \mathrm{E}+01$ & $*$ \\
\hline LP14II-024 & LA14II-007 & $3.62 E+00$ & - & LA15II-024 & $6.90 E+00$ & $*$ & $1.18 \mathrm{E}+01$ & $*$ \\
\hline LP16I-016 & LA14II-019 & $4.25 E+00$ & - & LA15II-034 & $6.11 E+00$ & $*$ & $1.20 \mathrm{E}+01$ & $*$ \\
\hline LP14II-066 & LA14II-032 & $4.60 \mathrm{E}+00$ & + & LA14III-006 & $5.28 \mathrm{E}+00$ & + & $1.19 \mathrm{E}+01$ & $*$ \\
\hline LP14III-004 & LA14III-001 & $9.07 \mathrm{E}+00$ & $*$ & LA15II-009 & $1.68 \mathrm{E}-01$ & & $1.14 \mathrm{E}+01$ & $*$ \\
\hline LP14III-013 & LA14III-001 & $8.15 E+00$ & $*$ & LA15II-020 & $-1.26 \mathrm{E}-01$ & & $1.14 \mathrm{E}+01$ & $*$ \\
\hline LP14III-008 & LA14III-001 & $7.41 \mathrm{E}+00$ & $*$ & LA16I-027 & $3.52 \mathrm{E}+00$ & - & $1.16 \mathrm{E}+01$ & $*$ \\
\hline LP14III-017 & LA14I-090 & 9.17E-01 & & LA14III-001 & $8.60 \mathrm{E}+00$ & $*$ & $1.26 \mathrm{E}+01$ & $*$ \\
\hline LP14III-002 & LA14I-091 & $1.56 \mathrm{E}+00$ & - & LA14III-001 & $8.33 E+00$ & $*$ & $1.24 \mathrm{E}+01$ & $*$ \\
\hline
\end{tabular}


Table 17 Parent pairs identified through Parentage Analysis. Offspring list is given with respective Parent pairs ( $P 1$ and $P 2$ ) and heights in $\mathrm{cm}$. Distance between offspring and parents and between parents is given in meters.

\begin{tabular}{|c|c|c|c|c|c|c|c|c|}
\hline $\begin{array}{l}\text { Offspring } \\
\text { (O) }\end{array}$ & Height.O & $\begin{array}{l}\text { Parent } 1 \\
\text { (P1) }\end{array}$ & Height.P1 & $\begin{array}{l}\text { Parent } 2 \\
\text { (P2) }\end{array}$ & Height.P2 & $\begin{array}{l}\text { Distance. } \\
\text { O-P1 }\end{array}$ & $\begin{array}{l}\text { Distance. } \\
\text { O-P2 }\end{array}$ & $\begin{array}{l}\text { Distance } \\
\text { P1-P2 }\end{array}$ \\
\hline LP14I-100 & 15 & LA14I-051 & 300 & LA14I-062 & 800 & 133 & 166 & 33 \\
\hline LP16I-045 & $\# N / A$ & LA14I-064 & 300 & LA16I-016 & $\# N / A$ & 292 & 13 & 290 \\
\hline LP14I-082 & 100 & LA14I-076 & 600 & LA14I-097 & 500 & 325 & 341 & 231 \\
\hline LP14I-070 & 40 & LA14I-087 & 500 & LA14I-091 & 400 & 118 & 210 & 99 \\
\hline LP14I-071 & 50 & LA14I-093 & 600 & LA16I-049 & $\# N / A$ & 244 & 322 & 240 \\
\hline LP16I-025 & $\# N / A$ & LA14I-102 & 600 & LA16I-053 & $\# N / A$ & 116 & 131 & 48 \\
\hline LP14I-061 & 10 & LA14I-112 & 700 & LA14I-113 & 300 & 208 & 209 & 8 \\
\hline LP14I-062 & 15 & LA14I-112 & 700 & LA14I-113 & 300 & 208 & 209 & 8 \\
\hline LP16I-135 & $\# N / A$ & LA14I-113 & 300 & LA16I-041 & $\# \mathrm{~N} / \mathrm{A}$ & 175 & 19 & 193 \\
\hline LP14II-024 & 10 & LA14II-007 & 500 & LA15II-024 & 500 & 52 & 20 & 35 \\
\hline LP16I-016 & $\# N / A$ & LA14II-019 & 700 & LA15II-034 & 600 & 887 & 361 & 620 \\
\hline LP14II-066 & 10 & LA14II-032 & 600 & LA14III-006 & 300 & 9 & 466 & 470 \\
\hline LP14III-004 & 15 & LA14III-001 & 700 & LA15II-009 & 500 & 4 & 296 & 292 \\
\hline LP14III-013 & 10 & LA14III-001 & 700 & LA15II-020 & 350 & 16 & 731 & 730 \\
\hline LP14III-008 & 20 & LA14III-001 & 700 & LA16I-027 & $\# N / A$ & 7 & 442 & 436 \\
\hline LP14III-017 & 10 & LA14I-090 & 700 & LA14III-001 & 200 & 739 & 615 & 1338 \\
\hline LP14III-002 & 30 & LA14I-091 & 400 & LA14III-001 & 200 & 717 & 615 & 1329 \\
\hline
\end{tabular}

\section{Genetic relatedness}

Pairwise genetic relatedness (QGM) between plant individuals growing in different home ranges was not significantly different from those of individuals growing on the same home range area [Seedlings $(P=0.989)$; Juveniles $(P=0.064)$, Adults $(P=0.546)$ ]. (Figure 30$)$. Distribution curve of pairwise relatedness values of plant individuals growing within the same home range area and those pairs growing on opposing home range areas strongly overlap. If the genetic composition of individuals growing on different home ranges was somehow differentiated, the distribution curve of individuals growing within the same home range would be shifted towards positive values, while the curve of individuals growing on opposing home range areas would be shifted to the negative values. Instead, the beta model regression shows no significant differences between these curves for all life stages. 


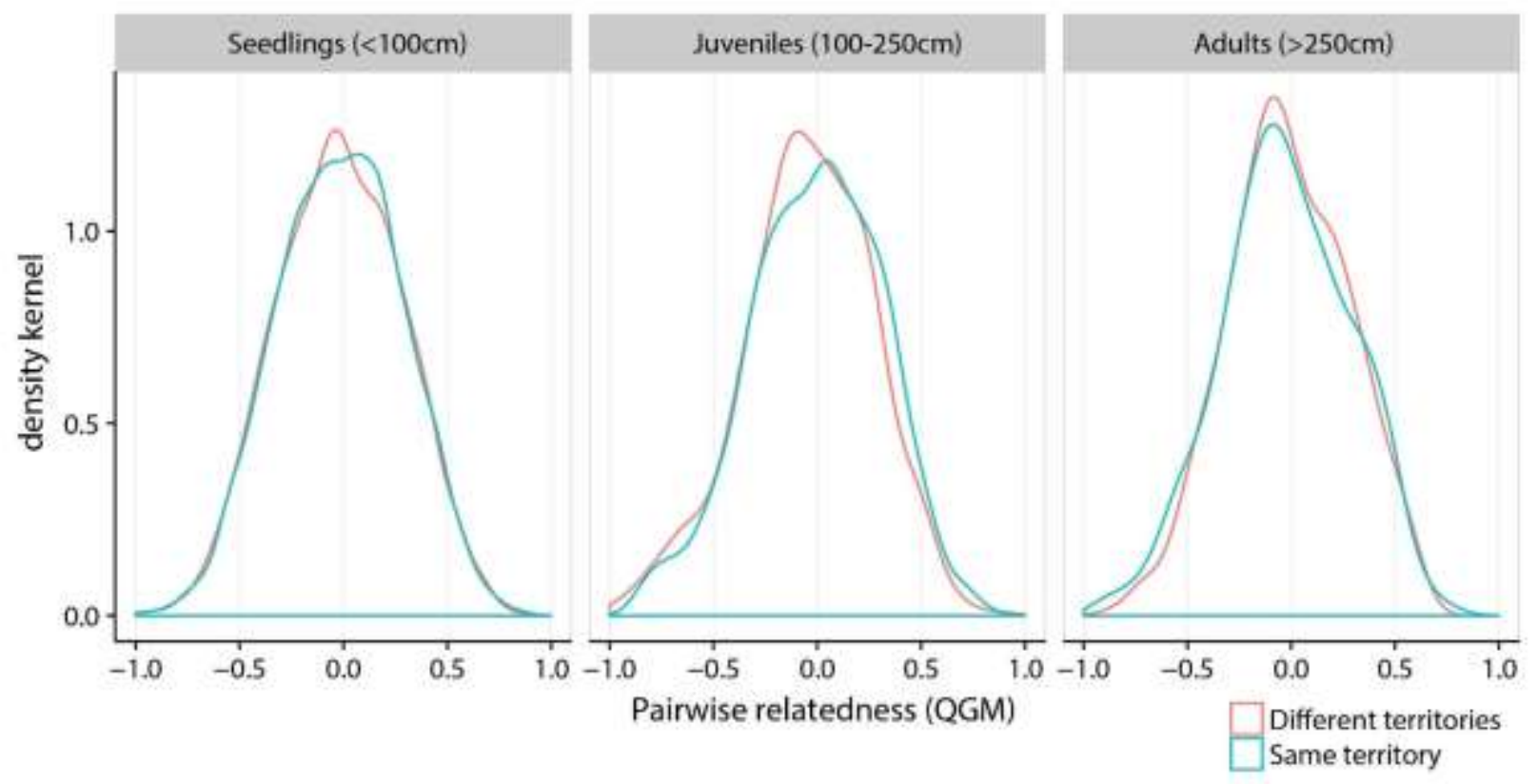

Figure 30 Distribution curves of pairwise relatedness values between individuals growing on different territories (grey), and within seedlings on the same territories (black). Life stages are considered separately: seedlings $(<100 \mathrm{~cm})$, juveniles $(100 \mathrm{~cm}-250 \mathrm{~cm})$, adults $(>250 \mathrm{~cm})$

\section{Discussion}

Even though parentage analysis showed almost no seed dispersal across home range areas, and tamarin movement patterns showed no overlap between Group 1 and Group 2 for the previous years, nor any movement of the tamarins from one area to the other exchanging home range areas, genetic relatedness of individuals showed that gene flow between home range areas is maintained. Plant subpopulations showed no significant genetic differences based on the home range area where they grow. We would've expected at least a significant difference between seedlings, given the clumped seed dispersal patterns by tamarins (Chapter II), and the presence of SGS (Chapter III). The absence of significant differences between seedlings from the two subpopulations suggests pollination is maintaining gene flow between home ranges. Supporting this theory, the distances between parent pairs are high $(377 \pm 406 \mathrm{~m}, \max =1338 \mathrm{~m})$. Given its flower morphology, and previous observations (Pfrommer, 2009), L. cymosa is likely pollinated by insects, possibly stingless bees (Euglossine). Previous research shows insects can have longdistance pollination range (Janzen, 1971; Williams and Dodson, 1972), for example a mean pollination distance of $303 \pm 206 \mathrm{~m}$ and a maximum of $1263 \mathrm{~m}$ by coleoptera and bees for Oenocarpus bataua (Ottewell et al., 2012), and foraging distances of up to $6 \mathrm{~km}$ by the carpenter bee Xylocopa flavorufa (Pasquet et al., 2008). Such pollination distances would be able to 
compensate any possible gene flow barrier created by seed dispersal, like it has been seen for bat pollination in areas where seed dispersal is limited (Thompson, 2014).

The lack of significance in adults could reflect the previous closeness between home range areas or indicate that small spatial shifts of tamarins' home ranges over time are relevant in terms of L. cymosa's life expectancy and reproductive span. The home range limits analyzed are from the last 10 years (2004-2013), and these have slowly but steadily shifted over the last 20 years. Heymann et al. (2017) showed tamarin Group 1 had shifted southward by around 250m from 1994 to 2008. In the historical data we analyzed (Table 14), we see that from 2008-2013, Group 1 has maintained its position but Group 2's western boundary has shifted towards east by around $270 \mathrm{~m}$, and Group 3 shifted southeastward by around 330m. If L. cymosa's reproductive span was beyond 30 years, these spatial shifts of the home ranges could slowly but steadily guarantee homogenization of gene flow over generations. Life span of $L$. cymosa is not known so this hypothesis cannot be discarded.

All life stages showed no significant values in genetic relatedness between subpopulations. Because of the results on previous chapters, we would've expected a stronger difference between seedlings than juveniles and a stronger difference between juveniles than between adults from different subpopulations. However, there is no gradual increase in difference, interms of $p$-value, going through the life stages. Juvenile life stage $(100-250 \mathrm{~cm})$ showed values of the beta model approaching significance $(p=0.06)$, while $p$-values of seedlings and adults were strongly not significant. Two hypotheses could explain this 1) Juveniles represent the generation dispersed while Group 1 and Group 2 were spatially more separated, and Group 3 had still not gained the terrain in-between, increasing the difference between subpopulations of this generation. However, since growth rate of L. cymosa is not known, we cannot assign the juvenile size range to a single generation nor attribute it to seed dispersal events of a determined year. 2) The recent presence of Group 3 in-between Group 1 and Group 2 may be taking seeds from one territory to the other reducing dissimilarities between subpopulations of seedlings. The latter would be visible on the parentage analysis, however given the small percentage of parent pairs found (6\%) we cannot exclude this. If these hypotheses were true, then we could strongly suspect the shifts in time of tamarins' home ranges are able to maintain gene flow regardless of spatial restrictions on seed dispersal by home range areas and areas of exclusive resource use. 
Further research on tamarin home ranges and spatio-temporal shifts could further illustrate the effects its exclusive use of resources could on plant spatial genetics. 


\section{CHAPTER V}

CHARACTERIZATION OF NUCLEAR MICROSATELLITE PRIMERS AND VALIDATION OF WHATMAN ${ }^{\text {TM }}$ FTA $^{\text {TM }}$ PLANTSAVER CARDS. FOR DNA SAMPLING IN THE NEOTROPICAL TREE,

LEONIA CYMOSA (VIOLACEAE) 


\begin{abstract}
Microsatellite primers were developed for the Neotropical understory tree, Leonia cymosa (Violaceae), to investigate potential effects of primate seed dispersal on plant population genetics. Primer pairs for eleven microsatellite markers were developed from samples stored as dried leaves and in Whatman ${ }^{\mathrm{TM}}$ FTA $^{\mathrm{TM}}$ PlantSaver cards. Primer were successfully amplified in two populations of $L$. cymosa $(N=648, N=6)$ and partially in two other species from the same genus: L. glycicarpa $(N=5)$ and $L$. crassa $(N=3)$. We compared results from different sampling and storage methods and got comparable results. These eleven microsatellites have applicability on congeneric species and can be successfully used for studies of genetic diversity, genetic population structure and parentage analysis. Whatman ${ }^{\mathrm{TM}} \mathrm{FTA}^{\mathrm{TM}}$ PlantSaver cards are a valid and more advantageous sample storage method for plant species in tropical study sites.
\end{abstract}




\section{Introduction}

Microsatellites were developed to investigate the effects of frugivore behavior and seed dispersal in spatial genetics of Leonia cymosa, a relatively unknown tree species for which markers were not available yet. Leonia cymosa (Violaceae) is a small Neotropical understorey tree, widely distributed among the Amazon basin, mainly in tierra firme forest (Vásquez 1997; Newing \& Parellada 1998). It grows up to $10 \mathrm{~m}$ in height, with a diameter at breast height of up to $10 \mathrm{~cm}$. L. cymosa has oblong-elliptical leaves, $10-18 \mathrm{~cm}$ long and $4-7.5 \mathrm{~cm}$ wide with the sides slightly serrated with alternate arrangement. It has small yellow-orange flowers, $3-4 \mathrm{~mm}$ each, irregularly arranged in a sympodial inflorescence (Macbride, 1941). The floral structure indicates that L. cymosa flowers are pollinated by insects (Michael Schwerdtfeger, personal communication). Fruits are spherical berries with a mean diameter of $1.8 \mathrm{~cm}$ (range 1-3.4 cm) and a mean mass of $2.1 \mathrm{~g}$ (range 1.2-15 g) (Reinehr 2010). Fruit crop size ranges between 1 to 120 fruits that ripen asynchronously from February to May which corresponds to the rainy season (Reinehr, 2010). During the ripening process, fruits change color from dark green to yellow, and also the complexity of their scent (Nevo, Heymann, Schulz, \& Ayasse, 2016). Fruits contain mostly 1-2, sometimes up to 7 seeds surrounded by an edible fibrous pulp (Reinehr 2010). The only known consumers and primary seed dispersers are tamarins (Saguinus spp. and Leontocebus spp.) and squirrel monkeys (Saimiri spp.) (Pfrommer, 2009; Reinehr, 2010). At our study site in north-eastern Peru, L. cymosa is exclusively dispersed by Leontocebus nigrifrons and Saguinus mystax, for which it was amongst the top five plant food resources in some of the years (Smith 1997; Culot 2009). Hallock and co-workers (2000) reported the presence of active anti-HIV macrocyclic peptides from in dry bark of L. cymosa.

Here, we describe three multiplex PCR reactions for genotyping with 11 microsatellite primers. We also report their transferability to two congeneric species: Leonia glycicarpa and Leonia crassa. Furthermore, we validated the application of WhatmanTM FTA ${ }^{\mathrm{TM}}$ PlantSaver cards for microsatellite genotyping by comparing DNA extracted from dried leaves and from the cards. These cards are already widely used on fungi (Mukuma 2016), viral pathogens (Ndunguru et al. 2005), yeast (Borman et al. 2006), lichens (Gueidan et al. 2016) and have been already been validated for agricultural analysis of Solanum spp., Sorghum bicolor and Hordeum vulgare (Drescher and Graner, 2002; Adugna et al., 2011; Aguoru et al., 2015) have not yet been used for 
microsatellite genotyping of tropical tree species where adequate storing of material for DNA extraction is particularly challenging.

\section{Methods and Results}

\section{Microsatellite characterization}

Samples of L. cymosa were collected at the Estación Biológica Quebrada Blanco in northeastern Peruvian Amazonia ( $4^{\circ} 21^{\prime} S, 73^{\circ} 09^{\prime} W$ ). Additional samples for L. cymosa, and samples from L. glycicarpa and L. crassa were collected near to Allpahuayo-Mishana, Peru (4 $4^{\circ} 29^{\prime} S, 73^{\circ}$ 35' W). Microsatellites were developed by Ecogenics (Balgach, Switzerland). Briefly, size-selected fragments from genomic DNA were enriched for SSR content by using magnetic streptavidin beads and biotin-labelled GATA, GTAT, AAAC and AAAG repeat oligonucleotides. The SSRenriched library was sequenced on an Illumina MiSeq platform using the Nano 2x250 v2 format. After assembly, 3'855 contigs or singlets contained a microsatellite insert with a tetra- or a trinucleotide of at least six repeat units or a dinucleotide of at least 10 repeat units. Suitable primer design was possible in 171 microsatellite candidates from which 13 polymorphic microsatellite markers were successfully generated. Markers were further tested, for optimal conditions, on 32 individuals using an automatic capillary sequencer (MegaBACE 1000, GE Healthcare, Uppsala, Sweden). Amplification products of 11 microsatellite primers showed scorable and polymorphic bands.

The primers for the targeted microsatellites were assembled in multiplexes according to their annealing temperatures. PCR reactions were performed with the Qiagen Type-it microsatellite PCR kit according to the manufacturer's instructions (Qiagen, Venlo, Netherlands). For each of the three multiplex reactions we used $20 \mathrm{ng}$ of template DNA, or alternatively, a 2 $\mathrm{mm}$ disk of the Whatman cards (for details on DNA extraction see below), 1x Type-it multiplex PCR master mix and $2 \mathrm{mM}$ of each primer (specific quantities used and fluorescent labels described on Table 18) in a total volume of $14.6 \mu$ l. The thermal cycler (T1, Biometra, Göttingen, Germany) was programmed with the following conditions: $5 \mathrm{~min}$ at $94{ }^{\circ} \mathrm{C}$ for denaturation, followed by 34 cycles with $30 \mathrm{~s}$ at $94^{\circ} \mathrm{C} 90 \mathrm{~s}$ at the respective annealing temperature (Table 18), and $30 \mathrm{~s}$ at $72^{\circ} \mathrm{C}$, and a final extension at $60^{\circ} \mathrm{C}$ for $30 \mathrm{~min}$. The PCR amplification products were 
separated by capillary electrophoresis using the MegaBACE 1000 automated sequencer (GE Healthcare) with the size standard MegaBACE ET400-R (GE Healthcare). Alleles were called using the MegaBACE Genetic Profiler version 2. An example of a resulting electropherogram from the three multiplexes is given in Figure 31.

Parameters for genetic diversity of L. cymosa samples were estimated using GenAlex version 6.2 (Peakall and Smouse, 2006). All eleven loci were polymorphic with a mean of 5.7 alleles per locus, ranging between two and 14 (Table 19). Expected heterozygosity ranged from 0.119 to 0.866 , with a mean of 0.410 . Significant deviations from HWE were observed for four primers and null alleles for only one. However, corrected estimated frequencies vary only by 0.02 in relationship to the observed frequencies, so these were not considered when using this marker for genetic analyses (Table 19). Microsatellite markers were compatible with two Neotropical Leonia species: L. glycicarpa, L. crassa and another L. cymosa population (Table 20). Cross-species amplification was found for six and seven markers, respectively, on the same fragment length range as L. cymosa. 

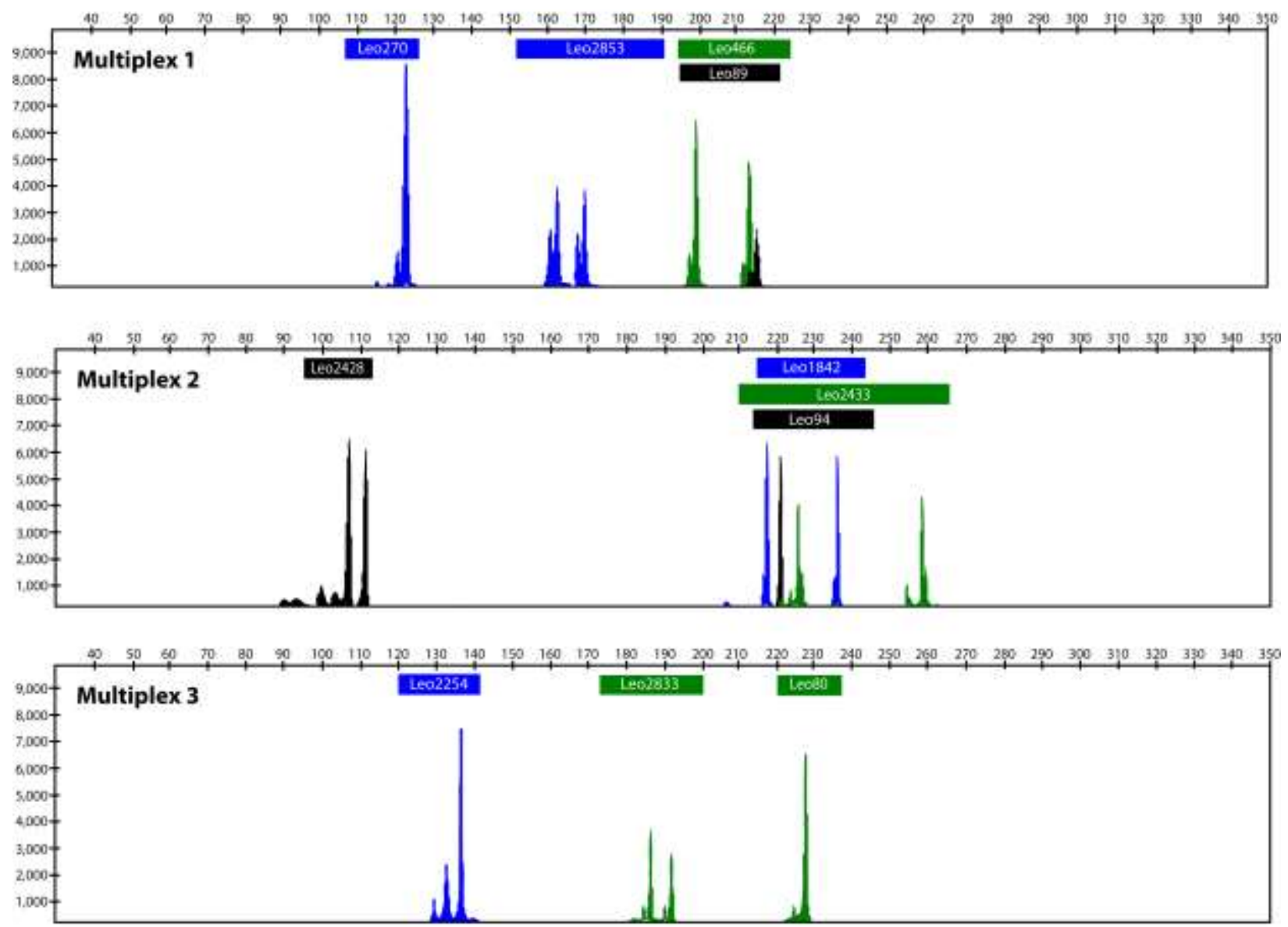

Figure 31 Example of genotyping results obtained using 3 multiplexes (1-3, upper left corner). Peaks are coloured according to the dyes used for each primer (FAM blue, HEX green, TMR black) 
Table 18. Characteristics of 11 nuclear microsatellite loci for Leonia cymosa. For each locus, we provide the forward and reverse primer sequence, the repeat motif, the optimized annealing temperature $\left(T_{a}\right)$, the NCBI accession number, the fluorescent dye used o multiplex number. Size ranges of the amplified fragments include all fragments discovered within all Leonia species used in this study. For explicit size ranges within a specific Leonia species see Table 19.

\begin{tabular}{|c|c|c|c|c|c|c|c|}
\hline Primer & Primer sequences $5^{\prime}-3^{\prime}$ & $\begin{array}{l}\text { Repeat } \\
\text { motif }\end{array}$ & $\mathrm{T}_{\mathrm{a}}\left({ }^{\circ} \mathrm{C}\right)$ & $\begin{array}{l}\text { Accession } \\
\text { No. }\end{array}$ & Dye & $\begin{array}{l}\text { Multiple } \\
\mathrm{x} \mathrm{N}^{\circ}\end{array}$ & $\begin{array}{l}\text { Primer } \\
2 \mu \mathrm{mol} \\
(\mu \mathrm{l})\end{array}$ \\
\hline Leocym89 & $\begin{array}{l}\text { F: GTTCGCCTCACCATAAAGGC } \\
\text { R: AAGAGTGAGCATGCGTGAAG }\end{array}$ & (TTTC)8 & 55 & MF002375 & TMR & 1 & 2 \\
\hline Leocym 270 & $\begin{array}{l}\text { F: GTACTTGCACCATGCCACC } \\
\text { R: TAGCACTTCTGCACTTGTTG }\end{array}$ & $(\mathrm{AAAC}) 8$ & 55 & MF002377 & FAM & 1 & 1.4 \\
\hline Leocym466 & $\begin{array}{l}\text { F: AGCATAGACACCACGGCTAC } \\
\text { R: AACTTGATCCCCAGTTTGGC }\end{array}$ & $(A A G A) 9$ & 55 & MF002378 & HEX & 1 & 1.4 \\
\hline Leocym 2853 & $\begin{array}{l}\text { F: TTGCAAGGCACAATGACGAC } \\
\text { R: TACACAGTGCCAACATGCAG }\end{array}$ & $($ ATAC) 8 & 55 & MF002384 & FAM & 1 & 1.4 \\
\hline Leocym94 & $\begin{array}{l}\text { F:AAACCCTTGTTTTCGAATTTAGATG } \\
\text { R: GGGGCCAATTTGACTTTTTGC }\end{array}$ & (TTTG)8 & 59 & MF002376 & TMR & 2 & 1.8 \\
\hline Leocym 1842 & $\begin{array}{l}\text { F: ACCCCATGACCCTTTAGTGC } \\
\text { R: TTTTATGTTAAGTTCTTGCAATGGG }\end{array}$ & $(\mathrm{AAAG}) 7$ & 59 & MF002379 & FAM & 2 & 1.4 \\
\hline Leocym 2428 & $\begin{array}{l}\text { F: TTATATTTGTCCTCCCTTCTGATAAC } \\
\text { R: GATCAATGGCTGCTCTCGTG }\end{array}$ & (TTTG)7 & 59 & MF002381 & TMR & 2 & 1.4 \\
\hline Leocym 2433 & $\begin{array}{l}\text { F: AGGAGTTAGCAATACAAAGTGAGTG } \\
\text { R: TCGTGTTAATCCCTTCTTTCCC }\end{array}$ & (ATAC)14 & 59 & MF002382 & HEX & 2 & 1.4 \\
\hline Leocym 80 & $\begin{array}{l}\text { F: TTTAGCGGTACGCTTTTCAC } \\
\text { R: AAAAGCATGGCCTTTCCAGC }\end{array}$ & (TTGT)7 & 53 & MF002374 & FAM & 3 & 1.7 \\
\hline Leocym 2254 & $\begin{array}{l}\text { F: ATGCACCATTGAACTTGGTC } \\
\text { R: AACCCACGCCTTTTATGCAG }\end{array}$ & $(A A G A) 8$ & 53 & MF002380 & HEX & 3 & 1.2 \\
\hline Leocym 2833 & $\begin{array}{l}\text { F: ACTATGTCACCTCACAAGCC } \\
\text { R: CTGAAATGCACCCTACGGAAC }\end{array}$ & (CATA) 8 & 53 & MF002383 & HEX & 3 & 1.2 \\
\hline
\end{tabular}

Table 19 Results of primer application in three Leonia species. The primers were originally developed in Leonia cymosa. For each locus the following information is shown: locus name, number of alleles (A), size range of PCR products in base pairs $(b p)$, observed $\left(H_{0}\right)$ and expected $\left(H_{e}\right)$ heterozygosity with significance regarding deviation from Hardy-Weinberg equilibrium $(*<0.05 ; * *>0.01 ; * * *<0.001)$, and mean null allele frequency with $(*)$ indicating significance. The sample size for each species is given in parentheses behind the species name. The second line shows the geographic coordinates of each study site, where the samples came from.

\begin{tabular}{|c|c|c|c|c|c|c|c|}
\hline \multirow[b]{2}{*}{ Locus } & \multicolumn{6}{|c|}{$\begin{array}{l}\text { L. cymosa [EBQB] (664) } \\
4^{\circ} 21^{\prime} \mathrm{S}, 73^{\circ} 09^{\prime} \mathrm{W}\end{array}$} & \multirow[b]{2}{*}{$A_{N}$ Freq. } \\
\hline & $\mathbf{N}$ & A & $A_{E}$ & Size & $\mathbf{H}_{\mathbf{o}}$ & $\mathbf{H}_{\mathrm{e}}$ & \\
\hline Leo80 & 662 & 3 & 1.9 & $224-236$ & 0.423 & 0.469 & 0.052 \\
\hline Leo89 & 662 & 6 & 1.4 & $197-221$ & 0.307 & 0.307 & -0.006 \\
\hline Leo94 & 664 & 3 & 1.1 & $220-236$ & 0.117 & 0.119 & 0.005 \\
\hline Leo270 & 663 & 4 & 1.1 & $110-122$ & 0.116 & 0.125 & 0.040 \\
\hline Leo466 & 662 & 4 & 1.9 & $196-216$ & 0.488 & 0.484 & -0.008 \\
\hline Leo1842 & 662 & 4 & 2.1 & $224-244$ & 0.495 & 0.514 & 0.018 \\
\hline Leo2254 & 664 & 8 & 2.7 & $126-166$ & 0.660 & 0.632 & -0.024 \\
\hline Leo2428 & 665 & 4 & 1.5 & $100-112$ & 0.317 & $0.349 *$ & 0.053 \\
\hline Leo2433 & 661 & 14 & 7.3 & $216-268$ & 0.817 & 0.863 & 0.028 \\
\hline Leo2833 & 664 & 6 & 2.6 & $178-206$ & 0.562 & 0.609 & 0.041 \\
\hline Leo2853 & 663 & 7 & 1.4 & $158-190$ & 0.256 & 0.271 & 0.045 \\
\hline
\end{tabular}


Table 20 Compatibility of SSR primers with other populations and other species. Sampling site [], Number of samples tested (), compatible loci (+) and incompatible loci (-) are described for each species.

\begin{tabular}{lllllllll}
\hline & \multicolumn{3}{l}{$\begin{array}{l}\text { L. cymosa [EBQB] } \\
\text { Loci }\end{array}$} & \multicolumn{2}{l}{$\begin{array}{l}\text { L. cymosa [Nauta] } \\
\text { (66) }\end{array}$} & \multicolumn{2}{l}{$\begin{array}{l}\text { L. crassa } \\
\text { [Nauta] (3) }\end{array}$} & \multicolumn{3}{l}{$\begin{array}{l}\text { L. glycicarpa } \\
\text { [Nauta] (5) }\end{array}$} \\
\hline Amp. & Seq. & Amp. & Seq. & Amp & Seq. & Amp. & Seq. \\
\hline Leo80 & + & + & + & + & + & - & + & - \\
Le089 & + & + & + & + & + & - & + & - \\
Leo94 & + & + & + & + & + & - & + & - \\
Leo270 & + & + & + & + & + & - & + & - \\
Leo466 & + & + & + & + & + & + & + & + \\
Leo1842 & + & + & + & + & + & + & + & + \\
Leo2254 & + & + & + & + & + & + & + & + \\
Leo2428 & + & + & + & + & + & + & + & + \\
Leo2433 & + & + & + & + & + & - & + & - \\
Leo2833 & + & + & + & + & + & + & + & + \\
Leo2853 & + & + & + & + & + & - & + & -
\end{tabular}

\section{Validation of Whatman ${ }^{T M}$ FTA $^{T M}$ PlantSaver cards for microsatellite genotyping}

In plant genetic studies, DNA is conventionally extracted from samples of dried tissue, often leaf or cambium material. Here, we tested an alternative sample storage method using Whatman $^{\mathrm{TM}}$ FTA $^{\mathrm{TM}}$ PlantSaver Cards, and the DNA extracted from these compared it to DNA extracted from leaf material. Sampling and storage with Flindex Technology Associates (FTA) plant saver cards are obtained by soaking plant material on the internal membrane of the card, achieved by positioning plant material within the card and applying physical pressure with a hammer. Cards are then left to dry and stored in plastic bags.

For validating this method, DNA storage and extraction was done with two parallel approaches. First, we dried leaves using silica beads and extracted DNA using an ATMAB protocol (Dumolin et al. 1995). Second, we collected plant material by pressing leaves on the membranes of Whatman ${ }^{\mathrm{TM}} \mathrm{FTA}^{\mathrm{TM}}$ PlantSaver Cards. For DNA extraction, $2 \mathrm{~mm}$ diameter disks of the membranes were then washed, using FTA reagent buffer and TE Buffer (TRIS, EDTA), and dried at $56^{\circ} \mathrm{C}$ for 20 minutes. Washed disks were either directly added to the reaction mix for PCR amplification or alternatively, for obtaining eluted DNA, an extra step was added where we incubated the washed disks for $5 \mathrm{~min}$ in TE buffer at $95^{\circ} \mathrm{C}$, cooled them on ice, transferred the to a clean well and discarded the disk. Afterwards, DNA was then stored at $-20^{\circ} \mathrm{C}$. Eluting DNA from 
disks decreases problems experienced with static electricity of disks and handling contamination when distributing disks to each PCR well and provides a higher yield of PCR repetitions for an equal amount of treated surface membrane.

DNA concentrations obtained from the DNA collected in Whatman ${ }^{\mathrm{TM}}$ FTA $^{\mathrm{TM}}$ PlantSaver cards and from dried leaves varied according to the surface area of material used for extraction. When using $2 \times 2 \mathrm{~mm}$ diameter disks, we obtained a mean of $4.75 \mu \mathrm{g} / \mu \mathrm{l}$ of DNA. Higher concentrations of DNA were obtained when we increased diameter, or the number of disks extracted per reaction well. We achieved successful extraction for a maximum of $85 \mathrm{~mm} 2$ ( $3 \times 6 \mathrm{~mm} \theta$ disks) in one reaction well, obtaining a maximum of $64.83 \mathrm{ng} / \mu \mathrm{l}$ of DNA. Surface area per reaction well might be successfully increased. DNA concentration obtained from a determined area of membrane might vary also according to quality of embedment and quantity of linfa absorbed. However, independently of DNA concentration, genotyping results showed no difference between sample storage methods. DNA quality obtained from both storage methods can therefore be considered equivalent. We found FTA cards to be more advantageous in terms of transportation and technical handling.

\section{Conclusions}

The microsatellites markers where highly variable in the investigated population of $L$. cymosa. Variability was confirmed with one additional population, and most of the markers also amplified in L. glycicarpa and L. crassa. Thus, these markers can be applied for studying genetic diversity, spatial genetic structure and parentage in L. cymosa in north-eastern Peru.

The alternative method for DNA sampling and storage with Whatman ${ }^{\mathrm{TM}}$ FTA $^{\mathrm{TM}}$ PlantSaver cards proved valid for all Leonia species, confirming the result from previous studies on agricultural species. FTA cards can be therefore used for tropical species, resisting the weather conditions and long transportation times between field and laboratory. 


\section{GENERAL DISCUSSION}


Previous research has identified a relationship between plant spatial genetics and plant characteristics, habitat, pollination and seed dispersal mechanisms (Vekemans \& Hardy 2004; Hardy et al. 2006; Dick et al. 2008). However, little was known about how animal behavior can affect spatial genetic structure through behavior-specific seed dispersal patterns. At our study site, research had found tamarins as seed dispersers of a high number of seeds for long distances (Knogge 1998) which could determine shape and extent of seed shadows based on their daily decisions (Bialozyt et al. 2014a), and resulting movement patterns which can remain stable over long periods of time (Heymann et al. 2017), influencing spatial genetic structure of Parkia panurensis (Bialozyt et al. 2014b). Nonetheless, little was known about another species exclusively dispersed by tamarins, Leonia cymosa, a smaller tree with different spatial distribution and fruit characteristics, that might influence foraging behavior of tamarins differently.

The aim of this study was to link animal behavior and plant spatial genetics, and further understand seed dispersal by tamarins and its effects on the spatial genetics of L. cymosa. This study successfully achieves its initial aims and contributes to further understand the influence of animal seed dispersal in plant gene flow and spatial genetic structure. Additionally, this study provides methodological advances for overcoming field and species-specific limitations. In this section, each aim will be approached separately, with their respective study limitations and future directions. Finally, we will briefly discuss the contribution of this study in terms of methodological alternatives.

\section{Objective I: Understanding the effects of animal behavior on spatial genetic structure.}

In Chapter I we found a relationship between foraging behavior and movement range, with presence and strength of spatial genetic structure. Animal vectors with short feeding bouts or long movement range were related to weaker plant spatial genetic structure than animals with long feeding bouts, regurgitation behavior or short movement range. From our results, animals can weaken the formation of SGS by taking seeds away from fruit sources on high proportions and spreading them around the landscape. Furthermore, seed disperser behavior that leads to the accumulation of seeds showed highly variable strength of SGS, likely resulting from the variability between study systems of factors such as relatedness of trees visited by the animals 
before the accumulation of seeds, number of seeds accumulated, and post-dispersal processes. Chapter I provides evidence that vector behavior impacts SGS by shaping seed shadows through their seed dispersal patterns (Stiles 2000). Previous research shows these patterns can be highly consistent over time (Heymann et al. 2017), potentially increasing its effect on SGS. Anthropogenic disturbances that might modify vector behavior, such as deforestation, urbanization, or introduction of competing alien species, are likely to influence seed dispersal patterns and in turn SGS (McConkey \& O'Farrill 2015; Jones et al. 2017). Chapter I emphasizes the need for future studies on population genetics of animal-dispersed plants to include ecological, and behavioral observations of dispersal vectors, for understanding gene flow and spatial distribution of their genetic diversity. Furthermore, we saw considerable differences on SGS results between marker types, however the number of species analyzed with markers other than microsatellites was low. Nonetheless, ideally, to identify potential factors influencing differences in SGS, more species sharing characteristics on only certain aspects of their phenology or their dispersal systems should be analyzed and compared using the same methodological approaches.

The analysis in Chapter I was done on adult spatial genetic structure, therefore, the results show how animal behavior can have long-term effects on plant spatial genetic structure. SGS in seedlings is more likely to reflect the initial spatial template created by seed dispersal, before density-dependent mortality, making its analysis more appropriate if the aim is to relate seed dispersal patterns to SGS.

In Chapter III, I related pattern and extent of seed dispersal to SGS on different life stages. Our results show seed dispersers, depending on their feeding behavior and post-feeding movement patterns, can create aggregation of seeds or can scatter seeds sparsely around the area. These two seed dispersal patterns are not mutually exclusive and, in presence of densitydependent mortality, can affect SGS differently on life stages. When few maternal sources are visited before the accumulating behavior or when seeds are the result of spitting or regurgitation on feeding sites, these aggregations have the potential to promote formation of SGS in seedlings, which will not necessarily be maintained into adulthood.

Differences in SGS of adults from Leonia cymosa and Parkia panurensis and differences on their seed dispersal curves shed light on factors determining SGS maintenance into adulthood. 
The probability of SGS being maintained into the adult life stage, in presence of densitydependent mortality, is likely reduced if in addition to clumped seed deposition, there is a high proportion of seeds scattered to moderate or long-distance, like in L. cymosa. The analysis of maternal source within clumps of $L$. cymosa and $P$. panurensis could further determine whether the maintenance of SGS into adulthood is due to a high density of seeds dispersed far, rather than a low number of maternal sources within clumps. Nonetheless, several studies show similar seed dispersal patterns and distances, and their SGS results support the idea that moderate to long distance seed dispersal might influence whether SGS in seedlings, created by seed clumping, will be maintained into adulthood. For example, studies with clumping of seeds, beneath feeding sites and short distance seed dispersal, show plant species with presence of SGS in seedlings and in adults (Hardesty et al. 2005; Choo et al. 2012; Berens et al. 2014). Studies with clumping and long-distance seed dispersal show SGS in seedlings but weak SGS in adults (Schroeder et al. 2014). Finally, where seed dispersal systems created no clumping of seeds and moderate to longdistance seed dispersal, SGS was absent in all life stages (Fuchs \& Hamrick 2010). Further studies comparing SGS in life stages and considering seed dispersal patterns and distance would further elaborate on this hypothesis.

Finally, we found a consistent importance of pollination as a determinant of SGS strength in Chapter I. However, we only distinguish between animal and wind pollination, and a much finer categorization of pollination vectors could help understand its effect on SGS. Heuertz et al. (2003) attributes mathematically a lower effect of pollination on gene dispersal than seed dispersal, and, in seed dispersal studies, insect pollination is commonly expected to be short distance (Degen et al. 2001). Yet, foraging range of insects can be highly variable (Chifflet et al. 2011), for example, bees can forage up to $6 \mathrm{~km}$ from their nest (Pasquet et al. 2008) and the overall distance can largely vary depending on their size (Greenleaf et al. 2007). Vertebrate pollination can also depend on animal behavior and social organization, e.g. solitary and territorial humming birds can have a restricted number of foraging resources (Cotton 2008) while bat foraging behavior can be affected by inter-specific competition and spatio-temporal distribution of resources (Arias-Cóyotl et al. 2006). Given the strong influence of pollination on spatial genetic structure at coarser scales and the fine-differences on foraging range between 
animal pollinators, future research should investigate how pollination by different animals can influence spatial genetic structure and inter-population gene-flow.

\section{Objective II: Closing the loop on seed dispersal by tamarins of Leonia cymosa.}

Seed dispersal patterns are highly dependent on feeding behavior and movement range (Russo et al. 2006). Reinehr (2010) showed feeding of Leonia cymosa by tamarins to be exhaustive, depleting the small fruit crops throughout the fruiting season. However, the same study also estimated only $60 \%$ of seeds were swallowed and dispersed, while the remaining $40 \%$ of seeds fell beneath feeding sites. Furthermore, Culot (2009) showed tamarins defecate seeds in low density throughout the day in a scattered manner, but a subsequent study, Culot (2011), estimated that during the rainy season (L. cymosa's fruiting period), $20 \%$ of seeds defecated by these tamarins are accumulated under resting sites. Our results in this study complements these previous findings on seed dispersal by tamarins. Chapter II shows moderate to long mean seed dispersal distance of L. cymosa, and a seed dispersal curve with a bell shape indicating a low number of seeds dispersed near fruiting sources. Chapter III shows high spatial genetic structure of seedlings, indicating clumped seeds are likely from the same fruiting trees or at least related fruiting trees. However, Chapter IV shows, through parentage analysis of a clumped seeds in the in-between home range area, seeds within clumps may also come from different parent pairs. Therefore, the results from this thesis give evidence of tamarins likely having three types of seed deposition pattern:1) clumps of half-siblings beneath fruiting trees, likely proportional to the amount of fruits produced by the fruiting tree, 2) clumps of possibly unrelated seeds beneath resting sites 3) randomly scattered dispersal throughout the home range area. Furthermore, recognition of fruit source from maternal DNA on seed coats in Chapter IV shows co-dispersion is likely, but limited, given the small number of seeds per fruit in L. cymosa. Further research on genetic relatedness of seeds clumped beneath feeding and resting sites, using uniparentally inherited markers or analysis of SGS of seed aggregations, can shed light on the number of maternal sources within aggregations. For example, SGS analysis solely of seeds dispersed beneath sleeping sites shows white-bellied spider monkeys aggregate seeds only from the few trees they feed on before going to sleep at their sleeping sites (Karubian et al. 2015).

Results from Chapter IV show, through parentage analysis, that seed dispersal is strongly correlated with limitations on the tamarin's movement patterns dictated by their social 
organization. Seed dispersal across home ranges is limited, showing home ranges of tamarins creates a barrier for gene flow through seed dispersal. Similarly, territorial behavior restricts movement patterns of acorn woodpeckers to a few seed sources, reducing the number of maternal sources per cache and shortening its dispersal distance (Scofield et al., 2010). This behavior can potentially increase spatial genetic structure within these exclusive areas, increasing biparental inbreeding and reducing genetic diversity within home range areas. In contrast, results in Chapter IV also show seedlings growing in-between home range areas have parent pairs coming from the two adjacent home range areas. This gives evidence of how social organization of seed dispersers can create an edge effect on the periphery of their home ranges. If tamarin groups have a higher rate of encounter on the periphery of the home ranges than within the exclusively used area, maternal sources within these areas will increase and so will local genetic diversity. Further research could shed light on whether the periphery area can act as source of heterozygosity for the whole population, maintaining genetic diversity high even in view of restricted seed dispersal.

Finally, differences between seed dispersal curves of Leonia cymosa and Parkia panurensis seed dispersal patterns are likely not dependent on the identity of the seed disperser. L. cymosa and P. panurensis have the same seed dispersal vectors, nonetheless seed dispersal patterns of $P$. panurensis show a higher proportion of seeds is dispersed closer to its source. Differences in plant characteristics are likely at the origin of changes in the behavior of tamarins during and after feeding on each plant species. First, feeding bouts of $P$. panurensis are between 36-144 min. likely related to number of fruits produced (Feldmann, unpub.) while feeding bouts on L. cymosa last an average of 2 minutes. This reduces the probability of dispersing seeds near conspecifics. Second, number of seeds within fruits of $P$. panurensis are 16-23 while L. cymosa fruits have 1-7 seeds, this increases the number of co-dispersed seeds for $P$. panurensis, directly influencing the kernel density curve. Third, pulp consistency of $P$. panurensis is jelly-like, while $L$. cymosa has fibrous pulp. Jelly consistence is likely linked to faster gut passage rates, while fibrous pulp consistency has been linked to slower gut passages (Knogge 1998). Empirical data shows $P$. panurensis has faster gut passage rates than L. cymosa (Knogge 1999). Therefore, shorter feeding times likely due to smaller fruit crops, lower seed numbers per fruit and longer gut passage times 
likely due to pulp consistency, are all factors that may lead to a higher proportion of seeds being dispersed for longer distances in L. cymosa.

\section{Objective III: Tamarin seed dispersal patterns and its influence on plant spatial genetics of Leonia cymosa.}

In Chapter III we analyze spatial genetic structure on different life stages of Leonia cymosa. We compare our results to seed dispersal patterns by tamarins studied by Reinehr (2010) and estimates of seed dispersal distance and seed dispersal curves of L. cymosa analyzed in Chapter II. Results from Chapter III show strong spatial genetic structure in seedlings, likely created by clumped seed dispersal by tamarins either beneath feeding sites or beneath resting and sleeping sites. However, our results indicate absence of SGS in adults. The effects of clumped seed dispersal are likely counteracted by density-dependent mortality and long mean seed dispersal distances, like those described in Chapter II. Therefore, the inefficiency of tamarins in transporting most seeds produced away from fruit sources can be compensated by the long seed dispersal distance of those seeds effectively dispersed by tamarins and likely their higher survival rates than those dispersed in clumps (Schupp \& Jordano 2011).

Chapter IV evaluates seed dispersal across tamarin's exclusive home range areas and differences in the genetic composition of L. cymosa individuals growing under the dispersal of different tamarin groups. Seed dispersal across home range areas was low, only one offspring out of 17 had one parent on the opposite tamarin home range area (likely the paternal source, given the location of the other parent, on the periphery of the home range area where the offspring was growing). However, contrary to what expected, we found no significant differences in the genetic composition of L. cymosa individuals growing in areas under the dispersal of different tamarin groups. The strongest difference we found was in the juvenile stage, which could coincide with recruitment happening in the year where the two home range areas where further apart from each other. This opens the possibility for the following explanations 1) the small overlap between home range areas combined with the small spatio-temporal shifts of territories over time (Heymann et al. 2017) might maintain a genetically homogenous recruitment within each home range area. Previous research shows a shift of home range areas in space and time can happen in response to changes in resource abundance (Culot, 2010). 2) Pollination across home range areas is sufficient to maintain gene flow, despite restricted seed 
dispersal between home ranges. The limitations of our study arise from the limited knowledge on pollination of L. cymosa. Therefore, further research on focal tree observations during the flowering period of L. cymosa might shed light on pollinator identity while gene flow analysis using markers on uniparentally inherited organelles (Torroba-balmori et al.; Agrawal et al. 2013) could confirm whether pollination distances are long enough to maintain gene flow across home range areas, or whether the small overlap between these and their small shifts in space and time are enough to maintain gene flow across home range areas. Future research could help understand the role of pollination in the maintenance of gene-flow when seed dispersal is restricted, and sub populations are biologically or physically separated.

Seed dispersal restrictions due to biological constraints is analog to seed dispersal restrictions due to physical constraints caused by anthropogenic disturbance. The effect of fragmentation in spatial genetic structure has been widely studied (WANG et al. 2011; Collevatti et al. 2014). Lack of connectivity between fragments can increase genetic differentiation between these. Similarly, social organizations with active defense of resources and little overlap with contiguous groups could also potentially lead to genetic differentiation. However, similar to our study model, pollination likely counteracts gene flow reduction from blocked seed dispersal by fragmentation (Wang et al. 2012). If we understand how other factors can compensate gene flow barrier due to restricted seed dispersal, we can potentially understand how fragmentation caused by deforestation and urbanization could be mitigated (Rands et al. 2011) .

Overall, our results suggest that fine-scale spatial genetic structure over life stages are the result of the combination between seed dispersal patterns and seed dispersal extent. While seed dispersal barriers created by the exclusive use of resources can be likely counteracted by longrange pollination but might not be sufficient to mitigate formation of spatial genetic structure at local scales in particular of younger life stages. One would expect that if pollination of L. cymosa is able to maintain gene flow across subpopulations it should also be sufficient to disrupt the formation of spatial genetic structure. Instead, we see strong spatial genetic structure up to the juvenile stage. If pollination is in fact counteracting a gene flow barrier cause by seed dispersal, it could indicate the strong potential of seed dispersal in determining the formation of SGS. To understand the different contributions of seed dispersal and pollination on SGS, future research 
could analyze, in parallel, SGS of dispersal systems with different pollination and seed dispersal combinations.

\section{Alternative methodological approaches presented in this study}

This study not only contributes to expand the knowledge on seed dispersal and its effects on plant population genetics, it also contributes to the advancement of methodological techniques in the field of molecular ecology. Field work can bring difficulties in terms of sampling storage and availability of data for collection. Tropical weather is suboptimal for sample conservation, space capacity is limited for sample transportation, and ecological processes can be unpredictable hampering data collection. Consequently, to overcome these challenges, during this study we tested alternative methods for sample collection, and techniques for estimating seed dispersal when fruit productivity fails.

Chapter $\mathrm{V}$ shows how DNA soaking membranes such as the Whatman ${ }^{\mathrm{TM}}$ FTA $^{\mathrm{TM}}$ PlantSaver cards can be used to store DNA samples from plants, optimizing storage space, reducing the need for expensive leaf grinders and time needed for DNA extraction. These cards can also be used for animal samples as well. FTA ${ }^{\mathrm{TM}}$ PlantSaver cards had been used in agricultural studies but not in tropical ecology studies. Our tests indicate these cards successfully maintain optimal DNA samples in tropical weather and increase DNA extraction rate, reducing time needed from three days for 36 samples to 96 samples in a few hours. The only limitation for this method is the transfer of linfa from old and hard leaves to the membranes and the quantity of DNA extracted from the membranes. Collecting younger leaves facilitated and increased the amount of DNA absorbed by the membranes.

Chapter II describes a method for estimating seed dispersal distance based solely on animal movement data and retention times of seeds without the need for plant sampling collection. This method has the potential to be an alternative for zoologists and conservation biologists characterizing the importance of animals as seed dispersers. Long distance seed dispersers are extremely important for the colonization of new habitats in front of climate change and habitat degradation (Soons \& Ozinga 2005; Abedi-Lartey et al. 2016). It is important to recognize which animals has such crucial ecological role to increase their protection status and implement the knowledge in conservation policies. 


\section{References}

Abe H, Matsuki R, Ueno S, Nashimoto M, Hasegawa M (2006) Dispersal of Camellia japonica seeds by Apodemus speciosus revealed by maternity analysis of plants and behavioral observation of animal vectors. Ecological Research, 21, 732-740.

Abedi-Lartey M, Dechmann DKN, Wikelski M, Scharf AK, Fahr J (2016) Long-distance seed dispersal by straw-coloured fruit bats varies by season and landscape. Global Ecology and Conservation, 7, 1224.

Adams WT (1992) Gene dispersal within forest tree populations. New Forests, 6, 217-240.

Addisalem AB, Duminil J, Wouters D, Bongers F, Smulders MJM (2016) Fine-scale spatial genetic structure in the frankincense tree Boswellia papyrifera (Del.) Hochst. and implications for conservation. Tree Genetics and Genomes, 12.

Adugna A, Sweeney PM, Snow AA (2011) Optimization of a High Throughput, Cost Effective, and All-stage DNA Extraction Protocol for Sorghum (Sorghum bicolor). Journal of Agricultural Science and Technology, 5, 243-250.

Agrawal R, Agrawal N, Tandon R, Raina SN (2013) Chloroplast genes as genetic markers for inferring patterns of change, maternal ancestry and phylogenetic relationships among Eleusine species. AoB PLANTS, 6.

Aguoru CU, Omoigui LO, Olasan JO (2015) Comparative Optimized Protocols of DNA Extraction and Purification Using FTA PlantSaver Card and DNAzol Methods for Eggplant (Solanum Species) Studies in North Central Nigeria. OALib, 2, 1-5.

Arias-Cóyotl E, Stoner KE, Casas A (2006) Effectiveness of bats as pollinators of Stenocereus stellatus (Cactaceae) in wild, managed in situ, and cultivated populations in La Mixteca Baja, central Mexico. American journal of botany, 93, 1675-83.

Augspurger CK (1984) Seedling Survival of Tropical Tree Species: Interactions of Dispersal Distance, LightGaps, and Pathogens. Ecology, 65, 1705-1712.

Beghè D, Piotti A, Satovic Z, de la Rosa R, Belaj A (2016) Pollen-mediated gene flow and fine-scale spatial genetic structure in Olea europaea subsp. europaea var. sylvestris. Annals of botany, mcw246.

Benítez-Malvido J, González-Di Pierro AM, Lombera R, Guillén S, Estrada A (2014) Seed source, seed traits, and frugivore habits: Implications for dispersal quality of two sympatric primates. American Journal 
of Botany, 101, 970-978.

Berens DG, Braun C, González-Martínez SC et al. (2014) Fine-scale spatial genetic dynamics over the life cycle of the tropical tree Prunus africana. Heredity, 113, 401-7.

Bialozyt R, Flinkerbusch S, Niggemann M, Heymann EW (2014a) Predicting the seed shadows of a Neotropical tree species dispersed by primates using an agent-based model with internal decision making for movements. Ecological Modelling, 278, 74-84.

Bialozyt R, Luettmann K, Michalczyk IM et al. (2014b) Primate seed dispersal leaves spatial genetic imprint throughout subsequent life stages of the Neotropical tree Parkia panurensis. Trees, 28, 1569-1575.

Birdlife International (2001) Threatened birds of Asia: The BirdLife International Red Data Book (N. J. COLLAR, A V. ANDREEV, S CHAN, et al., Eds,). BirdLife International, Cambridge, UK.

Bittencourt JVM, Sebbenn a M (2007) Patterns of pollen and seed dispersal in a small fragmented population of a wind pollinated Araucaria angustifolia in southern Brazil. Heredity, 99, 580-591.

Bizoux JP, Daïnou K, Bourland N et al. (2009) Spatial genetic structure in Milicia excelsa (Moraceae) indicates extensive gene dispersal in a low-density wind-pollinated tropical tree. Molecular Ecology, $18,4398-4408$.

Bodare S, Ravikanth G, Ismail SA et al. (2017) Fine- and local- scale genetic structure of Dysoxylum malabaricum, a late-successional canopy tree species in disturbed forest patches in the Western Ghats, India. Conservation Genetics, 18, 1-15.

Bonnin I, Ronfort J, Wozniak F, Olivieri I (2001) Spatial effects and rare outcrossing events in Medicago truncatula (Fabaceae). Molecular Ecology, 10, 1371-1383.

Borman AM, Linton CJ, Miles S-J, Campbell CK, Johnson EM (2006) Ultra-rapid preparation of total genomic DNA from isolates of yeast and mould using Whatman FTA filter paper technology - a reusable DNA archiving system. Medical mycology: official publication of the International Society for Human and Animal Mycology, 44, 389-98.

Bufalo FS, Galetti M, Culot L (2016) Seed Dispersal by Primates and Implications for the Conservation of a Biodiversity Hotspot, the Atlantic Forest of South America. International Journal of Primatology, 37, 333-349.

Burczyk J, Adams WT, Birkes DS, Chybicki IJ (2006) Using genetic markers to directly estimate gene flow and reproductive success parameters in plants on the basis of naturally regenerated seedlings. 
Genetics, 173, 363-372.

Burgman M a, Williams MR (1995) Analysis of the spatial pattern of arthropod fauna of Jarrah (EucalyptusMarginata) foliage using a mantel correlogram. Australian Journal of Ecology, 20, 455-457.

Bürkner P-C brms: An R Package for Bayesian Multilevel Models using Stan. Journal of statistical software.

Buston PM, Fauvelot C, Wong MYL, Planes S (2009) Genetic relatedness in groups of the humbug damselfish Dascyllus aruanus: Small, similar-sized individuals may be close kin. Molecular Ecology, $18,4707-4715$.

Cain ML, Milligan BG, Strand AE (2000) Long-distance seed dispersal in plant populations. American Journal of Botany, 87, 1217-1227.

Carlo T a., Morales JM (2008) Inequalities in fruit-removal and seed dispersal: Consequences of bird behavior, neighbourhood density and landscape aggregation. Journal of Ecology, 96, 609-618.

Chapman C a, Russo SE (2002) Primate Seed Dispersal: Linking Behavioral Ecology with Forest Community Structure. Primates in Perspective, 523-534.

Charlesworth D (2003) Effects of inbreeding on the genetic diversity of populations. Philosophical Transactions of the Royal Society of London B: Biological Sciences, 358, 1051-1070.

Chauvet S, Feer F, Forget P-M (2004) Seed fate of two Sapotaceae species in a Guianan rain forest in the context of escape and satiation hypotheses. Journal of Tropical Ecology, 20, 1-9.

Chifflet R, Klein EK, Lavigne C et al. (2011) Spatial scale of insect-mediated pollen dispersal in oilseed rape in an open agricultural landscape. Journal of Applied Ecology, 48, 689-696.

Choo J, Juenger TE, Simpson BB (2012) Consequences of frugivore-mediated seed dispersal for the spatial and genetic structures of a neotropical palm. Molecular Ecology, 21, 1019-1031.

Chung MY, Chung MG (2004) Spatial genetic structure in populations of Quercus mongolica var. grosseserrata (Fagaceae) from southern Korea. Canadian Journal of Botany, 82, 1402-1408.

Chung MG, Chung JM, Chung MY, Epperson BK (2000a) Spatial distribution of allozyme polymorphisms following clonal and sexual reproduction in populations of Rhus javanica (Anacardiaceae). Heredity, 84, 178-185.

Chung MG, Chung MY, Oh GS, Epperson BK (2000b) Spatial genetic structure in a Neolitsea sericea population (Lauraceae). Heredity, 85, 490-497. 
Chung MY, Nason JD, Epperson BK, Chung MG (2003) Temporal aspects of the fine-scale genetic structure in a population of Cinnamomum insularimontanum (Lauraceae). Heredity, 90, 98-106.

Clark JS (1998) Why Trees Migrate So Fast: Confronting Theory with Dispersal Biology and the Paleorecord. The American Naturalist, 152, 204-224.

Cloutier D, Hardy OJ, Caron H et al. (2007) Low inbreeding and high pollen dispersal distances in populations of two Amazonian forest tree species. Biotropica, 39, 406-415.

Collevatti RG, Telles MPC, Lima JS, Gouveia FO, Soares TN (2014) Contrasting spatial genetic structure in Annona crassiflora populations from fragmented and pristine savannas. Plant Systematics and Evolution, 300, 1719-1727.

Connell J (1971) On the role of natural enemies in preventing competitive exclusion in some marine animals and in rain forest trees. In: Dynamics of populations (eds Den Boer P, Gradwell G), pp. 298312. Centre for Agricultural Publishing and Documentation, Wageningen, Netherlands.

Corlett RT (1998) Frugivory and seed dispersal by vertebrates in the Oriental (Indomalayan) Region. Biological reviews of the Cambridge Philosophical Society, 73, 413-48.

Corlett RT (2017) Frugivory and seed dispersal by vertebrates in tropical and subtropical Asia: An update. Global Ecology and Conservation, 11, 1-22.

Corlett RT, Lucas PW (1990) Alternative seed-handling strategies in primates: seed-spitting by long-tailed macaques (Macaca fascicularis). Oecologia, 82, 166-171.

Côrtes MC, Uriarte M (2013) Integrating frugivory and animal movement: a review of the evidence and implications for scaling seed dispersal. Biological Reviews, 88, 255-272.

Cotton PA (2008) Temporal partitioning of a floral resource by territorial hummingbirds. Ibis, 140, 647653.

Cousens RD, Hill J, French K, Bishop ID (2010) Towards better prediction of seed dispersal by animals. Functional Ecology, 24, 1163-1170.

Crawford TJ (1984) The estimation of neighbourhood parameters for plant populations. Heredity, 52, 273283.

Cruse-Sanders JM, Hamrick JL (2004) Spatial and Genetic Structure within Populations of Wild American Ginseng (Panax quinquefolius L., Araliaceae). Journal of Heredity, 95, 309-321. 
Cuevas E, Medina E (1986) Nutrient dynamics within amazonian forest ecosystems. Oecologia, 68, 466472.

Culot L (2009) Primary seed dispersal by two sympatric species of tamarins, Saguinus fuscicollis and Saguinus mystax, and post-dispersal seed fate. Psychologie Schweizerische Zeitschrift Für Psychologie Und Ihre Andwendungen.

Culot L, Lazo FJJM, Huynen MC, Poncin P, Heymann EW (2010) Seasonal variation in seed dispersal by tamarins alters seed rain in a secondary rain forest. International Journal of Primatology, 31, 553569.

Darley-Hill S, Johnson WC (1981) Acorn dispersal by the blue jay (Cyanocitta cristata). Oecologia, 50, 231232.

Davidar P, Morton ES (1986) The relationship between fruit crop sizes and fruit removal rates by birds. Ecology, 67, 262-265.

Degen B, Caron H, Bandou E et al. (2001) Fine-scale spatial genetic structure of eight tropical tree species as analysed by RAPDs. Heredity, $87,497-507$.

Dev SA, Kjellberg F, Hossaert-McKey M, Borges RM (2011) Fine-Scale Population Genetic Structure of Two Dioecious Indian Keystone Species, Ficus hispida and Ficus exasperata (Moraceae). Biotropica, 43, 309-316.

Dewey S, Heywood J (1988) Spatial genetic structure in a population of Psychotria nervosa. Evolution, 42, 834-838.

Dick CW, Hardy OJ, Jones FA, Petit RJ (2008) Spatial scales of pollen and seed-mediated gene flow in Tropical rain forest trees. Tropical Plant Biology, 1, 20-33.

Dodd RS, Mayer W, Nettel A, Afzal-Rafii Z (2013) Clonal growth and fine-scale genetic structure in tanoak (Notholithocarpus densiflorus: Fagaceae). Journal of Heredity, 104, 105-114.

Dominy NJ, Duncan BW (2005) Seed-spitting primates and the conservation and dispersion of largeseeded trees. International Journal of Primatology, 26, 631-649.

Donatti Cl, Guimarães PR, Galetti M et al. (2011) Analysis of a hyper-diverse seed dispersal network: Modularity and underlying mechanisms. Ecology Letters, 14, 773-781.

Dow BD, Ashley M V (1996) Microsatellite analysis of seed dispersal and parentage of sapling in bur oak, Quercus macrocarpa. Molecular Ecology, 5, 615-627. 
Drescher A, Graner A (2002) PCR-genotyping of barley seedlings using DNA samples from tissue prints. Plant Breeding, 121, 228-231.

Duminil J, Daïnou K, Kaviriri DK et al. (2016) Relationships between population density, fine-scale genetic structure, mating system and pollen dispersal in a timber tree from African rainforests. Heredity, 116, 295-303.

Dumolin S, Demesure B, Petit RJ (1995) Inheritance of chloroplast and mitochondrial genomes in pedunculate oak investigated with an efficient PCR method. Theoretical and Applied Genetics, 91, $1253-1256$.

Duque A, Cavelier J (2003) Strategies of tree occupation at a local scale in terra firme forest in the Colombian Amazon.pdf. Biotropica, 35, 20-27.

Dutech C, Seiter J, Petronelli P, Joly HI, Jarne P (2002) Evidence of low gene flow in a neotropical clustered tree species in two rainforest stands of French Guiana. Molecular Ecology, 11, 725-738.

Ellstrand NC, Elam DR (1993) Population size: Implications for plant conservation. Annual Review of Ecology and Systematics, 24, 217-242.

Epperson BK (2003) Geographical genetics. Princeton University Press.

Escudero A, M. IJ, Torres ME (2003) Spatial analysis of genetic diversity as a tool for plant conservation. Biological Conservation, 113, 351-365.

Estrada A, Coates-Estrada R (1984) Fruit Eating and Seed Dispersal by Howling Monkeys (Alouatta Palliata) in the Tropical Rain-Forest of Los-Tuxtlas, Mexico. American Journal of Primatology, 6, 77-91.

Ferrari SF, Lopes Ferrari MA (1989) A re-evaluation of the social organisation of the Callitrichidae, with reference to the ecological differences between genera. Folia primatologica; international journal of primatology, 52, 132-47.

Fleming TH, Heithaus ER (1981) Frugivorous Bats, Seed Shadows, and the Structure of Tropical Forests. Biotropica, 13, 45.

Fleming TH, Williams CF (1990) Phenology, seed dispersal, and recruitment in Cecropia peltata (Moraceae) in Costa Rican tropical dry forest. Journal of Tropical Ecology, 6, 163.

Fuchs EJ, Hamrick JL (2010) Spatial genetic structure within size classes of the endangered tropical tree Guaiacum sanctum (Zygophyllaceae). American Journal of Botany, 97, 1200-1207. 
Fuzessy LF, Janson CH, Silveira FAO (2017) How far do Neotropical primates disperse seeds? American Journal of Primatology, 79, 1-6.

Gallegos SC, Hensen I, Schleuning M (2014) Secondary dispersal by ants promotes forest regeneration after deforestation. Journal of Ecology, 102, 659-666.

Ganzhorn SM, Thomas WW, Gaiotto FA, Lewis JD (2015) Spatial genetic structure of Manilkara maxima (Sapotaceae), a tree species from the Brazilian Atlantic forest. Journal of Tropical Ecology, 31, 437447.

Garber PA (1986) The ecology of seed dispersal in two species of Callitrichid primates (Saguinus mystax and Saguinus fuscicollis). American Journal of Primatology, 170, 155-170.

Garber P a, Lambert JE (1998) Primates as seed dispersers: ecological processes and directions for future research. American journal of primatology, 45, 3-8.

Garber PA, Ón FE, Moya L, Pruetz JD (1993) Demographic and reproductive patterns in moustached tamarin monkeys (Saguinus mystax): Implications for reconstructing platyrrhine mating systems. American Journal of Primatology, 29, 235-254.

García C, Jordano P, Arroyo JM, Godoy JA (2009) Maternal genetic correlations in the seed rain: Effects of frugivore activity in heterogeneous landscapes. Journal of Ecology, 97, 1424-1435.

Godoy JA, Jordano P (2001) Seed dispersal by animals: Exact identification of source trees with endocarp DNA microsatellites. Molecular Ecology, 10, 2275-2283.

Gómez JM, Puerta-Piñero C, Schupp EW (2008) Effectiveness of rodents as local seed dispersers of Holm oaks. Oecologia, 155, 529-537.

González-Martínez SC, Burczyk J, Nathan R et al. (2006) Effective gene dispersal and female reproductive success in Mediterranean maritime pine (Pinus pinaster Aiton). Molecular Ecology, 15, 4577-4588.

González-Varo JP, Arroyo JM, Jordano P (2014) Who dispersed the seeds? The use of DNA barcoding in frugivory and seed dispersal studies. Methods in Ecology and Evolution, 5, 806-814.

Greenleaf SS, Williams NM, Winfree R, Kremen C (2007) Bee foraging ranges and their relationship to body size. Oecologia, 153, 589-596.

Grivet D, Smouse PE, Sork VL (2005) A novel approach to an old problem: tracking dispersed seeds. Molecular Ecology, 14, 3585-3595. 
Gross-Camp ND, Kaplin BA (2011) Differential seed handling by two African primates affects seed fate and establishment of large-seeded trees. Acta Oecologica, 37, 578-586.

Gueidan C, Aptroot A, Cáceres ME da S, Binh NQ (2016) Molecular phylogeny of the tropical lichen family Pyrenulaceae: contribution from dried herbarium specimens and FTA card samples. Mycological Progress, $15,7$.

Guillot G, Leblois R, Coulon A, Frantz AC (2009) Statistical methods in spatial genetics. Molecular Ecology, $18,4734-4756$.

Hadfield JD, Richardson DS, Burke T (2006) Towards unbiased parentage assignment: combining genetic, behavioral and spatial data in a Bayesian framework. Molecular Ecology, 15, 3715-3730.

Hallock YF, Sowder RC, Pannell LK et al. (2000) Cycloviolins A-D, anti-HIV macrocyclic peptides from Leonia cymosa. Journal of Organic Chemistry, 65, 124-128.

Hämäläinen A, Broadley K, Droghini A et al. (2017) The ecological significance of secondary seed dispersal by carnivores. Ecosphere, 8.

Hamilton MBM (1999) Tropical tree gene flow and seed dispersal. Nature, 401, 8-9.

Hamrick JL, Godt MJW (1996) Effects of life history traits on genetic diversity in plant species. Philosophical Transactions of The Royal Society of London B, 351, 1291-1298.

Hamrick JL, Loveless MD (1986) The influence of seed dispersal mechanisms on the genetic structure of plant populations. In: Frugivores and seed dispersal Tasks for vegetation science. (eds Estrada A, Fleming TH), pp. 211-223. Dr. W. Junk Publishers, Dordrecht, Netherlands.

Hamrick JL, Murawski D a, Nason JD (1993) The influence of seed dispersal mechanisms on the genetic structure of tropical tree populations. Vegetatio, 107-108, 281-297.

Hamrick JL, Trapnell DW (2011) Using population genetic analyses to understand seed dispersal patterns. Acta Oecologica, 37, 641-649.

Hanson T, Brunsfeld S, Finegan B, Waits L (2007) Conventional and genetic measures of seed dispersal for Dipteryx panamensis (Fabaceae) in continuous and fragmented Costa Rican rain forest. Journal of Tropical Ecology, 23, 635-642.

Hardesty BD, Dick CW, Kremer A, Hubbell S, Bermingham E (2005) Spatial genetic structure of Simarouba amara Aubl. (Simaroubaceae), a dioecious, animal-dispersed Neotropical tree, on Barro Colorado Island, Panama. Heredity, 95, 290-297. 
Hardy OJ, Maggia L, Bandou E et al. (2006) Fine-scale genetic structure and gene dispersal inferences in 10 Neotropical tree species. Molecular Ecology, 15, 559-571.

Hardy OJ, Vekemans X (2002) SPAGeDi 1.4.

He T, Lamont BB, Krauss SL, Enright NJ (2010) Genetic connectivity and inter-population seed dispersal of Banksia hookeriana at the landscape scale. Annals of botany, 106, 457-66.

Heer K, Kalko EK V., Albrecht L et al. (2015) Spatial scales of genetic structure in free-standing and strangler figs (Ficus, Moraceae) inhabiting Neotropical forests. Plos One, 10, e0133581.

Heithaus ER, Fleming TH, Opler PA (1975) Foraging patterns and resource utilization in seven species of bats in a seasonal Tropical forest. Ecology, 56, 841-854.

Herrera CM, Jordano P (1981) Prunus mahaleb and Birds: The high-efficiency seed dispersal system of a temperate fruiting tree. Ecological monographs, 51, 203-218.

Herrera JM, Morales JM, García D (2011) Differential effects of fruit availability and habitat cover for frugivore-mediated seed dispersal in a heterogeneous landscape. Journal of Ecology, 99, 1100-1107.

Hershkovitz P (1977) Living New World monkeys (Platyrrhini): with an introduction to Primates. University of Chicago Press.

Heuertz M, Vekemans X, Hausman JF, Palada M, Hardy OJ (2003) Estimating seed vs. pollen dispersal from spatial genetic structure in the common ash. Molecular Ecology, 12, 2483-2495.

Heymann EW (1990) Interspecific relations in a mixed-species troop of moustached tamarins, Saguinus mystax, and saddle-back tamarins, Saguinus fuscicollis (Platyrrhini: Callitrichidae), at the Río Blanco, Peruvian Amazonia. American Journal of Primatology, 21, 115-127.

Heymann EW, Buchanan-Smith HM (2000) The behavioral ecology of mixed-species troops of callitrichine primates. Biological reviews of the Cambridge Philosophical Society, 75, 169-90.

Heymann EW, Culot L, Knogge C et al. (2017) Long-term consistency in spatial patterns of primate seed dispersal. Ecology and Evolution, 7, 1435-1441.

Heymann EW, Hartmann G (1991) Geophagy in moustached tamarins, Saguinus mystax (platyrrhini: Callitrichidae), at the Rio Blanco, Peruvian Amazonia. Primates, 32, 533-537.

Heymann EW, Lüttmann K, Michalczyk IM et al. (2012) DNA fingerprinting validates seed dispersal curves from observational studies in the neotropical legume Parkia (MA Smith, Ed,). PLoS ONE, 7, 1-7. 
Hirsch BT, Kays R, Jansen PA (2012) A telemetric thread tag for tracking seed dispersal by scatter-hoarding rodents. Plant Ecology, 213, 933-943.

Holbrook KM, Smith TB (2000) Seed Dispersal and Movement Patterns in Two Species of Ceratogymna Hornbills in a West African Tropical Lowland Forest. Oecologia, 125, 249-257.

Howe HF (1989) Scatter- and clump-dispersal and seedling demography: hypothesis and implications. Oecologia, 79, 417-426.

Howe HF (1993) Specialized and generalized dispersal systems: where does "the paradigm" stand? In: Frugivory and seed dispersal: ecological and evolutionary aspects, pp. 3-13. Springer Netherlands, Dordrecht.

Howe HF, Miriti MN (2004) When seed dispersal matters. BioScience, 54, 651.

Howe HF, Smallwood J (1982a) Ecology of seed dispersal. Annual Review of Ecology, Evolution, and Systematics, 13, 201-228.

Howe HF, Smallwood J (1982b) Ecology of Seed Dispersal. Annual Review of Ecology and Systematics, 13, 201-228.

Ibanes B, Sebbenn AM, Azevedo VCR et al. (2015) Genetic diversity and spatial genetic structure in populations of Orbignya phalerata Mart. under different exploitation intensities in the Brazilian savanna. Silvae Genetica, 64, 201-211.

Isagi Y, Kanazashi T, Suzuki W, Tanaka H, Abe T (2004) Highly variable pollination patterns in Magnolia obovata revealed by microsatellite paternity analysis. Int. J. Plant Sci., 165, 1047-1053.

Jankowska-Wroblewska S, Warmbier J, Burczyk J (2016) Spatial genetic structure within populations of Sorbus torminalis (L.) Crantz: comparative analysis of the self-incompatibility locus and nuclear microsatellites. Acta Biologica Cracoviensia s. Botanica, 58, 7-17.

Jansen PA, Hirsch BT, Emsens W-J et al. (2012) Thieving rodents as substitute dispersers of megafaunal seeds. Proceedings of the National Academy of Sciences of the United States of America, 109, 12610-5.

Janzen DH (1970) Herbivores and the number of tree Species in Tropical forests. The American Naturalist, $104,501-528$.

Janzen DH (1971) Euglossine Bees as Long-Distance Pollinators of Tropical Plants. Science, 171, 203-205. 
Jin Y, He T, Lu BR (2003) Fine scale genetic structure in a wild soybean (Glycine soja) population and the implications for conservation. New Phytologist, 159, 513-519.

Jones LR, Duke-Sylvester SM, Leberg PL, Johnson DM (2017) Closing the gaps for animal seed dispersal: Separating the effects of habitat loss on dispersal distances and seed aggregation. Ecology and Evolution.

Jordano P (2007) Frugivores, seeds and genes: Analysing the key elements of seed shadows. In: Seed dispersal: Theory and its application in a changing world (eds Dennis AJ, Schupp EW, Green RJ, Westcott DA), pp. 305-321. CAB International.

Jordano P, García C, Godoy J a, García-Castaño JL (2007) Differential contribution of frugivores to complex seed dispersal patterns. Proceedings of the National Academy of Sciences of the United States of America, 104, 3278-3282.

Jordano P, Godoy JA (2002) Frugivore-generated seed shadows: a landscape view of demographic and genetic effects. In: Seed dispersal and frugivory: Ecology, evolution and conservation, pp. 305-321.

Jordano P, Herrera CM (1995) Shuffling the offspring: Uncoupling and spatial discordance of multple stages in vertebrate seed dispersal. Ecoscience, 2, 230-237.

Julliot C (1997) Impact of seed dispersal by red howler monkeys Alouatta Seniculus on the seedling population in the understorey of Tropical Rain Forest. The Journal of Ecology, 85, 431.

Jump AS, Rico L, Coll M, Peñuelas J (2012) Wide variation in spatial genetic structure between natural populations of the European beech (Fagus sylvatica) and its implications for SGS comparability. Heredity, 108, 633-9.

Kalinowski ST, Waples RS (2002) Relationship of Effective to Census Size in Fluctuating Populations. Conservation Biology, 16, 129-136.

Kalisz S, Nason JD, Hanzawa FM, Tonsor SJ (2001) Spatial population genetic structure in Trillium grandiflorum: the roles of dispersal, mating, history, and selection. Evolution; international journal of organic evolution, 55, 1560-1568.

Karubian J, Durães R (2009) Effects of seed disperser social behavior on patterns of seed movement and deposition. Oecologia Australis, 13, 45-57.

Karubian J, Durães R, Storey JL, Smith TB (2012) Mating behavior drives seed dispersal by the Long-wattled umbrellabird Cephalopterus penduliger. Biotropica, 44, 689-698. 
Karubian J, Ottewell K, Link A, Di Fiore A (2015) Genetic consequences of seed dispersal to sleeping trees by white-bellied spider monkeys. Acta Oecologica, 68, 50-58.

Karubian J, Sork VL, Roorda T, Duraes R, Smith TB (2010) Destination-based seed dispersal homogenizes genetic structure of a tropical palm. Molecular Ecology, 19, 1745-1753.

Kitamura S, Suzuki S, Yumoto T, Wohandee P (2009) Evidence of the Consumption of Fallen Figs by Oriental Pied Hornbill Anthracoceros albirostris on the Ground in Khao Yai National Park, Thailand Ornithological Science, 8, 75-79.

Knogge C (1998) Tier-Pflanze-Interaktionen im Amazonas-Regenwald: Samenausbreitung durch die sympatrischen Tamarinarten Saguinus mystax und Saguinus fuscicollis ( Callitrichinae, Primates ).

Knogge C, Heymann EW (2003) Seed dispersal by sympatric tamarins, Saguinus mystax and Saguinus fuscicollis: Diversity and characteristics of plant species. Folia Primatologica, 74, 33-47.

Knogge C, Tirado Herrera ER, Heymann EW (2003) Effects of Passage Through Tamarin Guts on the Germination Potential of Dispersed Seeds. International Journal of Primatology, 24, 1121-1128.

Koike S (1994) Relationships Between the Fruiting Phenology of Prunus jamasakura and Timing of Visits by Mammals Estimation of the Feeding Period Using Camera Traps. Cdn.Intechopen.Com, 265, 1170.

Krauss SL, He T, Barrett LG et al. (2009) Contrasting impacts of pollen and seed dispersal on spatial genetic structure in the bird-pollinated Banksia hookeriana. Heredity, 102, 274-285.

Kubisch P (2009) Variabilität in der Nahrungsökologie benachbarter Gruppen von Saguinus fuscicollis (Callitrichidae, Primates). University of Göttingen.

Kupsch D (2009) Comparison in prey search and capture success of Saguinus fuscicollis between primary and secondary forest. University of Göttingen.

Kyndt T, Assogbadjo AE, Hardy OJ et al. (2009) Spatial genetic structuring of baobab (Adansonia digitata, Malvaceae) in the traditional agroforestry systems of west africa. American Journal of Botany, 96, 950-957.

Lambert F (1989) Fig-eating by birds in a Malaysian lowland rain forest. Journal of Tropical Ecology, 5, 401-412.

Lankau RA (2009) Genetic variation promotes long-term coexistence of Brassica nigra and its competitors. The American Naturalist, 174, 40-53. 
Laundré JW, Hernandez L, Ripple WJ (2010) The Landscape of Fear: Ecological Implications of Being Afraid. The Open Ecology Journal, 3, 1-7.

Lavelle P (Patrick), Spain A V. (2001) Soil ecology. Springer Science \& Business Media.

Lemos RPM, D'Oliveira CB, Stefenon VM (2015) Genetic structure and internal gene flow in populations of Schinus molle (Anacardiaceae) in the Brazilian Pampa. Tree Genetics \& Genomes, 11, 75.

Levey DJ, Sargent S (2000) A simple method for tracking vertebrate-dispersed seeds. Ecology, 81, 267274.

Levey DJ, Tewksbury JJ, Bolker BM (2008) Modelling long-distance seed dispersal in heterogeneous landscapes. Journal of Ecology, 96, 599-608.

Levin DA, Kerster HW (1974) Gene Flow in Seed Plants. In: Evolutionary Biology, pp. 139-220. Springer US, Boston, MA.

Lichti NI, Steele MA, Swihart RK (2017) Seed fate and decision-making processes in scatter-hoarding rodents. Biological Reviews, 92, 474-504.

Lind-Riehl J, Gailing O (2015) Fine-scale spatial genetic structure of two red oak species, Quercus rubra and Quercus ellipsoidalis. Plant Systematics and Evolution, 301, 1601-1612.

Linhart YB (1973) Ecological and Behavioral Determinants of Pollen Dispersal in Hummingbird- Pollinated Heliconia. The American Naturalist, 107, 511-523.

Lledo-Ferrer Y, Peláez F, Heymann EW (2011) The Equivocal Relationship Between Territoriality and Scent Marking in Wild Saddleback Tamarins (Saguinus fuscicollis). International Journal of Primatology, 32, 974-991.

Loiselle BA, Sork VL, Nason J, Graham C (1995) Spatial genetic structure of a tropical understory shrub, Psychotria officinalis (Rubiaceae). American Journal of Botany, 82, 1420-1425.

Löttker P, Huck M, Heymann EW (2004) Demographic parameters and events in wild moustached Tamarins (Saguinus mystax). American Journal of Primatology, 64, 425-449.

Lovette IJ, Fitzpatrick JW (2016) Cornell Lab of Ornithology's handbook of bird biology. John Wiley \& Sons. Lowe A (Plant ecologist), Harris S, Ashton P (2004) Ecological genetics: design, analysis, and application. Blackwell Pub.

Macbride F (1941) In Flora of Peru, Field Museum. Botanical Series, 13, 10-13. 
Matauschek C, Roos C, Heymann EW (2011) Mitochondrial phylogeny of Tamarins (Saguinus, Hoffmannsegg 1807) with taxonomic and biogeographic implications for the S. nigricollis species group. American Journal of Physical Anthropology, 144, 564-574.

Matsuda I, Higashi S, Otani Y et al. (2013) A short note on seed dispersal by colobines: the case of the proboscis monkey. Integrative Zoology, 8, 395-399.

McConkey KR, Brockelman WY, Saralamba C, Nathalang A (2015) Effectiveness of primate seed dispersers for an oversized fruit, Garcinia benthamii. Ecology, 96, 2737-2747.

McConkey KR, Chivers DJ (2007) Influence of gibbon ranging patterns on seed dispersal distance and deposition site in a Bornean forest. Journal of Tropical Ecology, 23, 269-275.

McConkey KR, O'Farrill G (2015) Cryptic function loss in animal populations. Trends in Ecology and Evolution, 30, 182-189.

McConkey KR, O'Farrill G (2016) Loss of seed dispersal before the loss of seed dispersers. Biological Conservation, 201, 38-49.

Meeus S, Honnay O, Jacquemyn H (2013) Differences in fine-scale spatial genetic structure across the distribution range of the distylous forest herb Pulmonaria officinalis (Boraginaceae). BMC Genetics, 14, 1-19.

Melo Júnior AF, Carvalho D, Brandão MM et al. (2015) Spatial genetic structure of Cavanillesia arborea K. Schum. (Malvaceae) in seasonally dry Tropical forest: Implications for conservation. Biochemical Systematics and Ecology, 58, 114-119.

de Mendonça BAF, Fernandes Filho El, Schaefer CEGR, de Mendonça JGF, Vasconcelos BNF (2017) Soilvegetation relationships and community structure in a "terra-firme"-whitesand vegetation gradient in Viruá National Park, Northern Amazon, Brazil. Anais da Academia Brasileira de Ciencias, 89, 12691293.

Milton K (1981) Food choice and digestive strategies of two sympatric primate species. The American Naturalist, 117, 496-505.

Milton K (1984) The Role of Food-Processing Factors in Primate Food Choice. Adaptations for Foraging in Nonhuman Primates, 249-279.

Miyaki M, Kikuzawa K (1988) Dispersal of Quercus mongolica acorns in a broadleaved deciduos forest 2. Scatterhoarding by Mice. Forest Ecology and Management, 25, 9-16. 
Mizuki I, Ishida K, Tani N, Tsumura Y (2010) Fine-scale spatial structure of genets and sexes in the dioecious plant Dioscorea japonica, which disperses by both bulbils and seeds. Evolutionary Ecology, 24, 13991415.

Mizuki I, Takahashi A (2009) Secondary dispersal of Dioscorea japonica (Dioscoreaceae) bulbils by rodents. Journal of Forest Research, 14, 95-100.

Montagnini F, Muñiz-Miret N (1999) Vegetation and soils of tidal floodplains of the amazon estuary: a comparison of Várzea and Terra firme forests in Pará, Brazil. Journal of Tropical Forest Science, 11, 420-437.

Moore JE, McEuen A, Swihart RK, Contreras TA, Steele M a. (2007) Scatter-Hoarding Rodents in Deciduous Forests., 88, 2529-2540.

Morales JM, García D, Martínez D, Rodriguez-Pérez J, Herrera JM (2013) Frugivore Behavioral Details Matter for Seed Dispersal: A Multi-Species Model for Cantabrian Thrushes and Trees. PLoS ONE, 8.

Mukuma C (2016) Morphological and Molecular Identification and Characterization of Dry Bean Fungal Root Rot Pathogens in Zambia.

Muñoz Lazo FJ, Culot L, Huynen M-CC, Heymann EW (2011) Effect of Resting Patterns of Tamarins (Saguinus fuscicollis and Saguinus mystax) on the Spatial Distribution of Seeds and Seedling Recruitment. International Journal of Primatology, 32, 223-237.

Murray DR (1986) Seed dispersal. Academic Press.

Nakagawa M (2010) Fine-scale genetic structure within plots of Polygala reinii (Polygalaceae) having an ant-dispersal seed. Journal of Plant Research, 123, 355-362.

Nathan R, Horn H, SChave J, Levin S a. (2001) Mechanistic models for tree seed dispersal by wind in dense forests and open landscapes. Seed Dispersal and frugivory-Ecologie, Evolution, Conservation, 69-83.

Nature (2010) How Does Inheritance Operate at the Level of Whole Populations? In: A Brief History of Genetics: Defining Experiments in Genetics. NPG Education, Cambridge, MA.

Nazareno AG, Alzate-Marin AL, Pereira RAS (2013) Dioecy, more than monoecy, affects plant spatial genetic structure: The case study of Ficus. Ecology and Evolution, 3, 3495-3508.

Ndunguru J, Taylor NJ, Yadav J et al. (2005) Application of FTA technology for sampling, recovery and molecular characterization of viral pathogens and virus-derived transgenes from plant tissues. Virology journal, 2, 45. 
Ness JH, Bronstein A, Andersen N, Holland JN (2004) Ant body size predicts dispersal distance of antadapted seeds: Implications of small-ant invasions. Ecology, 85, 1244-1250.

Neurath A (2009) Variabilität in der Nahrungsökologie von Schnurrbart-Tamarinen, Saguinus mystax (Callitrichidae; Primates). University of Göttingen.

Nevo O (2015) The Chemical Ecology of Primate Seed Dispersal.

Nevo O, Heymann EW, Schulz S, Ayasse M (2016) Fruit odor as a ripeness signal for seed-dispersing primates? A case study on four Neotropical plant species. Journal of Chemical Ecology.

Nevo O, Orts Garri R, Hernandez Salazar LT et al. (2015) Chemical recognition of fruit ripeness in spider monkeys (Ateles geoffroyi). Scientific Reports, 5, 14895.

Newing H, Parellada A (1998) From principles to practice: indigenous peoples and biodiversity conservation in Latin America. International Work Group for Indigenous Affairs.

Nielsen NH, Jacobsen MW, Graham LLLB et al. (2011) Successful germination of seeds following passage through orang-utan guts. Journal of Tropical Ecology, 27, 433-435.

Oddou-Muratorio S, Bontemps A, Klein EK et al. (2010) Comparison of direct and indirect genetic methods for estimating seed and pollen dispersal in Fagus sylvatica and Fagus crenata. Forest Ecology and Management, 259, 2151-2159.

Oddou-Muratorio S, Demesure-Musch B, Pélissier R, Gouyon PH (2004) Impacts of gene flow and logging history on the local genetic structure of a scattered tree species, Sorbus torminalis L. Crantz. Molecular Ecology, 13, 3689-3702.

de Oliveira A, Mori SA (1999) Central Amazonian terra firme forests: high tree species richness. Biodiversity and Conservation, 8, 1219-1244.

Olson KA, Fuller TK, Mueller T et al. (2010) Annual movements of Mongolian gazelles: Nomads in the Eastern Steppe. Journal of Arid Environments, 74, 1435-1442.

Otani T (2004) Effects of macaque ingestion on seed destruction and germination of a fleshy-fruited tree, Eurya emarginata. Ecological Research, 19, 495-501.

Ottewell K, Grey E, Castillo F, Karubian J (2012) The pollen dispersal kernel and mating system of an insectpollinated tropical palm, Oenocarpus bataua. Heredity, 109, 332-339.

Pasquet RS, Peltier A, Hufford MB et al. (2008) Long-distance pollen flow assessment through evaluation 
of pollinator foraging range suggests transgene escape distances. Proceedings of the National Academy of Sciences of the United States of America, 105, 13456-61.

Patterson TA, Thomas L, Wilcox C, Ovaskainen O, Matthiopoulos J (2008) State-space models of individual animal movement. Trends in Ecology and Evolution, 23, 87-94.

Peakall R, Beattie AJ (1995) Does ant dispersal of seeds in Sclerolaena diacantha (Chenopodiaceae) generate local spatial genetic structure? Heredity, 75, 351-361.

Peakall R, Smouse PE (2006) GENALEX 6: Genetic analysis in Excel. Population genetic software for teaching and research. Molecular Ecology Notes, 6, 288-295.

Perea R, González R, San Miguel A, Gil L (2011) Moonlight and shelter cause differential seed selection and removal by rodents. Animal Behavior, 82, 717-723.

Peres CA (1993) Diet and feeding ecology of saddle-back (Saguinus fuscicollis) and moustached (S. mystax) tamarins in an Amazonian terra firme forest. Journal of Zoology, 230, 567-592.

Peres C a. (1996) Food patch structure and plant resource partitioning in interspecific associations of amazonian tamarins. International Journal of Primatology, 17, 695-723.

Pérez-Méndez N, Jordano P, García C, Valido A (2016) The signatures of Anthropocene defaunation: cascading effects of the seed dispersal collapse. Nature Publishing Group, 1-9.

Pesendorfer MB, Sillett TS, Morrison SA, Kamil AC (2016) Context-dependent seed dispersal by a scatterhoarding corvid (M Wunder, Ed,). Journal of Animal Ecology, 85, 798-805.

Petre CA, Tagg N, Beudels-Jamar RC, Haurez B, Doucet JL (2015) Western lowland gorilla seed dispersal: Are seeds adapted to long gut retention times? Acta Oecologica, 67, 59-65.

Pfrommer A (2009) Seed dispersal ecology of Leonia cymosa (Violaceae) in the rain forest of Eastern Ecuador.

Pons J, Pausas JG (2007) Acorn dispersal estimated by radio-tracking. Oecologia, 153, 903-911.

Queller DC, Goodnight KF (1989) Estimating Relatedness Using Genetic Markers. Evolution, 43, 258.

Quevedo AA, Schleuning M, Hensen I, Saavedra F, Durka W (2013) Forest fragmentation and edge effects on the genetic structure of Clusia sphaerocarpa and C. lechleri (Clusiaceae) in tropical montane forests. Journal of Tropical Ecology, 29, 321-329.

Ramos SLF, Dequigiovanni G, Sebbenn AM et al. (2016b) Spatial genetic structure, genetic diversity and 
pollen dispersal in a harvested population of Astrocaryum aculeatum in the Brazilian Amazon. BMC Genetics, 17, 63.

Rands SA, Whitney HM, Gikungu M, Newton L, Sanderson R (2011) Field Margins, Foraging Distances and Their Impacts on Nesting Pollinator Success (A Dornhaus, Ed,). PLoS ONE, 6, e25971.

Razafindratsima OH, Jones TA, Dunham AE (2014) Patterns of movement and seed dispersal by three lemur species. American Journal of Primatology, 76, 84-96.

Reinehr A (2010) Diplomarbeit Samenausbreitung von Leonia cymosa (Violaceae) durch die sympatrischen Tamarine Saguinus mystax und Saguinus fuscicollis, Primates, Callitrichidae Seed-dispersal of Leonia cymosa (Violaceae) by the sympatric tamarins Saguinus mystax.

Rico Y, Wagner HH (2016) Reduced fine-scale spatial genetic structure in grazed populations of Dianthus carthusianorum. Heredity, 117, 367-374.

Ritland K (1996) Estimators for pairwise relatedness and individual inbreeding coefficients. Genetical Research, 67, 175-185.

Rodríguez-Pérez J, Larrinaga AR, Santamaría L (2012) Effects of frugivore preferences and habitat heterogeneity on seed rain: A multi-scale analysis. PLoS ONE, 7, 1-9.

Rousset (2000) Genetic differentiation between individuals. Journal of Evolutionary Biology, 13, 58-62.

Rundle HD, Nosil P (2005) Ecological speciation. Ecology Letters, 8, 336-352.

Russo SE, Portnoy S, Augspurger CK (2006) Incorporating animal behavior into seed dispersal models: Implications for seed shadows. Ecology, 87, 3160-3174.

Ruxton GD, Schaefer HM (2012) The conservation physiology of seed dispersal. Philosophical transactions of the Royal Society of London. Series B, Biological sciences, 367, 1708-18.

Rylands AB, Heymann EW, Lynch Alfaro J et al. (2016) Taxonomic review of the New World tamarins (Primates: Callitrichidae). Zoological Journal of the Linnean Society, 177, 1003-1028.

Rylands AB, Mittermeier RA (2014) Primate taxonomy: Species and conservation. Evolutionary Anthropology: Issues, News, and Reviews, 23, 8-10.

Sampaio R, Roehe F, Pinho G et al. (2015) Re-description and assessment of the taxonomic status of Saguinus fuscicollis cruzlimai Hershkovitz, 1966 (Primates, Callitrichinae). Primates, 56, 131-144.

Sant'Anna CS, Sebbenn AM, Klabunde GHF et al. (2013) Realized pollen and seed dispersal within a 
continuous population of the dioecious coniferous Brazilian pine [Araucaria angustifolia (Bertol.) Kuntze]. Conservation Genetics, 14, 601-613.

Sasal Y, Morales JM (2013) Linking frugivore behavior to plant population dynamics. Oikos, 122, 95-103.

Savolainen O, Pyhäjärvi T, Knürr T (2007) Gene flow and local adaptation. Annual Review of Ecology, Evolution, and Systematics, 38, 595-619.

Schaberg PG, DeHayes DH, Hawley GJ, Nijensohn SE (2008) Anthropogenic alterations of genetic diversity within tree populations: Implications for forest ecosystem resilience. Forest Ecology and Management, 256, 855-862.

Schroeder JW, Tran HT, Dick CW (2014) Fine scale spatial genetic structure in Pouteria reticulata (Engl.) Eyma (Sapotaceae), a dioecious, vertebrate dispersed tropical rain forest tree species. Global Ecology and Conservation, 1, 43-49.

Schueler S, Tusch A, Scholz F (2006) Comparative analysis of the within-population genetic structure in wild cherry (Prunus avium L.) at the self-incompatibility locus and nuclear microsatellites. Molecular Ecology, 15, 3231-3243.

Schupp EW (1993) Quantity, quality and the effectiveness of seed dispersal by animals. Vegetatio, 107$108,15-29$.

Schupp EW, Jordano P (2011) The full path of Janzen-Connell effects: Genetic tracking of seeds to adult plant recruitment. Molecular Ecology, 20, 3953-3955.

Schupp EW, Jordano P, Gómez JM (2010) Seed dispersal effectiveness a conceptual review. New Phytologist, 188, 333-353.

Schupp EW, Jordano P, Gómez JM (2017) A general framework for effectiveness concepts in mutualisms. Ecology Letters, 20, 577-590.

Schurr FM, Bond WJ, Midgley GF, Higgins SI (2005) A mechanistic model for secondary seed dispersal by wind and its experimental validation. Journal of Ecology, 93, 1017-1028.

Scofield, D. G., Sork, V. L. and Smouse, P. E. (2010), Influence of acorn woodpecker social behaviour on transport of coast live oak (Quercus agrifolia) acorns in a southern California oak savanna. Journal of Ecology, 98: 561-572. doi:10.1111/j.1365-2745.2010.01649.x

Scotti I, González-Martínez SC, Budde KB, Lalagüe H (2015) Fifty years of genetic studies: what to make of the large amounts of variation found within populations? Annals of Forest Science. 
Seidler TG, Plotkin JB (2006) Seed dispersal and spatial pattern in tropical trees. PLoS Biology, 4, 21322137.

Selkoe KA, Toonen RJ (2006) Microsatellites for ecologists: A practical guide to using and evaluating microsatellite markers. Ecology Letters, 9, 615-629.

Shilton L a., Altringham JD, Compton SG, Whittaker RJ (1999) Old World fruit bats can be long-distance seed dispersers through extended retention of viable seeds in the gut. Proceedings of the Royal Society B: Biological Sciences, 266, 219.

Sidhu S, Datta A (2015) Tracking seed fates of tropical tree species: Evidence for seed caching in a tropical forest in north-east India. PLoS ONE, 10, 1-21.

Slatkin M (1985) Gene flow in natural populations. Ann. Rev. Ecol. Syst., 16, 393-430.

Smith AC (1997) Comparative ecology of saddleback (Saguinus fuscicollis) and moustached (Saguinus mystax) tamarins. University of Reading.

Smith AC, Knogge C, Huck M et al. (2007) Long-term patterns of sleeping site use in wild saddleback (Saguinus fuscicollis) and mustached tamarins (S. mystax): Effects of foraging, thermoregulation, predation, and resource defense constraints. American Journal of Physical Anthropology, 134, 340353.

Smouse PE, Sork VL, Scofield DG, Grivet D (2012) Using seedling and pericarp tissues to determine maternal parentage of dispersed valley oak recruits. Journal of Heredity, 103, 250-259.

Snyder RE (2011) Leaving home ain't easy: non-local seed dispersal is only evolutionarily stable in highly unpredictable environments. Proceedings of the Royal Society B: Biological Sciences, 278, 739-744.

Sokal RR, Oden NL (1978) Spatial autocorrelation in biology: 1. Methodology. Biological Journal of the Linnean Society, 10, 199-228.

Sokal RR, Wartenberg DE (1983) A Test of Spatial Autocorrelation Analysis Using an Isolation-by-Distance Model. Genetics, 105, 219-237.

Solomon NG, French JA (1997) Cooperative breeding in mammals. Cambridge University Press.

Soons MB, Ozinga WA (2005) How important is long-distance seed dispersal for the regional survival of plant species? Diversity and Distributions, 11, 165-172.

Sork VL (2016) Examination of Seed Dispersal and Survival in Red Oak, Quercus Rubra (Fagaceae), Using 
Metal-Tagged Acorns. Ecology, 65, 1020-1022.

Sork VL, Smouse PE, Grivet D, Scofield DG (2015) Impact of asymmetric male and female gamete dispersal on allelic diversity and spatial genetic structure in valley oak (Quercus lobata Née). Evolutionary Ecology, 29, 927-945.

Soto A, Lorenzo Z, Gil L (2007) Differences in fine-scale genetic structure and dispersal in Quercus ilex L. and $Q$. suber L.: consequences for regeneration of mediterranean open woods. Heredity, 99, 601-7.

Stefenon VM, Gailing O, Finkeldey R (2008) The role of gene flow in shaping genetic structures of the subtropical conifer species Araucaria angustifolia. Plant Biology, 10, 356-364.

Stevenson PR (2000) Seed dispersal by woolly monkeys (Lagothrix lagothricha) at Tinigua National Park, Colombia: Dispersal distance, germination rates, and dispersal quantity. American Journal of Primatology, 50, 275-289.

Stiles EW (2000) Animals as seed dispersers. In: Seeds: The ecology of regeneration in plant communities (ed Fenner M), pp. 111-125. CAB International, Oxon.

Stojan-Dolar M (2009) The many faces of vigilance an examination of antipredator and social function of vigilance in mustached tamarin (Saguinus mystax). University of Göttingen.

Stojan-Dolar M, Heymann EW (2010a) Vigilance of mustached tamarins in single-species and mixedspecies groups-the influence of group composition. Behavioral Ecology and Sociobiology, 64, 325335.

Stojan-Dolar M, Heymann EW (2010b) Vigilance in a Cooperatively Breeding Primate. International Journal of Primatology, 31, 95-116.

Streiff R, Labbe T, Bacilieri R et al. (1998) Within-population genetic structure in Quercus robur L. and Quercus petraea (Matt.) Liebl. assessed with isozymes and microsatellites. Molecular Ecology, 7, 317-328.

Sussman RW, Kinzey WG (1984) The ecological role of the callitrichidae: A review. American Journal of Physical Anthropology, 64, 419-449.

Takahashi S, Itino T (2015) Larger Seeds are Dispersed Farther: The Long-Distance Seed Disperser ant Aphaenogaster famelica Prefers Larger Seeds. Sociobiology, 59, 1401-1411.

Tani N, Tomaru N, Tsumura Y, Araki M, Ohba K (1998) Genetic structure within a Japanese stone pine (Pinus pumila regel) population on Mt. Aino-dake in central Honshu, Japan. Journal of Plant 
Research, 111, 7-15.

Tavares De Oliveira Melo A, Siqueira Guedes Coelho A, Ferreira Pereira M, Vieira Blanco AJ, Villaron Franceschinelli E (2014) High genetic diversity and strong spatial genetic structure in Cabralea canjerana (Vell.) Mart. (Meliaceae): implications to Brazilian Atlantic Forest tree conservation. Natureza \& Conservação, 12, 129-133.

Team R (2015) RStudio: Integrated Development for R.

Team QD (2016) QGIS Geographic Information System.

Theim TJ, Shirk RY, Givnish TJ (2014) Spatial genetic structure in four understory Psychotria species (Rubiaceae) and implications for tropical forest diversity. American Journal of Botany, 101, 11891199.

Thompson R (1985) A note on restricted maximum likelihood estimation with an alternative outlier model. Journal of the Royal Statistical Society. Series B (Methodological), 47, 53-55.

Thompson PG (2014) Bat pollination, genetic structure and gene flow in Crescentia alata trees in Westrn Mexico.

Thompson PG, Smouse PE, Scofield DG, Sork VL (2014) What seeds tell us about birds: a multi-year analysis of acorn woodpecker foraging movements. Movement Ecology, 2, 1-10.

Thomson FJ, Moles AT, Auld TD, Kingsford RT (2011) Seed dispersal distance is more strongly correlated with plant height than with seed mass. Journal of Ecology, 99, 1299-1307.

Torroba-Balmori P, Budde KB, Heer K et al. (2017) Altitudinal gradients, biogeographic history and microhabitat adaptation affect fine-scale spatial genetic structure in African and Neotropical populations of an ancient tropical tree species. PLoS ONE, 12, 1-23.

Trapnell DW, Schmidt JP, Hamrick JL (2008) Spatial genetic structure of the southeastern North American endemic, Ceratiola ericoides (Empetraceae). Journal of Heredity, 99, 604-609.

Uriarte M, Anciães M, da Silva MTB et al. (2011) Disentangling the drivers of reduced long-distance seed dispersal by birds in an experimentally fragmented landscape. Ecology, 92, 924-37.

Valenta K, Fedigan LM (2010) Spatial patterns of seed dispersal by white-faced capuchins in Costa Rica: Evaluating distant-dependent seed mortality. Biotropica, 42, 223-228.

Valenta K, Hopkins ME, Meeking M, Chapman CA, Fedigan LM (2015) Spatial patterns of primary seed 
dispersal and adult tree distributions: Genipa americana dispersed by Cebus capucinus. Journal of Tropical Ecology, 31, 491-498.

Vásquez R (1997) Flórula de las reservas biológicas de lquitos, Perú: Allpahuayo-Mishana, Explornapo Camp, Explorama Lodge (CM. Rudas Lleras, Agustín; Taylor, Ed,). Missouri Botanical Garden.

Vekemans X, Hardy OJ (2004) New insights from fine-scale spatial genetic structure analyses in plant populations. Molecular Ecology, 13, 921-935.

Venables WN, Ripley BD (2002) Modern Applied Statistics with S. Springer New York, New York, NY.

Viana DS, Gangoso L, Bouten W, Figuerola J (2015) Overseas seed dispersal by migratory birds. Proceedings of the Royal Society B: Biological Sciences, 283, 20152406.

Vieira F a., Fajardo CG, de Souza AM, Reis CAF, de Carvalho D (2012) Fine-scale genetic dynamics of a dominant neotropical tree in the threatened Brazilian Atlantic Rainforest. Tree Genetics and Genomes, 8, 1191-1201.

Vieira MLC, Santini L, Diniz AL, Munhoz C de F (2016) Microsatellite markers: what they mean and why they are so useful. Genetics and Molecular Biology, 39, 312-328.

Walker AN, Fore S a., Collins B (2009) Fine-scale structure within a Trillium maculatum (Liliaceae) population. Botany, 87, 223-230.

Wang R, Ai B, Gao B-Q et al. (2009) Spatial genetic structure and restricted gene flow in a functionally dioecious fig, Ficus pumila L. var. pumila (Moraceae). Population Ecology, 51, 307-315.

Wang B, Chen J, Corlett RT (2014) Factors influencing repeated seed movements by scatter-hoarding rodents in an alpine forest. Scientific Reports, 4, 4786.

Wang R, Compton SG, Chen XY (2011) Fragmentation can increase spatial genetic structure without decreasing pollen-mediated gene flow in a wind-pollinated tree. Molecular Ecology, 20, 4421-4432.

Wang R, Compton SG, Shi Y-SS, Chen X-YY (2012) Fragmentation reduces regional-scale spatial genetic structure in a wind-pollinated tree because genetic barriers are removed. Ecology and Evolution, 2, $2250-2261$.

Wang BC, Smith TB (2002) Closing the seed dispersal loop. Trends in Ecology and Evolution, 17, 379-385.

Wehncke E V., Hubbell SP, Foster RB, Dalling JW (2003) Seed dispersal patterns produced by white-faced monkeys: Implications for the dispersal limitation of neotropical tree species. Journal of Ecology, 91, 
677-685.

Wehncke E V, Valdez CN, Domínguez CA, Valdezt CN, Dominguez CA (2004) Seed Dispersal and Defecation Patterns of Cebus capucinus and Alouatta palliata: Consequences for Seed Dispersal Effectiveness. Source Journal of Tropical Ecology Journal of Tropical Ecology, 20, 535-54353.

Wenny DG (2001) Advantages of seed dispersal: A re-evaluation of directed dispersal. Evolutionary Ecology Research, 3, 51-74.

Wenny DG, Levey DJ (1998) Directed seed dispersal by bellbirds in a tropical cloud forest. Proceedings of the National Academy of Sciences of the United States of America, 95, 6204-6207.

Wickham H (2009) ggplot2: Elegant Graphics for Data Analysis. Springer-Verlag New York.

Williams NH, Dodson CH (1972) Selective attraction of male Euglossine bees to orchid floral fragrances and its importance in long distance polen flow. Evolution, 26, 84-95.

Williams CF, Guries RP (1994) Genetic consequences of seed dispersal in three sympatric forest herbs. I. Hierarchical population-genetic structure. Evolution, 48, 791-805.

Williams CG, LaDeau SL, Oren R, Katul GG (2006) Modeling Seed Dispersal Distances: Implications for Transgenic Pinus taeda. Ecological Applications, 16, 117-124.

Wotton DM, Kelly D (2012) Do larger frugivores move seeds further? Body size, seed dispersal distance, and a case study of a large, sedentary pigeon (A Traveset, Ed,). Journal of Biogeography, 39, 19731983.

Wright S (1949) The genetical structure of populations. Annals of Eugenics, 15, 323-354.

Yao X, Zhang J, Ye Q, Huang H (2011) Fine-scale spatial genetic structure and gene flow in a small, fragmented population of Sinojackia rehderiana (Styracaceae), an endangered tree species endemic to China. Plant Biology, 13, 401-410.

Yeaman S, Jarvis A (2006) Regional heterogeneity and gene flow maintain variance in a quantitative trait within populations of lodgepole pine. Proceedings. Biological sciences / The Royal Society, 273, 1587-1593.

Yumoto T, Kimura K, Nishimura A (1999) Estimation of the retention times and distances of seed dispersal by two monkey species, Alouatta seniculus and Lagothrix lagotricha, in a Colombian forest. Ecological Research, 14, 179-191. 
Zhou HP, Chen J (2010) Spatial genetic structure in an understorey dioecious fig species: The roles of seed rain, seed and pollen-mediated gene flow, and local selection. Journal of Ecology, 98, 1168-1177.

Zhou H, Chen J, Chen F (2007) Ant-mediated seed dispersal contributes to the local spatial pattern and genetic structure of Globba lancangensis (Zingiberaceae). Journal of Heredity, 98, 317-324. 
Hereby, I declare that the work contained in the thesis "Frugivore behavior and plant spatial genetics" has been written in my own words, with no help by third parties, and references correctly cited.

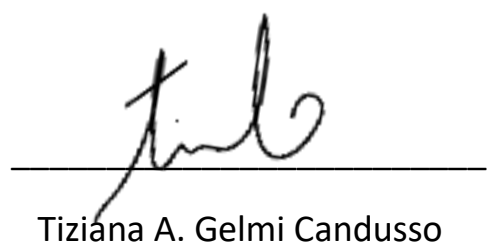

